University of New Orleans

ScholarWorks@UNO

8-6-2009

\title{
A Numerical Study of Unsteady Natural Convection in a Rectangular Enclosure - The Effect of Variable Thermodynamic and Transport Properties
}

\author{
Manohar Chidurala \\ University of New Orleans
}

Follow this and additional works at: https://scholarworks.uno.edu/td

\section{Recommended Citation}

Chidurala, Manohar, "A Numerical Study of Unsteady Natural Convection in a Rectangular Enclosure -- The Effect of Variable Thermodynamic and Transport Properties" (2009). University of New Orleans Theses and Dissertations. 973.

https://scholarworks.uno.edu/td/973

This Thesis is protected by copyright and/or related rights. It has been brought to you by ScholarWorks@UNO with permission from the rights-holder(s). You are free to use this Thesis in any way that is permitted by the copyright and related rights legislation that applies to your use. For other uses you need to obtain permission from the rightsholder(s) directly, unless additional rights are indicated by a Creative Commons license in the record and/or on the work itself.

This Thesis has been accepted for inclusion in University of New Orleans Theses and Dissertations by an authorized administrator of ScholarWorks@UNO. For more information, please contact scholarworks@uno.edu. 


\title{
A Numerical Study of Unsteady Natural Convection in a Rectangular Enclosure - The Effect of Variable Thermodynamic and Transport Properties
}

\author{
A Thesis \\ Submitted to the Graduate faculty of \\ University of New Orleans \\ in partial fulfillment of the \\ requirements for the degree of
}

\author{
Master of Science \\ in \\ Mechanical Engineering \\ Thermal Fluids Science
}

by

Manohar Chidurala

B.Tech., JNTU College of Engineering, 2006

M.S., University of New Orleans, 2009

August, 2009 
Copyright 2009, Manohar Chidurala 
To my Mom, Dad, Srinivas, Premalatha and Ambika 


\section{Acknowledgment}

I would like to attribute the success of this thesis project to Dr. Kazim M. Akyuzlu, Professor of Mechanical Engineering. Dr. Akyuzlu with his strong intellect and motivating personality inculcated a positive attitude in me. The present thesis would not have been possible without his elaborate guidance and full encouragement. I would also like to thank Dr. Carsie A. Hall, Associate Professor of Mechanical Engineering, for serving on my thesis committee. I have gained his esteemed guidance and help throughout my graduate studies.

I would like to express my sincere thanks to Dr. Ting Wang, Professor of Mechanical Engineering, and Dr. Dongming Wei, Professor of Mathematics for serving on my thesis committee and their help in courses and projects. I would like to thank Dr. Paul D. Herrington, Chair of Mechanical Engineering Department, and Dr. Martin J. Guillot, Associate Professor of Mechanical Engineering, for readily accepting to serve on my thesis committee. I would also like to thank the Department of Mechanical Engineering at the University of New Orleans for providing financial assistance.

I am extremely grateful to my seniors Antoniou and Pavri. They are responsible for the development of the code used in this study. I would like to thank my friends Manas, Dinesh and Rama Chandra for their encouragement and support throughout my studies. I would also thankful to my friends and roommates Rajesh, Rohit, Rakesh, Nitin, Prashant, Sharath, Murali and Sridhar for being so understanding and supportive of me during this journey.

I feel indebted to my family for their never ending support and encouragement. I would like to thank especially to my love Ambika and my brother Srinivas, without them, this part of journey would be inevitable. 


\section{Table of Contents}

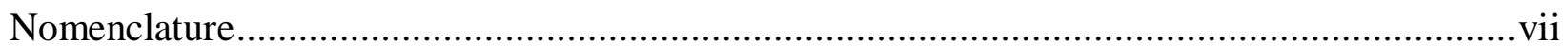

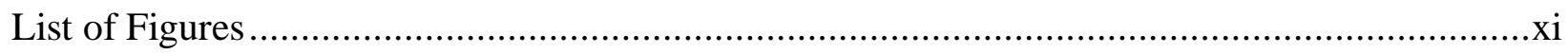

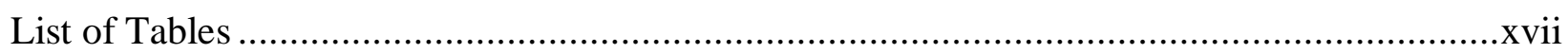

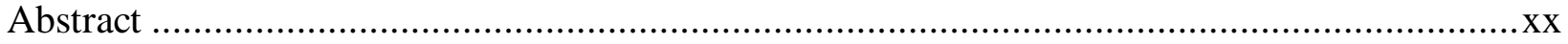

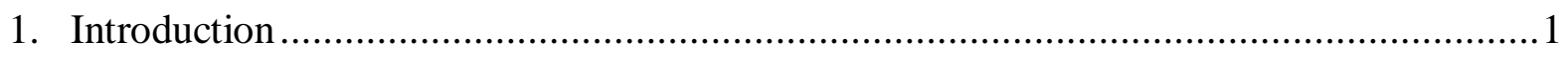

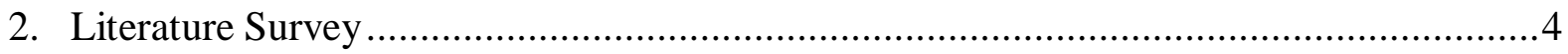

3. Description of the Physical Model ........................................................... 10

4. Description of the Mathematical Model ................................................................ 13

4.1.Assumptions for Mathematical Model...................................................... 13

4.2.Dimensional Formulation....................................................................... 14

4.3.Sub-models for Thermodynamic and Transport Properties ..................................15

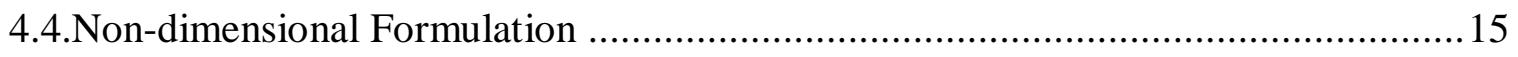

5. Numerical Formulation and Solution Technique ........................................... 20

5.1.Discretization of the Governing Differential Equations ...................................21

5.2.Linearization of the Governing Differential Equations ......................................23

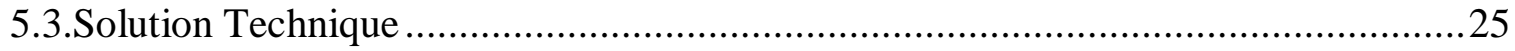

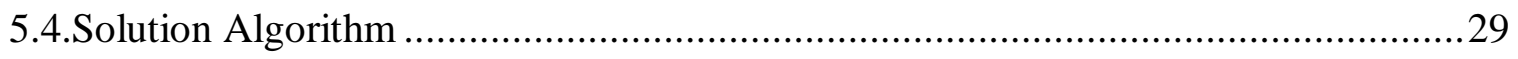

6. The Validation of the Mathematical Model and Computer Codes ..............................31

6.1.First Order Accurate in Time Model ......................................................... 31

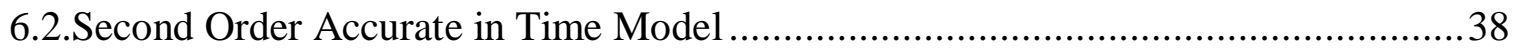


7. Parametric Study of Natural Convection Using

the First Order Accurate in Time Model

8. The Study of Effects of Variable Fluid Properties in Natural Convection Inside a Square

Enclosure .51

9. The Study of Effects of Inclination of the Enclosure on Natural Convection

10. Parametric Study of Natural Convection Using the Second Order Accurate in Time Model

11. The Study of Unsteady Natural Convection in Square Enclosures

12. Calculations of Wall Heat Flux and Nusselt Number 145

13. Conclusions

14. Recommendations 154

List of References

Appendices 160

I. Vector Form of the Governing Differential Equations 161

II. Dimensional form of Governing Differential Equation 163

III. Sub-models of Thermodynamic Properties and Transport Properties 165

IV. Non-dimensional Formulation of Governing Differential Equations.

V. Formulas for Calculate the Lower [L] and Upper [U] Matrices for CMSIP Method

VI. Flow Chart for the Computer Program

VII. List of Program Parameters 183

VIII. Specifics of each Run. 184

Vita 185 


\section{Nomenclature}

Symbols

$A R \quad$ Aspect ratio $(H / L)$

$c_{p} \quad$ Specific heat at constant pressure

$\bar{c}_{p} \quad$ Non-dimensional specific heat at constant pressure

$c_{v} \quad$ Specific heat at constant volume

$\bar{c}_{v} \quad$ Non-dimensional specific heat at constant volume

$E_{t} \quad$ Total energy per unit volume

$e \quad$ Internal energy per unit mass

$\vec{V} \quad$ Velocity vector

$\vec{f} \quad$ Force per unit mass

$\vec{\Pi} \quad$ Stress tensor

$\vec{q} \quad$ Heat transfer by conduction

$Q \quad$ Heat transfer by external agencies

Fr Froude number $\left(u_{\text {ref }}^{2} / g H\right)$

$g \quad$ Gravitational acceleration

$\vec{g} \quad$ Body force vector per unit volume

Gr Grashof number

$H \quad$ Height of the cavity

$\bar{H} \quad$ Non-dimensional height of the cavity

L Characteristic length 
$\bar{L} \quad$ Non-dimensional width of the cavity

$k \quad$ Thermal conductivity

$p \quad$ Thermodynamic pressure

$\bar{p} \quad$ Non-dimensional thermodynamic pressure

Pr Prandtl number

$R \quad$ Gas constant

$\bar{R} \quad$ Non-dimensional gas constant

Ra Rayleigh number (g $\left.\beta \Delta T H^{3} / v \alpha\right)$

$h \quad$ Heat transfer coefficient

$\mathrm{Nu} \quad$ Nusselt number

$T \quad$ Temperature

$\bar{T} \quad$ Non-dimensional temperature

$t \quad$ Time

$\bar{t} \quad$ Non-dimensional time

$u \quad$ Horizontal velocity

$\bar{u} \quad$ Non-dimensional horizontal velocity

$\tilde{u} \quad$ Non-dimensional horizontal velocity $(u H / \alpha)$

$u_{\text {ref }} \quad$ Reference velocity $\left(G r^{1 / 2} v / H\right)$

$v \quad$ Vertical velocity

$\bar{v} \quad$ Non-dimensional vertical velocity

$\tilde{v} \quad$ Non-dimensional vertical velocity $(v H / \alpha)$

$x \quad$ Horizontal spatial coordinate

$\bar{x} \quad$ Non-dimensional horizontal spatial coordinate 
$y \quad$ Vertical spatial coordinate

$\bar{y} \quad$ Non-dimensional vertical spatial coordinate

Greek Symbols

$\alpha \quad$ Thermal diffusivity; co-efficient of auxiliary matrix, $\mathrm{P}$

$\beta \quad$ Coefficient of thermal expansion

$\gamma \quad$ Isentropic constant

$\Delta \bar{t} \quad$ Non-dimensional time increment

$\Delta T \quad$ Temperature difference between hot and cold walls $\left(T_{h}-T_{c}\right)$

$\Delta \bar{x} \quad$ Non-dimensional increment in the horizontal direction

$\Delta \bar{y} \quad$ Non-dimensional increment in the vertical direction

$\varepsilon \quad$ Convergence criterion for SIP algorithm

$\varepsilon_{p} \quad$ Convergence criterion for pressure

$\mu \quad$ Absolute viscosity

$\bar{\mu} \quad$ Non-dimensional absolute viscosity

$v \quad$ Kinematic viscosity

$\bar{v} \quad$ Non-dimensional kinematic viscosity

$\rho \quad$ Density

$\delta \quad$ Kronecker delta function

$\theta \quad$ Angle of inclination of the enclosure

Subscripts

c Cold

h Hot

w Wall 
$i \quad$ Index for space increment in $\mathrm{x}$ direction

$j \quad$ Index for space increment in y direction

ref Reference

Superscripts

$k \quad$ Index for number of iterations ( $\mathrm{k}^{\text {th }}$ iteration in the CMSIP)

$n \quad$ Index for time increment 


\section{List of Figures}

Figure 1- Schematic of Physical Model (Square and Inclined Enclosure) in the Dimensional domain

Figure 2- $\quad$ Schematic of Physical Model in the Non-dimensional domain

Figure 3- Indexing of the Discretized Non-dimensional domain (Inner Nodes)

Figure 4- Computational Molecule for the Elements of A Matrix

Figure 5- Comparison of Steady State Non-dimensional Vertical Velocity Distribution along the Half of the Horizontal Centerline for $\Delta \bar{t}=1.0 \mathrm{E}-5, \Delta \bar{t}=5.0 \mathrm{E}-6$ and $\Delta \bar{t}=1.0 \mathrm{E}-6$ at $\mathrm{Ra}=10^{5}$

Figure 6- Comparison of Steady State Non-dimensional Vertical Velocity Distribution along the Half of the Horizontal Centerline for Grid Sizes of 21 x 21 and 41 x 41 at $\mathrm{Ra}=10^{5}$

Figure 7- Steady State Non-dimensional Vertical Velocity Distribution along the Horizontal Centerline for $\Delta \bar{t}=1.0 \mathrm{E}-5, \Delta \bar{t}=5.0 \mathrm{E}-6$ and $\Delta \bar{t}=1.0 \mathrm{E}-6$ at $\mathrm{Ra}=10^{5}$ in Second Order Time Accurate Approximation

Figure 8- $\quad$ Steady State Non-dimensional Vertical Velocity Distribution along the Horizontal Centerline for Grid Sizes of 21 × 21, 41 x 41 and $81 \times 81$ at $\mathrm{Ra}=10^{5}$ in Second Order Time Accurate Approximation

Figure 9- Comparison of Steady State Non-dimensional Vertical Velocity Distributions along the Horizontal Centerline of the Enclosure for $\mathrm{Ra}=10^{4}, \mathrm{Ra}=5 \times 10^{4}, \mathrm{Ra}=$ $10^{5}, \mathrm{Ra}=5 \times 10^{5}$ at $\mathrm{H}=0.0254 \mathrm{~m}$

Figure 10- Comparison of Steady State Non-dimensional Vertical Velocity Distributions along the Horizontal Centerline of the Enclosure for $\Delta \mathrm{T}=64.8 \mathrm{~K}, \Delta \mathrm{T}=356.6 \mathrm{~K}$ and $\Delta \mathrm{T}=648.4 \mathrm{~K}$ at $\mathrm{Ra}=10^{5}$

Figure 11- Comparison of Steady State Non-dimensional Horizontal Velocity Distributions along the Vertical Centerline of the Enclosure for Constant and Variable Fluid Properties at $\mathrm{Ra}=10^{5}(\Delta T=64.8 \mathrm{~K}, \mathrm{H}=0.0144 \mathrm{~m})$

Figure 12- Comparison of Steady State Non-dimensional Vertical Velocity Distributions along the Horizontal Centerline of the Enclosure for Constant and Variable Fluid Properties at $\mathrm{Ra}=10^{5}(\Delta T=64.8 \mathrm{~K}, \mathrm{H}=0.0144 \mathrm{~m})$

Figure 13- Comparison of Steady State Non-dimensional Temperature Distributions along the Horizontal Centerline of the Enclosure for Constant and Variable Fluid Properties at $\mathrm{Ra}=10^{5}(\Delta T=64.8 \mathrm{~K}, \mathrm{H}=0.0144 \mathrm{~m})$ 
Figure 14- Comparison of Non-dimensional Horizontal Histograms of Constant and Variable Properties for $\operatorname{Ra}=10^{5}$ at $\bar{X}=0.05$ and $\bar{Y}=0.5$

Figure 15- Comparison of Vertical Velocity Histograms of Constant and Variable Properties for $\mathrm{Ra}=10^{5}$ at $\bar{X}=0.05$ and $\bar{Y}=0.5$

Figure 16- Computational Mesh of the Non-dimensional domain for the Natural Convection Case for Variable Properties

Figure 17- Non-dimensional Horizontal Velocity Histogram for $\operatorname{Ra}=10^{5}$ at $\bar{X}=0.05$ and $\bar{Y}=$ 0.5 for Variable Properties $(21 \times 21, \Delta \bar{t}=1.0 \mathrm{E}-5)$

Figure 18- Non-dimensional Vertical Velocity Histogram for $\operatorname{Ra}=10^{5}$ at $\bar{X}=0.05$ and $\bar{Y}=0.5$ for Variable Properties ( $21 \times 21, \Delta \bar{t}=1.0 \mathrm{E}-5)$

Figure 19- Steady State Non-dimensional Temperature Contours for Ra $=10^{5}$ for Variable Properties $(21 \times 21, \Delta \bar{t}=1.0 \mathrm{E}-5)$

Figure 20- $\quad$ Steady State Non-dimensional Velocity Vectors for $\operatorname{Ra}=10^{5}(21 \times 21, \Delta \bar{t}=1.0 \mathrm{E}-5)$ for Variable Properties

Figure 21- Steady State Non-dimensional Velocity Streamlines for $\mathrm{Ra}=10^{5}$ for Variable Properties $(21 \times 21, \Delta \bar{t}=1.0 \mathrm{E}-5)$

Figure 22- Steady State Non-dimensional Horizontal Velocity Distribution along the Vertical Centerline of the Enclosure for $\mathrm{Ra}=10^{5}$ for Variable Properties

$(21 \times 21, \Delta \bar{t}=1.0 \mathrm{E}-5)$

Figure 23- Steady State Non-dimensional Vertical Velocity Distribution along the Horizontal Centerline of the Enclosure for $\mathrm{Ra}=10^{5}$ for Variable Properties

$(21 \times 21, \Delta \bar{t}=1.0 \mathrm{E}-5)$

Figure 24- Steady State Non-dimensional Temperature Distribution along the Horizontal Centerline of the Enclosure for $\mathrm{Ra}=10^{5}$ for Variable Properties

$(21 \times 21, \Delta \bar{t}=1.0 \mathrm{E}-5)$

Figure 25- Comparison of Steady State Non-dimensional Horizontal Velocity Distributions along the Vertical Centerline of the Enclosure for Constant and Variable Fluid Properties at $\mathrm{Ra}=10^{5}(\Delta T=356.6 \mathrm{~K}, \mathrm{H}=0.0115 \mathrm{~m})$

Figure 26- Comparison of Steady State Non-dimensional Vertical Velocity Distributions along the Horizontal Centerline of the Enclosure for Constant and Variable Fluid Properties at $\mathrm{Ra}=10^{5}(\Delta T=356.6 \mathrm{~K}, \mathrm{H}=0.0115 \mathrm{~m})$

Figure 27- Comparison of Steady State Non-dimensional Temperature Distributions along the Horizontal Centerline of the Enclosure for Constant and Variable Fluid Properties at $\mathrm{Ra}=10^{5}(\Delta T=356.6 \mathrm{~K}, \mathrm{H}=0.0115 \mathrm{~m})$ 
Figure 28- Comparison of Steady State Non-dimensional Horizontal Velocity Distributions along the Vertical Centerline of the Enclosure for Constant and Variable Fluid Properties at $\mathrm{Ra}=5 \times 10^{4}(\Delta T=356.6 \mathrm{~K}, \mathrm{H}=0.0115 \mathrm{~m})$

Figure 29- Comparison of Steady State Non-dimensional Vertical Velocity Distributions along the Horizontal Centerline of the Enclosure for Constant and Variable Fluid Properties at $\mathrm{Ra}=5 \times 10^{4}(\Delta T=356.6 \mathrm{~K}, \mathrm{H}=0.0115 \mathrm{~m})$

Figure 30- Comparison of Steady State Non-dimensional Temperature Distributions along the Horizontal Centerline of the Enclosure for Constant and Variable Fluid Properties at $\mathrm{Ra}=5 \times 10^{4}(\Delta T=356.6 \mathrm{~K}, \mathrm{H}=0.0115 \mathrm{~m})$

Figure 31- Comparison of Steady State Non-dimensional Horizontal Velocity Distributions along the Vertical Centerline of the Enclosure for Constant and Variable Fluid Properties at $\mathrm{Ra}=10^{4}(\Delta T=356.6 \mathrm{~K}, \mathrm{H}=0.0067 \mathrm{~m})$

Figure 32- Comparison of Steady State Non-dimensional Vertical Velocity Distributions along the Horizontal Centerline of the Enclosure for Constant and Variable Fluid Properties at $\mathrm{Ra}=10^{4}(\Delta T=356.6 \mathrm{~K}, \mathrm{H}=0.0067 \mathrm{~m})$

Figure 33- Comparison of Steady State Non-dimensional Temperature Distributions along the Horizontal Centerline of the Enclosure for Constant and Variable Fluid Properties at $\mathrm{Ra}=10^{4}(\Delta T=356.6 \mathrm{~K}, \mathrm{H}=0.0067 \mathrm{~m})$

Figure 34- Comparison of Non-dimensional Vertical Velocity Profiles along the Horizontal Centerline of the Enclosure between $\Delta T=64.8 \mathrm{~K}$ and $\Delta T=356.6 \mathrm{~K}\left(\mathrm{Ra}=10^{5}\right)$ for Variable Properties.

Figure 35- Comparison of Non-dimensional Vertical Velocity Profiles along the Horizontal Centerline of the Enclosure between $\mathrm{Ra}=10^{4}, \mathrm{Ra}=5 \times 10^{4}$, and $\mathrm{Ra}=10^{5}$ $(\Delta T=356.6 \mathrm{~K})$ for Variable Properties.

Figure 36- Steady State Non-dimensional Horizontal Velocity Distributions along the Vertical Centerline of the Inclined Enclosure for Constant Fluid Properties at $\mathrm{Ra}=$ $10^{5}$

Figure 37- Steady State Non-dimensional Vertical Velocity Distributions along the Horizontal Centerline of the Inclined Enclosure for Constant Fluid Properties at $\mathrm{Ra}=10^{5}$

Figure 38- Steady State Non-dimensional Temperature Distributions along the Horizontal Centerline of the Inclined Enclosure for Constant Fluid Properties at $\mathrm{Ra}=10^{5}$

Figure 39- Computational Mesh of the Non-dimensional domain for the Natural Convection Case in Second Order Time Accurate Approximation $\left(21 \times 21, \mathrm{Ra}=10^{5}\right)$

Figure 40- Non-dimensional Horizontal Velocity Histogram for $\operatorname{Ra}=10^{5}$ at $\bar{X}=0.2$ and $\bar{Y}=0.5$ $(21 \times 21, \Delta \bar{t}=1.0 \mathrm{E}-5)$ in Second Order Time Accurate Approximation 
Figure 41- Non-dimensional Vertical Velocity Histogram for $\operatorname{Ra}=10^{5}$ at $\bar{X}=0.2$ and $\bar{Y}=0.5$ $(21 \times 21, \Delta \bar{t}=1.0 \mathrm{E}-5)$ in Second Order Time Accurate Approximation

Figure 42- $\quad$ Steady State Non-dimensional Temperature Contours for $\mathrm{Ra}=10^{5}$ $(21 \times 21, \Delta \bar{t}=1.0 \mathrm{E}-5)$ in Second Order Time Accurate Approximation

Figure 43- Steady State Non-dimensional Velocity Vectors for $\mathrm{Ra}=10^{5}(21 \times 21, \Delta \bar{t}=1.0 \mathrm{E}-5)$ in Second Order Time Accurate Approximation

Figure 44- Steady State Non-dimensional Velocity Streamlines for $\mathrm{Ra}=10^{5}$ $(21 \times 21, \Delta \bar{t}=1.0 \mathrm{E}-5)$ in Second Order Time Accurate Approximation

Figure 45- Steady State Non-dimensional Horizontal Velocity Distribution along the Vertical Centerline of the Enclosure for $\mathrm{Ra}=10^{5}(21 \times 21, \Delta \bar{t}=1.0 \mathrm{E}-5)$ in Second Order Time Accurate Approximation

Figure 46- Steady State Non-dimensional Vertical Velocity Distribution along the Horizontal Centerline of the Enclosure for $\mathrm{Ra}=10^{5}(21 \times 21, \Delta \bar{t}=1.0 \mathrm{E}-5)$ in Second Order Time Accurate Approximation

Figure 47- Steady State Non-dimensional Temperature Distribution along the Horizontal Centerline of the Enclosure for $\mathrm{Ra}=10^{5}(21 \times 21, \Delta \bar{t}=1.0 \mathrm{E}-5)$ in Second Order Time Accurate Approximation

Figure 48- Computational Mesh of the Non-dimensional domain for the Natural Convection Case in Second Order Time Accurate Approximation $\left(81 \times 81, \mathrm{Ra}=10^{5}\right)$

Figure 49- $\quad$ Steady State Non-dimensional Velocity Vectors for $\mathrm{Ra}=10^{5}(81 \times 1, \Delta \bar{t}=1.0 \mathrm{E}-6)$ in Second Order Time Accurate Approximation

Figure 50- Steady State Non-dimensional Velocity Streamlines for $\mathrm{Ra}=10^{5}$ $(81 \times 81, \Delta \bar{t}=1.0 \mathrm{E}-6)$ in Second Order Time Accurate Approximation

Figure 51- Steady State Non-dimensional Temperature Contours for $\mathrm{Ra}=10^{5}$ $(81 \times 81, \Delta \bar{t}=1.0 \mathrm{E}-6)$ in Second Order Time Accurate Approximation

Figure 52- Comparison of Steady State Horizontal Velocity Distribution along the Vertical centerline of the Enclosure between First Order and Second Order Time Accurate Approximation for $\mathrm{Ra}=10^{5}$

Figure 53- Comparison of Steady State Vertical Velocity Distribution along the Horizontal Centerline of the Enclosure between First Order and Second Order Time Accurate Approximation for $\mathrm{Ra}=10^{5}$

Figure 54- Comparison of Steady State Temperature Distribution along the Horizontal Centerline of the Enclosure between First Order and Second Order Time Accurate Approximation for $\mathrm{Ra}=10^{5}$ 
Figure 55- Comparison of Steady State Horizontal Velocity Distribution along the Vertical Centerline of the Enclosure between First Order and Second Order Time Accurate Approximation for $\mathrm{Ra}=10^{4}$

Figure 56- Comparison of Steady State Vertical Velocity Distribution along the Horizontal Centerline of the Enclosure between First Order and Second Order Time Accurate Approximation for $\mathrm{Ra}=10^{4}$

Figure 57- Comparison of Steady State Temperature Distribution along the Horizontal Centerline of the Enclosure between First Order and Second Order Time Accurate Approximation for $\mathrm{Ra}=10^{4}$

Figure 58- Comparison of Steady State Horizontal Velocity Distribution along the Vertical Centerline of the Enclosure between $\mathrm{Ra}=10^{4}$ and $\mathrm{Ra}=10^{5}$ in Second Order Time Accurate Approximation

Figure 59- Comparison of Steady State Vertical Velocity Distribution along the Horizontal Centerline of the Enclosure between $\mathrm{Ra}=10^{4}$ and $\mathrm{Ra}=10^{5}$ in Second Order Time Accurate Approximation

Figure 60- Comparison of Steady State Temperature Distribution along the Horizontal Centerline of the Enclosure between $\mathrm{Ra}=10^{4}$ and $\mathrm{Ra}=10^{5}$ in Second Order Time Accurate Approximation

Figure 61- Non-dimensional Temperature Histogram for $\operatorname{Ra}=10^{5}$ at $\bar{x}=0.05$ and $\bar{y}=0.5$ $(41 \times 41, \Delta \bar{t}=5.0 \mathrm{E}-6)$ in Second Order Time Accurate Approximation

Figure 62- Unsteady State Non-dimensional Velocity Vectors for $\mathrm{Ra}=10^{5}$ at Nondimensional Time, $\bar{t}=1$ (41 x 41, $\Delta \bar{t}=5.0 \mathrm{E}-6)$ in Second Order Time Accurate Approximation

Figure 63- Unsteady State Non-dimensional Velocity Vectors for $\mathrm{Ra}=10^{5}$ at Nondimensional Time, $\bar{t}=5$ (41 x 41, $\Delta \bar{t}=5.0 \mathrm{E}-6)$ in Second Order Time Accurate Approximation

Figure 64- Unsteady State Non-dimensional Velocity Vectors for $\mathrm{Ra}=10^{5}$ at Nondimensional Time, $\bar{t}=10(41 \times 41, \Delta \bar{t}=5.0 \mathrm{E}-6)$ in Second Order Time Accurate Approximation

Figure 65- Unsteady State Non-dimensional Velocity Vectors for $\mathrm{Ra}=10^{5}$ at Nondimensional Time, $\bar{t}=15$ (41 x 41, $\Delta \bar{t}=5.0 \mathrm{E}-6)$ in Second Order Time Accurate Approximation

Figure 66- Unsteady State Non-dimensional Velocity Vectors for $\mathrm{Ra}=10^{5}$ at Nondimensional Time, $\bar{t}=20$ (41 x 41, $\Delta \bar{t}=5.0 \mathrm{E}-6)$ in Second Order Time Accurate Approximation

Figure 67- Unsteady State Non-dimensional Velocity Vectors for $\mathrm{Ra}=10^{5}$ at Nondimensional Time, $\bar{t}=50$ (41 x 41, $\Delta \bar{t}=5.0 \mathrm{E}-6)$ in Second Order Time Accurate Approximation 
Figure 68- Unsteady State Non-dimensional Temperature Contours for $\mathrm{Ra}=10^{5}$ at Nondimensional Time, $\bar{t}=1$ (41 x 41, $\Delta \bar{t}=5.0 \mathrm{E}-6)$ in Second Order Time Accurate Approximation

Figure 69- Unsteady State Non-dimensional Temperature Contours for $\mathrm{Ra}=10^{5}$ at Nondimensional Time, $\bar{t}=5(41 \times 41, \Delta \bar{t}=5.0 \mathrm{E}-6)$ in Second Order Time Accurate Approximation

Figure 70- Unsteady State Non-dimensional Temperature Contours for $\mathrm{Ra}=10^{5}$ at Nondimensional Time, $\bar{t}=10$ (41 x 41, $\Delta \bar{t}=5.0 \mathrm{E}-6)$ in Second Order Time Accurate Approximation

Figure 71- Unsteady State Non-dimensional Temperature Contours for $\mathrm{Ra}=10^{5}$ at Nondimensional Time, $\bar{t}=15$ (41 x 41, $\Delta \bar{t}=5.0 \mathrm{E}-6)$ in Second Order Time Accurate Approximation

Figure 72- Unsteady State Non-dimensional Temperature Contours for $\mathrm{Ra}=10^{5}$ at Nondimensional Time, $\bar{t}=20$ (41 x 41, $\Delta \bar{t}=5.0 \mathrm{E}-6)$ in Second Order Time Accurate Approximation

Figure 73- Unsteady State Non-dimensional Temperature Contours for $\mathrm{Ra}=10^{5}$ at Nondimensional Time, $\bar{t}=50$ (41 x 41, $\Delta \bar{t}=5.0 \mathrm{E}-6)$ in Second Order Time Accurate Approximation

Figure 74- Dimensional Temperature Distribution along the Horizontal Distance for Constant Properties $(\Delta T=64.8 \mathrm{deg} \mathrm{K})$

Figure 75- Dimensional Temperature Distribution along the Horizontal Distance for Variable Properties $(\Delta T=64.8 \mathrm{deg} \mathrm{K})$

Figure 76- Dimensional Temperature Distribution along the Horizontal Distance for Constant Properties $(\Delta T=356.6 \mathrm{deg} \mathrm{K})$

Figure 77- Dimensional Temperature Distribution along the Horizontal Distance for Variable Properties $(\Delta T=356.6 \mathrm{deg} \mathrm{K})$ 


\section{List of Tables}

Table 1- Steady State Non-dimensional values of Vertical Velocity along the Horizontal Centerline of the Enclosure for $\Delta \bar{t}=1.0 \mathrm{E}-5, \Delta \bar{t}=5.0 \mathrm{E}-6$ and $\Delta \bar{t}=1.0 \mathrm{E}-6$ $\left(\mathrm{Ra}=10^{5}\right.$ and $\left.21 \times 21\right)$

Table 2- $\quad$ Steady State Non-dimensional values of Vertical Velocity along the Horizontal Centerline of the Enclosure for $21 \times 21$ and $41 \times 41\left(\mathrm{Ra}=10^{5}\right.$ and $\left.21 \times 21\right)$

Table 3- $\quad$ Comparison of the Results of the Constant Properties and the Benchmark Case (de Vahl Davis) for Different Rayleigh Numbers

Table 4- Steady State Non-dimensional values of Vertical Velocity along the Horizontal Centerline of the Enclosure for $\Delta \bar{t}=1.0 \mathrm{E}-5$ and $\Delta \bar{t}=5.0 \mathrm{E}-6$ at $\mathrm{Ra}=10^{5}$ in Second Order Time Accurate Approximation

Table 5- Steady State Non-dimensional values of Vertical Velocity along the Horizontal Centerline of the Enclosure for 21 X 21 and 41 X 41 at $\mathrm{Ra}=10^{5}$ in Second Order Time Accurate Approximation

Table 6- $\quad$ Comparison of the Results of the First Order and the Second Order Time Accurate CMSIP Models using Constant Properties for Different Rayleigh Numbers

Table 7- Steady State Non-dimensional values of Vertical Velocity along the Horizontal Centerline of the Enclosure for $\mathrm{Ra}=10^{4}, \mathrm{Ra}=5 \times 10^{4}, \mathrm{Ra}=10^{5}, \mathrm{Ra}=5 \times 10^{5}$ at $\mathrm{H}=0.0254 \mathrm{~m}$

Table 8- Steady State Non-dimensional values of Vertical Velocity along the Horizontal Centerline of the Enclosure for $\Delta \mathrm{T}=64.8 \mathrm{~K}, \Delta \mathrm{T}=356.6 \mathrm{~K}, \Delta \mathrm{T}=648.4 \mathrm{~K}$ at $\mathrm{Ra}=10^{5}$

Table 9- Comparison of Predicted Non-dimensional values of Horizontal Velocity along the Vertical Centerline of the Enclosure for Constant and Variable Fluid Properties at $\mathrm{Ra}=10^{5}(\Delta T=64.8 \mathrm{~K}, \mathrm{H}=0.0254 \mathrm{~m}$ and $21 \mathrm{X} \mathrm{21})$

Table 10- Comparison of Predicted Non-dimensional values of Vertical Velocity along the Horizontal Centerline of the Enclosure for Constant and Variable Fluid Properties at $\mathrm{Ra}=10^{5}(\Delta T=64.8 \mathrm{~K}, \mathrm{H}=0.0254 \mathrm{~m}$ and $21 \mathrm{X} 21)$

Table 11- Comparison of Predicted Non-dimensional values of Temperature along the Horizontal Centerline of the Enclosure for Constant and Variable Fluid Properties at $\mathrm{Ra}=10^{5}(\Delta T=64.8 \mathrm{~K}, \mathrm{H}=0.0254 \mathrm{~m}$ and $21 \mathrm{X} 21)$ 
Table 12- Steady State Non-dimensional values of Primitive Variables along the Horizontal Centerline of the Enclosure for $\mathrm{Ra}=10^{5}(\Delta \bar{t}=1.0 \mathrm{E}-5$ and $21 \mathrm{X} 21)$

Table 13- Steady State Non-dimensional values of Primitive Variables along the Vertical Centerline of the Enclosure for $\mathrm{Ra}=10^{5}(\Delta \bar{t}=1.0 \mathrm{E}-5$ and21 X 21)

Table 14- Comparison of Predicted Non-dimensional values of Horizontal Velocity along the Vertical Centerline of the Enclosure for Constant and Variable Fluid Properties at $\mathrm{Ra}=10^{5}(\Delta T=356.6 \mathrm{~K}, \mathrm{H}=0.0144 \mathrm{~m}$ and $21 \mathrm{X} 21)$

Table 15- Comparison of Predicted Non-dimensional values of Vertical Velocity along the Horizontal Centerline of the Enclosure for Constant and Variable Fluid Properties at $\mathrm{Ra}=10^{5}(\Delta T=356.6 \mathrm{~K}, \mathrm{H}=0.0144 \mathrm{~m}$ and $21 \mathrm{X} 21)$

Table 16- Comparison of Predicted Non-dimensional values of Temperature along the Horizontal Centerline of the Enclosure for Constant and Variable Fluid Properties at $\mathrm{Ra}=10^{5}(\Delta T=356.6 \mathrm{~K}, \mathrm{H}=0.0144 \mathrm{~m}$ and $21 \mathrm{X} 21)$

Table-17- Comparison of Predicted Non-dimensional values of Horizontal Velocity along the Vertical Centerline of the Enclosure for Constant and Variable Fluid Properties at $\mathrm{Ra}=5 \times 10^{4}(\Delta T=356.6 \mathrm{~K}, \mathrm{H}=0.0115 \mathrm{~m}$ and $21 \mathrm{X} 21)$

Table 18- Comparison of Predicted Non-dimensional values of Vertical Velocity along the Horizontal Centerline of the Enclosure for Constant and Variable Fluid Properties at $\mathrm{Ra}=5 \times 10^{4}(\Delta T=356.6 \mathrm{~K}, \mathrm{H}=0.0115 \mathrm{~m}$ and $21 \mathrm{X} 21)$

Table 19- Comparison of Predicted Non-dimensional values of Temperature along the Horizontal Centerline of the Enclosure for Constant and Variable Fluid Properties at $\mathrm{Ra}=5 \times 10^{4}(\Delta T=356.6 \mathrm{~K}, \mathrm{H}=0.0115 \mathrm{~m}$ and $21 \mathrm{X} 21)$

Table 20- Comparison of Predicted Non-dimensional values of Horizontal Velocity along the Vertical Centerline of the Enclosure for Constant and Variable Fluid Properties at $\mathrm{Ra}=10^{4}(\Delta T=356.6 \mathrm{~K}, \mathrm{H}=0.0067 \mathrm{~m}$ and $21 \mathrm{X} 21)$

Table 21- Comparison of Predicted Non-dimensional values of Vertical Velocity along the Horizontal Centerline of the Enclosure for Constant and Variable Fluid Properties at $\mathrm{Ra}=10^{4}(\Delta T=356.6 \mathrm{~K}, \mathrm{H}=0.0067 \mathrm{~m}$ and $21 \mathrm{X} 21)$

Table 22- $\quad$ Comparison of Predicted Non-dimensional values of Temperature along the Horizontal Centerline of the Enclosure for Constant and Variable Fluid Properties at $\mathrm{Ra}=10^{4}(\Delta T=356.6 \mathrm{~K}, \mathrm{H}=0.0067 \mathrm{~m}$ and $21 \mathrm{X} 21)$

Table 23- Steady State Non-dimensional values of Vertical Velocity along the Horizontal Centerline of the Inclined Enclosure at Various Angles for $\mathrm{Ra}=10^{5}$ $(\Delta \bar{t}=1.0 \mathrm{E}-5$ and $21 \times 21)$

Table 24- Steady State Non-dimensional values of Horizontal Velocity along the Vertical Centerline of the Inclined Enclosure at Various Angles for $\mathrm{Ra}=10^{5}$ $(\Delta \bar{t}=1.0 \mathrm{E}-5$ and $21 \times 21)$ 
Table 25- Steady State Non-dimensional values of Primitive Variables along the Horizontal Centerline of the Enclosure for $\mathrm{Ra}=10^{5}$ in Second Order Time Accurate Approximation $(\Delta \bar{t}=1.0 \mathrm{E}-5$ and $21 \mathrm{X} 21)$

Table 26- Steady State Non-dimensional values of Primitive Variables along the Vertical Centerline of the Enclosure for $\mathrm{Ra}=10^{5}$ in Second Order Time Accurate Approximation $(\Delta \bar{t}=1.0 \mathrm{E}-5$ and $21 \mathrm{X} 21)$

Table 27- Comparison of Non-dimensional values of Horizontal Velocity along the Vertical Centerline between First Order and Second Order Time Accurate Approximations $\left(\mathrm{Ra}=10^{5}, \Delta \bar{t}=1.0 \mathrm{E}-5\right.$ and $\left.21 \times 21\right)$

Table 28- Comparison of Non-dimensional values of Vertical Velocity along the Horizontal Centerline between First Order and Second Order Time Accurate Approximations $\left(\mathrm{Ra}=10^{5}, \Delta \bar{t}=1.0 \mathrm{E}-5\right.$ and $\left.21 \mathrm{X} 21\right)$

Table 29- Comparison of Non-dimensional values of Temperature along the Horizontal Centerline between First Order and Second Order Time Accurate Approximations $\left(\mathrm{Ra}=10^{5}, \Delta \bar{t}=1.0 \mathrm{E}-5\right.$ and $\left.21 \times 21\right)$

Table 30- Comparison of Non-dimensional values of Horizontal Velocity along the Vertical Centerline between First Order and Second Order Time Accurate Approximations $\left(\mathrm{Ra}=10^{4}, \Delta \bar{t}=1.0 \mathrm{E}-6\right.$ and $\left.21 \mathrm{X} 21\right)$

Table 31- Comparison of Non-dimensional values of Vertical Velocity along the Horizontal Centerline between First Order and Second Order Time Accurate Approximations $\left(\mathrm{Ra}=10^{4}, \Delta \bar{t}=1.0 \mathrm{E}-6\right.$ and $\left.21 \times 21\right)$

Table 32- Comparison of Non-dimensional values of Temperature along the Horizontal Centerline between First Order and Second Order Time Accurate Approximations $\left(\mathrm{Ra}=10^{4}, \Delta \bar{t}=1.0 \mathrm{E}-6\right.$ and $\left.21 \mathrm{X} 21\right)$

Table 33- Comparison of the Results of the Present Study (Variable properties) and Constant Properties for Different Wall Temperature differences at $\mathrm{Ra}=10^{5}$ 


\begin{abstract}
A two-dimensional mathematical model is adopted to investigate the development of buoyancy driven circulation patterns and temperature contours inside a rectangular enclosure filled with a compressible fluid where one of the vertical walls of the enclosure is kept at a higher temperature than the opposite one. Fluid thermodynamic and transport properties are assumed to be functions of temperature. The governing equations are discretized using second order accurate differencing for spatial and temporal derivatives and then linearized using Newton's linearization method. The resulting set of algebraic equations is solved using the Coupled Modified Strongly Implicit Procedure for the unknowns of the problem. The results of this study show that the variable property model predicts lower values for wall heat fluxes and $\mathrm{Nu}$ number than the constant property one for Rayleigh numbers between $10^{4}$ and $10^{5}$.
\end{abstract}

Keywords: Natural convection, CMSIP, Buoyancy Driven flows with Variable Properties 


\section{Chapter 1}

\section{Introduction}

Natural convection within enclosures has been widely studied by many authors. Some of the applications of natural convection within enclosures include heat removal from electronic components, cooling of nuclear reactors, climate control in rooms, and crystal growth in liquids. Numerical studies of buoyancy driven flows have been carried out using finite difference, finite volume, and finite element techniques. Experimental studies have also been carried out utilizing PIV (Particle Image Velocimetry), LDA (Laser Doppler Anemometry), smoke visualization, and interferometry. A comprehensive literature survey is provided in Chapter 2.

The main objective of this thesis is to study the steady state and transient natural convection phenomenon of a compressible fluid (an ideal gas with $\operatorname{Pr}=0.72$ ) inside a square enclosure with differentially heated vertical walls and to determine the effect of variable thermodynamic and transport properties on circulation patterns, wall heat flux, and Nusselt number. A more detailed description of the physical problem is given in Chapter 3.

A physics based mathematical model is developed to obtain numerical solutions for the above problem by assuming the thermodynamic and transport properties of the fluid to be functions of temperature. The mathematical model comprises of conservation of mass, momentum, and energy equations. Formulation of conservation equations in terms of the primitive variables of the problem $(\mathrm{u}, \mathrm{v}, \mathrm{p}$, and $\mathrm{T})$ together with the appropriate boundary conditions and assumptions are provided in Chapter.4. All the dimensional variables are 
transformed into non-dimensional form. These variables are then used to transform the conservation equations and boundary conditions into their corresponding non-dimensional forms.

The discretization and linearization of the non-dimensional conservation equations are given in Chapter.5. This chapter also includes the numerical solution and algorithm employed to predict the values of the primitive variables of the problem. A detailed description of the Coupled Modified Strongly Implicit Procedure (CMSIP) used in the solution algorithm, which is second order accurate in time differencing is also given in this chapter.

The accuracy of the numerical code is verified by applying the developed code to predict the results of a benchmark case study. Grid independence and time convergence studies were carried to verify the solution algorithm is presented in Chapter 6. The study of the second order accurate in time model is also provided including the grid independence and time convergence studies and then compared to the first order accurate in time model in Chapter 6. A parametric study was carried out to determine the effect of various parameters such as Rayleigh number and wall temperature difference and the size of the enclosure on circulation patterns and heat transfer in Chapter 7.

The accuracy of the results achieved by variable properties is compared to those results of constant properties in Chapter 8. The orientation of the enclosure is also studied in the Chapter 9. In Chapter 10, the results of various case studies to verify the accuracy of the solution algorithm for second order accurate in time model are presented. Transient development of circulations and stratification patterns are provided in Chapter 11. The wall heat flux and Nusselt number calculations are presented in Chapter 12.

The conclusions drawn from the results of the present study are presented in Chapter 13. Recommendations to improve the mathematical and solution procedure proposed in this study 
are given in Chapter 14. A list of references used in the literature survey is provided in the "List of References" section of the thesis. 


\section{Chapter 2}

\section{Literature Survey}

Natural convection within enclosures has been widely studied by many researchers. An excellent review of the developments in understanding and modeling of these studies natural convection in enclosures can be found in the review paper by Ostrach [1]. This article discussed the complexities of the natural convection phenomenon that arise due to the inherent interaction between the boundary layer near the walls and the outer core region. Suggestions for different variable scaling are also made. Use of experimental results to support numerical predictions was strongly advocated. Moreover, enclosures with different geometries such as horizontal cylinders, high and low aspect ratio rectangular enclosures, and annuli were also reviewed.

Kimura and Bejan [4] have studied natural convection in a rectangular cavity with uniform heat flux imposed at the sides of the cavity. They specifically studied the heating of the cavity from the top and from the sides. Their results showed that the convection driven by the horizontal temperature gradients persists even when the vertical stabilizing gradient is larger than the horizontal gradient. Buoyancy induced flows subjected to partially heated flows studied by $\mathrm{T}$. H. Chen and L. Y. Chen [5] and also by Nithyadevi [6]. Cormack et al. [7] have considered the effect of the upper surface conditions on the buoyancy driven flow in a shallow cavity. The natural convective heat transfer with varying boundary conditions studied by many authors such as Sathiyamoorthy et al. [8], Calcagni [9], Ganzarolli [10], Le Peutrec and Lauriat [11], Mariani [12], Aydin[13], and Basak [14]. They have concluded that the surface boundary conditions have an important influence on the temperature and flow structure within a cavity. 
Nonlinear variations in liquid density with respect to temperature and its effect on buoyancy driven flow has been studied by Lin and Nansteel [15]. They have identified a dimensionless density distribution parameter which characterizes the distribution of the buoyancy force and how it determines the possible variations in flow structure. The effect of thermal stratification on natural convection in a vertical porous insulation layer has been studied by Rees and Lage [16].

Previous research indicates that the circulation patterns and thermal stratification in buoyancy driven flows are dependent on two-dimensional parameters: Prandtl and Rayleigh. Many researchers have carried out their studies for air $(\operatorname{Pr}=0.7)$. The results for low $\operatorname{Pr}$ number fluids (liquid metals) are reported by Viskanta et al. [17]. Fluid with high Pr numbers was studied by Hiller et al. [18]. Moh [19] studied the simulations of two-dimensional, low Prandtl number natural convection in harmonically oscillated, differentially heated enclosures. Buoyancy driven flows can be laminar or turbulent depending on the value of the Rayleigh number. The mathematical models proposed by Henkes et al. [20] can handle both types of flow regimes. Simulation of Laminar Buoyancy driven Flows in an Enclosure carried out by Evern Selamet et al. [21]. Numerical investigations have been conducted of flow transitions in Deep Cavities by Xia and Murthy [22]. Numerical investigation of turbulent natural convection in a square enclosure with localized heating from below and symmetrical cooling from the vertical side walls were carried out by Anil kumar Sharma et al. [23]. A numerical procedure to solve turbulent flow which makes use of k- $\varepsilon$ model has been developed by Elkaim et al [24]. Laminar and turbulent natural convection in irregular shaped enclosures has been investigated by Coulter and Guceri [25]. An experimental and numerical investigation is presented concerning the natural convection of water near its density in a differentially heated rectangular enclosure at high Rayleigh numbers by $\mathrm{Ho}$ and $\mathrm{Tu}$ [26], in which an oscillatory convection regime may arise. 
The unsteady, compressible effects were studied numerically by Akyuzlu et al. [27]. Their model included incompressible flow equations together with Boussinesq approximation and it was used to predict the transient circulation patterns and resulting thermal stratification of the propellant in a cryogenic storage tank for the constant heat flux boundary conditions. Steady, compressible effects were studied in closed cavities by Mazumder [28]. However, most of the researchers of natural convection in cavities and enclosures assume the density to be function of temperature only in the buoyancy term in the momentum equation (Boussinesq approximation.) According to Gray [29] a temperature difference less than 28.6 deg C between the hot and cold walls of the enclosure ensures the validity of this approximation.

There are many natural convection processes in various fields, and it is still a hot topic to investigate the fluid dynamics and heat transfer of natural convection. The analytical solutions are meaningful in both theoretical investigation and practical applications. Specially, they are very useful to computational fluid dynamics and heat transfer as benchmark solutions to check the numerical solutions and to develop numerical differencing schemes, and grid generation methods and so forth. An analytical study has been conducted for natural convection in a cavity of different aspect ratios with uniform volumetric heat generation by Joshi et al. [30]. Two explicit analytical solutions of 2-D steady laminar natural convection along a vertical porous plate and between two vertical plates were derived by Cai and Zhang [31]. The numerical study of natural convection in a differentially heated cavity with internal heat generation for different aspect ratios has been carried out by Fusegi et al. [32].

Most of the researchers have carried out their studies in two-dimension as it is done in the present study. This approach is being justified when the depth aspect ratio of the enclosure is greater than 5 [33]. Also, a three-dimensional approach may be the right choice when 
multicellular, transient flow characteristics are expected as in the case of high Grashof number flows where three-dimensional effects are important. Researchers like Viskanta [17], Hiller [18], Fusegi [33], and Wakitani [34] have addressed this problem by proposing three-dimensional mathematical models which required a new method of solution then the previously adopted ones. (See publications by de Vahl Davis [35] and Kublbeck [36]). The effect of wall thermal boundary conditions on the development of three-dimensional and unsteady natural convective flows was studied by Oosthizen et al. [37]. In 1997, multicellular solutions for air filled enclosure were developed by Wakitani [38]. A high aspect ratio $(\mathrm{AR}=16)$ enclosure was considered in his study. A numerical study is conducted to investigate the effect of subcooling on natural convection in a densified cryogenic propellant by Akyuzlu et al. [39].

Validation of a proposed model can be done by comparing the predicted values of velocity and temperature fields to those obtained in experiments. Although limited, there are published experimental data in the literature. (See work done by Viskanta [17], Nicolette [40], Kirkpatrick [41], Hiller [18], and Linthorst [42]). The experimental analysis through 2D-PIV system was provided by Corvaro and Paroncini in 2009 [43]. The same authors developed interferometry techniques in 2007 [44]. Natural convection of air in a tall vertical cavity was studied using a smoke patterns and interferometry by Wright et al. [45]. An experimental study of high Rayleigh number natural convection in an enclosure was conducted by Giel and Schmidt [46]. The experimental benchmark data for turbulent natural convection to validate a proposed CFD code is presented in a publication by Ampofo et al. [47]. Akyuzlu, Nemani, and Chakravarthy [48] used the Particle Velocimetry (PIV) system to experimentally investigate the effect of different heat transfer boundary conditions on natural convection inside a rectangular storage tank. Water was used as the working fluid. Another method of validation of a newly proposed 
mathematical model or solver is to predict the results of the benchmark case (heating of a square enclosure by isothermal walls.) In 1983, De Vahl Davis [2] numerically investigated the natural convection of air in a square enclosure. This study has widely been accepted as the benchmark case. The study used the non-dimensional stream function-vorticity formulation of the governing equations. The well known Boussinesq approximation was also incorporated.

Natural convection flows were also studied numerically inside rectangular cavities with inclination. Two dimensional natural convection flows in titled cavities for porous media and homogeneous fluids has been studied by Baez and Nicolas [49]. Natural convection in two dimensional enclosures with three flat and one wavy wall is numerically investigated by Dalal and Das [50]. In this study, one wall is having a sinusoidal temperature profile and other three walls including the wavy wall are maintained at constant cold temperature. A numerical study of the effect of a hot wavy wall of laminar natural convection in an inclined square cavity, differentially heated, was carried out by Adjlout et al. [51]. Flow visualization observations are described for natural convection flows in rectangular inclined enclosures by Linthorst et al. [42]. Variable property mathematical models were also developed to study natural convection in cavities and enclosures. The transient version of the classical differentially heated square cavity problem, considering fluid properties as functions of temperature has been studied by De Souza et al. [52]. Same problem with constant and variable fluid properties has been also studied by Leal et al. [53]. Variable property effects in laminar natural convection in a square enclosure were studied by Zhong et al. [54] and Emery et al. [55]. They indicate that the variable properties produced observable changes in the temperature and velocities, however, the overall heat transfer was found to be unaffected by it. The effects of combined temperature dependent thermodynamics and transport fluid properties on the heat transfer rate, heat function fields and 
profiles in a fluid filled square enclosure was quantitatively studied by Waheed [56]. The variations in fluid properties were also considered in the numerical studies conducted by Markatos and Pericleous [57].

Present study is a continuation of an effort undertaken in the Cryogenics Laboratory at the University of New Orleans in collaboration with the Advanced Programs division of LMMO in New Orleans and NASA Stennis Space Center to study the transient heating of densified liquid propellants in a cryogenic storage tank. Previous studies conducted by one of the authors of this paper [58 and 59] has indicated the importance of predicting, accurately, the circulation patterns that develop inside the propellant due to natural convection. This process dominates the heating of the propellant and is driven by the heat leak at the walls of the storage tank which leads to unwanted thermal stratification in the tank. This fact led our research group in the Cryogenics lab to adopt a compressible flow model (without Boussinesq assumption) with constant properties to study natural convection in square enclosures [27]. i.e., a two-dimensional rectangular enclosure with insulated top and bottom and with vertical walls kept at a prescribed temperature difference.

To solve the governing equations of the proposed mathematical model, an in-house numerical solver based on an implicit finite difference technique, a modified version of the SIP algorithm [60] called Coupled Modified Strongly Implicit Procedure (CMSIP) [61], was developed by our group. (See reference 35 for the details of this algorithm.) In the first set of numerical experiments using this solver, the fluid was assumed to be an ideal gas with $\operatorname{Pr}=1$ [27]. In the present study, the mathematical model has been improved by assuming the thermodynamic and transport properties of the fluid to be functions of temperature. The solution algorithm had to be modified accordingly. Furthermore, the present study uses a second order accurate time differencing for the CMSIP solution algorithm (see references [76] and [77]). 


\section{Chapter 3}

\section{Description of the Physical Model}

A two dimensional square enclosure is considered for this present study. The left wall of enclosure is maintained at a constant but higher temperature than the right wall. The top and bottom walls of the enclosure are assumed to be perfectly insulated. The enclosure is filled with air, which is considered to be a compressible ideal gas. Initially, the fluid inside the tank is assumed to be at an average temperature of the hot and cold walls. This temperature is called the reference temperature. The aspect ratio (ratio of height to width) is determined by the geometry

of the enclosure. In this study, since the length of the enclosure is taken to be equal to the height, the aspect ratio is computed to be unity. No slip conditions are assumed on all the walls of the enclosure and the walls are presumed to be impermeable. Orientation of the enclosure is depends on direction of gravitational force. Refer to Figure 1 for more details of the physical model.

The driving mechanism behind the natural convection phenomenon is buoyancy. In this case, the buoyancy is associated with gravity. Heat is transferred from the hot wall to the adjacent air particles resulting in a decrease in the density of the air near the hot wall. The less dense air begins to rise while the heavier (more dense) air starts falling downward near the cold wall consequently introducing a clockwise circulation. This type of buoyancy induced flow can be seen in heating or cooling of rooms and in cooling of transistors and transformers. 


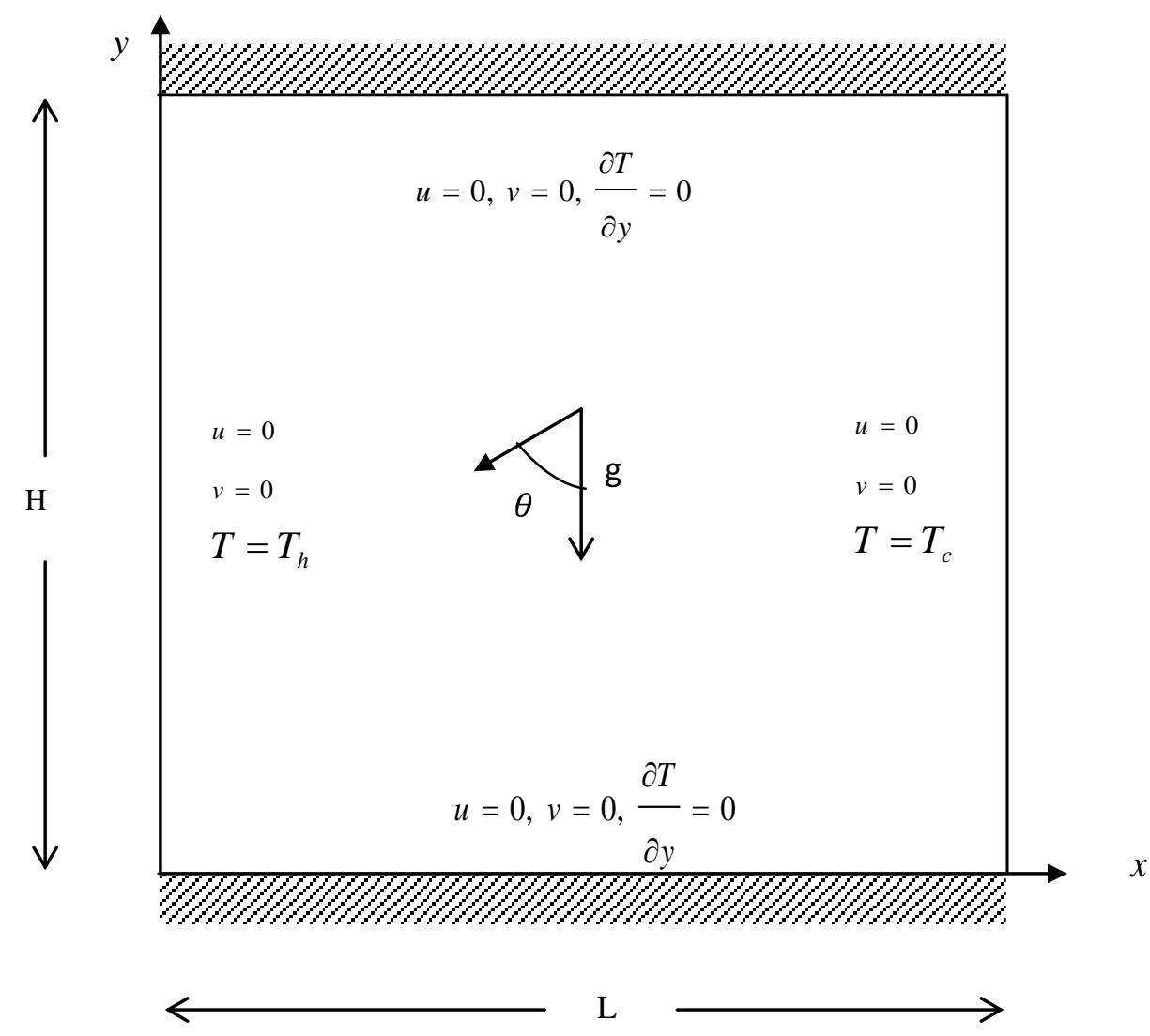

Figure 1- Schematic of the Physical Domain (Dimensional) and the Boundary Conditions

Depending on the Rayleigh number, the flow within the enclosure can be categorized as laminar, transitional, or turbulent. In this study, only laminar flows are considered. The Rayleigh numbers are kept below the transition limit (less than $1 \times 10^{7}$ ). The Rayleigh number is dependent on the properties of the working fluid, temperature differential between the vertical walls, and the characteristic length of the enclosure.

All the dimensional variables are transformed into a non-dimensional domain. The nondimensional physical model is shown in Figure 2. 


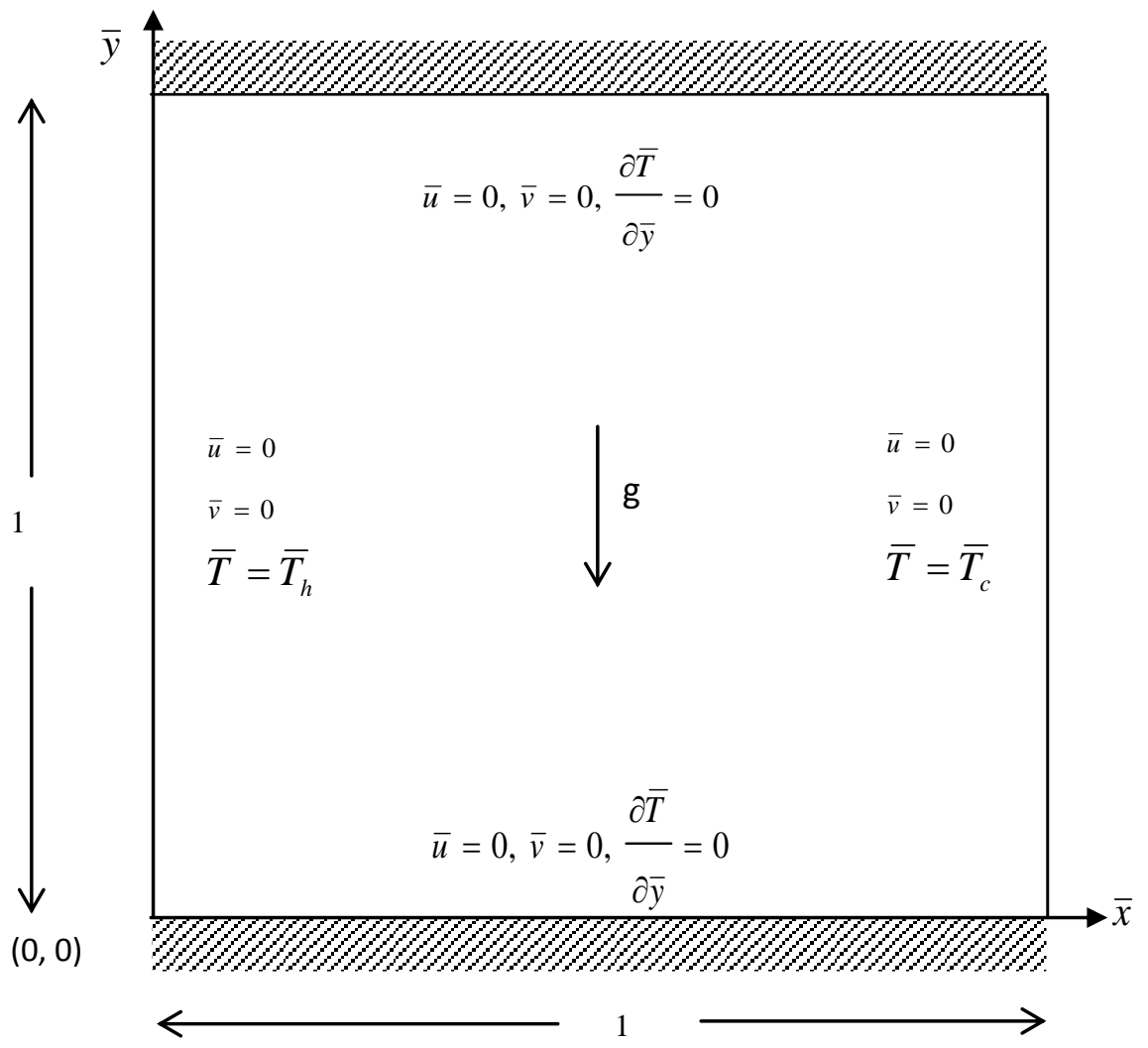

Figure 2- Schematic of the Physical Domain (Non- dimensional) and the Boundary Conditions 


\section{Chapter 4}

\section{Description of Mathematical Model}

The mathematical formulation of the conservation equations together with the initial and boundary conditions in first order and second order accurate in time models are given below. The dimensional governing equations were derived from the respective vector form (refer to Appendix I) and together with the initial and boundary conditions were then transformed into non-dimensional form. The non-dimensional forms of these equations as well as the assumptions made in the derivation of these equations are presented in this chapter.

\subsection{Assumptions of Mathematical Model}

The following assumptions were made for the present study.

1. The physical domain is two-dimensional and the equations are in Cartesian coordinates

2. The working fluid forms a continuum

3. The flow is unsteady, laminar, and viscous

4. The working fluid (air) is compressible (the density of the fluid is a function of temperature and pressure) and can be treated as an ideal gas.

5. The working fluid behaves like a Newtonian fluid with stokes assumptions

6. Pressure work term is negligible in the energy equation

7. Effects of viscous dissipation in the energy equation are insignificant

8. The kinetic and potential energy terms in the energy equations are neglected

9. Radiation heat transfer is ignored 
10. There are no internal heat sources

11. Heat conduction within the fluid follows Fourier's law

12. The physical properties of the fluid are assumed to be constant

13. Thermodynamic and transport properties are assumed to be function of temperature

\subsection{Dimensional Formulation}

After making the necessary assumptions given in section 4.1, each individual conservation equation was then derived from the respective vector form of that equation. The dimensional form of governing differential equations in conservative form can be referred to Appendix IIA. Then the equation of state was substituted in the conservational equations. The dimensional formulations of the governing equations for the four primitive variables $(u, v, p$ and $T$ ) of the present problem are given as follows

Continuity equation

$$
\frac{\partial}{\partial t}\left(\frac{p}{T}\right)+\frac{\partial}{\partial x}\left(\frac{p u}{T}\right)+\frac{\partial}{\partial y}\left(\frac{p v}{T}\right)=0
$$

Momentum equation in the $\mathrm{x}$-direction

$$
\begin{aligned}
\frac{\partial}{\partial t}\left(\frac{p u}{T}\right)+\frac{\partial}{\partial x}\left(\frac{p u u}{T}\right)+\frac{\partial}{\partial y}\left(\frac{p u v}{T}\right) & \frac{\partial(R p)}{\partial x}-\frac{\partial}{\partial x}\left[\frac{2}{3} R \mu\left(2 \frac{\partial u}{\partial x}-\frac{\partial v}{\partial y}\right)\right] \\
& -\frac{\partial}{\partial y}\left[R \mu\left(\frac{\partial u}{\partial y}+\frac{\partial v}{\partial x}\right)\right]+\left(\frac{p}{T}\right) g \sin \theta=0
\end{aligned}
$$

Momentum equation in the $y$-direction

$$
\begin{aligned}
\frac{\partial}{\partial t}\left(\frac{p v}{T}\right)+\frac{\partial}{\partial x}\left(\frac{p u v}{T}\right) & +\frac{\partial}{\partial y}\left(\frac{p v v}{T}\right)+\frac{\partial(R p)}{\partial y} \\
& -\frac{\partial}{\partial x}\left[R \mu\left(\frac{\partial u}{\partial y}+\frac{\partial v}{\partial x}\right)\right]-\frac{\partial}{\partial y}\left[\frac{2}{3} R \mu\left(2 \frac{\partial v}{\partial y}-\frac{\partial u}{\partial x}\right)\right]+\left(\frac{p}{T}\right) g \cos \theta=0
\end{aligned}
$$


Energy equation

$$
\frac{\partial}{\partial t}\left(c_{p} p\right)+\frac{\partial}{\partial x}\left(c_{p} p u\right)+\frac{\partial}{\partial y}\left(c_{p} p v\right)-\frac{\partial}{\partial x}\left(R k \frac{\partial T}{\partial x}\right)-\frac{\partial}{\partial y}\left(R k \frac{\partial T}{\partial y}\right)=0
$$

In both momentum equations, $\theta$ assumed to be zero for square enclosure with variable thermodynamic and transport properties, and also orientation of the enclosure was studied at different angles of $\theta$.

\subsection{Sub Models for Variable Thermodynamic and Transport Properties}

Specific heat at constant pressure and viscosity are assumed to be functions of temperature in the present study of natural convection. That is,

$$
C_{p}=f(T) \text { and } \mu=f(T)
$$

The specific heat at constant pressure is function of temperature for an ideal gas, $C_{p 0}$, can be given as (refer to appendix III)

$$
C_{p 0}=C_{0}+C_{1} \phi+C_{2} \phi^{2}+C_{3} \phi^{3}
$$

The viscosity function of temperature for an ideal gas can be given as (refer to appendix III)

$$
\frac{\mu}{\mu_{0}}=\left(\frac{T}{T_{0}}\right)^{3 / 2} \frac{T_{0}+S}{T+S}
$$

\subsection{Non-dimensional Formulation}

The non-dimensional conservation equations were transformed from the dimensional form of the equations given in the previous section 4.2 for present study of natural convection. The definitions of non-dimensional variables used in these governing differential equations are given below. In this study $\rho_{\text {ref }}$ was determined at $T_{\infty}$ and $P_{\infty}$. Reference characteristic length, $\mathrm{L}_{\text {ref, }}$ is then to be the initial height of the cavity, $\mathrm{H}$; i.e. $\mathrm{L}_{\text {ref }}=\mathrm{H}$ and also $\mathrm{T}_{\text {ref }}=T_{\infty}$ 


$$
\begin{aligned}
& R a=\frac{g \beta \Delta T H^{3}}{v \alpha} \\
& G r=\frac{g \beta \Delta T H^{3}}{v^{2}} \\
& u_{r e f}=\sqrt{G r} \frac{v}{H} \\
& \bar{t}=\frac{t}{L_{r e f} / u_{r e f}} \\
& \bar{x}=\frac{x}{L_{r e f}} \\
& \bar{y}=\frac{\rho_{r e f}^{2}}{\mu_{r e f}} \\
& \bar{p}=\frac{\rho}{\rho_{r e f} u_{r e f}} \\
& \bar{u}=\frac{\rho_{r e f}}{u_{r e f}} \\
& u_{r e f}
\end{aligned}
$$




$$
\begin{aligned}
& \bar{c}_{p}=\frac{c_{p}}{u_{r e f}^{2} / T_{r e f}} \\
& \operatorname{Pr}=\frac{c_{p} \mu}{k} \\
& F r=\frac{u_{r e f}}{\sqrt{g H}}
\end{aligned}
$$

Using the above parameters, the dimensional forms of equations were transformed into their non-dimensional forms.

\section{Continuity Equation}

$$
\frac{\partial}{\partial \bar{t}}\left(\frac{\bar{p}}{\bar{T}}\right)+\frac{\partial}{\partial \bar{x}}\left(\frac{\bar{p} \bar{u}}{\bar{T}}\right)+\frac{\partial}{\partial \bar{y}}\left(\frac{\bar{p} \bar{v}}{\bar{T}}\right)=0
$$

Momentum equation in $\mathrm{x}$-direction

$$
\begin{aligned}
\frac{\partial}{\partial \bar{t}}\left(\frac{\bar{p} \bar{u}}{\bar{T}}\right)+\frac{\partial}{\partial \bar{x}}\left(\frac{\bar{p} \bar{u} \bar{u}}{\bar{T}}\right) & +\frac{\partial}{\partial \bar{y}}\left(\frac{\bar{p} \bar{u} \bar{v}}{\bar{T}}\right)+\frac{\partial}{\partial \bar{x}}(\bar{R} \bar{p}) \\
& +\frac{1}{G r^{1 / 2}} \frac{\partial}{\partial \bar{x}}\left[\frac{2}{3} \bar{R} \bar{\mu}\left(2 \frac{\partial \bar{u}}{\partial \bar{x}}-\frac{\partial \bar{v}}{\partial \bar{y}}\right)\right]-\frac{1}{G r^{1 / 2}} \frac{\partial}{\partial y}\left[\bar{R} \bar{\mu}\left(\frac{\partial \bar{u}}{\partial \bar{y}}+\frac{\partial \bar{v}}{\partial \bar{x}}\right)\right]+\frac{1}{F r}\left(\frac{\bar{p}}{\bar{T}}\right) \sin \theta=0
\end{aligned}
$$

Momentum equation in $\mathrm{y}$-direction

$$
\begin{aligned}
\frac{\partial}{\partial \bar{t}}\left(\frac{\bar{p} \bar{v}}{\bar{T}}\right)+\frac{\partial}{\partial \bar{x}}\left(\frac{\bar{p} \bar{u} \bar{v}}{\bar{T}}\right)+\frac{\partial}{\partial \bar{y}}\left(\frac{\bar{p} \bar{v} \bar{v}}{\bar{T}}\right)+\frac{\partial}{\partial \bar{y}}(\bar{R} \bar{p}) \\
-\frac{1}{G r^{1 / 2}} \frac{\partial}{\partial \bar{x}}\left[\bar{R} \bar{\mu}\left(\frac{\partial \bar{v}}{\partial \bar{x}}+\frac{\partial \bar{u}}{\partial \bar{y}}\right)\right]-\frac{1}{G r^{1 / 2}} \frac{\partial}{\partial \bar{y}}\left[\frac{2}{3} \bar{R} \bar{\mu}\left(2 \frac{\partial \bar{v}}{\partial \bar{y}}-\frac{\partial \bar{u}}{\partial \bar{x}}\right)\right]+\frac{1}{F r}\left(\frac{\bar{p}}{\bar{T}}\right) \cos \theta \quad=0
\end{aligned}
$$


Energy equation

$$
\begin{aligned}
\frac{\partial}{\partial \bar{t}}\left(\bar{c}_{p} \bar{p}\right)+\frac{\partial}{\partial \bar{x}}\left(\bar{c}_{p} \bar{p} \bar{u}\right)+\frac{\partial}{\partial \bar{y}}\left(\bar{c}_{p} \bar{p} \bar{v}\right)- & \frac{1}{\operatorname{Pr} G r^{1 / 2}} \frac{\partial}{\partial \bar{x}}\left(\bar{R} \bar{c}_{p} \bar{\mu} \frac{\partial \bar{T}}{\partial \bar{x}}\right) \\
& -\frac{1}{\operatorname{Pr} G r^{1 / 2}} \frac{\partial}{\partial \bar{y}}\left(\bar{R}_{\bar{c}} \bar{\mu} \frac{\partial \bar{T}}{\partial \bar{y}}\right)=0
\end{aligned}
$$

\subsubsection{Boundary Conditions}

To complete the mathematical formulation, the following boundary conditions were used.

a. No slip condition was imposed on all the walls of the cavity

$$
\begin{array}{llll}
\bar{v}(0, \bar{y})=0 & \text { at } & \bar{x}=0 \\
\bar{v}(1, \bar{y})=0 & \text { at } & \bar{x}=1 \\
\bar{u}(\bar{x}, 0)=0 & \text { at } & \bar{y}=0 \\
\bar{u}(\bar{x}, 1)=0 & \text { at } & \bar{y}=1
\end{array}
$$

b. All the walls of the cavity were considered to be impermeable

$$
\begin{array}{lll}
\bar{u}(0, \bar{y})=0 & \text { at } & \bar{x}=0 \\
\bar{u}(1, \bar{y})=0 & \text { at } & \bar{x}=1 \\
\bar{v}(\bar{x}, 0)=0 & \text { at } & \bar{y}=0 \\
\bar{v}(\bar{x}, 1)=0 & \text { at } & \bar{y}=1
\end{array}
$$

c. All the walls of the cavity were assumed to be perfectly insulated. The walls were considered to be adiabatic i.e., no heat flux

$$
\begin{array}{lll}
\bar{T}(0, \bar{y})=\bar{T}_{h} & \text { at } & \bar{x}=0 \\
\bar{T}(1, \bar{y})=\bar{T}_{c} & \text { at } & \bar{x}=1
\end{array}
$$




$$
\begin{aligned}
& \frac{\partial \bar{T}}{\partial \bar{y}}(\bar{x}, 0)=0 \quad \text { at } \quad \bar{y}=0 \\
& \frac{\partial \bar{T}}{\partial \bar{y}}(\bar{x}, 1)=0 \quad \text { at } \quad \bar{y}=1
\end{aligned}
$$

\subsubsection{Initial Conditions}

Initially, the fluid within the enclosure was assumed to be motionless and isothermal. The initial temperature was assumed to be the reference temperature. The initial pressure distribution was calculated such that the steady state momentum equations were satisfied everywhere in the computational domain.

$$
\begin{aligned}
& \bar{u}(\bar{x}, \bar{y})=0 \quad \text { at } \quad \bar{t}=0 \\
& \bar{u}(\bar{x}, \bar{y})=0 \quad \text { at } \quad \bar{t}=0 \\
& \bar{T}(\bar{x}, \bar{y})=\bar{T}_{\text {ref }} \quad \text { at } \quad \bar{t}=0
\end{aligned}
$$




\section{Chapter 5}

\section{Numerical Formulation and Solution Technique}

The governing differential equations for the comprehensive mathematical model are coupled therefore the Coupled Modified Strongly Implicit Procedure (CMSIP) was used to solve them in terms of the primitive variables.

The descretization method used for the inner points of the computational domains, which are represented by a uniform orthogonal structured mesh, will be given in the next section. The discretization method used for boundary conditions are different and described in section 5.2 separately. The Newton's Linearization technique was developed to linearize the resulting nonlinear discretized governing differential equations in the section 5.3. The computational cell used for the discretization is shown below in figure 3 .

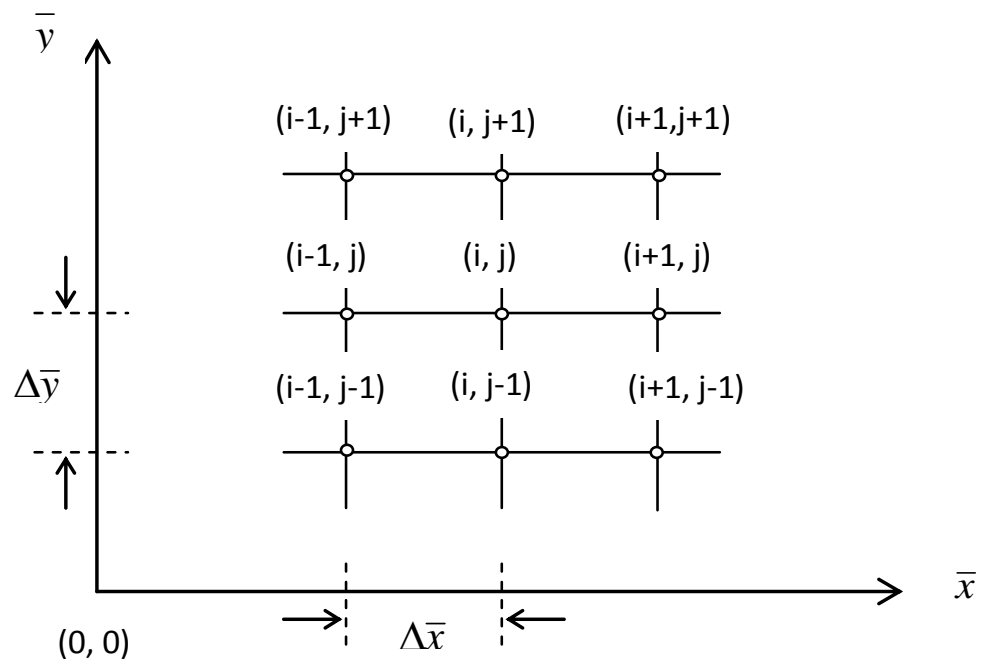

Figure 3- Computational Cell used for the Discretization of the Governing Differential Equations 


\subsection{Discretization of the Governing Differential Equations}

The governing differential equations are discretized using second order accurate central differencing for spatial derivatives and second order (based on Taylor Expansion) finite differencing for time derivatives.

Second order accurate approximation for the time term in the inertial term becomes

$$
\begin{gathered}
\left(\frac{\bar{p} \bar{u}}{\bar{T}}\right)_{i, j}^{n+1}=\left(\frac{\bar{p} \bar{u}}{\bar{T}}\right)_{i, j}^{n}+\frac{\Delta t}{2}\left[\frac{\partial}{\partial t}\left(\frac{\bar{p} \bar{u}}{\bar{T}}\right)_{i, j}^{n}+\frac{\partial}{\partial t}\left(\frac{\bar{p} \bar{u}}{\bar{T}}\right)_{i, j}^{n+1}\right]+O\left(\Delta t^{2}, \Delta x^{2}, \Delta y^{2}\right) \\
\frac{\partial}{\partial t}\left(\frac{\bar{p} \bar{u}}{\bar{T}}\right)_{i, j}^{n+1}=\frac{2}{\Delta t}\left[\left(\frac{\bar{p} \bar{u}}{\bar{T}}\right)_{i, j}^{n+1}-\left(\frac{\bar{p} \bar{u}}{\bar{T}}\right)_{i, j}^{n}\right]-\frac{\partial}{\partial t}\left(\frac{\bar{p} \bar{u}}{\bar{T}}\right)_{i, j}^{n}
\end{gathered}
$$

$\frac{\partial}{\partial t}\left(\frac{\bar{p} \bar{u}}{\bar{T}}\right)_{i, j}^{n}$ was derived from the Navier-Stokes equation at $\mathrm{n}^{\text {th }}$ time.

A central differencing was used for the first derivative of convection term in the axial direction:

$$
\frac{\partial}{\partial \bar{x}}\left(\frac{\bar{p} \bar{u} \bar{u}}{\bar{T}}\right)=\left[\left(\frac{\bar{p} \bar{u} \bar{u}}{\bar{T}}\right)_{i+1, j}^{n+1}-\left(\frac{\bar{p} \bar{u} \bar{u}}{\bar{T}}\right)_{i-1, j}^{n+1}\right] / 2 \Delta \bar{x}
$$

The diffusion term in the vertical direction was descritized using central differencing as given below:

$$
\frac{\partial}{\partial \bar{y}}\left(\bar{R} \bar{\mu} \frac{\partial \bar{v}}{\partial \bar{y}}\right)_{i, j}^{n+1}=\left[\left(\bar{R} \bar{\mu} \frac{\partial \bar{v}}{\partial \bar{y}}\right)_{i+\frac{1}{2}, j}^{n+1}-\left(\bar{R} \bar{\mu} \frac{\partial \bar{v}}{\partial \bar{y}}\right)_{i-\frac{1}{2}, j}^{n+1}\right] / \Delta \bar{y}
$$

The term evaluated at the $i+1 / 2$ nodal point is evaluated by taking the average value at i+1 and i nodes.

$$
(\bar{R} \bar{\mu})_{i+\frac{1}{2}}=\left[(\bar{R} \bar{\mu})_{i, j}+(\bar{R} \bar{\mu})_{i+1, j}\right] / 2
$$

The term evaluated at the $\mathrm{i}-1 / 2$ nodal point is evaluated by taking the average value at $\mathrm{i}-1$ and i nodes. 


$$
(\bar{R} \bar{\mu})_{i-\frac{1}{2}}=\left[(\bar{R} \bar{\mu})_{i, j}+(\bar{R} \bar{\mu})_{i-1, j}\right] / 2
$$

The first order derivative at plus half nodal point is evaluated as it shows below

$$
\left(\frac{\partial \bar{v}}{\partial \bar{y}}\right)_{i+\frac{1}{2}, j}^{n+1}=\left[\quad \bar{v}_{i+1, j}^{n+1}-\bar{v}_{i, j}^{n+1}\right] / \Delta \bar{y}
$$

and the same way the first order derivative for the minus half nodal point was evaluated

$$
\left(\frac{\partial \bar{v}}{\partial \bar{y}}\right)_{i-\frac{1}{2}, j}^{n+1}=\left[\quad \bar{v}_{i, j}^{n+1}-\bar{v}_{i-1, j}^{n+1}\right] / \Delta \bar{y}
$$

The second order mixed derivative was evaluated using central differencing as follows

$$
\frac{\partial}{\partial \bar{y}}\left(\bar{R} \bar{\mu} \frac{\partial \bar{u}}{\partial \bar{x}}\right)==\left[\left(\bar{R} \bar{\mu} \frac{\partial \bar{u}}{\partial \bar{x}}\right)_{i, j+1}^{n+1}-\left(\bar{R} \bar{\mu} \frac{\partial \bar{u}}{\partial \bar{x}}\right)_{i, j-1}^{n+1}\right] /(2 \Delta \bar{y})
$$

and

$$
\begin{aligned}
& \left(\frac{\partial \bar{u}}{\partial \bar{x}}\right)_{i, j+1}^{n+1}=\left[\quad \bar{u}_{i+1, j+1}^{n+1}-\bar{u}_{i-1, j+1}^{n+1}\right] /(2 \Delta \bar{x}) \\
& \left(\frac{\partial \bar{u}}{\partial \bar{x}}\right)_{i, j-1}^{n+1}=\left[\quad \bar{u}_{i+1, j-1}^{n+1}-\bar{u}_{i-1, j-1}^{n+1}\right] /(2 \Delta \bar{x})
\end{aligned}
$$

\subsubsection{Finite Difference Approximation for Boundary Conditions}

The first order derivative for the temperature gradient at the bottom and top boundaries was approximated by the four point forward and backward difference formulas, respectively. The elevation of the temperature gradient at the bottom wall is presented below as an example.

$$
\frac{\partial \bar{T}}{\partial \bar{y}}=0
$$

The approximation of the non-dimensional temperature at the all as given by the four point formula can be given by: 


$$
\bar{T}_{1}=\frac{1}{11}\left(18 \bar{T}_{2}-9 \bar{T}_{3}+2 \bar{T}_{4}\right)
$$

\subsection{Linearization of the Governing Differential Equations}

After discretization the non-linear equations are linearized for the unknown variables by Newton's method using the following general formula

$$
[u v \ldots . .]^{k+1}=[u v \ldots]^{k}+\frac{\partial[u v \ldots]^{k}}{\partial u}\left(u^{k+1}-u^{k}\right)+\frac{\partial[u v \ldots]^{k}}{\partial v}\left(v^{k+1}-v^{k}\right)+\ldots \ldots
$$

As an example the application of the above formula to various terms in the transform equation is presented below.

Consider the non-linear term $\quad\left(\frac{\bar{p}}{\bar{T}}\right)_{i, j}^{n+1}$ from the discritazation of the time term in the xmomentum equation, where the primitive variables are $\quad \bar{p}, \quad \bar{u}, \quad T$ application of Equation 5.14 results in:

$$
\begin{aligned}
\frac{\bar{p}_{i, j}^{n+1} \bar{u}_{i, j}^{n+1}}{\bar{T}_{i, j}}= & {\left[\frac{\bar{p} \bar{u}}{\bar{T}}\right]_{i, j}^{n+1, k}+\frac{\partial\left[\frac{\bar{p} \bar{u}}{\bar{T}}\right]_{i, j}^{n+1, k}\left(u_{i, j}^{n+, k+1}-u_{i, j}^{n+1, k}\right)}{\partial \bar{u}} } \\
& +\frac{\partial\left[\frac{\bar{p} \bar{u}}{\bar{T}}\right]_{i, j}^{n+1, k}\left(\bar{v}_{i, j}^{n+, k+1}-\bar{v}_{i, j}^{n+1, k}\right)+\frac{\partial[\bar{p} \bar{u}]_{i, j}^{n+1, k}}{\partial \bar{v}}\left(\bar{T}_{i, j}^{n+1, k+1}-\bar{T}_{i, j}^{n+1, k}\right)}{\partial \bar{T}} \\
= & {\left[\frac{\bar{p} \bar{u}}{\bar{T}}\right]_{i, j}^{n+1, k}+\left[\frac{\bar{p}}{\bar{T}}\right]_{i, j}^{n+1, k}\left(u_{i, j}^{n+1, k+1}-u_{i, j}^{n+1, k}\right) } \\
& +\left[\frac{\bar{u}}{\bar{T}}\right]_{i, j}^{n+1, k}\left(\bar{p}_{i, j}^{n+1, k+1}-\bar{p}_{i, j}^{n+1, k}\right)+\left[-\frac{\bar{p} \bar{u}}{\bar{T}^{2}}\right]_{i, j}^{n+1, k}\left(\bar{T}_{i, j}^{n+1, k+1}-\bar{T}_{i, j}^{n+1, k}\right) \\
= & {\left[\frac{\bar{p}}{\bar{T}}\right]_{i, j}^{n+1, k}\left(u_{i, j}^{n+1, k+1}\right)+\left[\frac{\bar{u}}{\bar{T}}\right]_{i, j}^{n+1, k}\left(\bar{p}_{i, j}^{n+1, k+1}\right)+\left[-\frac{\bar{p}^{n} \bar{u}}{\bar{T}^{2}}\right]_{i, j}^{n+1, k}\left(\bar{T}_{i, j}^{n+1, k+1}\right) }
\end{aligned}
$$


where $\mathrm{n}$ stands for a discrete time step and $\mathrm{k}$ for the number of iteration. In Equation (5.15), $\bar{p}_{i, j}^{n+1, k+1}, \bar{u}_{i, j}^{n+1, k+1}$, and $\bar{T}_{i, j}^{n+1, k+1}$ are the unknown and the rest are known coefficients from the previous iteration.

Another example of anon-linear term with four variables is $\quad\left(\frac{\bar{p} \bar{u} \bar{v}}{\bar{T}}\right)_{i, j+1}^{n+1}$ which is one of the convective terms in the y-momentum equation. Application of the linearization formula as given by Equation 5.14 yields:

$$
\begin{aligned}
& \frac{\bar{p}_{i, j+1}^{n+1} \bar{u}_{i, j+1}^{n+1} \bar{v}_{i, j+1}^{n+1}}{\bar{T}_{i, j+1}}=\left[\frac{\bar{p} \bar{u} \bar{v}}{\bar{T}}\right]_{i, j+1}^{n+1, k}+\frac{\partial\left[\frac{\bar{p} \bar{u} \bar{\nu}}{\bar{T}}\right]_{i, j+1}^{n+1, k}}{\partial \bar{u}}\left(\bar{p}_{i, j+1}^{n+1, k+1}-\bar{p}_{i, j+1}^{n+1, k}\right) \\
& +\frac{\partial\left[\frac{\bar{p} \bar{u} \bar{v}}{\bar{T}}\right]_{i, j+1}^{n+1, k}}{\partial \bar{u}}\left(\bar{u}_{i, j+1}^{n+1, k+1}-\bar{u}_{i, j+!}^{n+1, k}\right)+\frac{\partial\left[\frac{\bar{p} \bar{u} \bar{T}}{\bar{T}}\right]_{i, j+1}^{n+1, k}}{\partial \bar{v}}\left(\bar{v}_{i, j+1}^{n+1, k+1}-\bar{v}_{i, j+1}^{n+1, k}\right) \\
& +\frac{\partial\left[\frac{\bar{p} \bar{u} \bar{v}}{\bar{T}}\right]_{i, j+1}^{n+1, k}}{\partial \bar{T}}\left(\bar{T}_{i, j+1}^{n+1, k+1}-\bar{T}_{i, j+1}^{n+1, k}\right) \\
& =\left[\frac{\bar{p} \bar{u} \bar{v}}{\bar{T}}\right]_{i, j+1}^{n+1, k}+\left[\frac{\bar{u} \bar{v}}{\bar{T}}\right]_{i, j+1}^{n+1, k}\left(\bar{p}_{i, j+1}^{n+1, k+1}-\bar{p}_{i, j+!}^{n+1, k}\right)\left[\frac{\bar{p} \bar{v}}{\bar{T}}\right]_{i, j+!}^{n+1, k}\left(u_{i, j+!}^{n+1, k+1}-u_{i, j+!}^{n+1, k}\right) \\
& +\left[\frac{\bar{p} \overline{\bar{u}}}{\bar{T}}\right]_{i, j+1}^{n+1, k}\left(\bar{v}_{i, j+1}^{n+1, k+1}-\bar{v}_{i, j+!}^{n+1, k}\right)+\left[-\frac{\bar{p} \bar{u} \bar{v}}{\bar{T}^{2}}\right]_{i, j+!}^{n+1, k}\left(\bar{T}_{i, j+1}^{n+1, k+1}-\bar{T}_{i, j+!}^{n+1, k}\right) \\
& =\left[\frac{\bar{u}}{\bar{v}}\right]_{i, j+1}^{n+1, k}\left(\bar{p}_{i . j+1}^{n+1, k}\right)+\left[\frac{\bar{p} \bar{\nu}}{\bar{T}}\right]_{i, j+1}^{n+1, k}\left(u_{i, j+1}^{n+1, k+1}\right)+\left[\frac{\bar{p} \bar{u}}{\bar{T}}\right]_{i, j+1}^{n+1, k}\left(\bar{v}_{i, j+!}^{n+1, k+1}\right) \\
& +\left[-\frac{\bar{p} \bar{u}}{\bar{T}^{2}}\right]_{i, j+!}^{n+1, k}\left(\bar{T}_{i, j+1}^{n+1, k+1}\right)-\left[\frac{\bar{p} \bar{u} \bar{v}}{\bar{T}}\right]_{i, j+1}^{n+1, k}
\end{aligned}
$$




\subsection{Solution Technique}

A modified version of the Coupled Strongly Implicit Procedure (CSIP) developed by Zedan and Schneider [60] was used to solve for the primitive variables of the non-dimensional conservation equations. This modified version was proposed by Chen and Pletcher [67] and is called the Coupled Modified Strongly Implicit Procedure (CMSIP).

The descritized non-dimensional conservation equations after linearized are put into the following form for any nodal point $(i, j)$ of the computational domain

$$
\begin{aligned}
A_{i, j}^{6} x_{i-1, j-1}+A_{i, j}^{5} x_{i, j-1}+A_{i, j}^{4} x_{i+1, j-1}+A_{i, j}^{7} x_{i-1, j}+A_{i, j}^{9} x_{i, j} & \\
+ & A_{i, j}^{3} x_{i+1, j}+A_{i, j}^{8} x_{i-1, j+1}+A_{i, j}^{1} x_{i, j+1}+A_{i, j}^{2} x_{i+1, j+1}=b_{i, j}
\end{aligned}
$$

In the present study, where we have four primitive variables, the $\mathrm{x}$ in Equation 5.17 is 4 element vectors and $\mathrm{A}$ is a 4 by 4 matrix.

The computational molecule for $A^{1}, A_{i}^{2}, A^{3}, \ldots$ and $A^{9}$ in Equation 5.17 is shown in Figure 4.

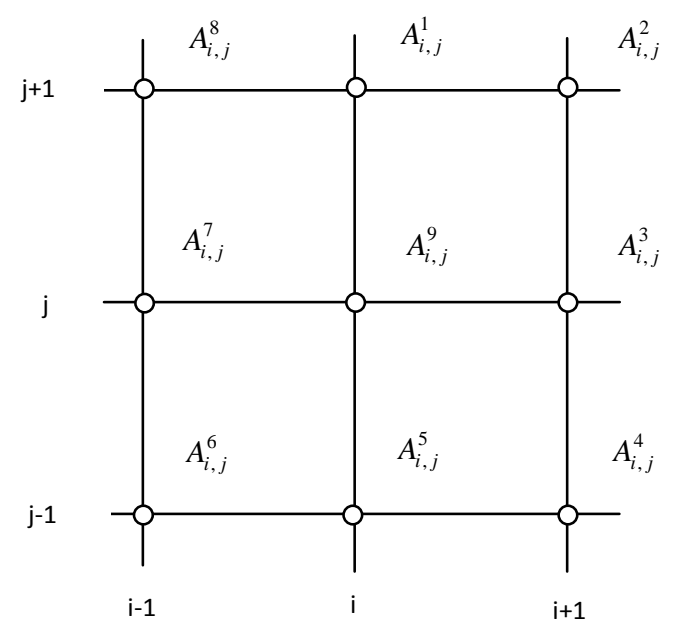

Figure 4- Two Dimensional Computational Molecules for the Elements of the A Matrix 
Similar equations are generated for the rest of the inner nodal points of the computational domain. The resulting sets of algebraic equations (as many as the number of the unknowns) are then put into block matrix in the following form:

$$
[A] \mathrm{x}=\mathrm{b}
$$

where $[\mathrm{A}]$ is the coefficient matrix, $\mathrm{x}$ is the unknown vector to solve for and $\mathrm{b}$ is the known vector. Except for boundaries with no slip condition, all boundary conditions were treated implicitly by writing the governing differential equations on the boundary points and then discretized and linearized before incorporating them into the block matrix form. The unknown vector has as many elements as the number of inner nodes in the computational domain. The [A] matrix is a block matrix and is defined as shown below:

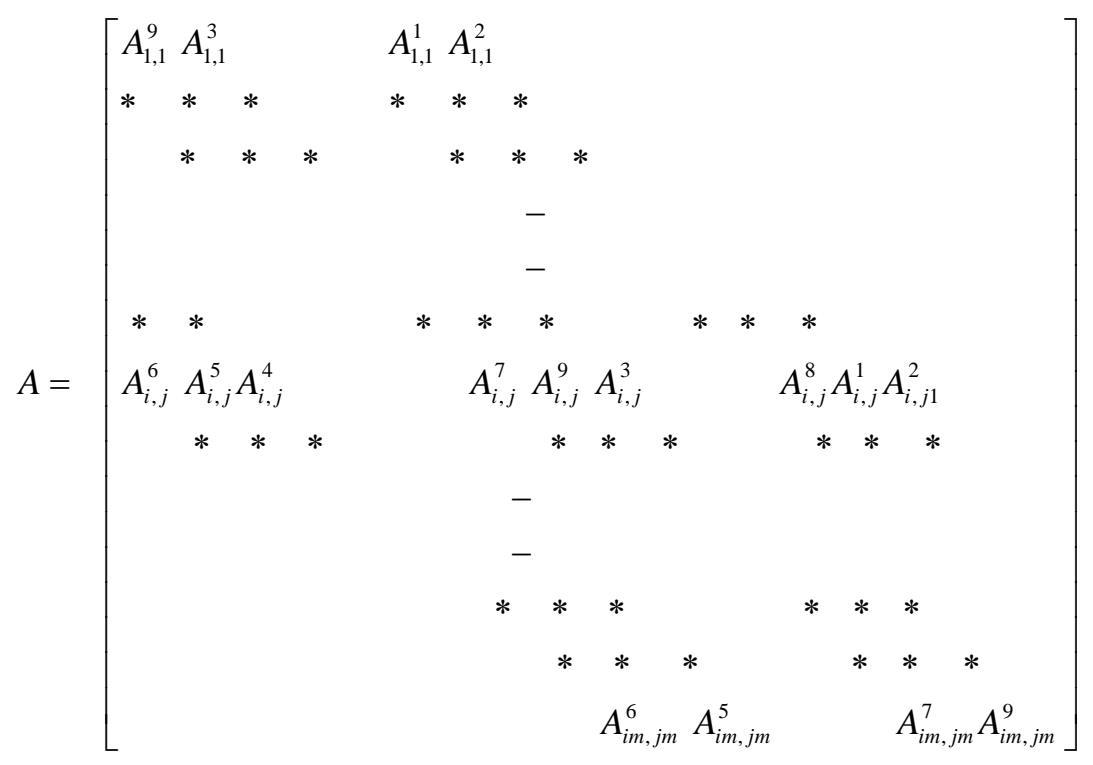


The vectors $\mathrm{x}$ and $\mathrm{b}$ are also of block form are presented below:
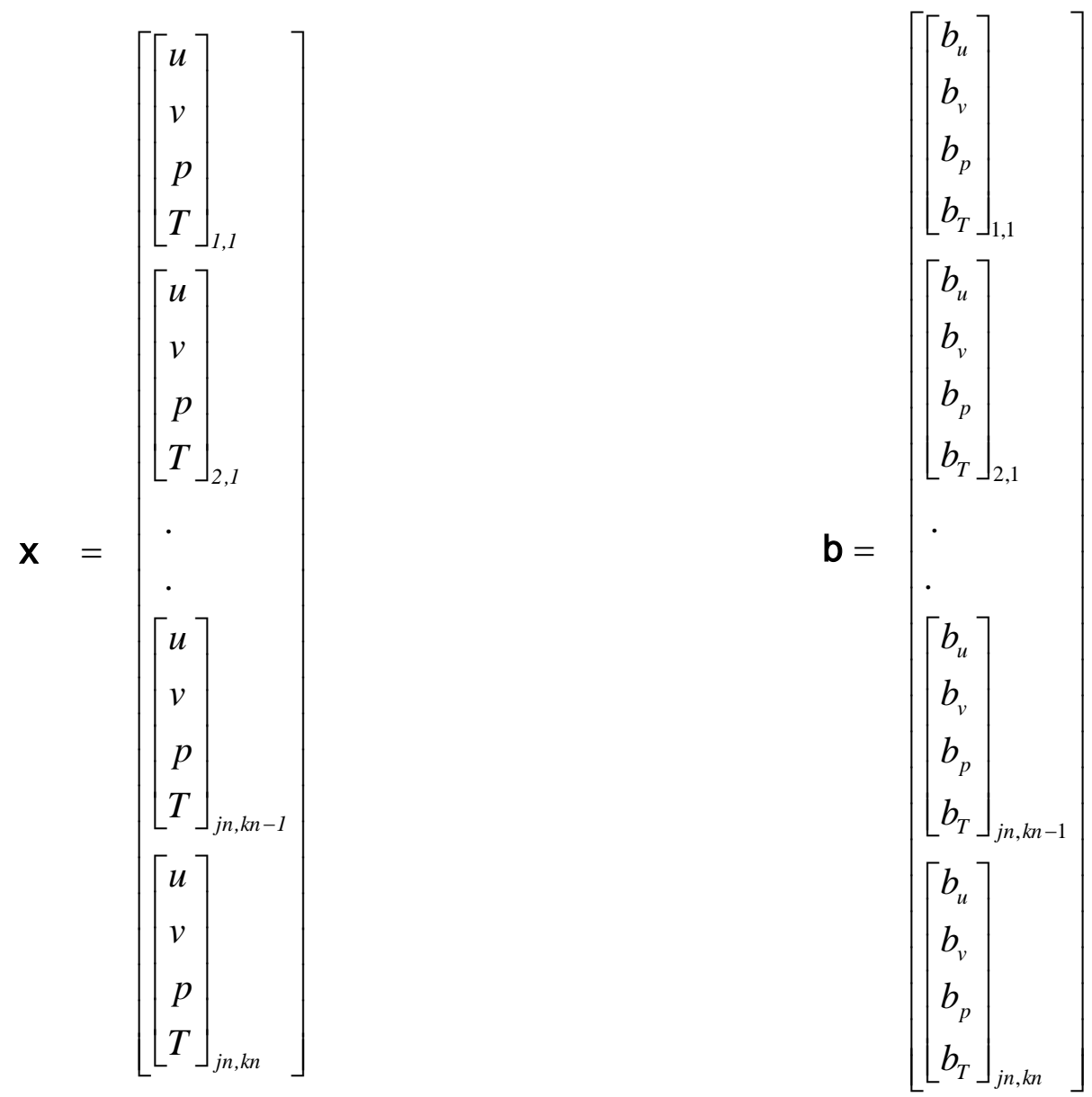

The coefficient matrix [A] is decomposed into upper and lower diagonal matrices [U] and [L] to solve the equation 5.18 and to make this possible an auxiliary matrix $[\mathrm{P}]$ was added to both sides of the equation.

$$
[A+P] x^{k+1}=b+[P] x^{k}
$$

where transcript $\mathrm{k}$ is for iteration

setting

$$
\delta^{k+1}=x^{k+1}-x^{k}
$$

and 


$$
R^{k}=b-[A] x^{k}
$$

in equation (5.19) becomes

$$
[A+P] \delta^{k+1}=R^{k}
$$

Replacing the matrix $[\mathrm{A}+\mathrm{P}]$ with the product of Lower-block triangular matrix $[\mathrm{L}]$ and Upperblock triangular matrix [U] in equation 5.20 (see appendix V), it becomes

$$
[L][U] \delta^{k+1}=R^{k}
$$

Defining the vector $\mathrm{W}$ by

$$
W^{k+1}=[U] \delta^{k+1}
$$

then equation (5.22) can be written as

$$
[L] W^{k+1}=R^{k}
$$

The solution of equation 5.19 is as follows:

The vector $\mathrm{W}^{\mathrm{k}+1}$ is calculated from equation (5.23) by forward substitution procedure and then vector $\delta^{\mathrm{k}+1}$ is computed from equation (5.22) by backward substitution. This procedure was repeated for the calculation of the new residual vector $\mathrm{R}$ followed by direct calculation of the $\mathrm{W}$ and $\delta$ until the convergence of $\mathrm{X}$ is attained.

The convergence depends upon the following criterion:

$$
\left(\frac{\sum_{i, j=1}^{i m, j m} \sum_{n=1}^{n=4}\left|\frac{\varphi_{n}^{k+1}-\varphi_{n}^{k}}{\varphi_{n, r m s}^{k+1}}\right|^{2}}{4 \times i m \times j m}\right)^{0.5} \leq \varepsilon
$$

where,

$\mathrm{k}$ is the iteration level, 
im is the number of grid points in the $\mathrm{x}$-direction

$\mathrm{jm}$ is the number of grid points in the $\mathrm{y}$ direction

$\mathrm{n}$ is the variable index

$\varphi_{\mathrm{n}}$ is the component of the unknown vector $\varphi$

$\varphi_{\mathrm{n}, \mathrm{rms}}$ is the root mean square value of $\varphi$

The value of $\varepsilon$ was set to $1 \times 10^{-7}$. This value of $\varepsilon$ was chooses by numerical experimentation.

A separate criterion for pressure was also considered.

$$
\left|p_{n}^{k+1}-p_{n}^{k}\right| \leq \varepsilon_{p}
$$

Its convergence value was set to $1 \times 10^{-7}$.

Second order time accuracy approximation was stabilized by adding pressure smoothening function as shown below.

$$
p_{i, j}=\sum_{i=2, j=2}^{i m-1, j m-1}\left(p_{i, j}+\frac{w}{2 \Delta x}\left(p_{i+1, j}-2 p_{i, j}+p_{i-1, j}\right)+\frac{w}{2 \Delta y}\left(p_{i, j+1}-2 p_{i, j}+p_{i, j-1}\right)+\right)
$$

where

$w$ is small constant assigned as 0.0005

\subsection{Solution Algorithm}

The solution was developed to implement the solution procedure (presented in previous section) used to solve the governing equations of this study.

The steps of this algorithm are given below.

1. All the necessary variables were defined and the corresponding arrays were dimensioned 
2. The input parameters such as non-dimensional computational, geometrical, and operational parameters were defined

3. The initial conditions were imposed, the velocities were set to zero and the temperature was assumed to be uniform with a value of unity. For natural convection, a hydrostatic pressure distribution was assumed in the vertical direction while the pressure distribution in the horizontal direction was assumed invariant.

4. The appropriate boundary conditions were imposed on all the walls of the enclosure. The velocities were set to zero. The temperatures on the left and right vertical walls were set to the corresponding non-dimensional hot and cold values.

5. The matrices for the corresponding inner nodes were generated

6. The Coupled Modified Strongly Implicit Procedure was implemented as explained in the previous section and counter for linearization is activated.

7. Values of the primitive variables were computed for the future time step. This was an iterative process. The iteration was stopped when the difference between the predicted values at iteration level $\mathrm{k}+1$ and $\mathrm{k}$ was smaller than a given criteria. The separate criterion was also verified for pressure.

8. Steps 5 through 7 were repeated for each time step until the final simulation time was reached.

9. Steady state was verified for all the nodal points in the domain.

The above solution algorithm was implemented into a computer code in Fortran by Akyuzlu and Antoniou [62]. This code was executed to generate the simulations of natural convection of an incompressible fluid inside an enclosure with differentially heated side walls. 


\section{Chapter 6}

\section{The Validation of the Mathematical and Computer Codes}

In this study, various numerical studies have been carried out to establish the validity of the natural convection phenomenon. When numerical methods are used to solve differential equations, getting a numerical stable solution does not immediately imply that this is the correct one. A time convergence study and grid independence study requires that there are not significant changes in the results when the computational time increment and grid size are varied. Furthermore, the computer code developed for the present study was tested for accuracy using benchmark studies. These case studies are presented in this chapter.

\subsection{First Order Accurate in Time Model}

Time convergence and grid independent studies were presented for first order accurate in time model in the following section.

\subsubsection{Time Convergence Study}

A time convergence study was carried out using three different non-dimensional time steps $1 \times 10^{-5}, 5 \times 10^{-6}$ and $1 \times 10^{-6}$ for the present study. Once the grid size is set, the time computational time convergence is determined by satisfying the diagonal dominance condition of the coefficient matrix. For the present code validation study, the biggest non-dimensional computational time step is $1 \times 10^{-5}$. It was found that a time increment smaller than this did not result in any significant changes in qualitative and quantitative results. To illustrate this point, non-dimensional vertical velocity distribution along the horizontal centerline of the enclosure were compared for different time increments such as $\Delta \bar{t}=1 \times 10^{-5}, \Delta \bar{t}=5 \times 10^{-6}$ and $\Delta \bar{t}=1 \mathrm{x}$ 
$10^{-6}$ for $\mathrm{Ra}=10^{5}$ and $21 \times 21$ mesh points. The quantitative comparison is presented in Table 1

and the comparison of predicted non-dimensional vertical velocity profiles is presented in Figure

5.

Table 1- Steady State Non-dimensional values of Vertical Velocity along the Horizontal Centerline of the Enclosure for $\Delta \bar{t}=1.0 \mathrm{E}-5, \Delta \bar{t}=5.0 \mathrm{E}-6$ and $\Delta \bar{t}=1.0 \mathrm{E}-6$

$$
\left(\mathrm{Ra}=10^{5} \text { and } 21 \times 21\right)
$$

\begin{tabular}{|c|c|c|c|}
\hline $\begin{array}{c}\text { Non-dimensional } \\
\text { Horizontal } \\
\text { Distance, } \bar{x}\end{array}$ & $\begin{array}{c}\text { Non-dimensional } \\
\text { Vertical } \\
\text { Velocity, } \bar{v} \\
(\Delta \bar{t}=1.0 \mathrm{E}-5)\end{array}$ & $\begin{array}{c}\text { Non-dimensional } \\
\text { Vertical } \\
\text { Velocity, } \bar{v} \\
(\Delta \bar{t}=5.0 \mathrm{E}-6)\end{array}$ & $\begin{array}{c}\text { Non-dimensional } \\
\text { Vertical } \\
\text { Velocity, } \bar{v} \\
(\Delta \bar{t}=1.0 \mathrm{E}-6)\end{array}$ \\
\hline 1.00 & 0.0000000 & 0.0000000 & 0.0000000 \\
\hline 0.95 & -0.2465031 & -0.2405049 & -0.2455756 \\
\hline 0.90 & -0.2011154 & -0.2007765 & -0.2008536 \\
\hline 0.85 & -0.1036450 & -0.1085817 & -0.1036823 \\
\hline 0.80 & -0.0343976 & -0.1489494 & -0.0347446 \\
\hline 0.75 & -0.0019368 & -0.0411735 & -0.0023072 \\
\hline 0.70 & 0.0096405 & 0.0066313 & 0.0093005 \\
\hline 0.65 & 0.0114227 & 0.0093207 & 0.0111182 \\
\hline 0.60 & 0.0103105 & 0.0085196 & 0.0100377 \\
\hline 0.55 & 0.0077418 & 0.0060819 & 0.0074892 \\
\hline 0.50 & 0.0049455 & 0.0033997 & 0.0047312 \\
\hline 0.45 & 0.0020850 & 0.0008425 & 0.0019073 \\
\hline 0.40 & 0.0001912 & -0.0005219 & 0.0000633 \\
\hline 0.35 & 0.0011802 & 0.0012908 & 0.0010889 \\
\hline 0.30 & 0.0084302 & 0.0096339 & 0.0083634 \\
\hline 0.25 & 0.0281221 & 0.0306583 & 0.0280601 \\
\hline 0.20 & 0.0667380 & 0.0706031 & 0.0666712 \\
\hline 0.15 & 0.1275761 & 0.1322839 & 0.1275338 \\
\hline 0.10 & 0.1938100 & 0.1977258 & 0.1938031 \\
\hline 0.05 & 0.2009478 & 0.2019970 & 0.2009947 \\
\hline 0.00 & 0.0000000 & 0.0000000 & 0.0000000 \\
\hline & & & \\
\hline
\end{tabular}




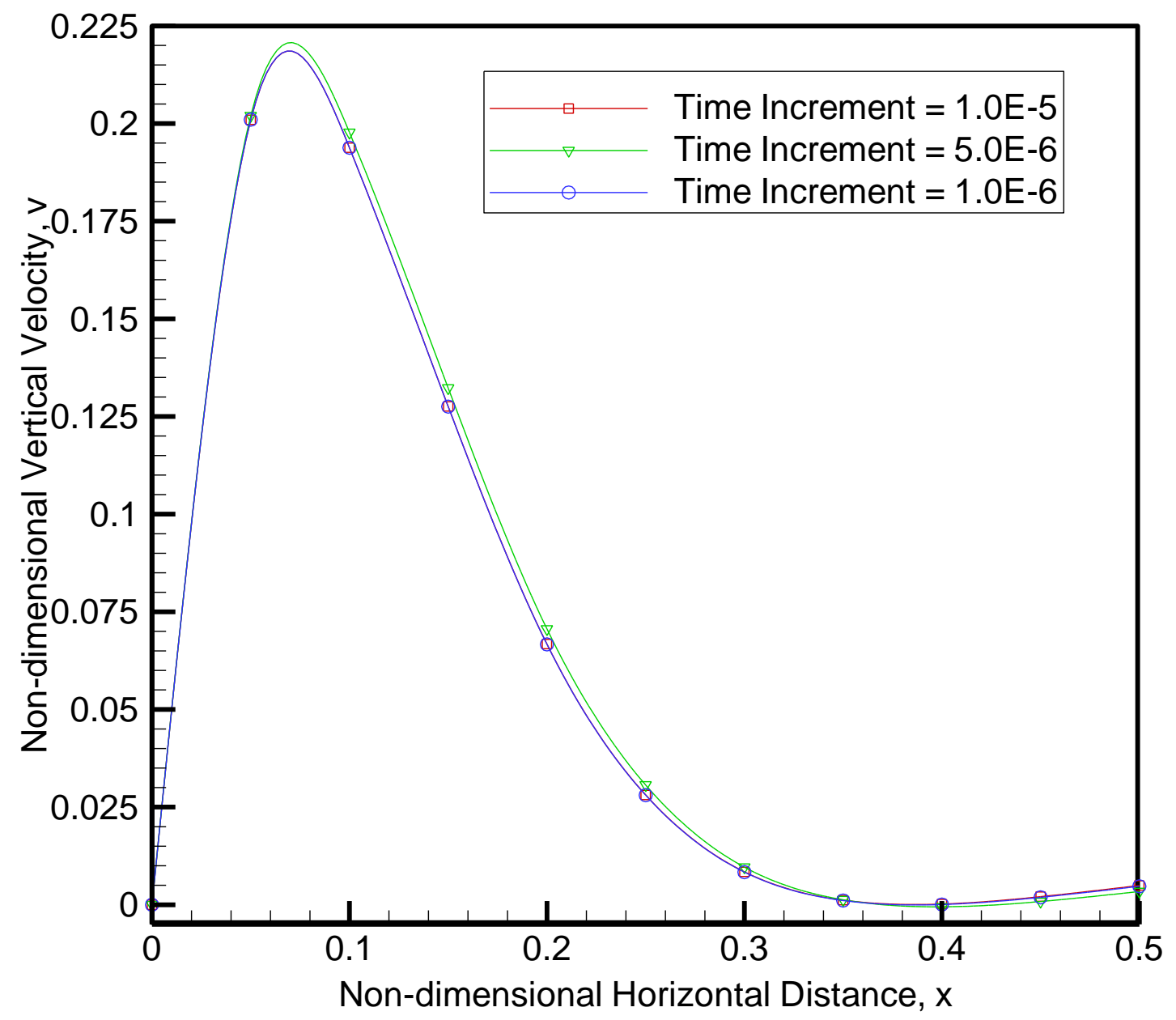

Figure 5- Comparison of Steady State Non-dimensional Vertical Velocity Distribution along the Half of the Horizontal Centerline for $\Delta \bar{t}=1.0 \mathrm{E}-5, \Delta \bar{t}=5.0 \mathrm{E}-6$ and $\Delta \bar{t}=1.0 \mathrm{E}-6$ at $\mathrm{Ra}=10^{5}$ 


\subsubsection{Grid Independence Study}

In order to validate the accuracy and convergence of the computer code, a grid independence study for the present study $\left(\mathrm{Ra}=10^{5}\right)$ was also conducted. The grid size chosen for the present study was $21 \times 21$. To verify that the converged solutions were independent of the grid chosen one more study was carried out with grid size of $41 \mathrm{x} 41$. Steady state results using uniform, orthogonal $21 \times 21$ and $41 \times 41$ meshes were obtained using the present computer code. The Comparison of the predicted non-dimensional vertical velocity profiles along the $\mathrm{x}$-axis for

grid independence study at $\mathrm{Ra}=10^{5}$ is presented in Figure 6 and the quantitative comparison is presented in Table 2. 
Table 2- Steady State Non-dimensional values of Vertical Velocity along the Horizontal Centerline of the Enclosure for $21 \times 21$ and $41 \times 41\left(\mathrm{Ra}=10^{5}\right.$ and $\left.21 \times 21\right)$

\begin{tabular}{|c|c|c|c|}
\hline $\begin{array}{c}\text { Non-dimensional } \\
\text { Horizontal } \\
\text { Distance, } \bar{x}\end{array}$ & $\begin{array}{l}\text { Non-dimensional } \\
\text { Vertical } \\
\text { Velocity, } \bar{v} \\
(21 \times 21)\end{array}$ & $\begin{array}{l}\text { Non-dimensional } \\
\text { Vertical } \\
\text { Velocity, } \bar{v} \\
(41 \times 41)\end{array}$ & $\begin{array}{c}\% \text { Deviation } \\
\text { in } \bar{v}\end{array}$ \\
\hline 1.00 & 0.0000000 & 0.0000000 & 0.0000000 \\
\hline 0.95 & -0.2440615 & -0.2412806 & -1.1525584 \\
\hline 0.90 & -0.2006345 & -0.2090486 & 4.0249492 \\
\hline 0.85 & -0.1048553 & -0.1148455 & 8.6988170 \\
\hline 0.80 & -0.0364389 & -0.0460759 & 20.915360 \\
\hline 0.75 & -0.0036786 & -0.0116106 & 68.316591 \\
\hline 0.70 & 0.0081803 & 0.0014213 & -475.55753 \\
\hline 0.65 & 0.0103389 & 0.0043900 & -135.50819 \\
\hline 0.60 & 0.0093217 & 0.0034348 & -171.38688 \\
\hline 0.55 & 0.0069599 & 0.0011907 & -484.48458 \\
\hline 0.50 & 0.0042331 & -0.0013476 & 414.12458 \\
\hline 0.45 & 0.0016037 & -0.0037290 & 143.00665 \\
\hline 0.40 & -0.0001891 & -0.0053963 & 96.496226 \\
\hline 0.35 & 0.0010085 & -0.0050037 & 120.15436 \\
\hline 0.30 & 0.0082728 & 0.0007297 & -1033.7072 \\
\hline 0.25 & 0.0281219 & 0.0187185 & -50.235167 \\
\hline 0.20 & 0.0668939 & 0.0602751 & -10.981119 \\
\hline 0.15 & 0.1284077 & 0.1349891 & 4.8755048 \\
\hline 0.10 & 0.1954522 & 0.2255438 & 13.341798 \\
\hline 0.05 & 0.2031731 & 0.2394256 & 15.141447 \\
\hline 0.00 & 0.0000000 & 0.0000000 & 0.0000000 \\
\hline
\end{tabular}




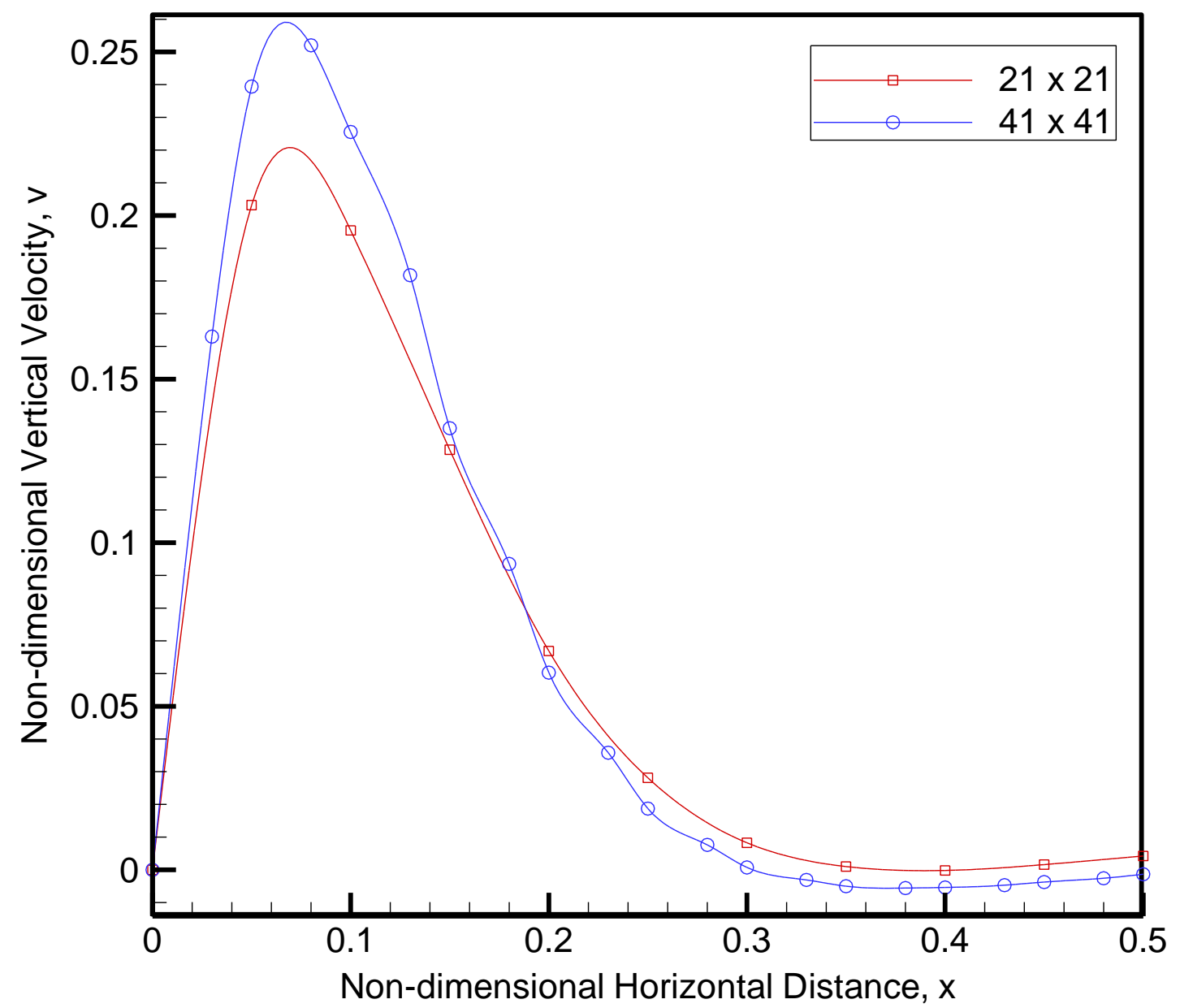

Figure 6- Comparison of Steady State Non-dimensional Vertical Velocity Distribution along the Half of the Horizontal Centerline for Grid Sizes of 21 x 21 and 41 x 41 at

$$
\mathrm{Ra}=10^{5}
$$

It is evident in these comparisons that the accuracy of the results increased with finer grid sizes, as expected. 


\subsubsection{Benchmarking of the Developed Code}

After verifying the time convergence and grid dependence studies, the computer code was developed for this study was tested for the accepted benchmark case provided by de Vaul Davis [2] (for incompressible flow with Boussinesq approximation). A quantitative comparison of maximum velocities in the horizontal and vertical directions as predicted by this study and de Vaul Davis is presented below in Table 3 where $\tilde{u}=u H / \alpha$ and $\tilde{v}=v H / \alpha$.

Table 3- Comparison of the Results of the Constant Properties [27] and the Benchmark Case (de Vahl Davis, [2]) for Different Rayleigh Numbers

\begin{tabular}{|c|c|c|c|}
\hline $\begin{array}{c}\text { Rayleigh } \\
\text { Number }\end{array}$ & $\begin{array}{c}\text { Constant } \\
\text { Properties } \\
\tilde{u}_{\max }\end{array}$ & $\begin{array}{c}\text { Benchmark } \\
\text { Case } \\
\tilde{u}_{\max }\end{array}$ & $\begin{array}{c}\% \\
\text { Deviation } \\
\text { in } \tilde{u}_{\max }\end{array}$ \\
\hline $10^{4}$ & 15.772 & 16.178 & -2.509 \\
\hline $10^{5}$ & 37.241 & 34.730 & +7.230 \\
\hline
\end{tabular}

\begin{tabular}{|c|c|c|c|}
\hline $\begin{array}{c}\text { Rayleigh } \\
\text { Number }\end{array}$ & $\begin{array}{c}\text { Constant } \\
\text { Properties } \\
\tilde{v}_{\max }\end{array}$ & $\begin{array}{c}\text { Benchmark } \\
\text { Case } \\
\tilde{v}_{\max }\end{array}$ & $\begin{array}{c}\% \\
\text { Deviation } \\
\text { in } \tilde{\boldsymbol{v}}_{\max }\end{array}$ \\
\hline $10^{4}$ & 18.927 & 19.617 & -3.517 \\
\hline $10^{5}$ & 68.629 & 68.590 & +0.057 \\
\hline
\end{tabular}

A comparison of the results of this study (which is based on compressible flow with constant properties assumption) and that of de Vahl Davis's study [2] indicates observable differences. The absolute value of maximum computed horizontal velocity underestimated corresponding benchmark value by $2.5 \%$ for $\mathrm{Ra}=10^{4}$. However, for $\mathrm{Ra}=10^{5}$, same value overestimated by $7.2 \%$. Similarly, the maximum difference between the benchmark vertical value and the present value is $3.5 \%$ for $\mathrm{Ra}=10^{4}$, and almost negligible difference in the same value for $\mathrm{Ra}=10^{5}$. 


\subsection{Second Order Accurate in Time Model}

A numerical study was carried out to determine the differences between the predicted unsteady velocity and temperature profiles, while the circulation patterns were developing after a step change in wall temperatures using the first order and second order accurate in time CMSIP algorithms. Time convergence and grid dependence studies were conducted to verify the accuracy of the second order accuracy in time model.

\subsubsection{Time Convergence Study}

A time convergence study was carried out for the present study which is second order accurate in time. As presented in section 6.1.1, once the grid size is set, the time computational time convergence is determined by satisfying the diagonal dominance condition of the coefficient matrix. For the present code validation study, a non-dimensional computational time increment of $1 \times 10^{-5}$ was considered. It was found that a time increment smaller than this did not result in any significant changes in qualitative and quantitative results. To illustrate, nondimensional vertical velocity distribution along the horizontal centerline of the enclosure were compared for different time increments such as $\Delta \bar{t}=1 \times 10^{-5}$ and $\Delta \bar{t}=5 \times 10^{-6}$ for $\mathrm{Ra}=10^{5}$ and $21 \times 21$ mesh points. The quantitative comparison is presented in Table 4 and qualitative comparison is presented in Figure 7. 
Table 4- Steady State Non-dimensional values of Vertical Velocity along the Horizontal Centerline of the Enclosure for $\Delta \bar{t}=1.0 \mathrm{E}-5$ and $\Delta \bar{t}=5.0 \mathrm{E}-6$ at $\mathrm{Ra}=10^{5}$ in Second Order Time Accurate Approximation

\begin{tabular}{|c|c|c|}
\hline $\begin{array}{c}\text { Non-dimensional } \\
\text { Horizontal } \\
\text { Distance, } \bar{x}\end{array}$ & $\begin{array}{c}\text { Non-dimensional } \\
\text { Vertical } \\
\text { Velocity, } \bar{v} \\
(\Delta \bar{t}=1.0 \mathrm{E}-5)\end{array}$ & $\begin{array}{c}\text { Non-dimensional } \\
\text { Vertical } \\
\text { Velocity, } \bar{v} \\
(\Delta \bar{t}=5.0 \mathrm{E}-6)\end{array}$ \\
\hline 1.00 & 0.0000000 & 0.0000000 \\
\hline 0.95 & -0.2440447 & -0.2461275 \\
\hline 0.90 & -0.2002889 & -0.2023205 \\
\hline 0.85 & -0.1043035 & -0.1047269 \\
\hline 0.80 & -0.0357540 & -0.0352146 \\
\hline 0.75 & -0.0031484 & -0.0024742 \\
\hline 0.70 & 0.0086785 & 0.0092366 \\
\hline 0.65 & 0.0106349 & 0.0110582 \\
\hline 0.60 & 0.0095869 & 0.0099664 \\
\hline 0.55 & 0.0070514 & 0.0074107 \\
\hline 0.50 & 0.0043028 & 0.0046463 \\
\hline 0.45 & 0.0015101 & 0.0017887 \\
\hline 0.40 & -0.0003056 & -0.0001617 \\
\hline 0.35 & 0.0007269 & 0.0006464 \\
\hline 0.30 & 0.0079743 & 0.0075860 \\
\hline 0.25 & 0.0276678 & 0.0269726 \\
\hline 0.20 & 0.0664488 & 0.0656514 \\
\hline 0.15 & 0.1278468 & 0.1274489 \\
\hline 0.10 & 0.1949693 & 0.1957688 \\
\hline 0.05 & 0.2027110 & 0.2048181 \\
\hline 0.00 & 0.0000000 & 0.0000000 \\
\hline
\end{tabular}




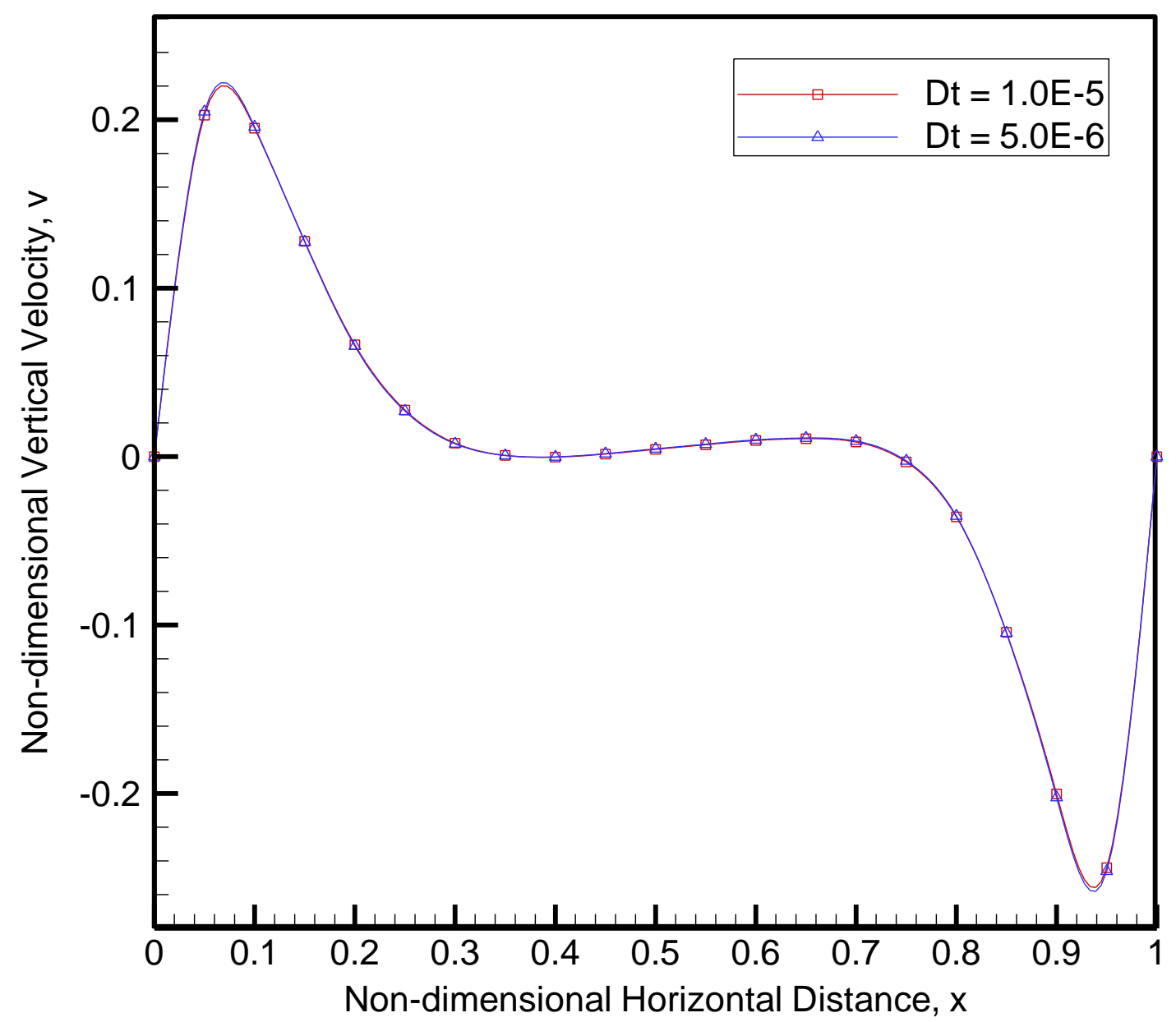

Figure 7- Steady State Non-dimensional Vertical Velocity Distribution along the Horizontal Centerline for $\Delta \bar{t}=1.0 \mathrm{E}-5, \Delta \bar{t}=5.0 \mathrm{E}-6$ and $\Delta \bar{t}=1.0 \mathrm{E}-6$ at $\mathrm{Ra}=10^{5}$ in Second Order Time Accurate Approximation 


\subsubsection{Grid Independence Study}

In order to validate the accuracy and convergence of the previous published results in the first order accurate in time, a grid independence study for the present study $\left(\mathrm{Ra}=10^{5}\right)$ was also conducted. Steady state results using uniform, orthogonal 21 x 21 and 41 x 41 meshes were obtained using the present computer code. The centerline non-dimensional vertical velocity profiles for are presented in Figure 8 and in Table 5, quantitative comparison is presented. It is evident in these comparisons that the accuracy of the results increased with finer grid sizes. 
Table 5- Steady State Non-dimensional values of Vertical Velocity along the Horizontal Centerline of the Enclosure for 21 X 21 and 41 X 41 at $\mathrm{Ra}=10^{5}$ in Second Order Time Accurate Approximation

\begin{tabular}{|c|c|c|c|}
\hline $\begin{array}{c}\text { Non-dimensional } \\
\text { Horizontal } \\
\text { Distance, } \bar{x}\end{array}$ & $\begin{array}{l}\text { Non-dimensional } \\
\text { Vertical } \\
\text { Velocity, } \bar{v} \\
(21 \times 21)\end{array}$ & $\begin{array}{c}\text { Non-dimensional } \\
\text { Vertical Velocity, } \\
\bar{v} \\
(41 \times 41)\end{array}$ & $\begin{array}{c}\% \text { Deviation } \\
\text { in } \bar{v}\end{array}$ \\
\hline 1.00 & 0.0000000 & 0.0000000 & 0.0000000 \\
\hline 0.95 & -0.2440447 & -0.2408513 & -1.3258803 \\
\hline 0.90 & -0.2002889 & -0.2085564 & 3.9641554 \\
\hline 0.85 & -0.1043035 & -0.1143165 & 8.7590155 \\
\hline 0.80 & -0.0357540 & -0.0455260 & 21.464604 \\
\hline 0.75 & -0.0031484 & -0.0110939 & 71.619711 \\
\hline 0.70 & 0.0086785 & 0.001856 & -367.35998 \\
\hline 0.65 & 0.0106349 & 0.0047221 & -125.21089 \\
\hline 0.60 & 0.0095869 & 0.0036587 & -162.02546 \\
\hline 0.55 & 0.0070514 & 0.0013085 & -438.88896 \\
\hline 0.50 & 0.0043028 & -0.0013337 & 422.59862 \\
\hline 0.45 & 0.0015100 & -0.0038197 & 139.53328 \\
\hline 0.40 & -0.0003056 & -0.0055958 & 94.538590 \\
\hline 0.35 & 0.0007269 & -0.0053183 & 113.66860 \\
\hline 0.30 & 0.0079743 & 0.0002984 & -2571.8144 \\
\hline 0.25 & 0.0276678 & 0.0181909 & -52.097092 \\
\hline 0.20 & 0.0664488 & 0.0597164 & -11.273841 \\
\hline 0.15 & 0.1278468 & 0.1345171 & 4.9587004 \\
\hline 0.10 & 0.1949693 & 0.2252853 & 13.456714 \\
\hline 0.05 & 0.2027110 & 0.2394137 & 15.330242 \\
\hline 0.00 & 0.0000000 & 0.0000000 & 0.0000000 \\
\hline
\end{tabular}




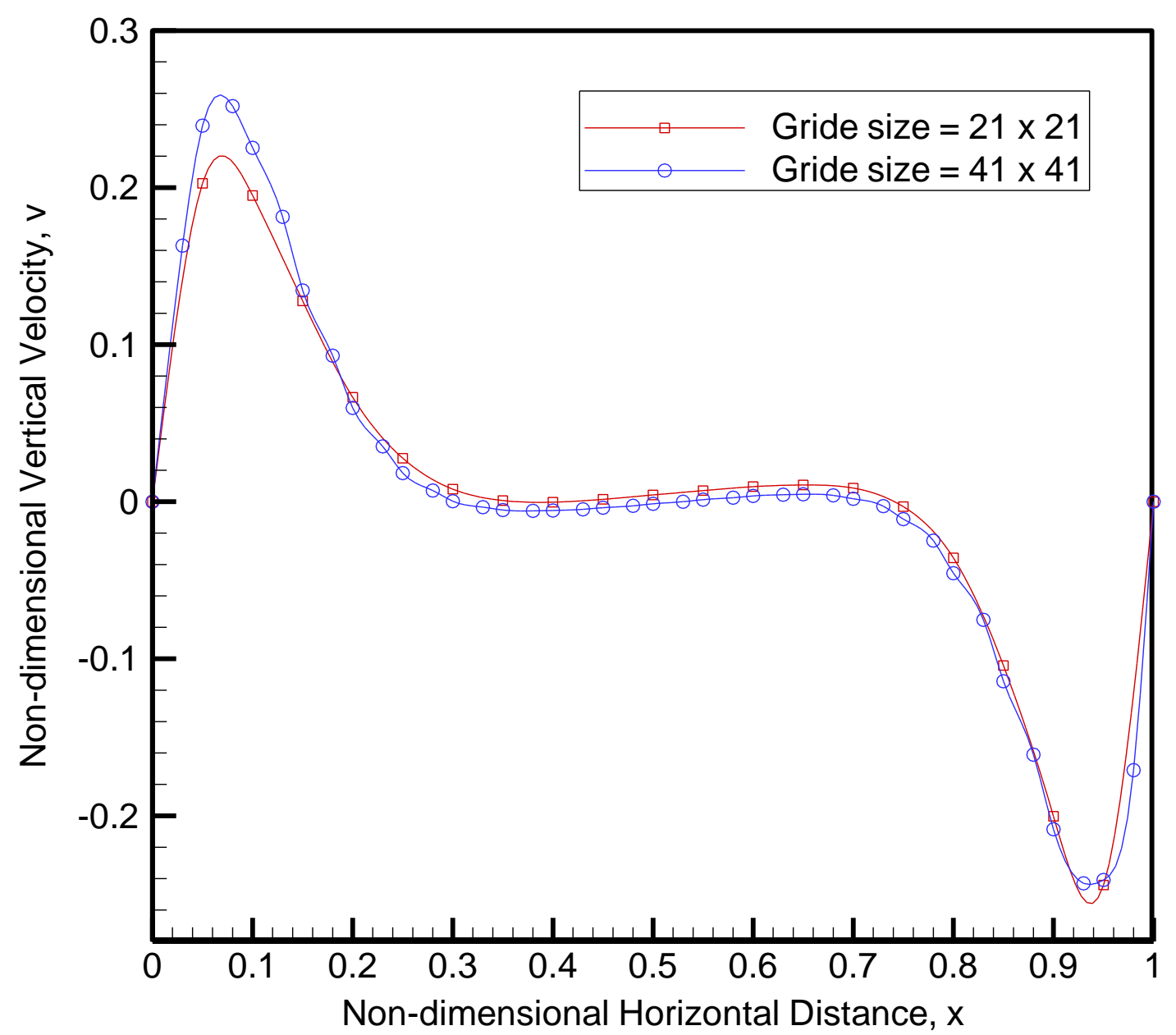

Figure 8- Steady State Non-dimensional Vertical Velocity Distribution along the Horizontal Centerline for Grid Sizes of 21 x 21, 41 × 41 and 81 x 81 at Ra $=10^{5}$ in Second Order Time Accurate Approximation 


\subsubsection{Base Model Comparison with First Order Accurate in Time Model}

The present study employs a second order accurate in time CMSIP procedure [74, 75, and 76] to solve the unsteady governing equations of the problem. This new algorithm uses Taylor expansion based second order accurate differencing of temporal terms and a second order accurate central difference approximations for all the spatial terms in the governing equations. Previous CMSIP algorithm used by Akyuzlu [27] and also by Chen and Pletcher [67] are first order accurate in time. The comparison of maximum values of horizontal and vertical velocities in first order and second order accurate in time models are presented in the Table 6.

Table 6- Comparison of the Results of the First Order and the Second Order Time Accurate CMSIP Models using Constant Properties for Different Rayleigh Numbers

\begin{tabular}{|c|c|c|c|}
\hline $\begin{array}{c}\text { Rayleigh } \\
\text { Number }\end{array}$ & $\begin{array}{c}\text { Second Order } \\
\bar{u}_{\max }\end{array}$ & $\begin{array}{c}\text { First Order } \\
\bar{u}_{\max }\end{array}$ & $\begin{array}{c}\% \\
\text { Deviation } \\
\text { in } \bar{u}_{\max }\end{array}$ \\
\hline $\begin{array}{c}10^{4} \\
\text { (Location) }\end{array}$ & $\begin{array}{c}0.154 \\
(\bar{y}=0.782)\end{array}$ & $\begin{array}{c}0.155 \\
(\bar{y}=0.780)\end{array}$ & -0.649 \\
\hline $\begin{array}{c}10^{5} \\
\text { (Location) }\end{array}$ & $\begin{array}{c}0.109 \\
\bar{y}=0.840)\end{array}$ & $\begin{array}{c}0.110 \\
(\bar{y}=0.838)\end{array}$ & -0.909 \\
\hline
\end{tabular}

\begin{tabular}{|c|c|c|c|}
\hline $\begin{array}{c}\text { Rayleigh } \\
\text { Number }\end{array}$ & $\begin{array}{c}\text { Second Order } \\
\bar{v}_{\text {max }}\end{array}$ & $\begin{array}{c}\text { First Order } \\
\bar{v}_{\max }\end{array}$ & $\begin{array}{c}\% \\
\text { Deviation } \\
\text { in } \bar{v}_{\max }\end{array}$ \\
\hline $\begin{array}{c}10^{4} \\
\text { (Location) }\end{array}$ & $\begin{array}{c}0.900 \\
(\bar{x}=0.125)\end{array}$ & $\begin{array}{c}0.900 \\
(\bar{x}=0.125)\end{array}$ & +0.000 \\
\hline $\begin{array}{c}10^{5} \\
\text { (Location) }\end{array}$ & $\begin{array}{c}0.220 \\
(\bar{x}=0.070)\end{array}$ & $\begin{array}{c}0.220 \\
(\bar{x}=0.070)\end{array}$ & +0.000 \\
\hline
\end{tabular}

The results of the second order accurate in time model has almost negligible difference with that of first order accurate in time model. The maximum computed values of horizontal velocity (non-dimensional), corresponding first order accurate in time model are deviated by $0.6 \%$ for $\mathrm{Ra}=$ $10^{4}$ and $0.9 \%$ for $\mathrm{Ra}=10^{5}$. However, these differences in vertical velocities are negligible. 


\section{Chapter 7}

\section{Parametric Study of Natural Convection using the First Order}

\section{Accurate in Time Model}

A parametric study was conducted using the constant property model to investigate how the flow fields are affected by different Rayleigh numbers and wall temperature differences. In this chapter two case studies are presented.

\subsection{The Effects of Variations in Rayleigh Numbers}

In the first case of parametric study, the effects of variations in Rayleigh number was observed by changing the wall temperature difference at constant size of the enclosure. In this study, for different Rayleigh numbers $\left(10^{4}, 5 \times 10^{4}, 10^{5}\right.$, and $\left.5 \times 10^{5}\right)$ the non dimensional vertical velocity distribution along the horizontal centerline of the enclosure was compared and it is concluded that there was a notable difference in magnitudes of velocities for higher Rayleigh numbers. As Rayleigh number increases the location of the maximum velocity point moves towards the hot side of the enclosure with increase in magnitude. The results are presented quantitatively and qualitatively in Table 7 and Figure 9, respectively. 
Table 7-Steady State Non-dimensional values of Vertical Velocity along the Horizontal Centerline of the Enclosure for $\mathrm{Ra}=10^{4}, \mathrm{Ra}=5 \times 10^{4}, \mathrm{Ra}=10^{5}, \mathrm{Ra}=5 \times 10^{5}$ at $\mathrm{H}=0.0254 \mathrm{~m}$

\begin{tabular}{|c|c|c|c|c|}
\hline $\begin{array}{c}\text { Non- } \\
\text { dimensional } \\
\begin{array}{c}\text { Horizontal } \\
\text { Distance, } \bar{x}\end{array}\end{array}$ & $\begin{array}{c}\text { Non-dimensional } \\
\text { Vertical } \\
\text { Velocity, } \bar{v} \\
(\mathrm{Ra}=1.0 \mathrm{E} 4)\end{array}$ & $\begin{array}{c}\text { Non-dimensional } \\
\text { Vertical } \\
\text { Velocity, } \bar{v} \\
(\text { Ra }=5.0 \mathrm{E} 4)\end{array}$ & $\begin{array}{c}\text { Non-dimensional } \\
\text { Vertical } \\
\text { Velocity, } \bar{v} \\
(\text { Ra }=1.0 \mathrm{E} 5)\end{array}$ & $\begin{array}{c}\text { Non-dimensional } \\
\text { Vertical } \\
\text { Velocity, } \bar{v} \\
(\text { Ra }=5.0 \mathrm{E} 5)\end{array}$ \\
\hline 1.00 & 0.0000000 & 0.0000000 & 0.0000000 & 0.0000000 \\
\hline 0.95 & -0.1453714 & -0.2379227 & -0.2465031 & -0.2087094 \\
\hline 0.90 & -0.2075329 & -0.2362243 & -0.2011154 & -0.0919643 \\
\hline 0.85 & -0.2082459 & -0.1565491 & -0.1036450 & -0.0152543 \\
\hline 0.80 & -0.1759759 & -0.0801576 & -0.0343975 & 0.0045337 \\
\hline 0.75 & -0.1342380 & -0.0316080 & -0.0019367 & 0.0073687 \\
\hline 0.70 & -0.0945000 & -0.0380077 & 0.0096405 & 0.0087798 \\
\hline 0.65 & -0.0614451 & 0.0038054 & 0.0114227 & 0.0097664 \\
\hline 0.60 & -0.0348230 & 0.0069824 & 0.0103105 & 0.0107504 \\
\hline 0.55 & -0.0129692 & 0.0067456 & 0.0077417 & 0.0109685 \\
\hline 0.50 & -0.0129692 & 0.0058315 & 0.0049454 & 0.0102460 \\
\hline 0.45 & 0.0259200 & 0.0056771 & 0.0020850 & 0.0080060 \\
\hline 0.40 & 0.0471586 & 0.0081480 & 0.0001911 & 0.0037837 \\
\hline 0.35 & 0.0720149 & 0.0158039 & 0.0011802 & -0.0022495 \\
\hline 0.30 & 0.1011022 & 0.0318961 & 0.0084302 & -0.0085098 \\
\hline 0.25 & 0.1340680 & 0.0610267 & 0.0281221 & -0.0087953 \\
\hline 0.20 & 0.1668373 & 0.1055469 & 0.0667380 & 0.0085259 \\
\hline 0.15 & 0.1915537 & 0.1621978 & 0.1275761 & 0.0582169 \\
\hline 0.10 & 0.1922468 & 0.2081509 & 0.1938100 & 0.1449731 \\
\hline 0.05 & 0.1453591 & 0.1878341 & 0.2009478 & 0.2161246 \\
\hline 0.00 & 0.0000000 & 0.0000000 & 0.0000000 & 0.0000000 \\
\hline
\end{tabular}




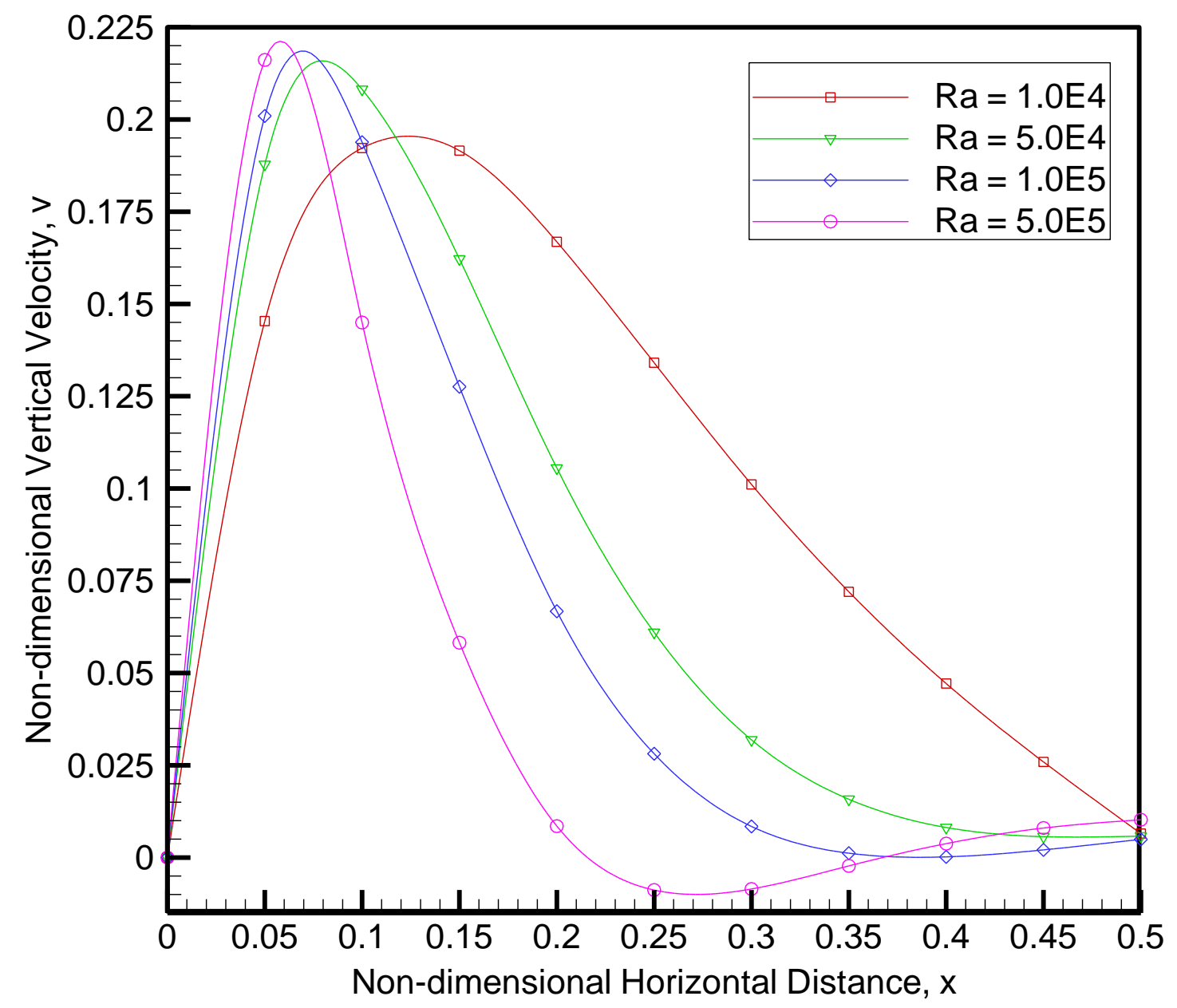

Figure 9- Comparison of Steady State Non-dimensional Vertical Velocity Distributions along the Horizontal Centerline of the Enclosure for $\mathrm{Ra}=10^{4}, \mathrm{Ra}=5 \times 10^{4}, \mathrm{Ra}=10^{5}, \mathrm{Ra}=$ $5 \times 10^{5}$ at $\mathrm{H}=0.0254 \mathrm{~m}$ 


\subsection{The Effects of Variations in Wall Temperature Differences}

In the second case of the parametric study, the effects of variations in wall temperature difference were observed by changing the size of the enclosure at constant Rayleigh number $10^{5}$. In this study, for different wall temperature difference $(64.8 \mathrm{~K}, 356.6 \mathrm{~K}$, and $648.4 \mathrm{~K})$ the non dimensional vertical velocity distributions along the horizontal centerline of the enclosure were compared and it is concluded that there is notable difference in velocity magnitudes for higher temperature difference. As wall temperature difference increases the location of the maximum velocity moves towards the cold side of the enclosure with increase in magnitude. The results are presented quantitatively and qualitatively in Table 8 and Figure 10, respectively. 
Table 8- Steady State Non-dimensional values of Vertical Velocity along the Horizontal Centerline of the Enclosure for $\Delta \mathrm{T}=64.8 \mathrm{~K}, \Delta \mathrm{T}=356.6 \mathrm{~K}, \Delta \mathrm{T}=648.4 \mathrm{~K}$ at $\mathrm{Ra}=10^{5}$

\begin{tabular}{|c|c|c|c|}
\hline $\begin{array}{c}\text { Non-dimensional } \\
\text { Horizontal } \\
\text { Distance, } \bar{x}\end{array}$ & $\begin{array}{c}\text { Non-dimensional } \\
\text { Vertical } \\
\text { Velocity, } \bar{v} \\
(\Delta \mathrm{T}=64.8 \mathrm{~K})\end{array}$ & $\begin{array}{c}\text { Non-dimensional } \\
\text { Vertical } \\
\text { Velocity, } \bar{v} \\
(\Delta \mathrm{T}=356.6 \mathrm{~K})\end{array}$ & $\begin{array}{c}\text { Non-dimensional } \\
\text { Vertical } \\
\text { Velocity, } \bar{v} \\
(\Delta \mathrm{T}=648.4 \mathrm{~K})\end{array}$ \\
\hline 1.00 & 0.0000000 & 0.0000000 & 0.0000000 \\
\hline 0.95 & -0.2465031 & -0.2084725 & -0.2020537 \\
\hline 0.90 & -0.2011154 & -0.1727811 & -0.1657409 \\
\hline 0.85 & -0.1036450 & -0.0984031 & -0.1009974 \\
\hline 0.80 & -0.0343975 & -0.0445509 & -0.0577585 \\
\hline 0.75 & -0.0019367 & -0.0179709 & -0.0366760 \\
\hline 0.70 & 0.0096405 & -0.0078904 & -0.0281754 \\
\hline 0.65 & 0.0114227 & -0.0064076 & -0.0281754 \\
\hline 0.60 & 0.0103105 & -0.0077848 & -0.0229883 \\
\hline 0.55 & 0.0077417 & -0.0099892 & -0.0192403 \\
\hline 0.50 & 0.0049454 & -0.0113427 & -0.0120143 \\
\hline 0.45 & 0.0020850 & -0.0107910 & 0.0017215 \\
\hline 0.40 & 0.0001911 & -0.0066578 & 0.0244202 \\
\hline 0.35 & 0.0011802 & 0.0042894 & 0.0606051 \\
\hline 0.30 & 0.0084302 & 0.0266349 & 0.1129162 \\
\hline 0.25 & 0.0281221 & 0.0673053 & 0.1836736 \\
\hline 0.20 & 0.0667380 & 0.1305537 & 0.2656362 \\
\hline 0.15 & 0.1275760 & 0.2118118 & 0.3355243 \\
\hline 0.10 & 0.1938100 & 0.2762716 & 0.3393019 \\
\hline 0.05 & 0.2009478 & 0.2377315 & 0.2282922 \\
\hline 0.00 & 0.0000000 & 0.0000000 & 0.0000000 \\
\hline
\end{tabular}




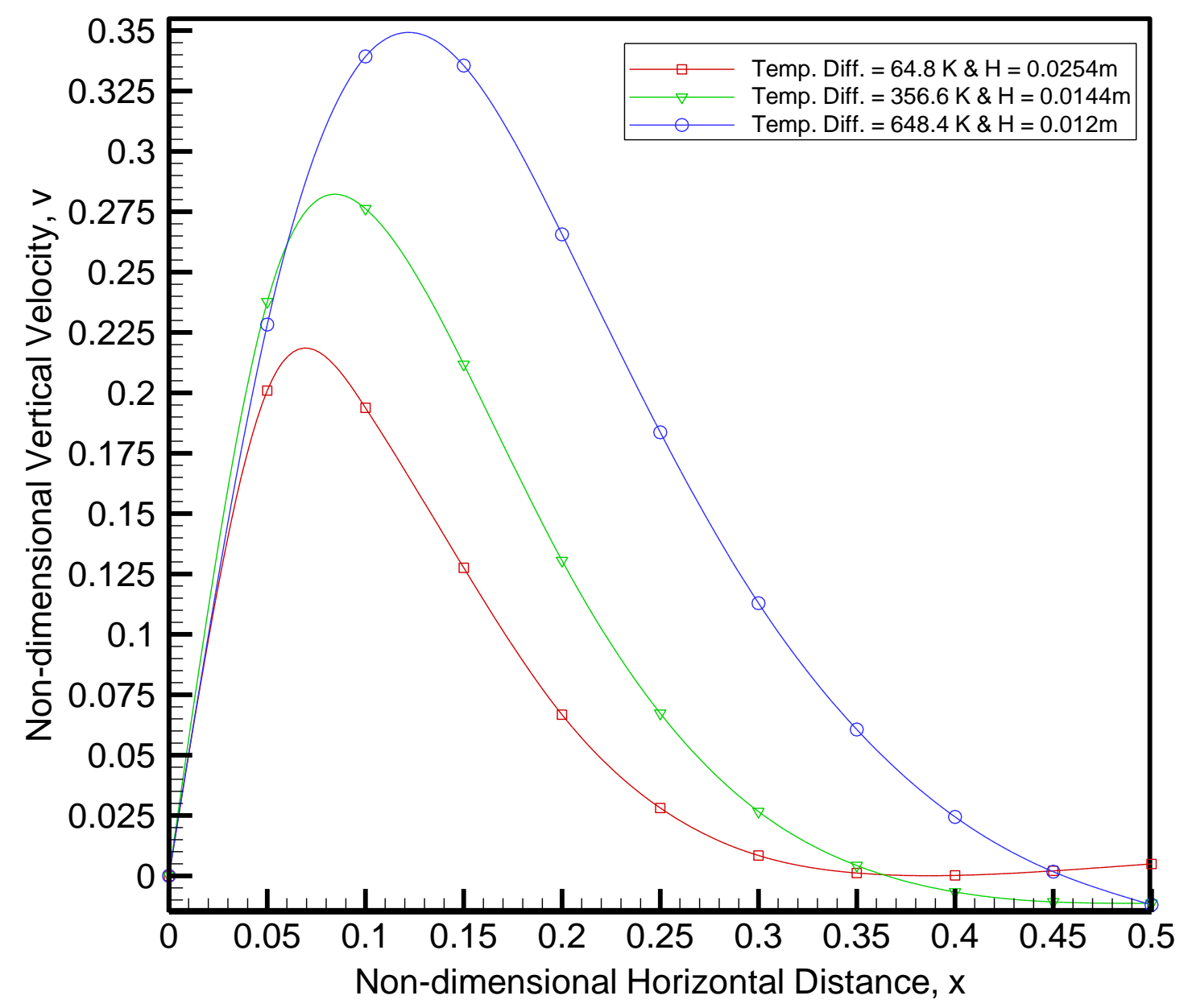

Figure 10- Comparison of Steady State Non-dimensional Vertical Velocity Distributions along the Horizontal Centerline of the Enclosure for $\Delta \mathrm{T}=64.8 \mathrm{~K}, \Delta \mathrm{T}=356.6 \mathrm{~K}$ and $\Delta \mathrm{T}=$ $648.4 \mathrm{~K}$ at $\mathrm{Ra}=10^{5}$ 


\section{Chapter 8}

\section{The Study of Effects of Variable Fluid Properties in Natural Convection inside a Square Enclosure}

In this chapter, the results of the constant property model are compared to that of variable property model. Then the variable property model was proposed as a base model in the present study. Also, the effects of variations in Rayleigh number for variable property model inside a square enclosure are presented in this chapter.

\subsection{The Study of Base Model}

In this study, the results of the constant property and variable property models are compared for $\mathrm{Ra}=10^{5}(\Delta T=64.8 \mathrm{~K})$. There is notable difference in the predicted values of velocity and temperature. These differences are presented quantitatively in Tables 9 through 11 . The comparisons between these models are presented in terms of velocity and temperature distributions in Figure 11 through 13. From Figure 11, the predicted values of non-dimensional horizontal velocities along the vertical centerline of the enclosure are observed higher for variable property model at cold side of the enclosure and lower at hot side of the enclosure compared to constant property model. However, non-dimensional vertical velocity and temperature values along the horizontal centerline of the enclosure are predicted higher at hot side of the enclosure and lower at cold side of the enclosure for variable property model as shown in Figure 12 and 13. Horizontal and vertical velocity histograms are also compared in Figure 14 and 15, respectively. Horizontal velocities are predicted higher for variable property model and vertical velocities are predicted higher for constant property model. 
The variable property model is proposed as the base model and is considered for Ra $10^{5}$ with uniform, orthogonal mesh of $21 \times 21$, in which wall temperature difference is $64.8 \mathrm{~K}$. The predicted primitive variables along the horizontal centerline and vertical centerline of the enclosure are presented in Table 12 and Table 13, respectively. The computational domain used in the present study is shown in Figure 16. The velocity ( $u$ and $v$ ) histograms at a point closer to the high temperature wall where $\bar{x}=0.05$ and $\bar{y}=0.5$ are presented in Figures 17 and 18 . The temperature stratification is shown in Figure 19. Temperature gradients are higher bear the walls and are close to zero near the center. This fact is easily illustrated by the isotherms being almost horizontal in the center of the enclosure. The formation of the two vertices can be seen in Figure 20. The flow is not unicellular; instead, it separates into boundary layer and core flow. The core flow is more stagnant relative to the boundary regions. This characteristic is also observed in the streamlines shown in Figure 21. The non-dimensional horizontal velocity distribution along the vertical centerline, vertical velocity distribution along the horizontal centerline and temperature distribution along the horizontal centerline are presented in Figure 22, 23 and 24, respectively. 
Table 9- Comparison of Predicted Non-dimensional values of Horizontal Velocity along the Vertical Centerline of the Enclosure for Constant and Variable Fluid Properties at $\mathrm{Ra}=10^{5}$ $(\Delta T=64.8 \mathrm{~K}, \mathrm{H}=0.0254 \mathrm{~m}$ and $21 \mathrm{X} 21)$

\begin{tabular}{|c|c|c|c|}
\hline $\begin{array}{c}\text { Non-dimensional } \\
\text { Vertical } \\
\text { Distance, } \bar{y}\end{array}$ & $\begin{array}{c}\text { Non-dimensional } \\
\text { Horizontal } \\
\text { Velocity, } \bar{u} \\
\text { (Constant) }\end{array}$ & $\begin{array}{c}\text { Non-dimensional } \\
\text { Horizontal } \\
\text { Velocity, } \bar{u} \\
\text { (Variable) }\end{array}$ & $\begin{array}{c}\text { \% Deviation } \\
\text { in } \bar{u}\end{array}$ \\
\hline 1.00 & 0.0000000 & 0.0000000 & 0.0000000 \\
\hline 0.95 & 0.0535207 & 0.0571390 & 6.3324524 \\
\hline 0.90 & 0.0810651 & 0.0876302 & 7.4917753 \\
\hline 0.85 & 0.1004595 & 0.1072624 & 6.3422970 \\
\hline 0.80 & 0.1009580 & 0.1071562 & 5.7842663 \\
\hline 0.75 & 0.0929973 & 0.0981868 & 5.2853213 \\
\hline 0.70 & 0.0789586 & 0.0821039 & 3.8308866 \\
\hline 0.65 & 0.0645284 & 0.0656531 & 1.7130632 \\
\hline 0.60 & 0.0495355 & 0.0484717 & -2.1946804 \\
\hline 0.55 & 0.0381889 & 0.0351714 & -8.5795203 \\
\hline 0.50 & 0.0241282 & 0.0201633 & -19.663835 \\
\hline 0.45 & 0.0125497 & 0.0079409 & -58.039436 \\
\hline 0.40 & -0.0046300 & -0.0088292 & 47.559387 \\
\hline 0.35 & -0.0228675 & -0.0268213 & 14.741480 \\
\hline 0.30 & -0.0460588 & -0.0497550 & 7.4286760 \\
\hline 0.25 & -0.0767948 & -0.0800412 & 4.0558706 \\
\hline 0.20 & -0.1056613 & -0.1087645 & 2.8531368 \\
\hline 0.15 & -0.1387613 & -0.1398505 & 0.7788316 \\
\hline 0.10 & -0.1406555 & -0.1405555 & -0.0711462 \\
\hline 0.05 & -0.0878570 & -0.0882356 & 0.4290444 \\
\hline 0.00 & 0.0000000 & 0.0000000 & 0.0000000 \\
\hline
\end{tabular}


Table 10- Comparison of Predicted Non-dimensional values of Vertical Velocity along the Horizontal Centerline of the Enclosure for Constant and Variable Fluid Properties at $\mathrm{Ra}=10^{5}(\Delta T=64.8 \mathrm{~K}, \mathrm{H}=0.0254 \mathrm{~m}$ and $21 \mathrm{X} 21)$

\begin{tabular}{|c|c|c|c|}
\hline $\begin{array}{c}\text { Non-dimensional } \\
\text { Horizontal } \\
\text { Distance, } \bar{x}\end{array}$ & $\begin{array}{l}\text { Non-dimensional } \\
\text { Vertical } \\
\text { Velocity, } \bar{v} \\
\text { (Constant ) }\end{array}$ & $\begin{array}{c}\text { Non-dimensional } \\
\text { Vertical } \\
\text { Velocity, } \bar{v} \\
\text { (Variable) }\end{array}$ & $\begin{array}{c}\% \text { Deviation } \\
\text { in } \bar{v}\end{array}$ \\
\hline 1.00 & 0.0000000 & 0.0000000 & 0.0000000 \\
\hline 0.95 & -0.2502395 & -0.2475826 & -1.0731368 \\
\hline 0.90 & -0.1944804 & -0.1971463 & 1.3522445 \\
\hline 0.85 & -0.0930081 & -0.1008293 & 7.7567929 \\
\hline 0.80 & -0.0257422 & 0.0334961 & 176.85118 \\
\hline 0.75 & 0.0031427 & -0.0018893 & 266.33759 \\
\hline 0.70 & 0.0122860 & 0.0094903 & -29.458318 \\
\hline 0.65 & 0.0130391 & 0.0111882 & -16.543233 \\
\hline 0.60 & 0.0117409 & 0.0099772 & -17.677062 \\
\hline 0.55 & 0.0092661 & 0.0073344 & -26.337007 \\
\hline 0.50 & 0.0065152 & 0.0045396 & -43.518607 \\
\hline 0.45 & 0.0034166 & 0.0018026 & -89.540905 \\
\hline 0.40 & 0.0008496 & 0.0001795 & -373.20101 \\
\hline 0.35 & 0.0005829 & 0.0016220 & 64.059846 \\
\hline 0.30 & 0.0059338 & 0.0095263 & 37.710790 \\
\hline 0.25 & 0.0231456 & 0.0300361 & 22.940638 \\
\hline 0.20 & 0.0591808 & 0.0693695 & 14.687566 \\
\hline 0.15 & 0.1184252 & 0.1299771 & 8.8876425 \\
\hline 0.10 & 0.1861128 & 0.1934348 & 3.7852547 \\
\hline 0.05 & 0.1988817 & 0.1948903 & -2.0480239 \\
\hline 0.00 & 0.0000000 & 0.0000000 & 0.0000000 \\
\hline
\end{tabular}


Table 11- Comparison of Predicted Non-dimensional values of Temperature along the Horizontal Centerline of the Enclosure for Constant and Variable Fluid Properties at $\mathrm{Ra}=10^{5}(\Delta T=64.8 \mathrm{~K}, \mathrm{H}=0.0254 \mathrm{~m}$ and $21 \mathrm{X} 21)$

\begin{tabular}{|c|c|c|c|}
\hline $\begin{array}{c}\text { Non-dimensional } \\
\text { Horizontal } \\
\text { Distance, } \bar{x}\end{array}$ & $\begin{array}{l}\text { Non-dimensional } \\
\text { Temperature, } \bar{T} \\
\text { (Constant ) }\end{array}$ & $\begin{array}{l}\text { Non-dimensional } \\
\text { Temperature, } \bar{T} \\
\text { (Variable ) }\end{array}$ & $\begin{array}{c}\text { \% Deviation } \\
\text { in } \bar{T}\end{array}$ \\
\hline 1.00 & 0.8907647 & 0.8907647 & 0.0000000 \\
\hline 0.95 & 0.9560220 & 0.9560723 & 0.0000005 \\
\hline 0.90 & 1.0042400 & 1.0029240 & -0.0000131 \\
\hline 0.85 & 1.0271800 & 1.0256300 & -0.0000113 \\
\hline 0.80 & 1.0341910 & 1.0331320 & -0.0000102 \\
\hline 0.75 & 1.0347690 & 1.0340560 & -0.0000068 \\
\hline 0.70 & 1.0339310 & 1.0332200 & -0.0000068 \\
\hline 0.65 & 1.0333490 & 1.0324500 & -0.0000087 \\
\hline 0.60 & 1.0331680 & 1.0320330 & -0.0000110 \\
\hline 0.55 & 1.0332070 & 1.0318370 & -0.0000132 \\
\hline 0.50 & 1.0331700 & 1.0315720 & -0.0000155 \\
\hline 0.45 & 1.0327950 & 1.0309780 & -0.0000176 \\
\hline 0.40 & 1.0318170 & 1.0298150 & -0.0000194 \\
\hline 0.35 & 1.0300450 & 1.0279460 & -0.0000204 \\
\hline 0.30 & 1.0275110 & 1.0255040 & -0.0000196 \\
\hline 0.25 & 1.0247950 & 1.0232280 & -0.0000153 \\
\hline 0.20 & 1.0236580 & 1.0230580 & -0.0000059 \\
\hline 0.15 & 1.0276350 & 1.0285710 & 0.0000091 \\
\hline 0.10 & 1.0420280 & 1.0445690 & 0.0000243 \\
\hline 0.05 & 1.0709450 & 1.0736000 & 0.0000247 \\
\hline 0.00 & 1.1092350 & 1.1092350 & 0.0000000 \\
\hline
\end{tabular}




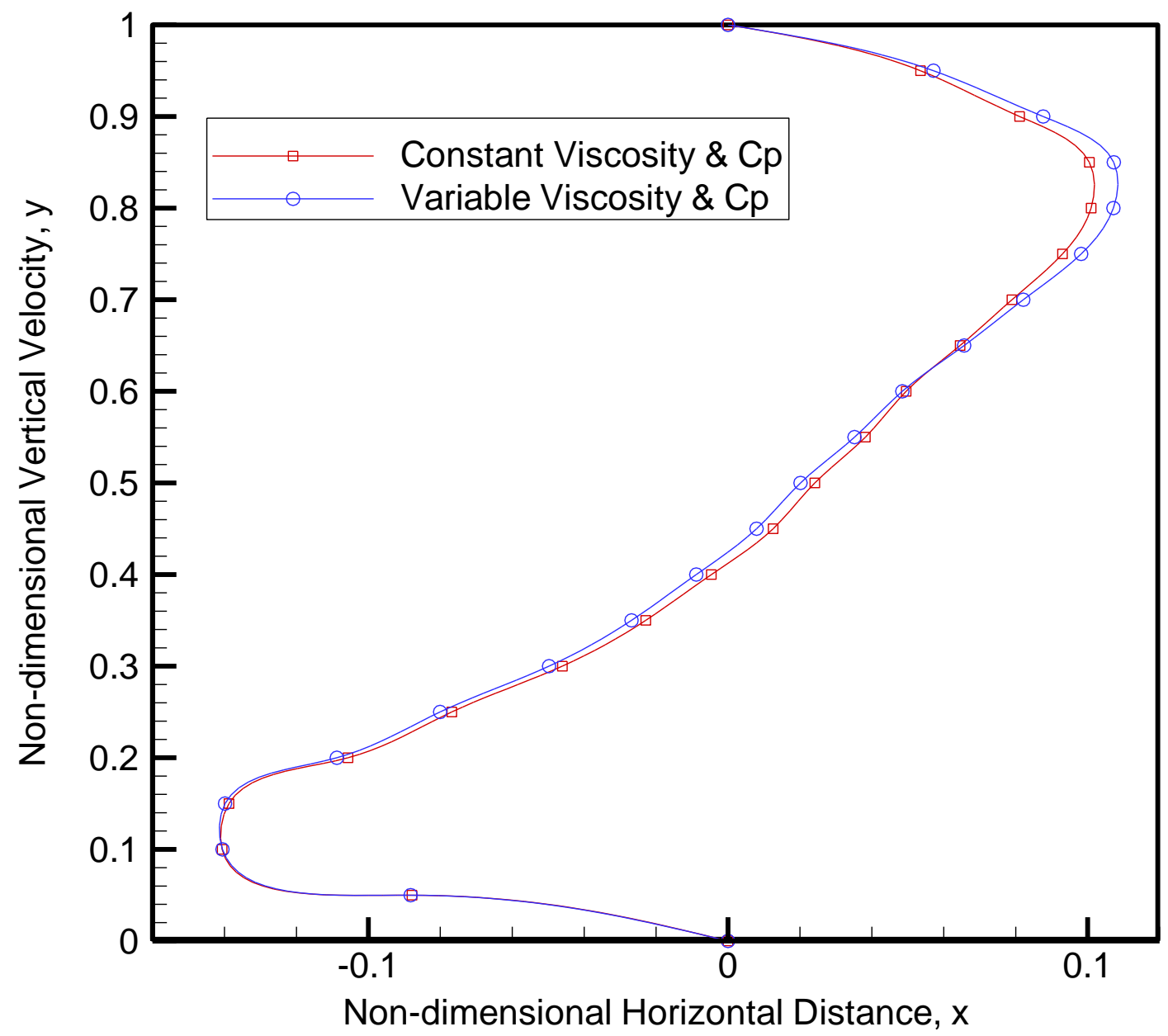

Figure 11- Comparison of Steady State Non-dimensional Horizontal Velocity Distributions along the Vertical Centerline of the Enclosure for Constant and Variable Fluid Properties at $\mathrm{Ra}=10^{5}(\Delta T=64.8 \mathrm{~K}, \mathrm{H}=0.0144 \mathrm{~m})$ 


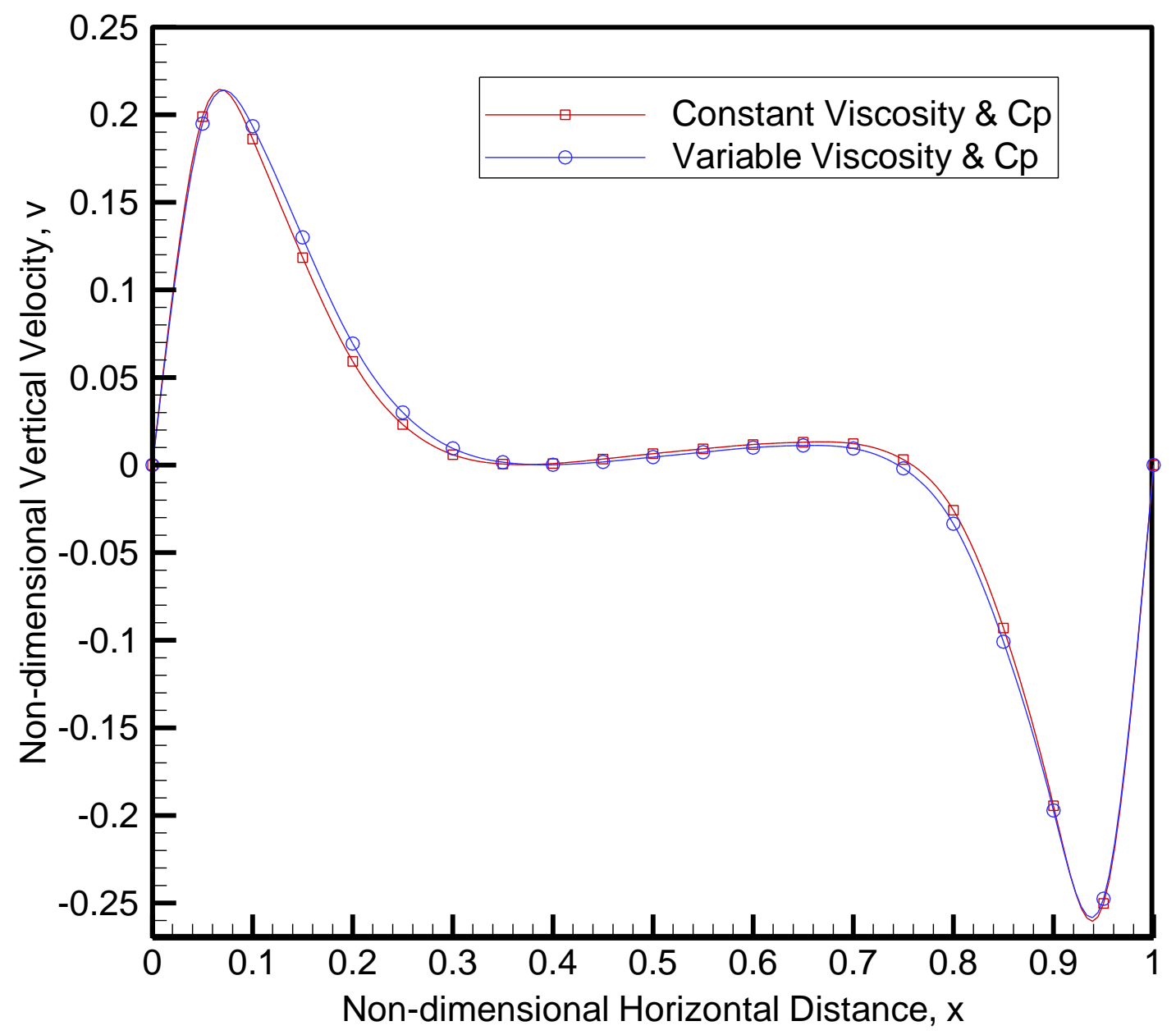

Figure 12- Comparison of Steady State Non-dimensional Vertical Velocity Distributions along the Horizontal Centerline of the Enclosure for Constant and Variable Fluid Properties at $\mathrm{Ra}=10^{5}(\Delta T=64.8 \mathrm{~K}, \mathrm{H}=0.0144 \mathrm{~m})$ 


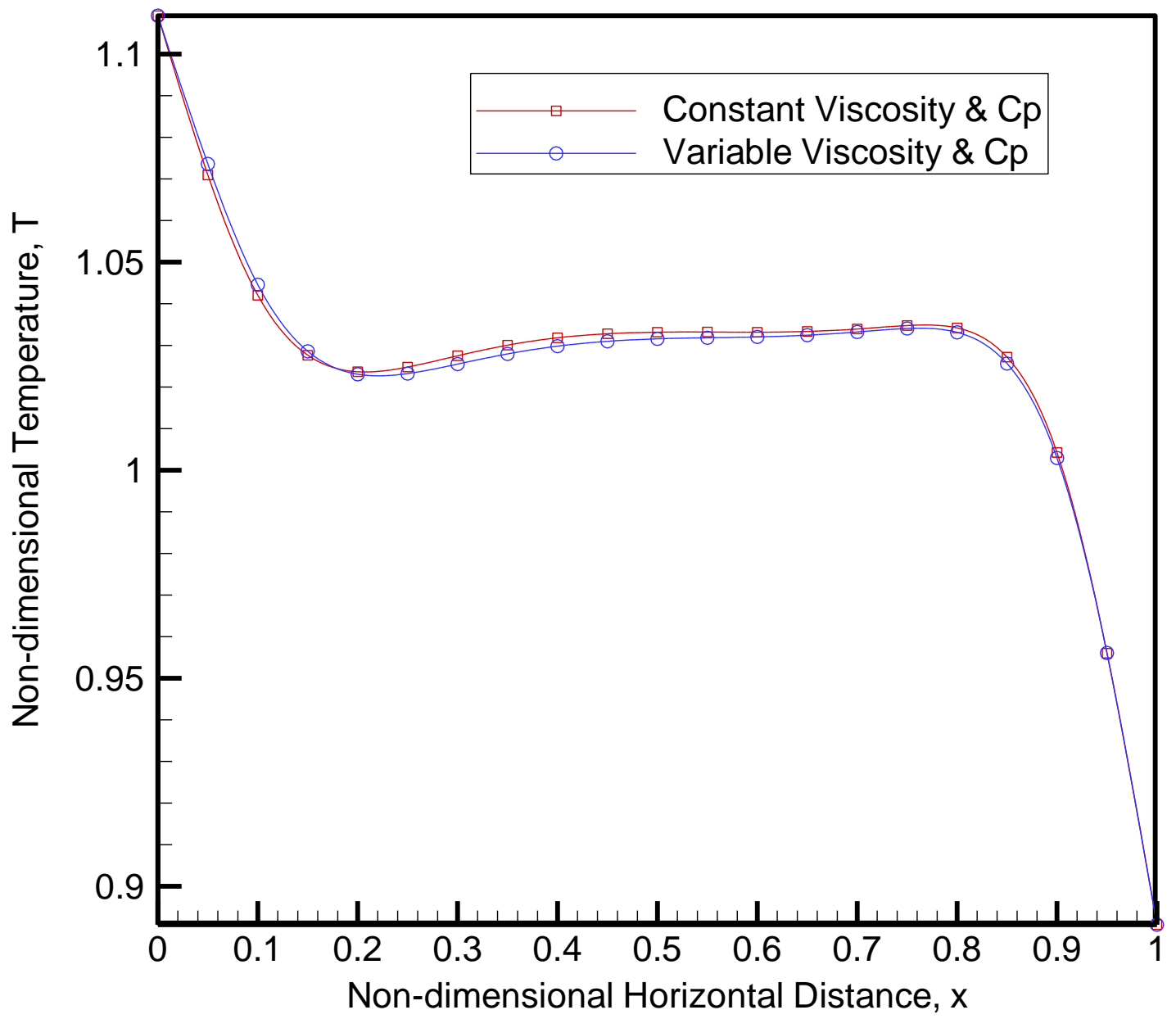

Figure 13- Comparison of Steady State Non-dimensional Temperature Distributions along the Horizontal Centerline of the Enclosure for Constant and Variable Fluid Properties at $\mathrm{Ra}=10^{5}(\Delta T=64.8 \mathrm{~K}, \mathrm{H}=0.0144 \mathrm{~m})$ 


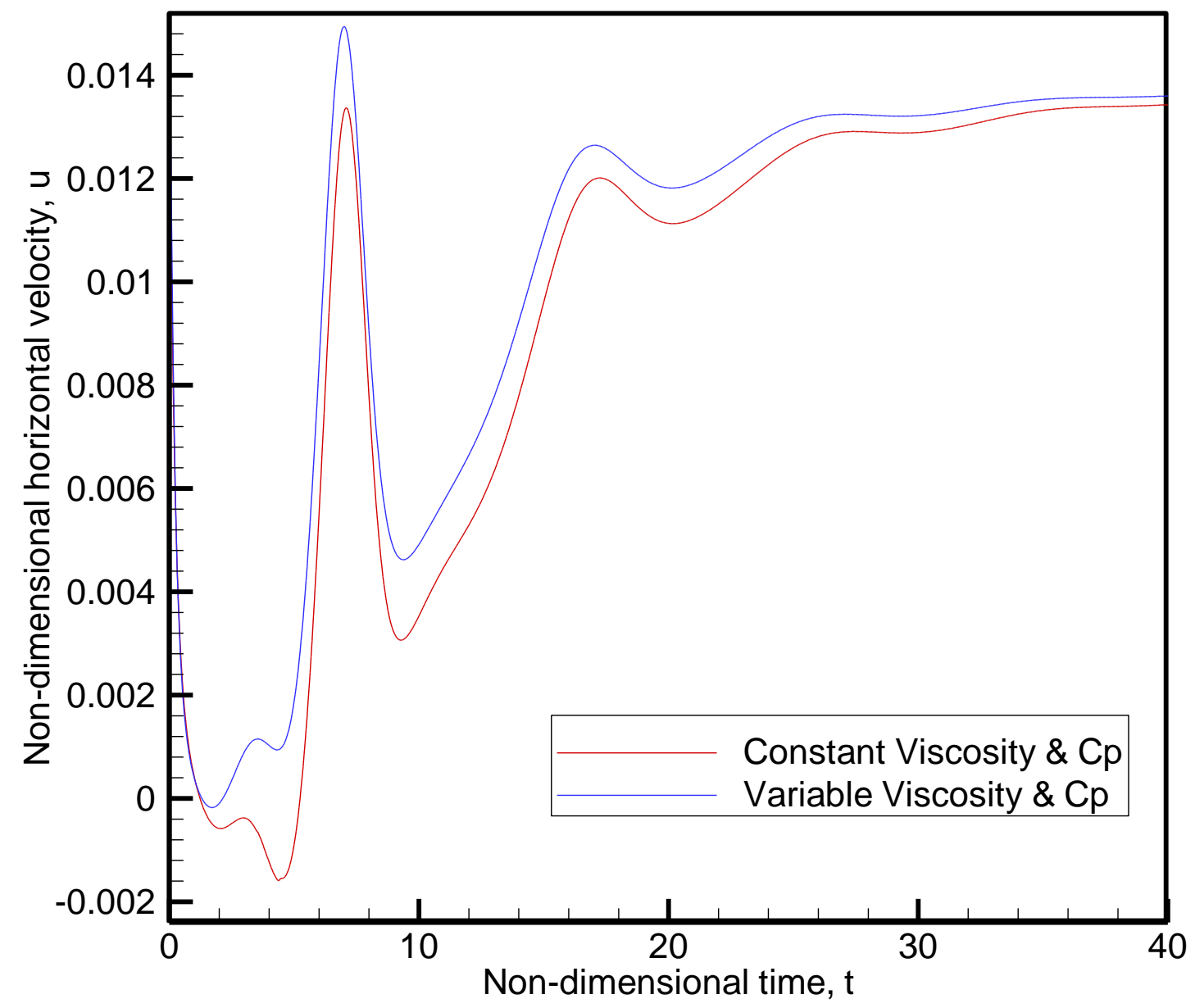

Figure 14- Comparison of Non-dimensional Horizontal Histograms of Constant and Variable Properties for $\mathrm{Ra}=10^{5}$ at $\bar{X}=0.05$ and $\bar{Y}=0.5$ 


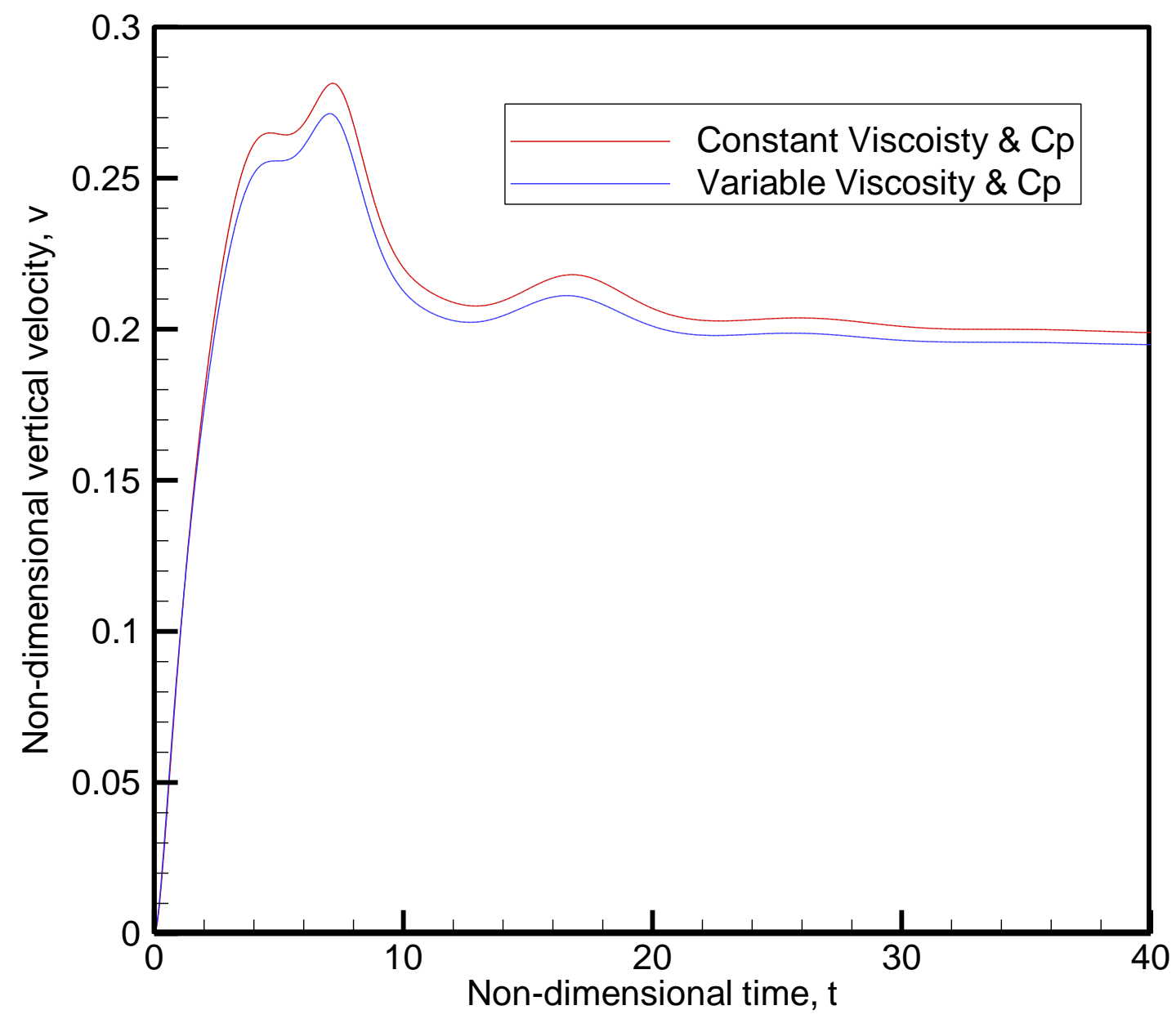

Figure 15- Comparison of Vertical Velocity Histograms of Constant and Variable Properties for $\mathrm{Ra}=10^{5}$ at $\bar{X}=0.05$ and $\bar{Y}=0.5$ 
Table 12- Steady State Non-dimensional values of Primitive Variables along the Horizontal Centerline of the Enclosure for $\mathrm{Ra}=10^{5}(\Delta \bar{t}=1.0 \mathrm{E}-5$ and $21 \mathrm{X} 21)$

\begin{tabular}{|c|c|c|c|}
\hline $\begin{array}{c}\text { Non-dimensional } \\
\text { Horizontal } \\
\text { Distance, } \bar{x}\end{array}$ & $\begin{array}{c}\text { Non-dimensional } \\
\text { Vertical } \\
\text { Velocity, } \bar{v}\end{array}$ & $\begin{array}{l}\text { Non-dimensional } \\
\text { Pressure, } \bar{p}\end{array}$ & $\begin{array}{l}\text { Non-dimensional } \\
\text { Temperature, } \bar{T}\end{array}$ \\
\hline 1.00 & 0.0000000 & 1622.1422 & 0.8907647 \\
\hline 0.95 & -0.2475826 & 1622.1422 & 0.9560722 \\
\hline 0.90 & -0.1971463 & 1622.1422 & 1.0029243 \\
\hline 0.85 & -0.1008293 & 1622.1422 & 1.0256303 \\
\hline 0.80 & -0.0334962 & 1622.1422 & 1.0331324 \\
\hline 0.75 & -0.0018894 & 1622.1422 & 1.0340564 \\
\hline 0.70 & 0.0094903 & 1622.1422 & 1.0332203 \\
\hline 0.65 & 0.0111883 & 1622.1422 & 1.0324496 \\
\hline 0.60 & 0.0099773 & 1622.1422 & 1.0320333 \\
\hline 0.55 & 0.0073344 & 1622.1422 & 1.0318368 \\
\hline 0.50 & 0.0045396 & 1622.1422 & 1.0315717 \\
\hline 0.45 & 0.0018026 & 1622.1422 & 1.0309784 \\
\hline 0.40 & 0.0001795 & 1622.1422 & 1.0298149 \\
\hline 0.35 & 0.0016221 & 1622.1422 & 1.0279456 \\
\hline 0.30 & 0.0095263 & 1622.1422 & 1.0255036 \\
\hline 0.25 & 0.0300361 & 1622.1422 & 1.0232275 \\
\hline 0.20 & 0.1299771 & 1622.1422 & 1.0230579 \\
\hline 0.15 & 0.1299770 & 1622.1422 & 1.0285707 \\
\hline 0.10 & 0.1934348 & 1622.1422 & 1.0445688 \\
\hline 0.05 & 0.1948903 & 1622.1422 & 1.0736002 \\
\hline 0.00 & 0.0000000 & 1622.1422 & 1.1092353 \\
\hline
\end{tabular}


Table 13- Steady State Non-dimensional values of Primitive Variables along the Vertical Centerline of the Enclosure for $\mathrm{Ra}=10^{5}(\Delta \bar{t}=1.0 \mathrm{E}-5$ and $21 \mathrm{X} 21)$

\begin{tabular}{|c|c|c|c|}
\hline $\begin{array}{c}\text { Non-dimensional } \\
\text { Vertical } \\
\text { Distance, } \bar{y}\end{array}$ & $\begin{array}{c}\text { Non-dimensional } \\
\text { Horizontal } \\
\text { Velocity, } \bar{u}\end{array}$ & $\begin{array}{l}\text { Non-dimensional } \\
\text { Pressure, } \bar{p}\end{array}$ & $\begin{array}{l}\text { Non-dimensional } \\
\text { Temperature, } \bar{T}\end{array}$ \\
\hline 1.00 & 0.0000000 & 1622.1400 & 1.0854359 \\
\hline 0.95 & 0.0571390 & 1622.1401 & 1.0853203 \\
\hline 0.90 & 0.0876302 & 1622.1404 & 1.0843379 \\
\hline 0.85 & 0.1072624 & 1622.1406 & 1.0815360 \\
\hline 0.80 & 0.1071562 & 1622.1409 & 1.0778722 \\
\hline 0.75 & 0.0981868 & 1622.1410 & 1.0720498 \\
\hline 0.70 & 0.0821039 & 1622.1413 & 1.0663142 \\
\hline 0.65 & 0.0656531 & 1622.1415 & 1.0585184 \\
\hline 0.60 & 0.0484717 & 1622.1417 & 1.0510841 \\
\hline 0.55 & 0.0351714 & 1622.1420 & 1.0410634 \\
\hline 0.50 & 0.0201634 & 1622.1422 & 1.0315717 \\
\hline 0.45 & 0.0079409 & 1622.1424 & 1.0192259 \\
\hline 0.40 & -0.0088292 & 1622.1426 & 1.0082883 \\
\hline 0.35 & -0.0268214 & 1622.1429 & 0.9951756 \\
\hline 0.30 & -0.0497550 & 1622.1431 & 0.9846475 \\
\hline 0.25 & -0.0800413 & 1622.1434 & 0.9729092 \\
\hline 0.20 & -0.1087645 & 1622.1436 & 0.9638571 \\
\hline 0.15 & -0.1398505 & 1622.1439 & 0.9534625 \\
\hline 0.10 & -0.1405555 & 1622.1440 & 0.9461181 \\
\hline 0.05 & -0.0882356 & 1622.1444 & 0.9393139 \\
\hline 0.00 & 0.0000000 & 1622.1446 & 0.9363195 \\
\hline
\end{tabular}




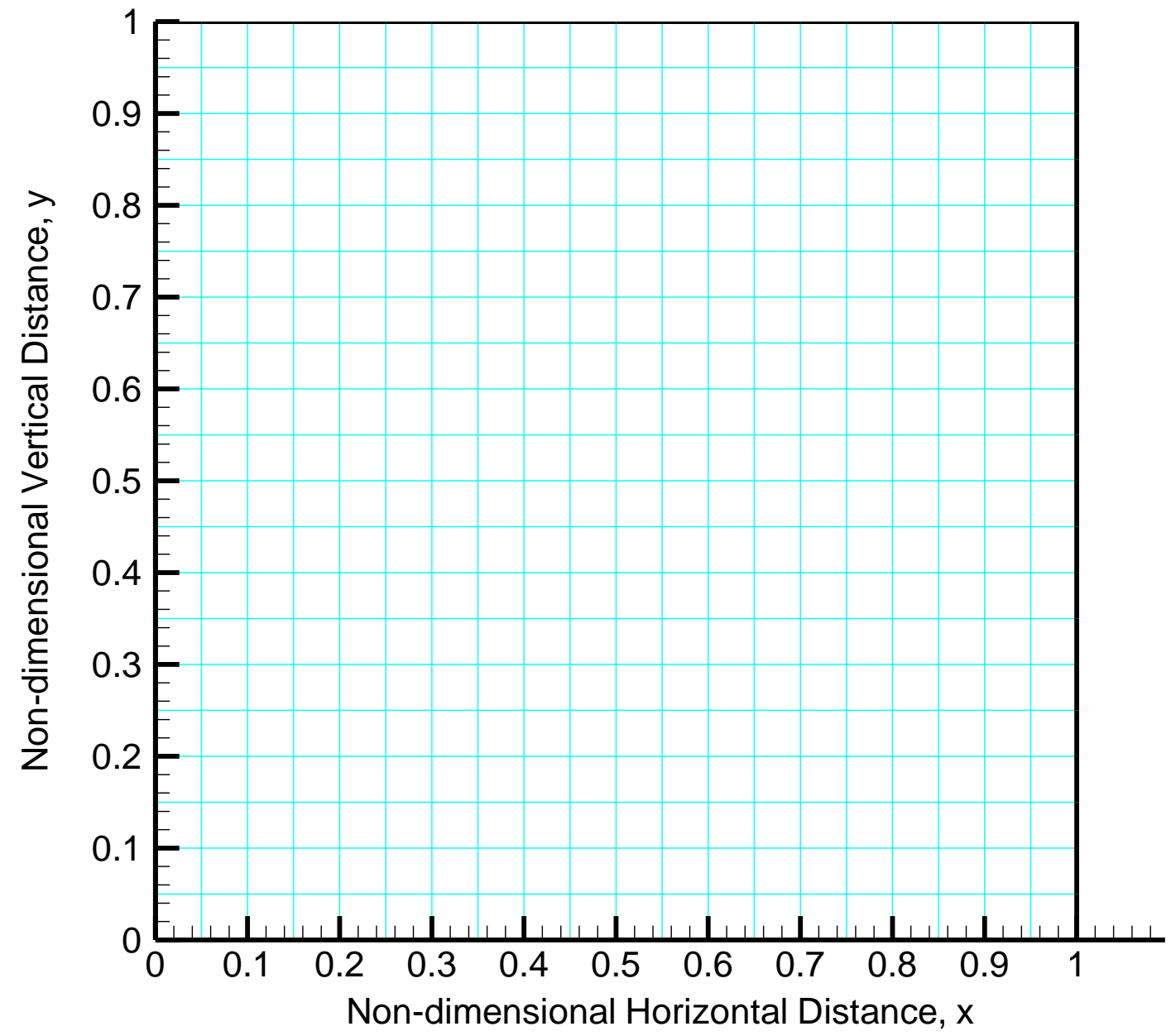

Figure 16- Computational Mesh of the Non-dimensional domain for the Natural Convection Case for Variable Properties 


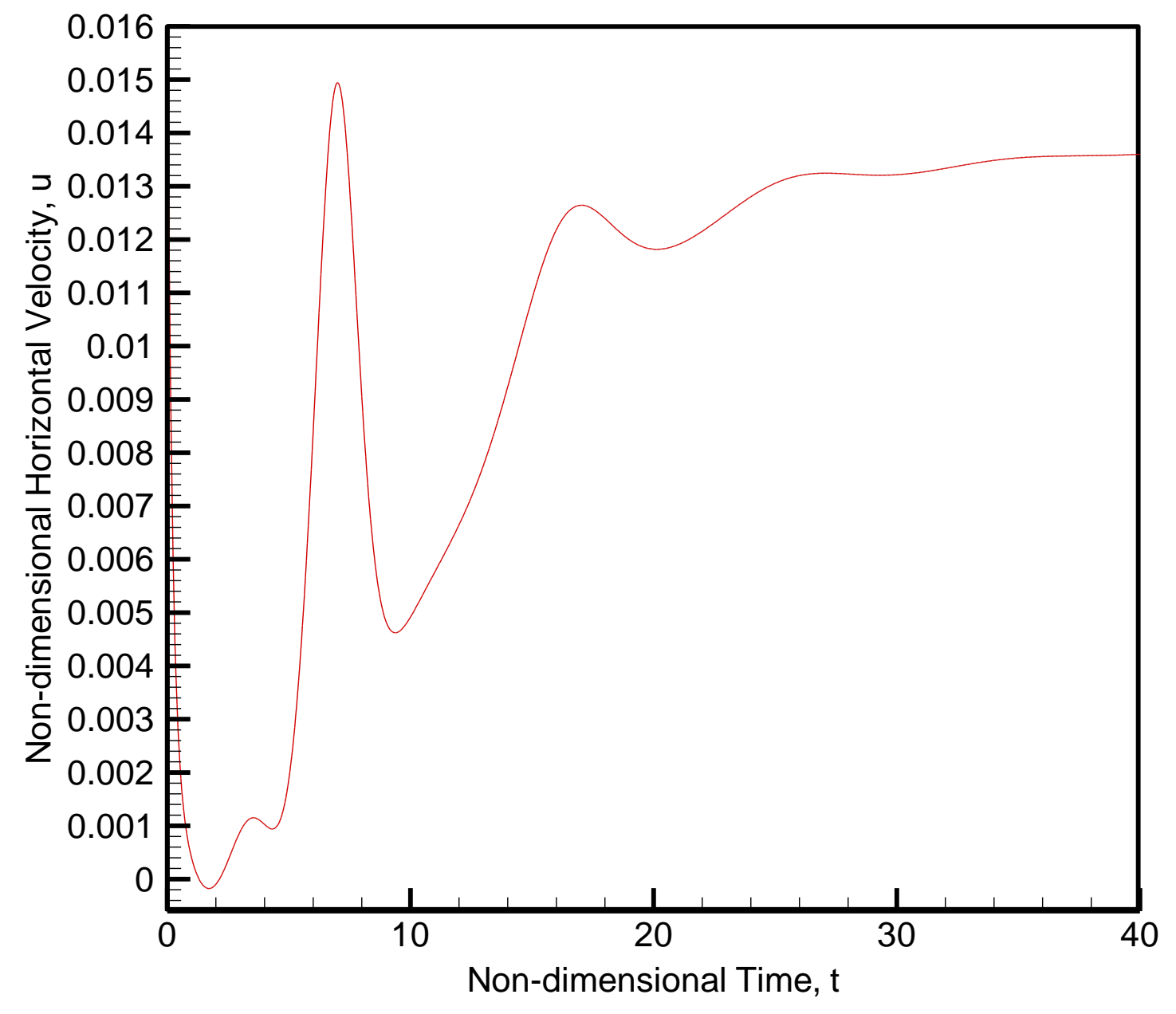

Figure 17- Non-dimensional Horizontal Velocity Histogram for $\operatorname{Ra}=10^{5}$ at $\bar{X}=0.05$ and $\bar{Y}=0.5$ for Variable Properties $(21 \times 21, \Delta \bar{t}=1.0 \mathrm{E}-5)$ 


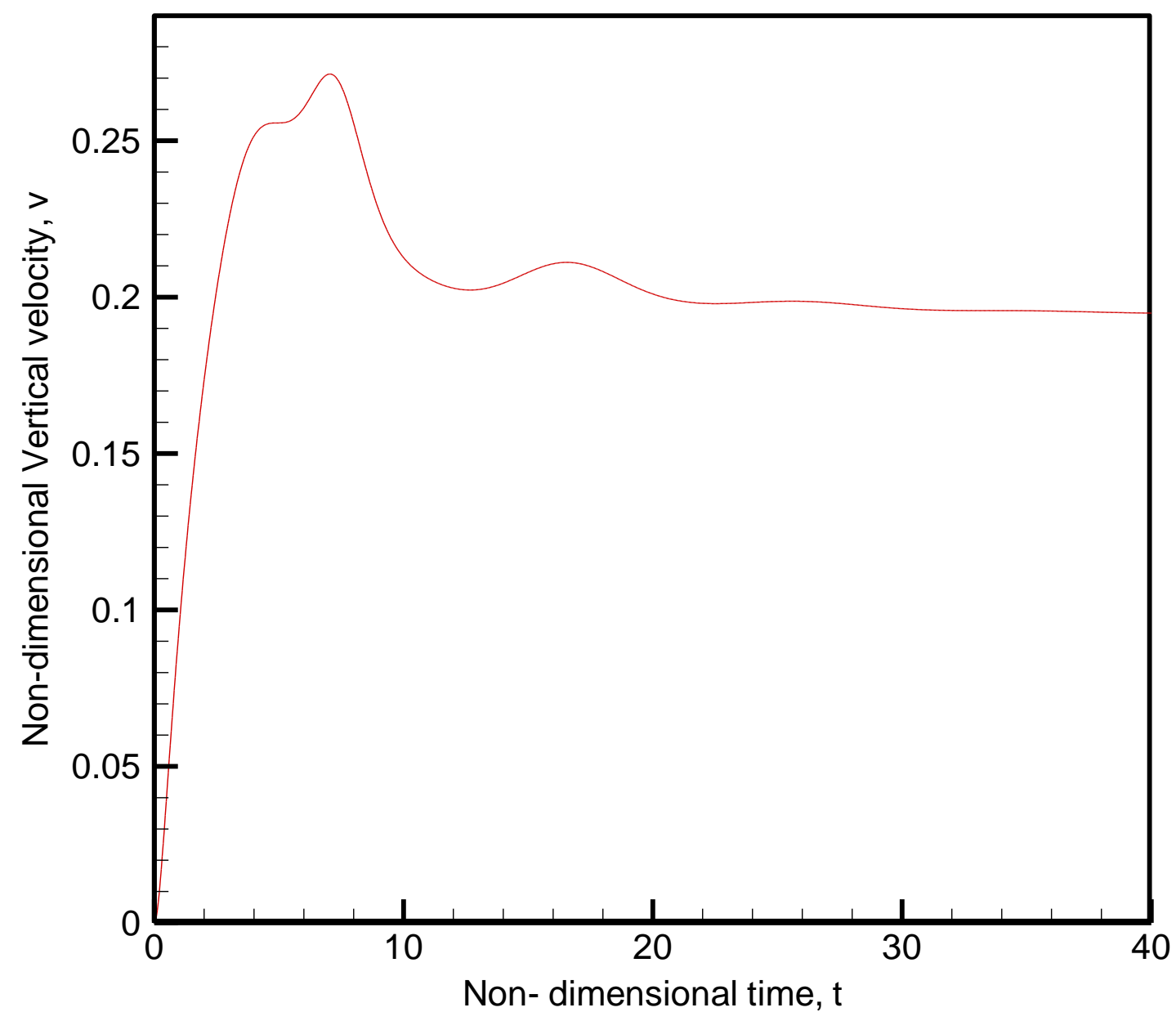

Figure 18- Non-dimensional Vertical Velocity Histogram for $\operatorname{Ra}=10^{5}$ at $\bar{X}=0.05$ and $\bar{Y}=0.5$ for Variable Properties $(21 \times 21, \Delta \bar{t}=1.0 \mathrm{E}-5)$ 


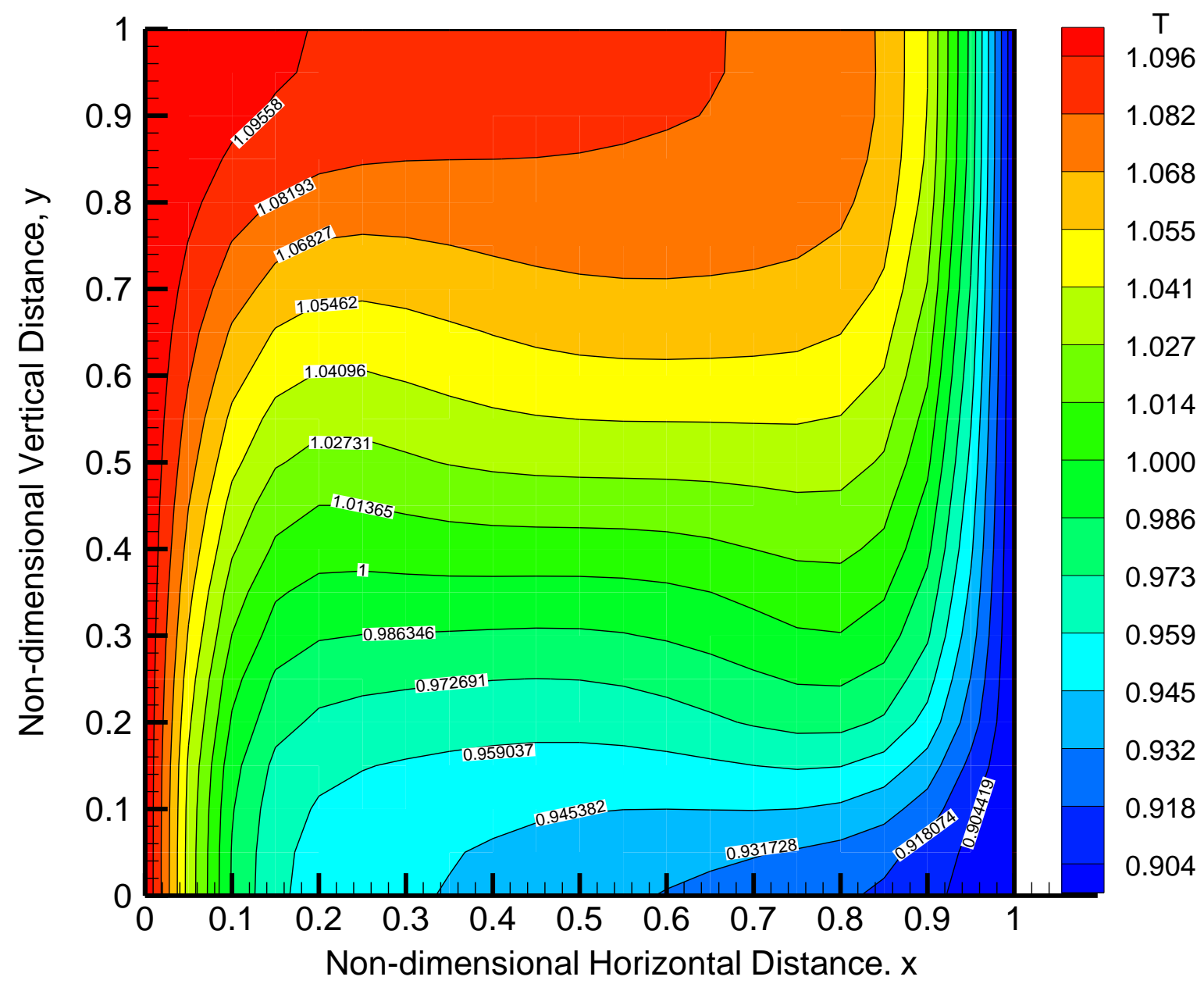

Figure 19- Steady State Non-dimensional Temperature Contours for $\mathrm{Ra}=10^{5}$ for Variable Properties $(21 \times 21, \Delta \bar{t}=1.0 \mathrm{E}-5)$ 


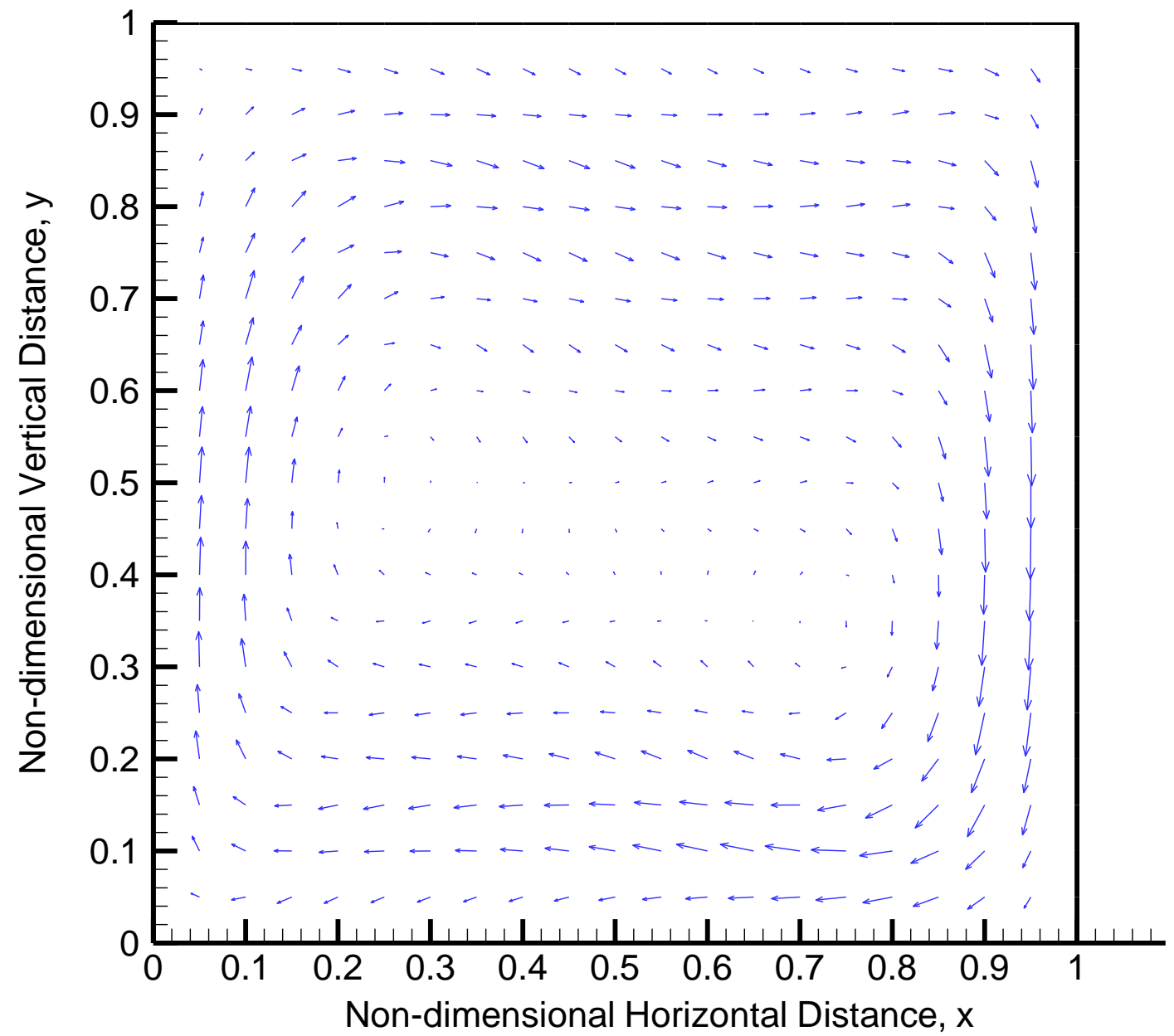

Figure 20- Steady State Non-dimensional Velocity Vectors for $\mathrm{Ra}=10^{5}(21 \times 21, \Delta \bar{t}=1.0 \mathrm{E}-5)$ for Variable Properties 


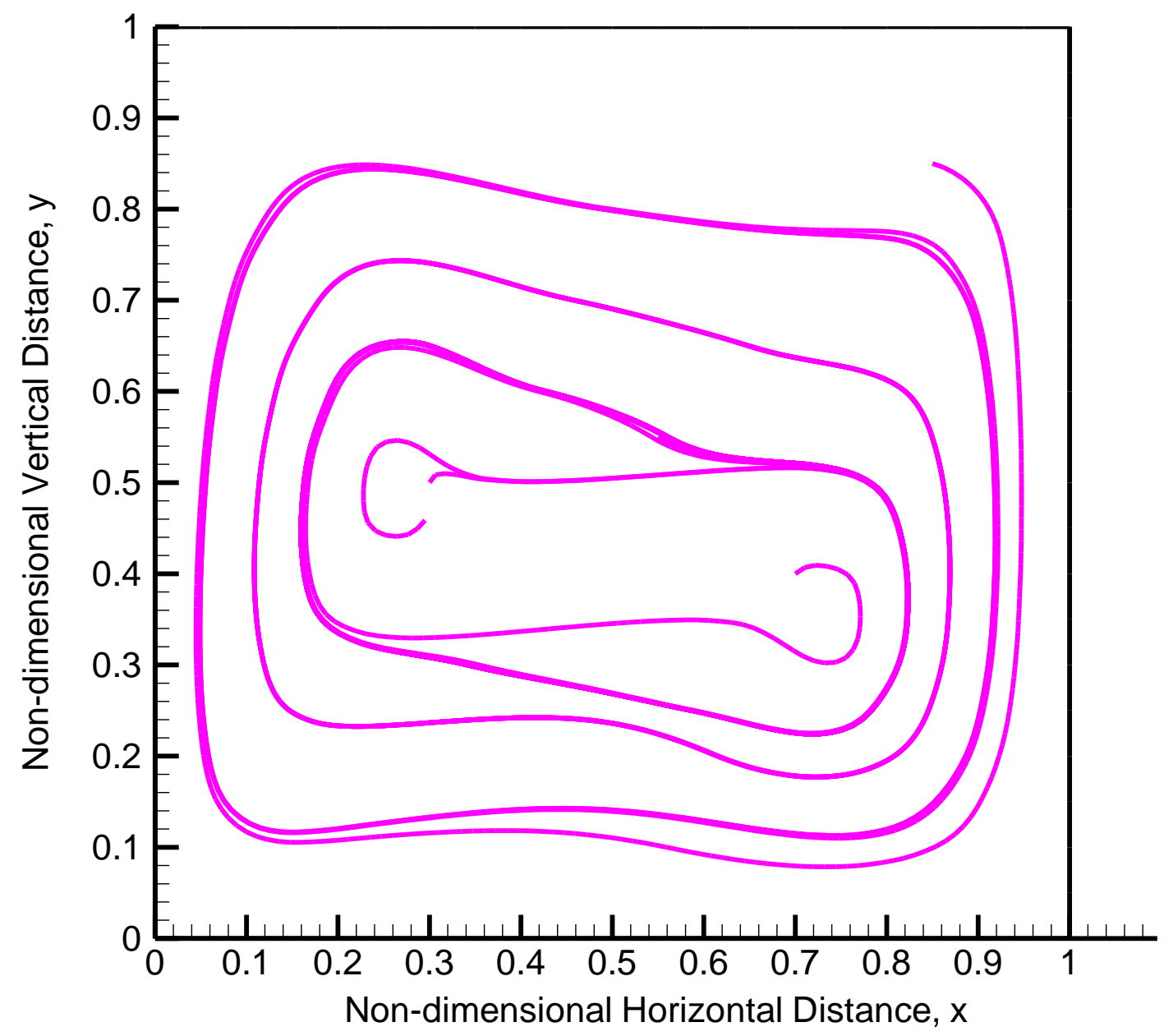

Figure 21- Steady State Non-dimensional Velocity Streamlines for $\mathrm{Ra}=10^{5}$ for Variable Properties ( $21 \times 21, \Delta \bar{t}=1.0 \mathrm{E}-5)$ 


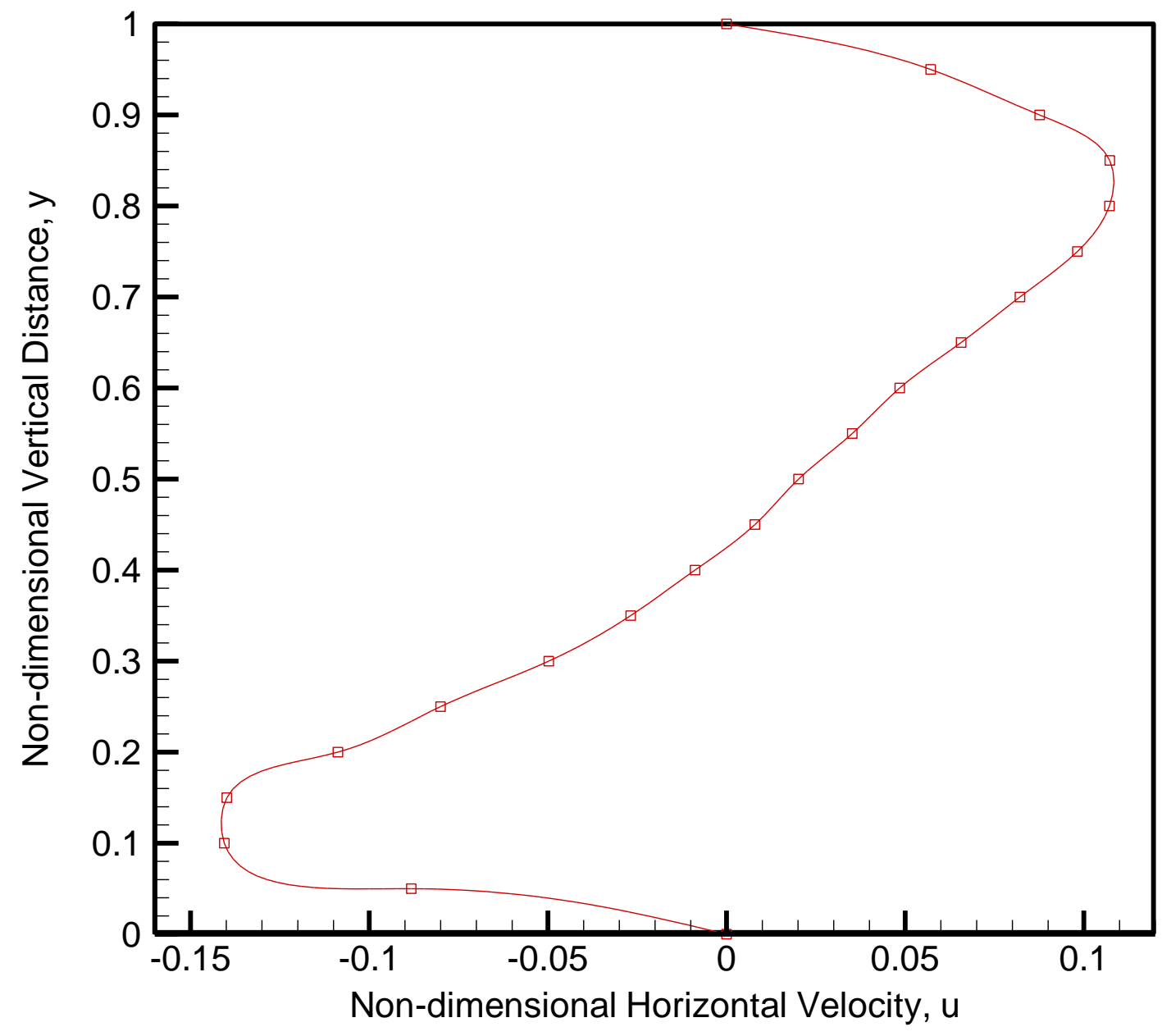

Figure 22- Steady State Non-dimensional Horizontal Velocity Distribution along the Vertical Centerline of the Enclosure for $\mathrm{Ra}=10^{5}$ for Variable Properties $(21 \times 21, \Delta \bar{t}=1.0 \mathrm{E}-5)$ 


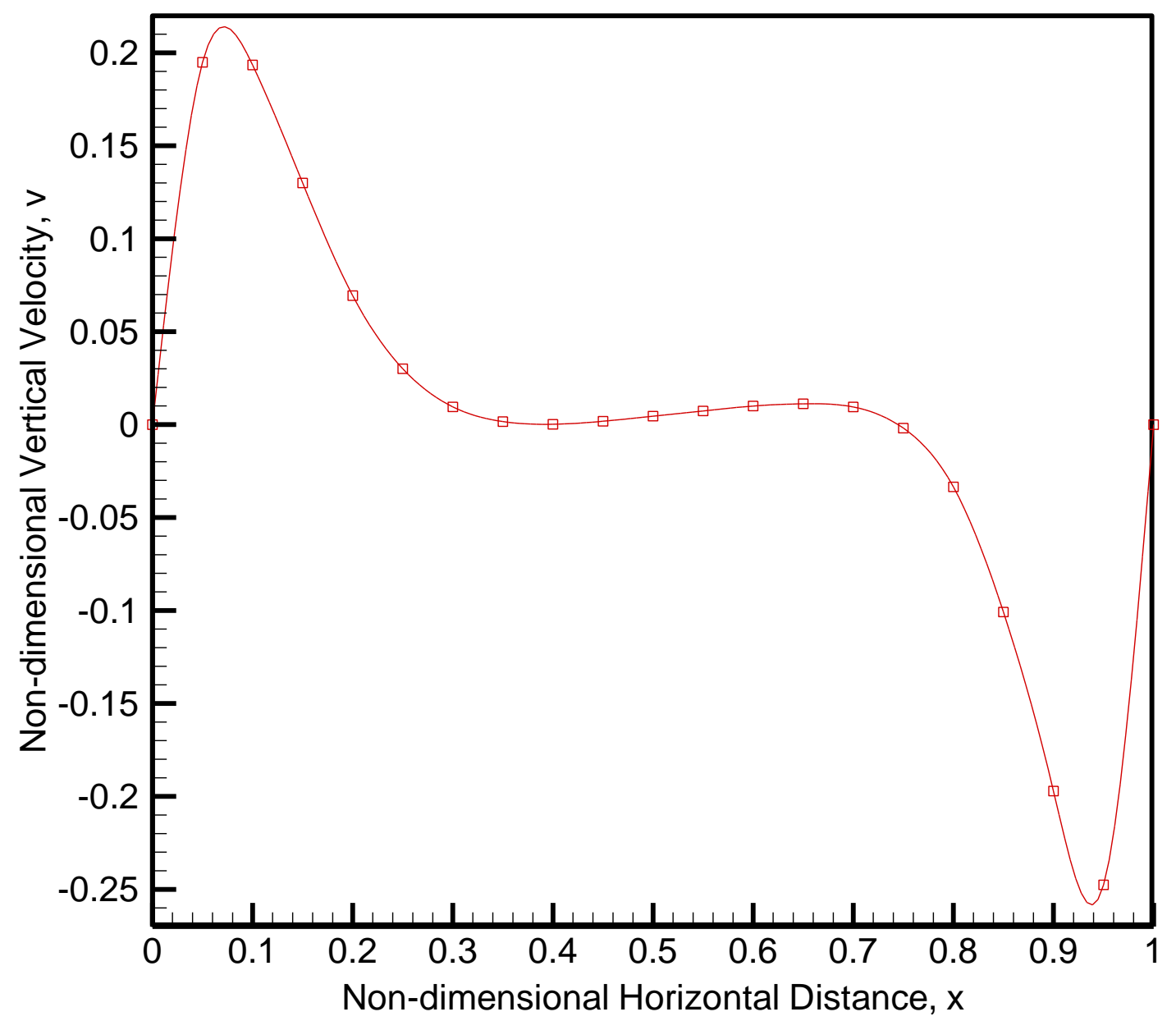

Figure 23- Steady State Non-dimensional Vertical Velocity Distribution along the Horizontal Centerline of the Enclosure for $\mathrm{Ra}=10^{5}$ for Variable Properties $(21 \times 21, \Delta \bar{t}=1.0 \mathrm{E}-5)$ 


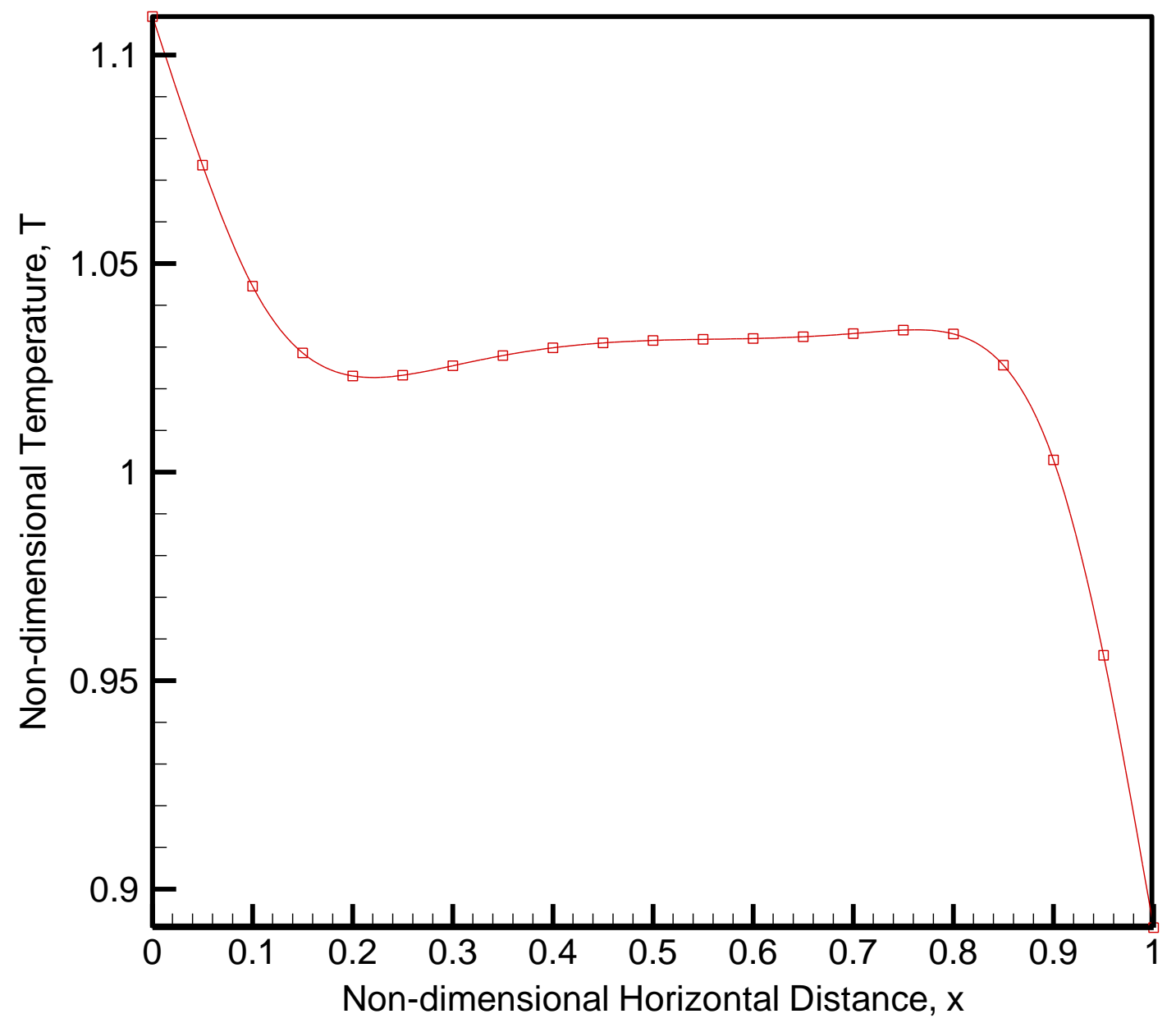

Figure 24- Steady State Non-dimensional Temperature Distribution along the Horizontal Centerline of the Enclosure for $\mathrm{Ra}=10^{5}$ for Variable Properties $(21 \times 21, \Delta \bar{t}=1.0 \mathrm{E}-5)$ 


\subsection{The Effects of Variable Fluid Properties in Square Enclosures}

The comparison of the present model with variable thermodynamic and transport properties to that with constant properties shows noticeable differences when the temperature difference between the enclosure walls is high. These differences can be seen when one compares the velocity and temperature profiles in horizontal and vertical directions. The quantitative comparisons of the results of constant and variable properties are presented for Rayleigh numbers $10^{5}, 5 \times 10^{4}$ and $10^{4}$ with $\Delta T=356.6 \mathrm{deg} \mathrm{K}$ in Table 14 through 22 respectively. These results are compared graphically as shown in Figures 25 through 33, respectively. The nondimensional velocity values of the variable property model are predicted lower than the constant property model and these differences are increasing as the Rayleigh number decreases. However, the non-dimensional temperature values are predicted higher for variable property model than the constant property model and these differences are also increasing as the Rayleigh number decreases.

The comparison of the vertical velocity profiles for the different temperature differences $(\Delta T$ $=64.84 \mathrm{deg} \mathrm{K}$ and $\Delta T=356.6 \mathrm{deg} \mathrm{K}$ ) at Ra number $10^{5}$ are also presented in this chapter. As wall temperature difference increases the maximum velocity in vertical direction increases in magnitude and moves towards the cold side of the enclosure as shown in Figure 34. For different Rayleigh numbers $10^{4}, 5 \times 10^{4}$ and $10^{5}$ at same wall temperature difference $\Delta T=356.6$ $\operatorname{deg} \mathrm{K}$, the same comparison is presented in Figure 35. In this case, the maximum value of the vertical velocity higher as increases Rayleigh numbers and the location of this point moves towards the hot side of the enclosure. 
Table 14- Comparison of Predicted Non-dimensional values of Horizontal Velocity along the Vertical Centerline of the Enclosure for Constant and Variable Fluid Properties at $\mathrm{Ra}=10^{5}(\Delta T=356.6 \mathrm{~K}, \mathrm{H}=0.0144 \mathrm{~m}$ and $21 \mathrm{X} 21)$

\begin{tabular}{|c|c|c|c|}
\hline $\begin{array}{c}\text { Non-dimensional } \\
\text { Vertical } \\
\text { Distance, } \bar{y}\end{array}$ & $\begin{array}{c}\text { Non-dimensional } \\
\text { Horizontal } \\
\text { Velocity, } \bar{u} \\
\text { (Constant) }\end{array}$ & $\begin{array}{c}\text { Non-dimensional } \\
\text { Horizontal } \\
\text { Velocity, } \bar{u} \\
\text { (Variable) }\end{array}$ & $\begin{array}{c}\text { \% Deviation } \\
\text { in } \bar{u}\end{array}$ \\
\hline 1.00 & 0.0000000 & 0.0000000 & 0.0000000 \\
\hline 0.95 & 0.0936828 & 0.0838684 & -11.702097 \\
\hline 0.90 & 0.1488197 & 0.1341210 & -10.959283 \\
\hline 0.85 & 0.1716902 & 0.1341210 & -28.011422 \\
\hline 0.80 & 0.1652194 & 0.1595315 & -3.5653773 \\
\hline 0.75 & 0.1426628 & 0.1461648 & 2.3959256 \\
\hline 0.70 & 0.1111090 & 0.1217983 & 8.7762308 \\
\hline 0.65 & 0.0794429 & 0.0934810 & 15.017077 \\
\hline 0.60 & 0.0512550 & 0.0639186 & 19.811995 \\
\hline 0.55 & 0.0290225 & 0.0372387 & 22.063447 \\
\hline 0.50 & 0.0118728 & 0.0144168 & 17.646169 \\
\hline 0.45 & -0.0025051 & -0.0047551 & 47.316622 \\
\hline 0.40 & -0.0157795 & -0.0207039 & 23.784529 \\
\hline 0.35 & -0.0313873 & -0.0365194 & 14.053032 \\
\hline 0.30 & -0.0475436 & -0.0509674 & 6.7175475 \\
\hline 0.25 & -0.0669880 & -0.0677428 & 1.1142725 \\
\hline 0.20 & -0.0828617 & -0.0808987 & -2.4264911 \\
\hline 0.15 & -0.0962331 & -0.0929094 & -3.5773448 \\
\hline 0.10 & -0.0923184 & -0.0889011 & -3.8439314 \\
\hline 0.05 & -0.0646962 & -0.0638143 & -1.3819460 \\
\hline 0.00 & 0.0000000 & 0.0000000 & 0.0000000 \\
\hline & & &
\end{tabular}


Table 15- Comparison of Predicted Non-dimensional values of Vertical Velocity along the Horizontal Centerline of the Enclosure for Constant and Variable Fluid Properties at $\mathrm{Ra}=10^{5}(\Delta T=356.6 \mathrm{~K}, \mathrm{H}=0.0144 \mathrm{~m}$ and $21 \mathrm{X} 21)$

\begin{tabular}{|c|c|c|c|}
\hline $\begin{array}{c}\text { Non-dimensional } \\
\text { Horizontal } \\
\text { Distance, } \bar{x}\end{array}$ & $\begin{array}{c}\text { Non-dimensional } \\
\text { Vertical } \\
\text { Velocity, } \bar{v} \\
\text { (Constant })\end{array}$ & $\begin{array}{c}\text { Non-dimensional } \\
\text { Vertical } \\
\text { Velocity, } \bar{v} \\
\text { ( Variable) }\end{array}$ & $\begin{array}{c}\% \text { Deviation } \\
\text { in } \bar{v}\end{array}$ \\
\hline 1.00 & 0.0000000 & 0.0000000 & 0.0000000 \\
\hline 0.95 & -0.2093566 & -0.2203230 & 4.9774195 \\
\hline 0.90 & -0.1630863 & -0.1482642 & -9.9970862 \\
\hline 0.85 & -0.0850964 & -0.0773353 & -10.035699 \\
\hline 0.80 & -0.0337917 & -0.0353622 & 4.4411213 \\
\hline 0.75 & -0.0113363 & -0.0141749 & 20.025142 \\
\hline 0.70 & -0.0043228 & -0.0075802 & 42.972368 \\
\hline 0.65 & -0.0045029 & -0.0060678 & 25.789552 \\
\hline 0.60 & -0.0066290 & -0.0078408 & 15.455837 \\
\hline 0.55 & -0.0092771 & -0.0088425 & -4.9148134 \\
\hline 0.50 & -0.0112224 & -0.0094607 & -18.620428 \\
\hline 0.45 & -0.0117948 & -0.0069627 & -69.400468 \\
\hline 0.40 & -0.0096178 & -0.0008446 & -1038.7143 \\
\hline 0.35 & -0.0017328 & 0.0132710 & 113.05706 \\
\hline 0.30 & 0.0165154 & 0.0388702 & 57.511265 \\
\hline 0.25 & 0.0526970 & 0.0820472 & 35.772274 \\
\hline 0.20 & 0.1129559 & 0.1426556 & 20.819161 \\
\hline 0.15 & 0.1957559 & 0.2091187 & 6.3900550 \\
\hline 0.10 & 0.2702196 & 0.2412191 & -12.022472 \\
\hline 0.05 & 0.2444604 & 0.1800874 & -35.745421 \\
\hline 0.00 & 0.0000000 & 0.0000000 & 0.0000000 \\
\hline & & & \\
\hline
\end{tabular}


Table 16- Comparison of Predicted Non-dimensional values of Temperature along the Horizontal Centerline of the Enclosure for Constant and Variable Fluid Properties at $\mathrm{Ra}=10^{5}(\Delta T=356.6 \mathrm{~K}, \mathrm{H}=0.0144 \mathrm{~m}$ and $21 \mathrm{X} 21)$

\begin{tabular}{|c|c|c|c|}
\hline $\begin{array}{c}\text { Non-dimensional } \\
\text { Horizontal } \\
\text { Distance, } \bar{x}\end{array}$ & $\begin{array}{l}\text { Non-dimensional } \\
\text { Temperature, } \bar{T} \\
\text { (Constant ) }\end{array}$ & $\begin{array}{c}\text { Non-dimensional } \\
\text { Temperature, } \bar{T} \\
\text { (Variable ) }\end{array}$ & $\begin{array}{c}\% \text { Deviation } \\
\text { in } \bar{T}\end{array}$ \\
\hline 1.00 & 0.4005175 & 0.4005175 & 0.0000000 \\
\hline 0.95 & 0.6880814 & 0.8184327 & 15.926941 \\
\hline 0.90 & 0.8781839 & 0.9827196 & 10.637388 \\
\hline 0.85 & 0.9661263 & 1.0501240 & 7.9988363 \\
\hline 0.80 & 0.9919955 & 1.0705230 & 7.3354332 \\
\hline 0.75 & 0.9937108 & 1.0724990 & 7.3462259 \\
\hline 0.70 & 0.9900559 & 1.0697560 & 7.4503064 \\
\hline 0.65 & 0.9867782 & 1.0664140 & 7.4676251 \\
\hline 0.60 & 0.9838625 & 1.0631580 & 7.4584868 \\
\hline 0.55 & 0.9801099 & 1.0588480 & 7.4362042 \\
\hline 0.50 & 0.9741970 & 1.0527800 & 7.4643325 \\
\hline 0.45 & 0.9652914 & 1.0442670 & 7.5627784 \\
\hline 0.40 & 0.9531033 & 1.0338590 & 7.8110941 \\
\hline 0.35 & 0.9384271 & 1.0233100 & 8.2949350 \\
\hline 0.30 & 0.9243982 & 1.0176280 & 9.1614814 \\
\hline 0.25 & 0.9186205 & 1.0261480 & 10.478751 \\
\hline 0.20 & 0.9359822 & 1.0637710 & 12.012811 \\
\hline 0.15 & 0.9999081 & 1.1468870 & 12.815464 \\
\hline 0.10 & 1.1384730 & 1.2812960 & 11.146760 \\
\hline 0.05 & 1.3570710 & 1.4443730 & 6.0442835 \\
\hline 0.00 & 1.5994830 & 1.5994830 & 0.0000000 \\
\hline
\end{tabular}




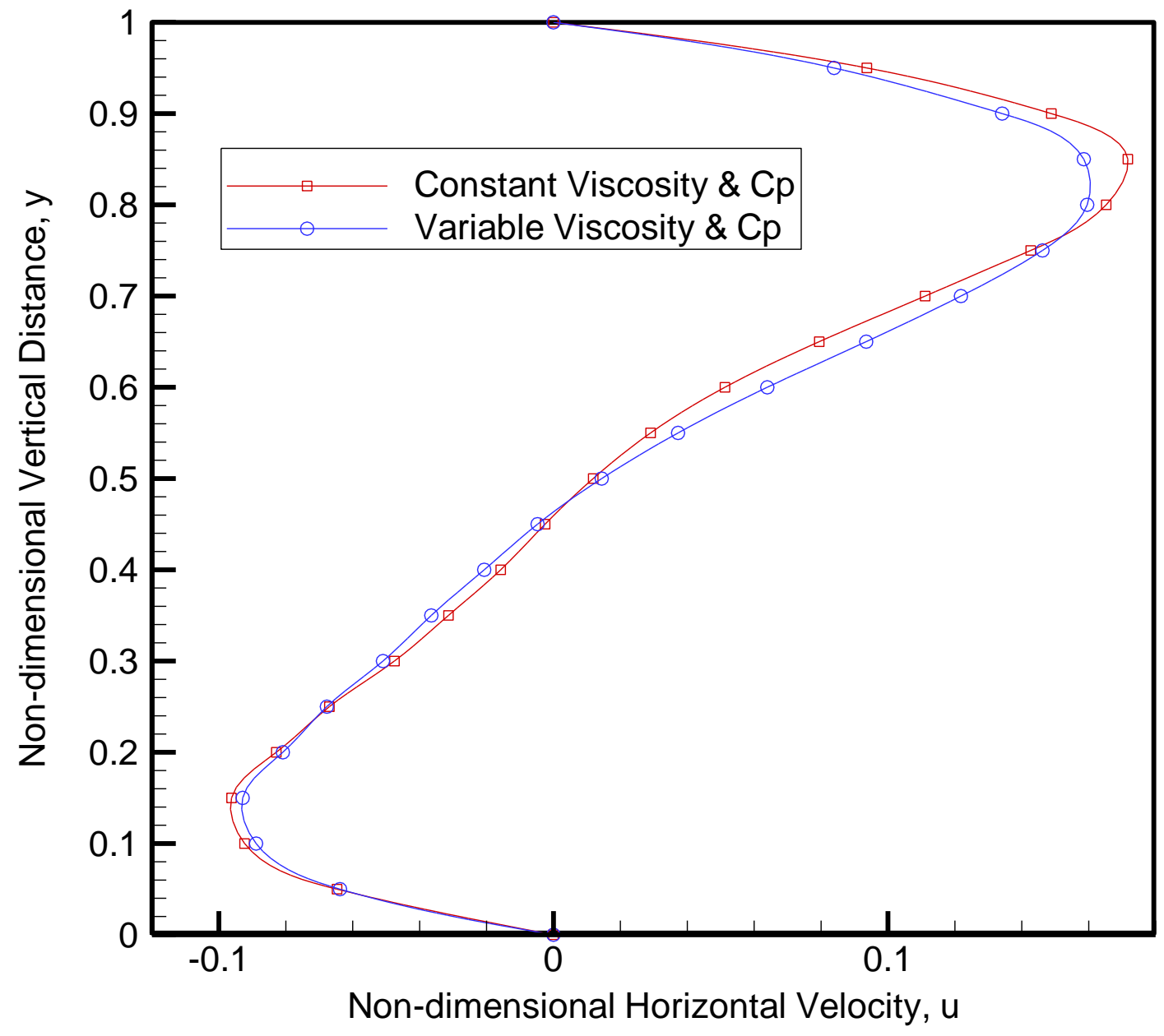

Figure 25- Comparison of Steady State Non-dimensional Horizontal Velocity Distributions along the Vertical Centerline of the Enclosure for Constant and Variable Fluid Properties at $\mathrm{Ra}=10^{5}(\Delta T=356.6 \mathrm{~K}, \mathrm{H}=0.0115 \mathrm{~m})$ 


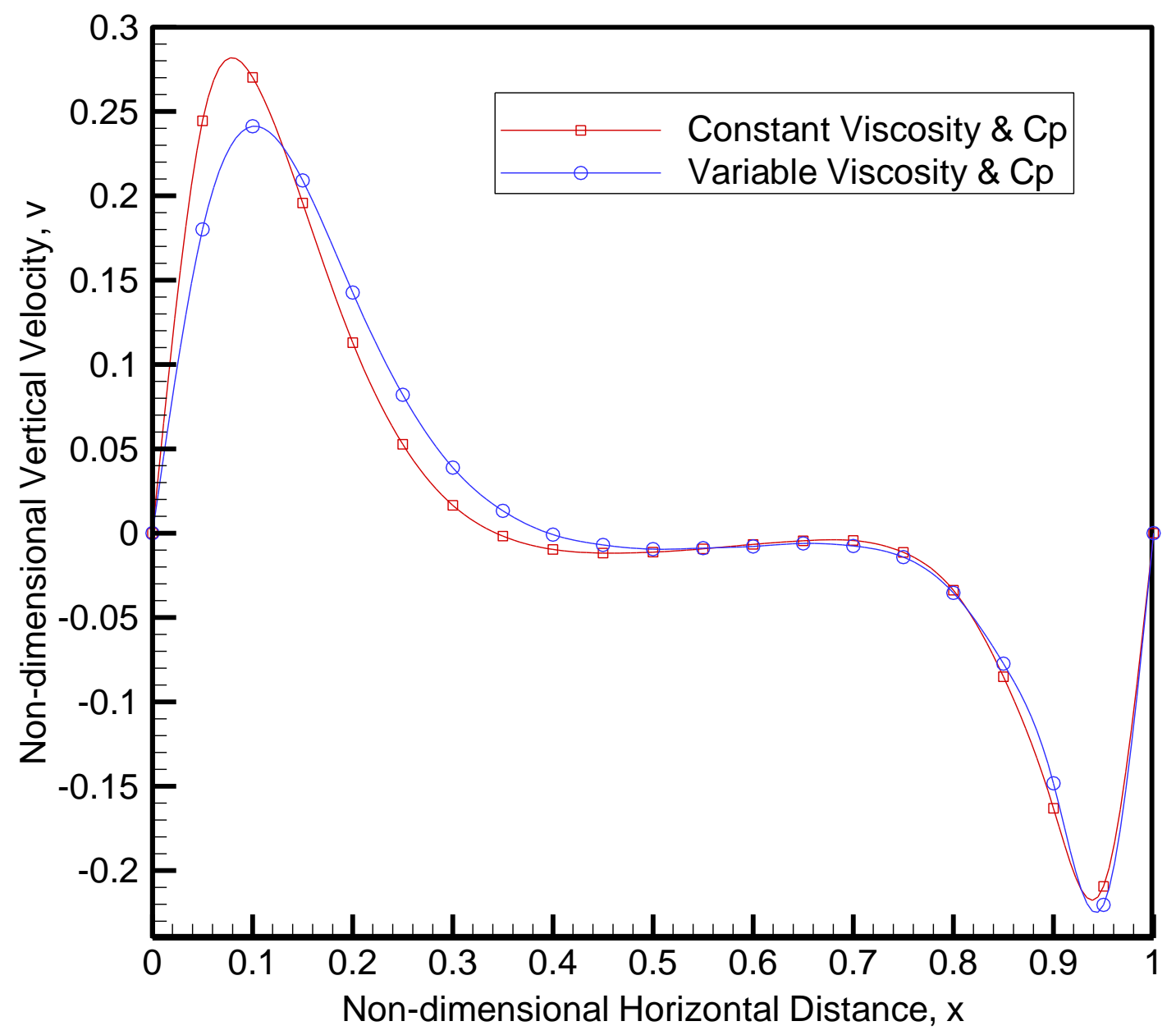

Figure 26- Comparison of Steady State Non-dimensional Vertical Velocity Distributions along the Horizontal Centerline of the Enclosure for Constant and Variable Fluid Properties at $\mathrm{Ra}=10^{5}(\Delta T=356.6 \mathrm{~K}, \mathrm{H}=0.0115 \mathrm{~m})$ 


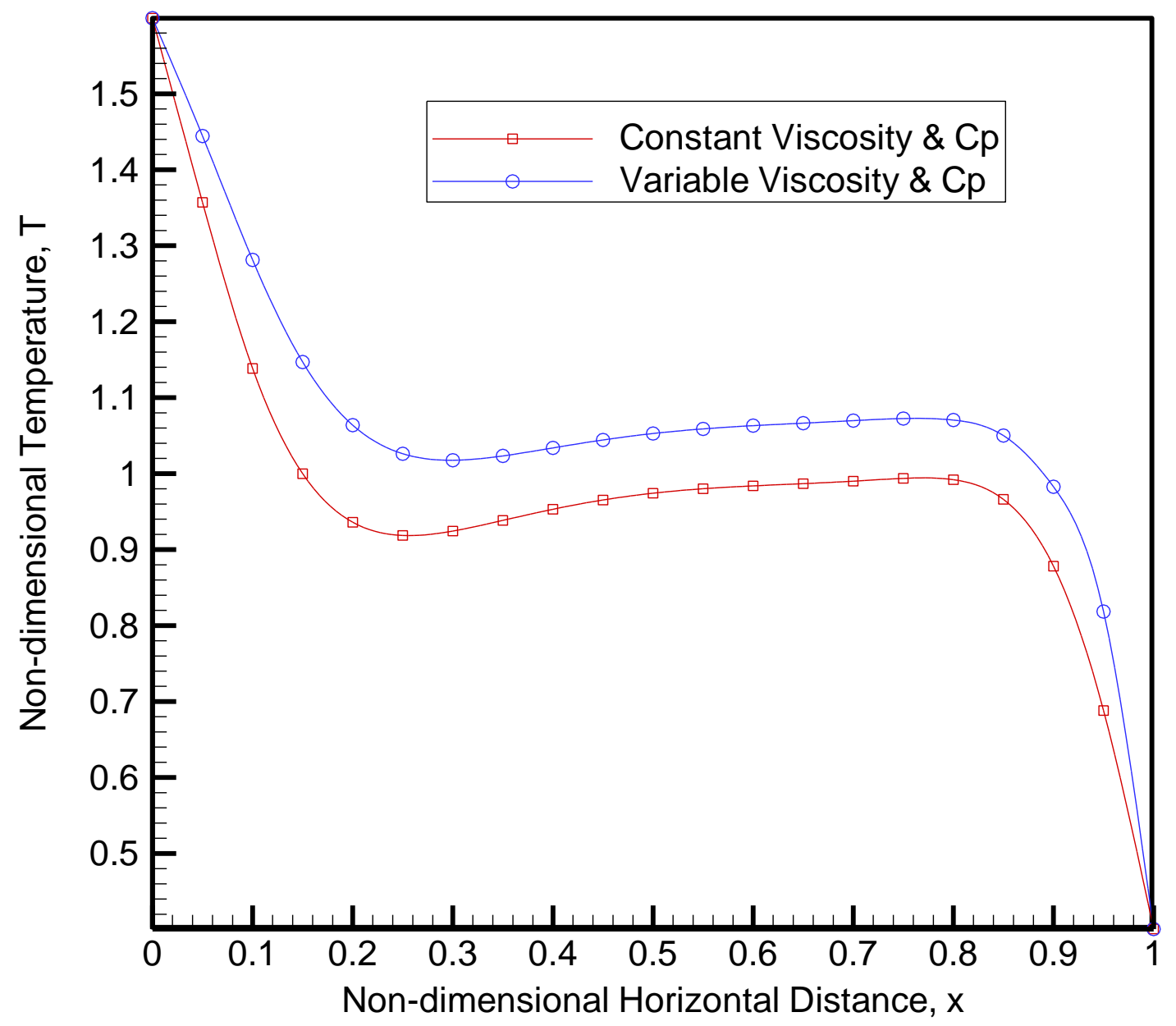

Figure 27- Comparison of Steady State Non-dimensional Temperature Distributions along the Horizontal Centerline of the Enclosure for Constant and Variable Fluid Properties at $\operatorname{Ra}=10^{5}(\Delta T=356.6 \mathrm{~K}, \mathrm{H}=0.0115 \mathrm{~m})$ 
Table-17: $\quad$ Comparison of Predicted Non-dimensional values of Horizontal Velocity along the Vertical Centerline of the Enclosure for Constant and Variable Fluid Properties at $\mathrm{Ra}=5 \times 10^{4}(\Delta T=356.6 \mathrm{~K}, \mathrm{H}=0.0115 \mathrm{~m}$ and $21 \mathrm{X} 21)$

\begin{tabular}{|c|c|c|c|}
\hline $\begin{array}{c}\text { Non-dimensional } \\
\text { Vertical } \\
\text { Distance, } \bar{y}\end{array}$ & $\begin{array}{c}\text { Non-dimensional } \\
\text { Horizontal } \\
\text { Velocity, } \bar{u} \\
\text { (Constant) }\end{array}$ & $\begin{array}{c}\text { Non-dimensional } \\
\text { Horizontal } \\
\text { Velocity, } \bar{u} \\
\text { (Variable) }\end{array}$ & $\begin{array}{c}\text { \% Deviation } \\
\text { in } \bar{u}\end{array}$ \\
\hline 1.00 & 0.0000000 & 0.0000000 & 0.0000000 \\
\hline 0.95 & 0.1010880 & 0.0842762 & -19.948369 \\
\hline 0.90 & 0.1608237 & 0.1356474 & -18.560105 \\
\hline 0.85 & 0.1867887 & 0.1616705 & -15.536662 \\
\hline 0.80 & 0.1832999 & 0.1652628 & -10.914192 \\
\hline 0.75 & 0.1625545 & 0.1544248 & -5.2645041 \\
\hline 0.70 & 0.1307763 & 0.1320511 & 0.9653838 \\
\hline 0.65 & 0.0965233 & 0.1042924 & 7.4492772 \\
\hline 0.60 & 0.0635012 & 0.0735256 & 13.633982 \\
\hline 0.55 & 0.0353098 & 0.0439724 & 19.700226 \\
\hline 0.50 & 0.0122669 & 0.0172566 & 28.914988 \\
\hline 0.45 & -0.0068705 & -0.0058550 & -17.344015 \\
\hline 0.40 & -0.0233795 & -0.0251376 & 6.9936982 \\
\hline 0.35 & -0.0407417 & -0.0433361 & 5.9866850 \\
\hline 0.30 & -0.0581902 & -0.0596543 & 2.4543729 \\
\hline 0.25 & -0.0785703 & -0.0780983 & -0.6044561 \\
\hline 0.20 & -0.0957358 & -0.0932317 & -2.6859203 \\
\hline 0.15 & -0.1085417 & -0.1062663 & -2.1412244 \\
\hline 0.10 & -0.1023104 & -0.1009673 & -1.3302326 \\
\hline 0.05 & -0.0692979 & -0.0701084 & 1.1561509 \\
\hline 0.00 & 0.0000000 & 0.0000000 & 0.0000000 \\
\hline
\end{tabular}


Table 18- Comparison of Predicted Non-dimensional values of Vertical Velocity along the Horizontal Centerline of the Enclosure for Constant and Variable Fluid Properties at $\mathrm{Ra}=5 \times 10^{4}(\Delta T=356.6 \mathrm{~K}, \mathrm{H}=0.0115 \mathrm{~m}$ and $21 \mathrm{X} 21)$

\begin{tabular}{|c|c|c|c|}
\hline $\begin{array}{c}\text { Non-dimensional } \\
\text { Horizontal } \\
\text { Distance, } \bar{x}\end{array}$ & $\begin{array}{c}\text { Non-dimensional } \\
\text { Vertical } \\
\text { Velocity, } \bar{v} \\
\text { (Constant ) }\end{array}$ & $\begin{array}{c}\text { Non-dimensional } \\
\text { Vertical } \\
\text { Velocity, } \bar{v} \\
\text { ( Variable) }\end{array}$ & $\begin{array}{c}\text { \% Deviation } \\
\text { in } \bar{v}\end{array}$ \\
\hline 1.00 & 0.0000000 & 0.0000000 & 0.0000000 \\
\hline 0.95 & -0.2079249 & -0.2181263 & 4.6768317 \\
\hline 0.90 & -0.1805588 & -0.1735712 & -4.0257830 \\
\hline 0.85 & -0.1105591 & -0.1065565 & -3.7563170 \\
\hline 0.80 & -0.0555643 & -0.0564429 & 1.5565636 \\
\hline 0.75 & -0.0254680 & -0.0274957 & 7.3747006 \\
\hline 0.70 & -0.0122137 & -0.0132682 & 7.9472724 \\
\hline 0.65 & -0.0085119 & -0.0080180 & -6.1597252 \\
\hline 0.60 & -0.0085827 & -0.0067362 & -27.411106 \\
\hline 0.55 & -0.0098464 & -0.0066076 & -49.015896 \\
\hline 0.50 & -0.0102490 & -0.0053554 & -91.375590 \\
\hline 0.45 & -0.0082766 & -0.0009993 & -728.21051 \\
\hline 0.40 & -0.0019325 & 0.0087003 & 122.21279 \\
\hline 0.35 & 0.0122559 & 0.0273276 & 55.151703 \\
\hline 0.30 & 0.0386824 & 0.0584576 & 33.828290 \\
\hline 0.25 & 0.0833502 & 0.1055321 & 21.019045 \\
\hline 0.20 & 0.1483615 & 0.1650306 & 10.100611 \\
\hline 0.15 & 0.2259767 & 0.221059 & -2.2246097 \\
\hline 0.10 & 0.2786205 & 0.2356686 & -18.225550 \\
\hline 0.05 & 0.2286864 & 0.1671887 & -36.783407 \\
\hline 0.00 & 0.0000000 & 0.0000000 & 0.0000000 \\
\hline
\end{tabular}


Table 19- Comparison of Predicted Non-dimensional values of Temperature along the Horizontal Centerline of the Enclosure for Constant and Variable Fluid Properties at $\mathrm{Ra}=5 \times 10^{4}(\Delta T=356.6 \mathrm{~K}, \mathrm{H}=0.0115 \mathrm{~m}$ and $21 \mathrm{X} 21)$

\begin{tabular}{|c|c|c|c|}
\hline $\begin{array}{c}\text { Non-dimensional } \\
\text { Horizontal } \\
\text { Distance, } \bar{x}\end{array}$ & $\begin{array}{l}\text { Non-dimensional } \\
\text { Temperature, } \bar{T} \\
\text { (Constant ) }\end{array}$ & $\begin{array}{c}\text { Non-dimensional } \\
\text { Temperature, } \bar{T} \\
\text { (Variable ) }\end{array}$ & $\begin{array}{c}\% \text { Deviation } \\
\text { in } \bar{T}\end{array}$ \\
\hline 1.00 & 0.4115081 & 0.4115081 & 0.0000000 \\
\hline 0.95 & 0.6617610 & 0.7668620 & 13.705334 \\
\hline 0.90 & 0.8384050 & 0.9422544 & 11.021375 \\
\hline 0.85 & 0.9328032 & 1.0257650 & 9.0626800 \\
\hline 0.80 & 0.9688077 & 1.0578800 & 8.4198869 \\
\hline 0.75 & 0.9757017 & 1.0652240 & 8.4040821 \\
\hline 0.70 & 0.9720609 & 1.0628410 & 8.5412681 \\
\hline 0.65 & 0.9660809 & 1.0577420 & 8.6657332 \\
\hline 0.60 & 0.9598690 & 1.0521630 & 8.7718347 \\
\hline 0.55 & 0.9532482 & 1.0462480 & 8.8888867 \\
\hline 0.50 & 0.9453675 & 1.0394670 & 9.0526683 \\
\hline 0.45 & 0.9356530 & 1.0315640 & 9.2976296 \\
\hline 0.40 & 0.9243249 & 1.0232780 & 9.6702069 \\
\hline 0.35 & 0.9131055 & 1.0171590 & 10.229816 \\
\hline 0.30 & 0.9065261 & 1.0188430 & 11.023965 \\
\hline 0.25 & 0.9133821 & 1.0377910 & 11.987856 \\
\hline 0.20 & 0.9482343 & 1.0867650 & 12.747070 \\
\hline 0.15 & 1.0301340 & 1.1763090 & 12.426581 \\
\hline 0.10 & 1.1754250 & 1.3047870 & 9.9144151 \\
\hline 0.05 & 1.3757300 & 1.4503020 & 5.1418256 \\
\hline 0.00 & 1.5884920 & 1.5884920 & 0.0000000 \\
\hline
\end{tabular}




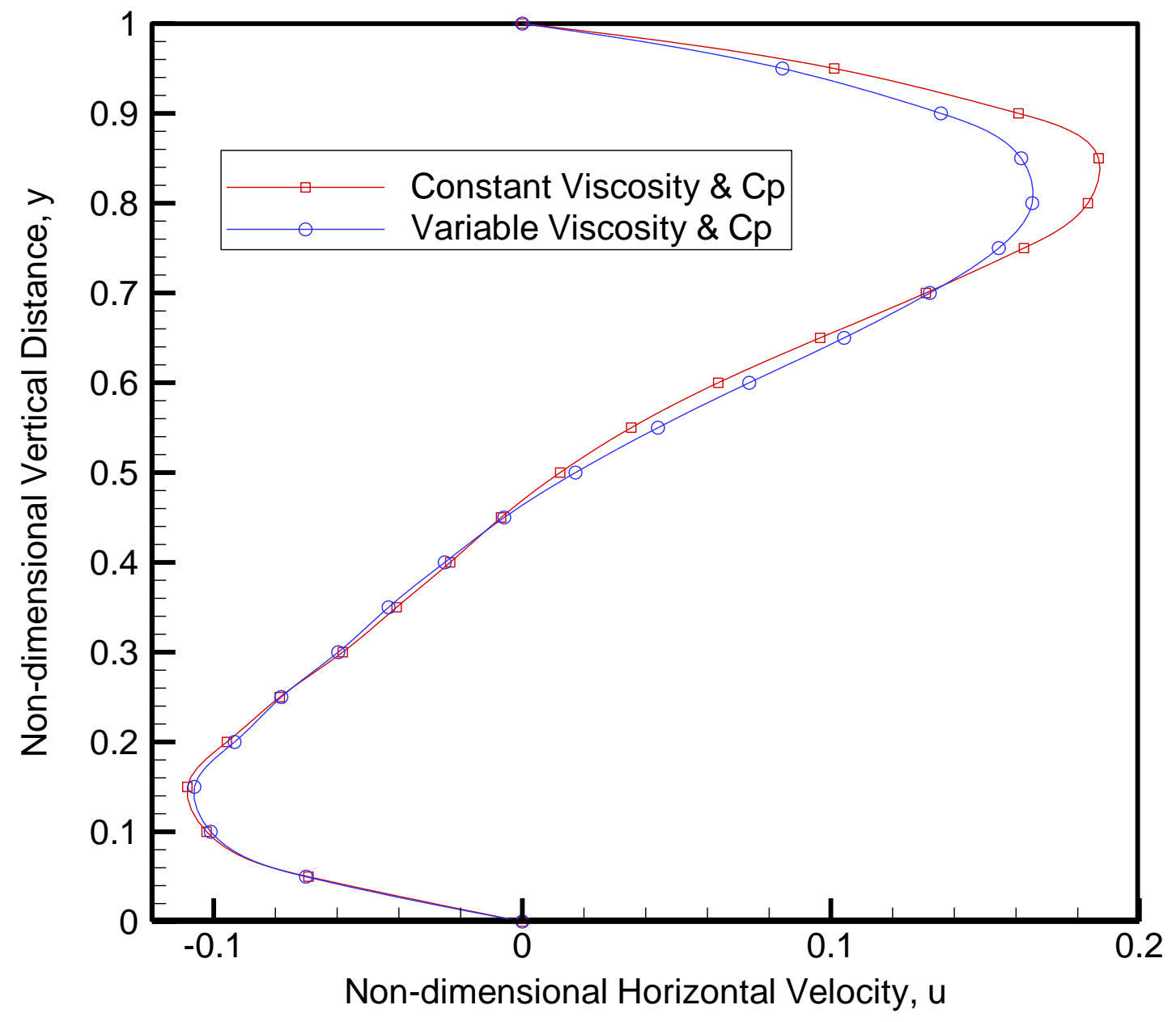

Figure 28- Comparison of Steady State Non-dimensional Horizontal Velocity Distributions along the Vertical Centerline of the Enclosure for Constant and Variable Fluid

Properties at $\mathrm{Ra}=5 \times 10^{4}(\Delta T=356.6 \mathrm{~K}, \mathrm{H}=0.0115 \mathrm{~m})$ 


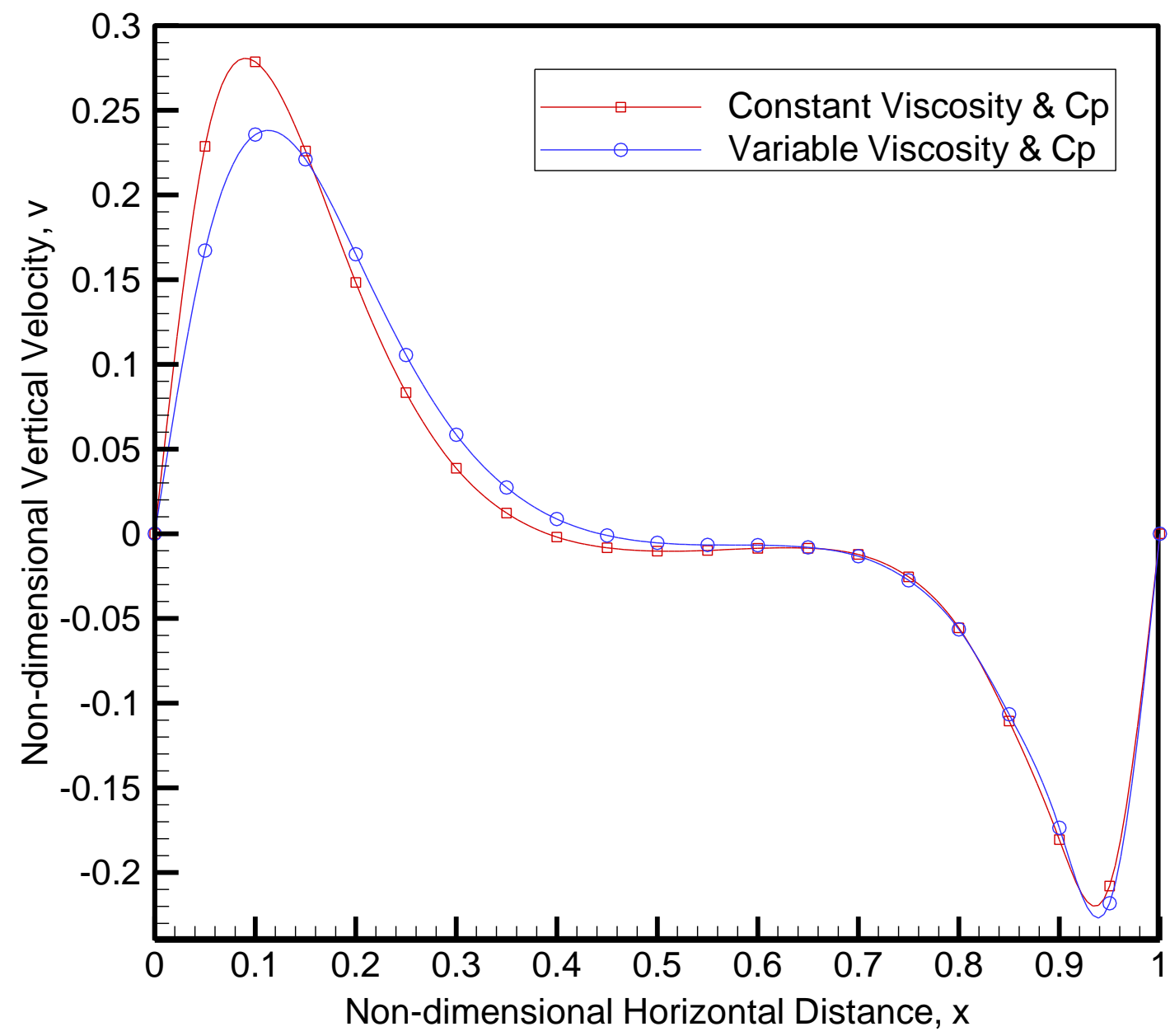

Figure 29- Comparison of Steady State Non-dimensional Vertical Velocity Distributions along the Horizontal Centerline of the Enclosure for Constant and Variable Fluid Properties at $\mathrm{Ra}=5 \times 10^{4}(\Delta T=356.6 \mathrm{~K}, \mathrm{H}=0.0115 \mathrm{~m})$ 


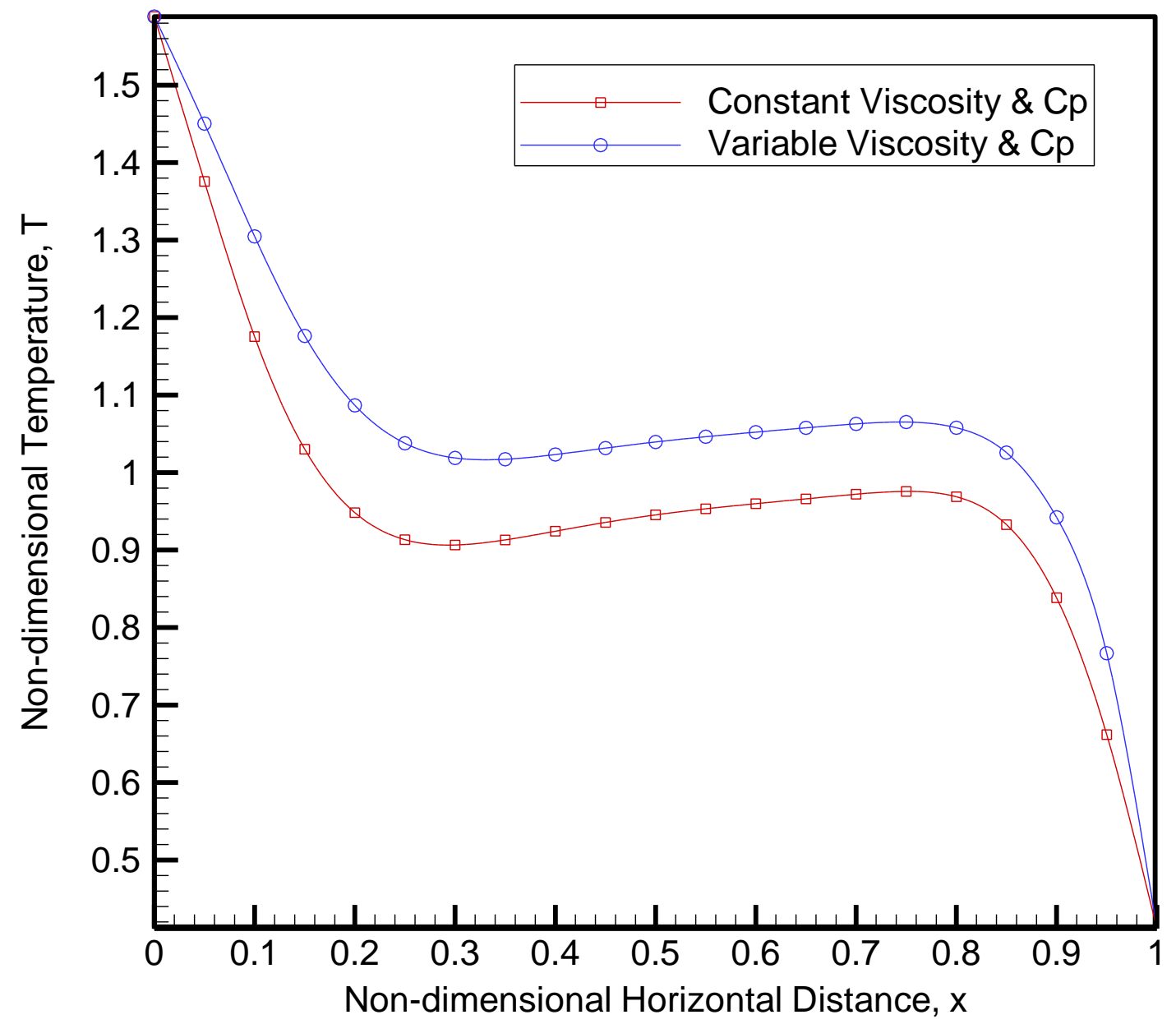

Figure 30- Comparison of Steady State Non-dimensional Temperature Distributions along the Horizontal Centerline of the Enclosure for Constant and Variable Fluid Properties at $\mathrm{Ra}=5 \times 10^{4}(\Delta T=356.6 \mathrm{~K}, \mathrm{H}=0.0115 \mathrm{~m})$ 
Table 20- Comparison of Predicted Non-dimensional values of Horizontal Velocity along the Vertical Centerline of the Enclosure for Constant and Variable Fluid Properties at $\mathrm{Ra}=10^{4}(\Delta T=356.6 \mathrm{~K}, \mathrm{H}=0.0067 \mathrm{~m}$ and $21 \mathrm{X} 21)$

\begin{tabular}{|c|c|c|c|}
\hline $\begin{array}{c}\text { Non-dimensional } \\
\text { Vertical } \\
\text { Distance, } \bar{y}\end{array}$ & $\begin{array}{c}\text { Non-dimensional } \\
\text { Horizontal } \\
\text { Velocity, } \bar{u} \\
\text { (Constant) }\end{array}$ & $\begin{array}{c}\text { Non-dimensional } \\
\text { Horizontal } \\
\text { Velocity, } \bar{u} \\
\text { (Variable) }\end{array}$ & $\begin{array}{c}\text { \% Deviation } \\
\text { in } \bar{u}\end{array}$ \\
\hline 1.00 & 0.0000000 & 0.0000000 & 0.0000000 \\
\hline 0.95 & 0.1083175 & 0.0862691 & -25.557658 \\
\hline 0.90 & 0.1756615 & 0.1418459 & -23.839673 \\
\hline 0.85 & 0.2116735 & 0.1744832 & -21.314544 \\
\hline 0.80 & 0.2217043 & 0.1879760 & -17.942875 \\
\hline 0.75 & 0.2141084 & 0.1879882 & -13.894595 \\
\hline 0.70 & 0.1926927 & 0.1765157 & -9.1646238 \\
\hline 0.65 & 0.1629599 & 0.1569659 & -3.8186637 \\
\hline 0.60 & 0.1272570 & 0.1303389 & 2.3645281 \\
\hline 0.55 & 0.0889332 & 0.0988132 & 9.9986813 \\
\hline 0.50 & 0.0497051 & 0.0637028 & 21.973478 \\
\hline 0.45 & 0.0108663 & 0.0265779 & 59.115146 \\
\hline 0.40 & -0.0264220 & -0.0105711 & -149.94404 \\
\hline 0.35 & -0.0627750 & -0.0475411 & -32.043747 \\
\hline 0.30 & -0.0961872 & -0.0818469 & -17.520782 \\
\hline 0.25 & -0.1268682 & -0.1145173 & -10.785182 \\
\hline 0.20 & -0.1486439 & -0.1396459 & -6.4434401 \\
\hline 0.15 & -0.1578665 & -0.1546874 & -2.0551770 \\
\hline 0.10 & -0.1419982 & -0.1439025 & 1.3233265 \\
\hline 0.05 & -0.0931065 & -0.0969537 & 3.9680692 \\
\hline 0.00 & 0.0000000 & 0.0000000 & 0.0000000 \\
\hline
\end{tabular}


Table 21- Comparison of Predicted Non-dimensional values of Vertical Velocity along the Horizontal Centerline of the Enclosure for Constant and Variable Fluid Properties at $\mathrm{Ra}=10^{4}(\Delta T=356.6 \mathrm{~K}, \mathrm{H}=0.0067 \mathrm{~m}$ and $21 \mathrm{X} 21)$

\begin{tabular}{|c|c|c|c|}
\hline $\begin{array}{c}\text { Non-dimensional } \\
\text { Horizontal } \\
\text { Distance, } \bar{x}\end{array}$ & $\begin{array}{c}\text { Non-dimensional } \\
\text { Vertical } \\
\text { Velocity, } \bar{v} \\
\text { (Constant })\end{array}$ & $\begin{array}{c}\text { Non-dimensional } \\
\text { Vertical } \\
\text { Velocity, } \bar{v} \\
\text { ( Variable) }\end{array}$ & $\begin{array}{c}\% \text { Deviation } \\
\text { in } \bar{v}\end{array}$ \\
\hline 1.00 & 0.0000000 & 0.0000000 & 0.0000000 \\
\hline 0.95 & -0.1823712 & -0.2083991 & 12.489449 \\
\hline 0.90 & -0.2134350 & -0.2101146 & -1.5802804 \\
\hline 0.85 & -0.1835589 & -0.1661266 & -10.493382 \\
\hline 0.80 & -0.1361653 & -0.1167885 & -16.591359 \\
\hline 0.75 & -0.0923559 & -0.0752924 & -22.662900 \\
\hline 0.70 & -0.0569510 & -0.0426731 & -33.458736 \\
\hline 0.65 & -0.0304331 & -0.0179429 & -69.610304 \\
\hline 0.60 & -0.0094573 & 0.0021489 & 540.08904 \\
\hline 0.55 & 0.0083900 & 0.0200227 & 58.097265 \\
\hline 0.50 & 0.0263901 & 0.0386682 & 31.752292 \\
\hline 0.45 & 0.0469496 & 0.0603234 & 22.170256 \\
\hline 0.40 & 0.0727090 & 0.0869015 & 16.331734 \\
\hline 0.35 & 0.1055913 & 0.1189967 & 11.265354 \\
\hline 0.30 & 0.1459709 & 0.1546759 & 5.6278967 \\
\hline 0.25 & 0.1914424 & 0.1888658 & -1.3642491 \\
\hline 0.20 & 0.2335142 & 0.2121595 & -10.065398 \\
\hline 0.15 & 0.2573774 & 0.2139577 & -20.293590 \\
\hline 0.10 & 0.2404851 & 0.1834930 & -31.059549 \\
\hline 0.05 & 0.1609832 & 0.1140888 & -41.103421 \\
\hline 0.00 & 0.0000000 & 0.0000000 & 0.0000000 \\
\hline & & & \\
\hline
\end{tabular}


Table 22- Comparison of Predicted Non-dimensional values of Temperature along the Horizontal Centerline of the Enclosure for Constant and Variable Fluid Properties at $\mathrm{Ra}=10^{4}(\Delta T=356.6 \mathrm{~K}, \mathrm{H}=0.0067 \mathrm{~m}$ and $21 \mathrm{X} 21)$

\begin{tabular}{|c|c|c|c|}
\hline $\begin{array}{c}\text { Non-dimensional } \\
\text { Horizontal } \\
\text { Distance, } \bar{x} \\
\end{array}$ & $\begin{array}{c}\text { Non-dimensional } \\
\text { Temperature, } \bar{T} \\
\text { (Constant ) }\end{array}$ & $\begin{array}{c}\text { Non-dimensional } \\
\text { Temperature, } \bar{T} \\
\text { (Variable ) }\end{array}$ & $\begin{array}{c}\text { \% Deviation } \\
\text { in } \bar{T}\end{array}$ \\
\hline 1.00 & 0.4048320 & 0.4048320 & 0.0000000 \\
\hline 0.95 & 0.5606439 & 0.6564321 & 14.592248 \\
\hline 0.90 & 0.6961532 & 0.8109570 & 14.156582 \\
\hline 0.85 & 0.7969056 & 0.9066408 & 12.103492 \\
\hline 0.80 & 0.8610080 & 0.9619112 & 10.489866 \\
\hline 0.75 & 0.8953147 & 0.9905590 & 9.6152071 \\
\hline 0.70 & 0.9093859 & 1.0029400 & 9.3279857 \\
\hline 0.65 & 0.9116908 & 1.0064310 & 9.4134818 \\
\hline 0.60 & 0.9082556 & 1.0060100 & 9.7170405 \\
\hline 0.55 & 0.9031278 & 1.0051570 & 10.150573 \\
\hline 0.50 & 0.8991418 & 1.0065670 & 10.672434 \\
\hline 0.45 & 0.8988663 & 1.0128870 & 11.257001 \\
\hline 0.40 & 0.9052760 & 1.0271490 & 11.865172 \\
\hline 0.35 & 0.9222708 & 1.0528780 & 12.404780 \\
\hline 0.30 & 0.9548032 & 1.0936110 & 12.692611 \\
\hline 0.25 & 1.0082650 & 1.1516130 & 12.447584 \\
\hline 0.20 & 1.0870050 & 1.2264310 & 11.368434 \\
\hline 0.15 & 1.1917150 & 1.3141070 & 9.3137012 \\
\hline 0.10 & 1.3177410 & 1.4085590 & 6.4475822 \\
\hline 0.05 & 1.4555180 & 1.5036310 & 3.1997877 \\
\hline 0.00 & 1.5951680 & 1.5951680 & 0.0000000 \\
\hline
\end{tabular}




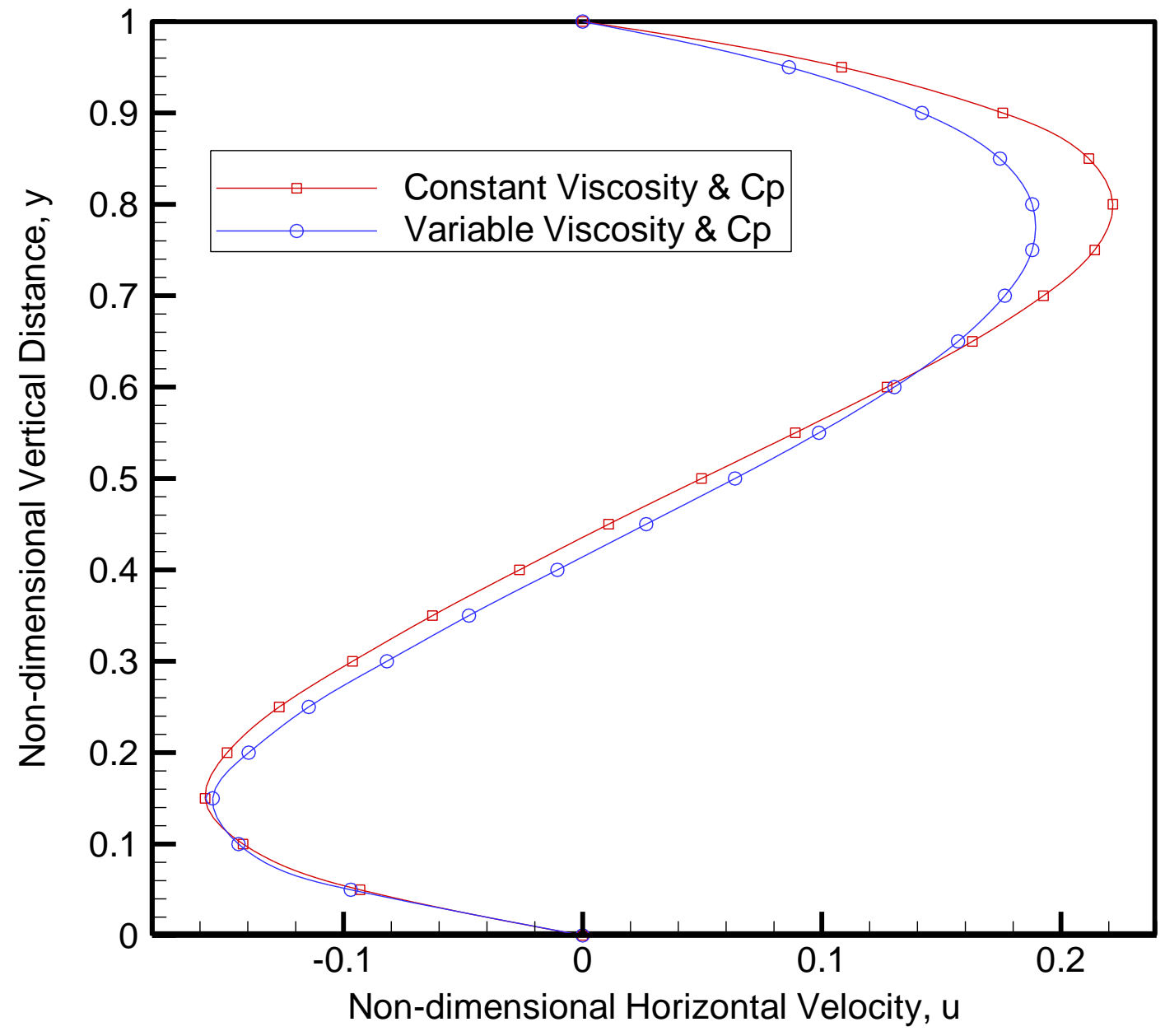

Figure 31- Comparison of Steady State Non-dimensional Horizontal Velocity Distributions along the Vertical Centerline of the Enclosure for Constant and Variable Fluid

Properties at $\mathrm{Ra}=10^{4}(\Delta T=356.6 \mathrm{~K}, \mathrm{H}=0.0067 \mathrm{~m})$ 


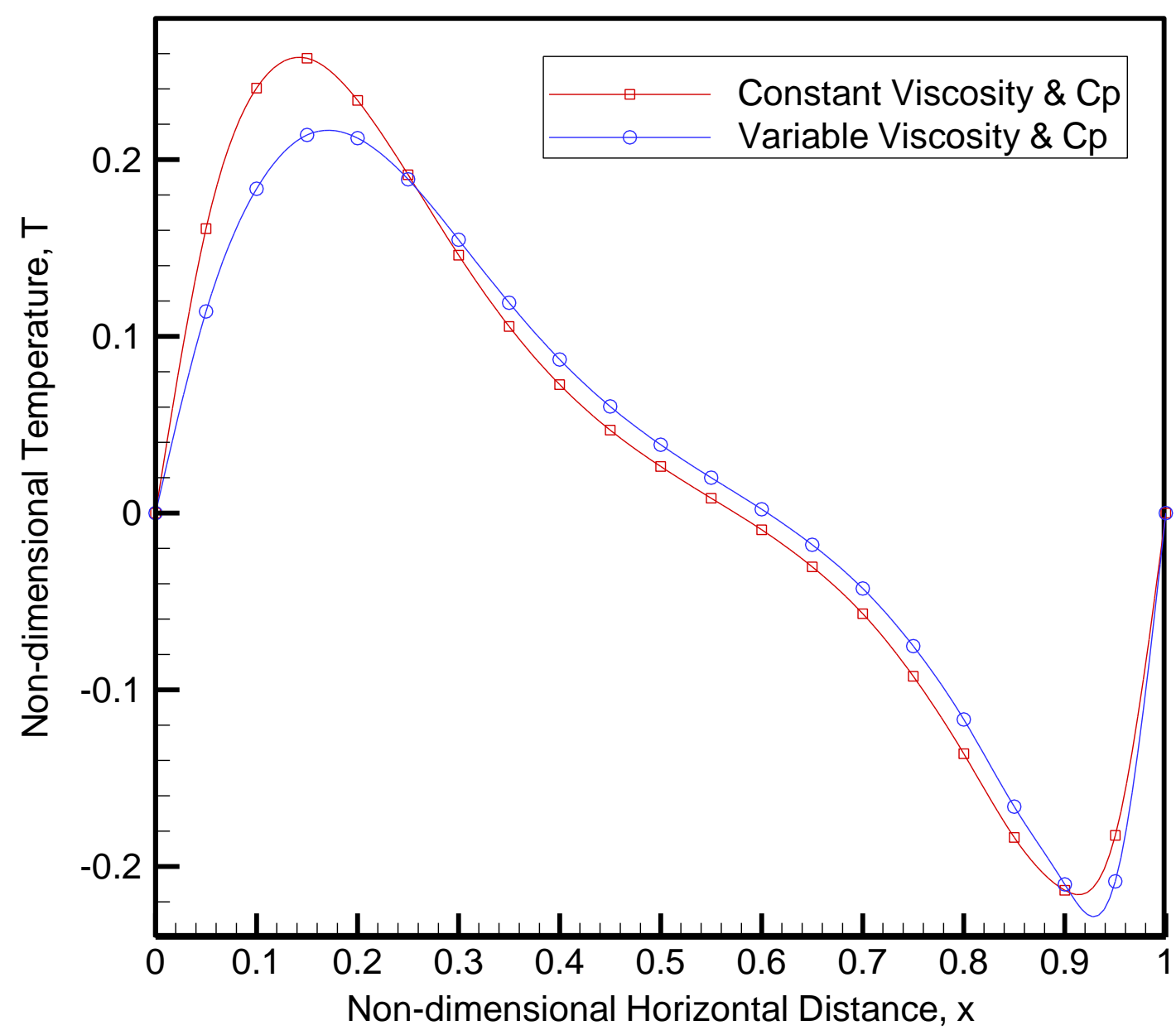

Figure 32- Comparison of Steady State Non-dimensional Vertical Velocity Distributions along the Horizontal Centerline of the Enclosure for Constant and Variable Fluid Properties at $\mathrm{Ra}=10^{4}(\Delta T=356.6 \mathrm{~K}, \mathrm{H}=0.0067 \mathrm{~m})$ 


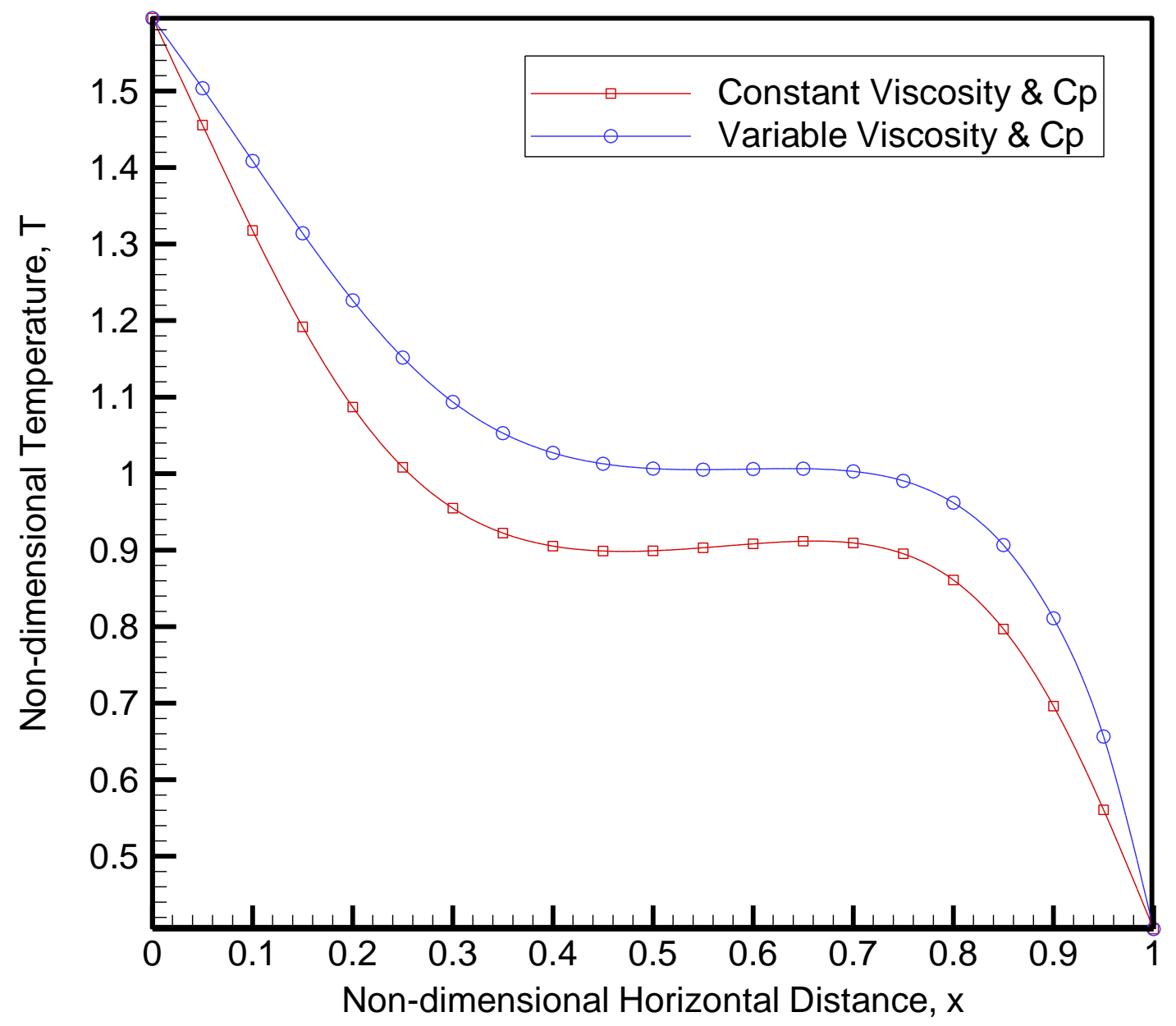

Figure 33- Comparison of Steady State Non-dimensional Temperature Distributions along the Horizontal Centerline of the Enclosure for Constant and Variable Fluid Properties at $\mathrm{Ra}=10^{4}(\Delta T=356.6 \mathrm{~K}, \mathrm{H}=0.0067 \mathrm{~m})$ 


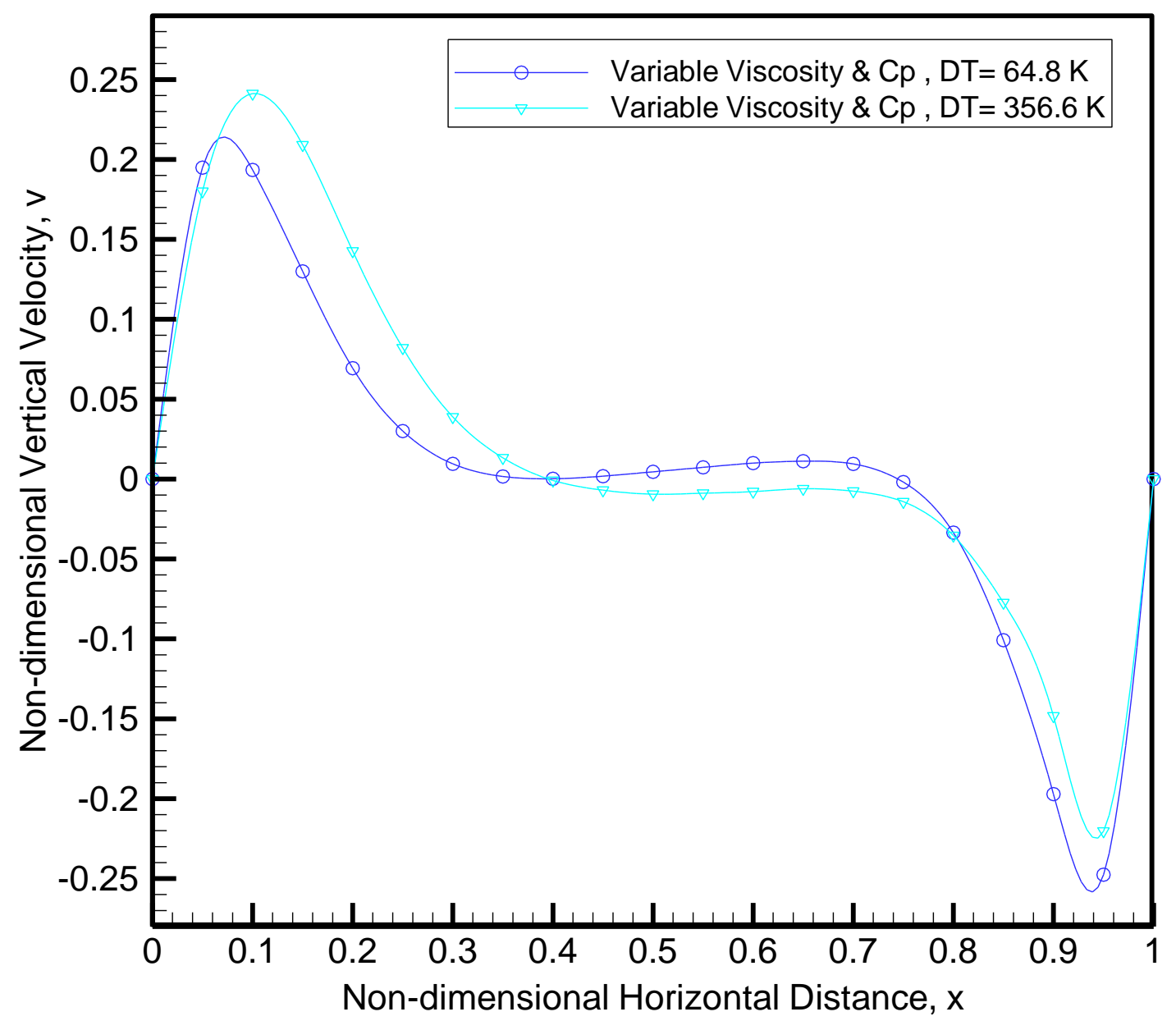

Figure 34- Comparison of Non-dimensional Vertical Velocity Profiles along the Horizontal Centerline of the Enclosure between $\Delta T=64.8 \mathrm{~K}$ and $\Delta T=356.6 \mathrm{~K}\left(\mathrm{Ra}=10^{5}\right)$ for Variable Properties. 


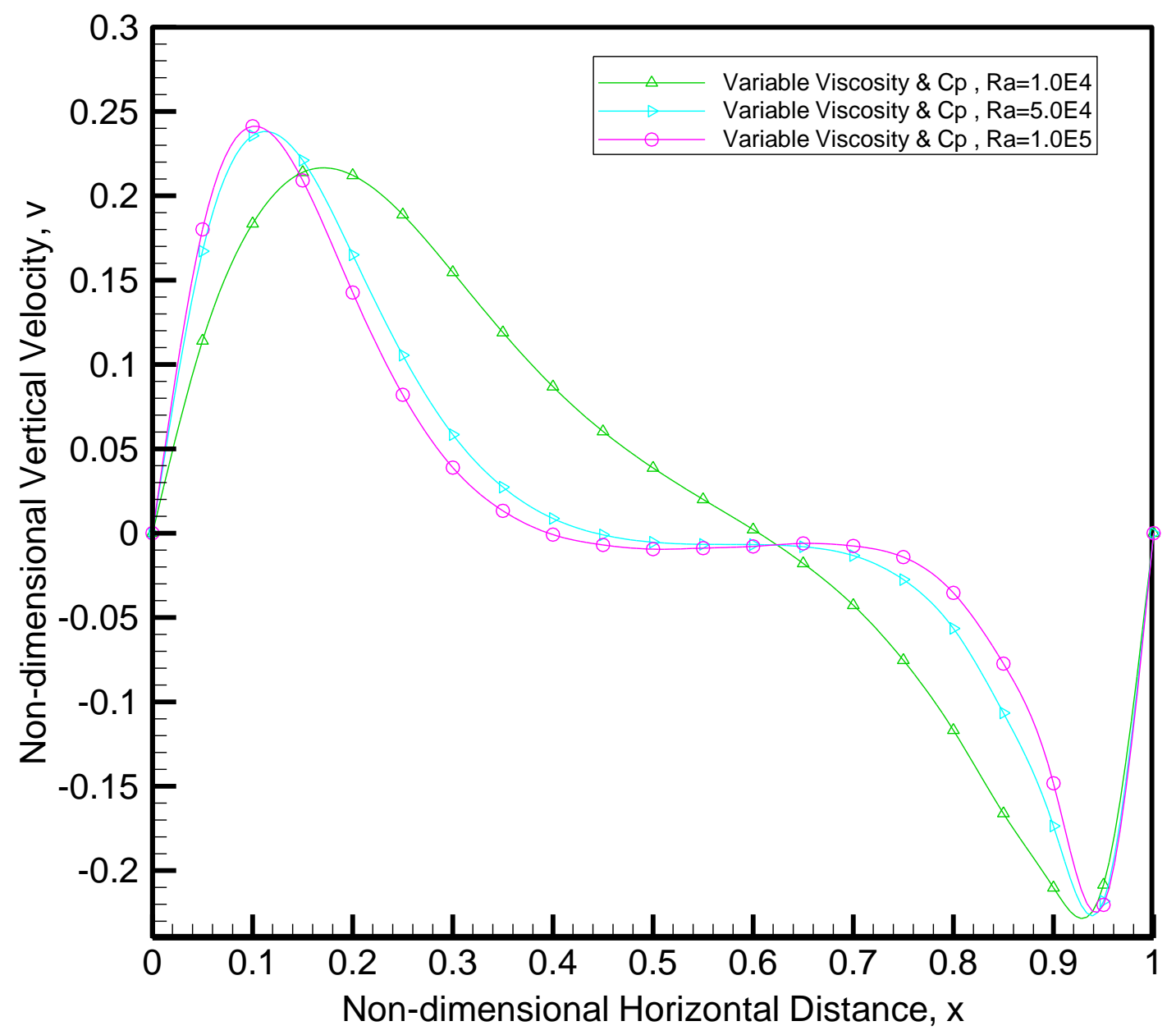

Figure 35- Comparison of Non-dimensional Vertical Velocity Profiles along the Horizontal Centerline of the Enclosure between $\mathrm{Ra}=10^{4}, \mathrm{Ra}=5 \times 10^{4}$, and $\mathrm{Ra}=10^{5}$ $(\Delta T=356.6 \mathrm{~K})$ for Variable Properties. 


\section{Chapter 9}

\section{The Study of Effects of Inclination of the Enclosure on Natural Convection}

The effects of inclination of the enclosure are presented for the laminar natural convection phenomenon in this chapter. The velocity fields and temperature distributions were observed at different angles of the enclosure.

In this study, primitive variables are predicted for different angles ( $0 \mathrm{deg}, 30 \mathrm{deg}, 45 \mathrm{deg}$, $60 \mathrm{deg}$ and $90 \mathrm{deg}$ ) of the enclosure. The predicted non-dimensional values of horizontal and vertical velocities are presented for various angles of the enclosure in Table 23 and 24, respectively. As the inclination of the enclosure increases, the magnitudes of the horizontal and vertical velocities are increasing. When inclined angle becomes $90 \mathrm{deg}$, the velocity profile is observed in opposite direction to the previous cases as shown in Figure 36 and 37 . The predicted temperature distribution is presented in Figure 38 for different angles of the enclosure. This shows that as angle of the enclosure increases, the magnitudes of the temperature are decreasing. 
Table 23- Steady State Non-dimensional values of Vertical Velocity along the Horizontal Centerline of the Inclined Enclosure at Various Angles for $\mathrm{Ra}=10^{5}$ $(\Delta \bar{t}=1.0 \mathrm{E}-5$ and $21 \times 21)$

\begin{tabular}{|c|c|c|c|c|c|}
\hline $\begin{array}{c}\text { Non- } \\
\text { dimensional } \\
\text { Horizontal } \\
\text { Distance, } \bar{x}\end{array}$ & $\begin{array}{c}\text { Non- } \\
\text { dimensional } \\
\text { Vertical } \\
\text { Velocity, } \bar{v} \\
\text { Angle 0) }\end{array}$ & $\begin{array}{c}\text { Non- } \\
\text { dimensional } \\
\text { Vertical } \\
\text { Velocity, } \bar{v} \\
\text { (Angle 30) }\end{array}$ & $\begin{array}{c}\text { Non- } \\
\text { dimensional } \\
\text { Vertical } \\
\text { Velocity, } \bar{v} \\
\text { (Angle 45) }\end{array}$ & $\begin{array}{c}\text { Non- } \\
\text { dimensional } \\
\text { Vertical } \\
\text { Velocity, } \bar{v} \\
\text { Angle 60) }\end{array}$ & $\begin{array}{c}\text { Non- } \\
\text { dimensional } \\
\text { Vertical } \\
\text { Velocity, } \bar{v} \\
\text { Angle 90) }\end{array}$ \\
\hline 1.00 & 0.00000 & 0.00000 & 0.00000 & 0.00000 & 0.00000 \\
\hline 0.95 & -0.24602 & -0.26058 & -0.25779 & -0.24928 & 0.21951 \\
\hline 0.90 & -0.20141 & -0.24630 & -0.27096 & -0.28980 & 0.30641 \\
\hline 0.85 & -0.10434 & -0.16668 & -0.21887 & -0.26821 & 0.34053 \\
\hline 0.8 & -0.03502 & -0.10694 & -0.17004 & -0.22956 & 0.31293 \\
\hline 0.75 & -0.00233 & -0.07122 & -0.13153 & -0.18897 & 0.26161 \\
\hline 0.70 & 0.00942 & -0.04878 & -0.09502 & -0.14116 & 0.19542 \\
\hline 0.65 & 0.01127 & -0.03580 & -0.06627 & -0.09980 & 0.13691 \\
\hline 0.60 & 0.01016 & -0.02174 & -0.03761 & -0.05934 & 0.08114 \\
\hline 0.55 & 0.00757 & -0.01251 & -0.01921 & -0.03202 & 0.03820 \\
\hline 0.50 & 0.00476 & -0.00042 & 0.00002 & -0.00343 & -0.00849 \\
\hline 0.45 & 0.00190 & 0.00849 & 0.01290 & 0.01678 & -0.04752 \\
\hline 0.40 & 0.00004 & 0.02114 & 0.03239 & 0.04633 & -0.09612 \\
\hline 0.35 & 0.00109 & 0.03349 & 0.05384 & 0.07773 & -0.14396 \\
\hline 0.30 & 0.00842 & 0.05287 & 0.08696 & 0.12320 & -0.20211 \\
\hline 0.25 & 0.02823 & 0.07945 & 0.12814 & 0.17658 & -0.26020 \\
\hline 0.20 & 0.06702 & 0.12094 & 0.17873 & 0.23593 & -0.31358 \\
\hline 0.15 & 0.12808 & 0.18484 & 0.23919 & 0.29394 & -0.33307 \\
\hline 0.10 & 0.19448 & 0.25241 & 0.29254 & 0.33381 & -0.31983 \\
\hline 0.05 & 0.20148 & 0.25950 & 0.27693 & 0.29038 & -0.22554 \\
\hline 0.00 & 0.00000 & 0.00000 & 0.00000 & 0.00000 & 0.00000 \\
\hline & & & & & \\
\hline
\end{tabular}


Table 24- Steady State Non-dimensional values of Horizontal Velocity along the Vertical Centerline of the Inclined Enclosure at Various Angles for $\mathrm{Ra}=10^{5}$

$(\Delta \bar{t}=1.0 \mathrm{E}-5$ and $21 \mathrm{X} 21)$

\begin{tabular}{|c|c|c|c|c|c|}
\hline $\begin{array}{c}\text { Non- } \\
\text { dimensional } \\
\text { Vertical } \\
\text { Distance, } \bar{y}\end{array}$ & $\begin{array}{c}\text { Non- } \\
\text { dimensional } \\
\text { Horizontal } \\
\text { Velocity, } \bar{u} \\
\text { (Angle 0) }\end{array}$ & $\begin{array}{c}\text { Non- } \\
\text { dimensional } \\
\text { Horizontal } \\
\text { Velocity, } \bar{u} \\
\text { (Angle 30) }\end{array}$ & $\begin{array}{c}\text { Non- } \\
\text { dimensional } \\
\text { Horizontal } \\
\text { Velocity, } \bar{u} \\
\text { (Angle 45) } \\
\end{array}$ & $\begin{array}{c}\text { Non- } \\
\text { dimensional } \\
\text { Horizontal } \\
\text { Velocity, } \bar{u} \\
\text { (Angle 60) } \\
\end{array}$ & $\begin{array}{c}\text { Non- } \\
\text { dimensional } \\
\text { Horizontal } \\
\text { Velocity, } \bar{u} \\
\text { (Angle 90) }\end{array}$ \\
\hline 1.00 & 0.00000 & 0.00000 & 0.00000 & 0.00000 & 0.00000 \\
\hline 0.95 & -0.08853 & -0.22133 & -0.28419 & -0.31367 & 0.31299 \\
\hline 0.90 & -0.14139 & -0.28811 & -0.34372 & -0.37180 & 0.37906 \\
\hline 0.85 & -0.14126 & -0.24311 & -0.28114 & -0.30926 & 0.33793 \\
\hline 0.80 & -0.11099 & -0.15650 & -0.18309 & -0.21767 & 0.27140 \\
\hline 0.75 & -0.08158 & -0.08556 & -0.10562 & -0.14397 & 0.21131 \\
\hline 0.70 & -0.05042 & -0.03216 & -0.05050 & -0.09015 & 0.16028 \\
\hline 0.65 & -0.02672 & -0.00095 & -0.01738 & -0.05259 & 0.11681 \\
\hline 0.60 & -0.00818 & 0.01021 & -0.00296 & -0.02824 & 0.07712 \\
\hline 0.55 & 0.00879 & 0.01594 & 0.00743 & -0.00613 & 0.03956 \\
\hline 0.50 & 0.02091 & 0.01190 & 0.00873 & 0.00929 & 0.00203 \\
\hline 0.45 & 0.03566 & 0.01725 & 0.01842 & 0.03015 & -0.03673 \\
\hline 0.40 & 0.04859 & 0.02441 & 0.02831 & 0.04963 & -0.07771 \\
\hline 0.35 & 0.06550 & 0.04901 & 0.05506 & 0.08079 & -0.12216 \\
\hline 0.30 & 0.08214 & 0.08378 & 0.09221 & 0.11902 & -0.17037 \\
\hline 0.25 & 0.09846 & 0.13280 & 0.14878 & 0.17484 & -0.22378 \\
\hline 0.20 & 0.10825 & 0.18676 & 0.21675 & 0.24286 & -0.27964 \\
\hline 0.15 & 0.10867 & 0.22557 & 0.27849 & 0.31166 & -0.33096 \\
\hline 0.10 & 0.08889 & 0.22107 & 0.29699 & 0.34198 & -0.34849 \\
\hline 0.05 & 0.05825 & 0.15283 & 0.22115 & 0.26664 & -0.27077 \\
\hline 0.00 & 0.00000 & 0.00000 & 0.00000 & 0.00000 & 0.00000 \\
\hline
\end{tabular}




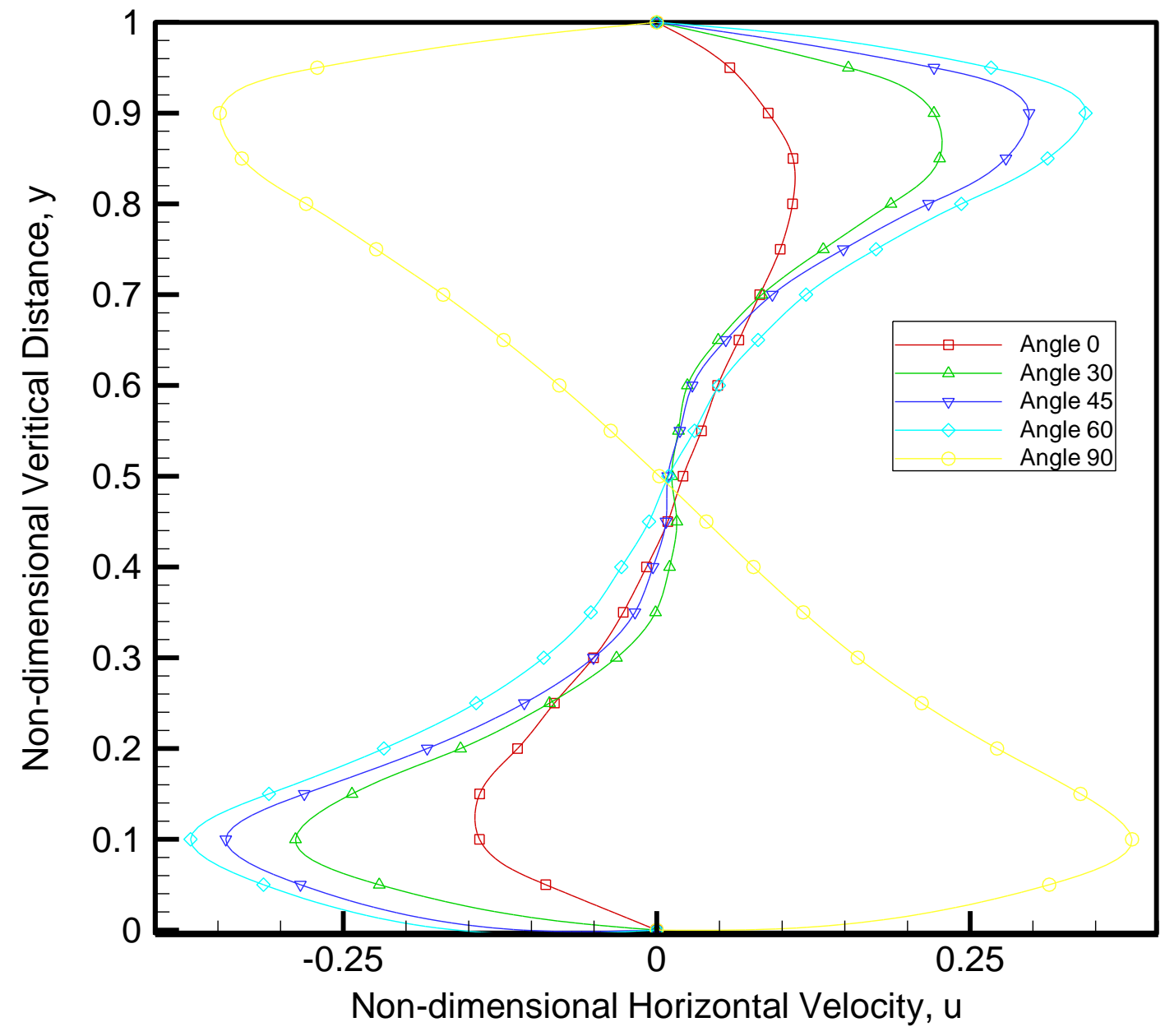

Figure 36- Steady State Non-dimensional Horizontal Velocity Distributions along the Vertical Centerline of the Inclined Enclosure for Constant Fluid Properties at $\mathrm{Ra}=10^{5}$ 


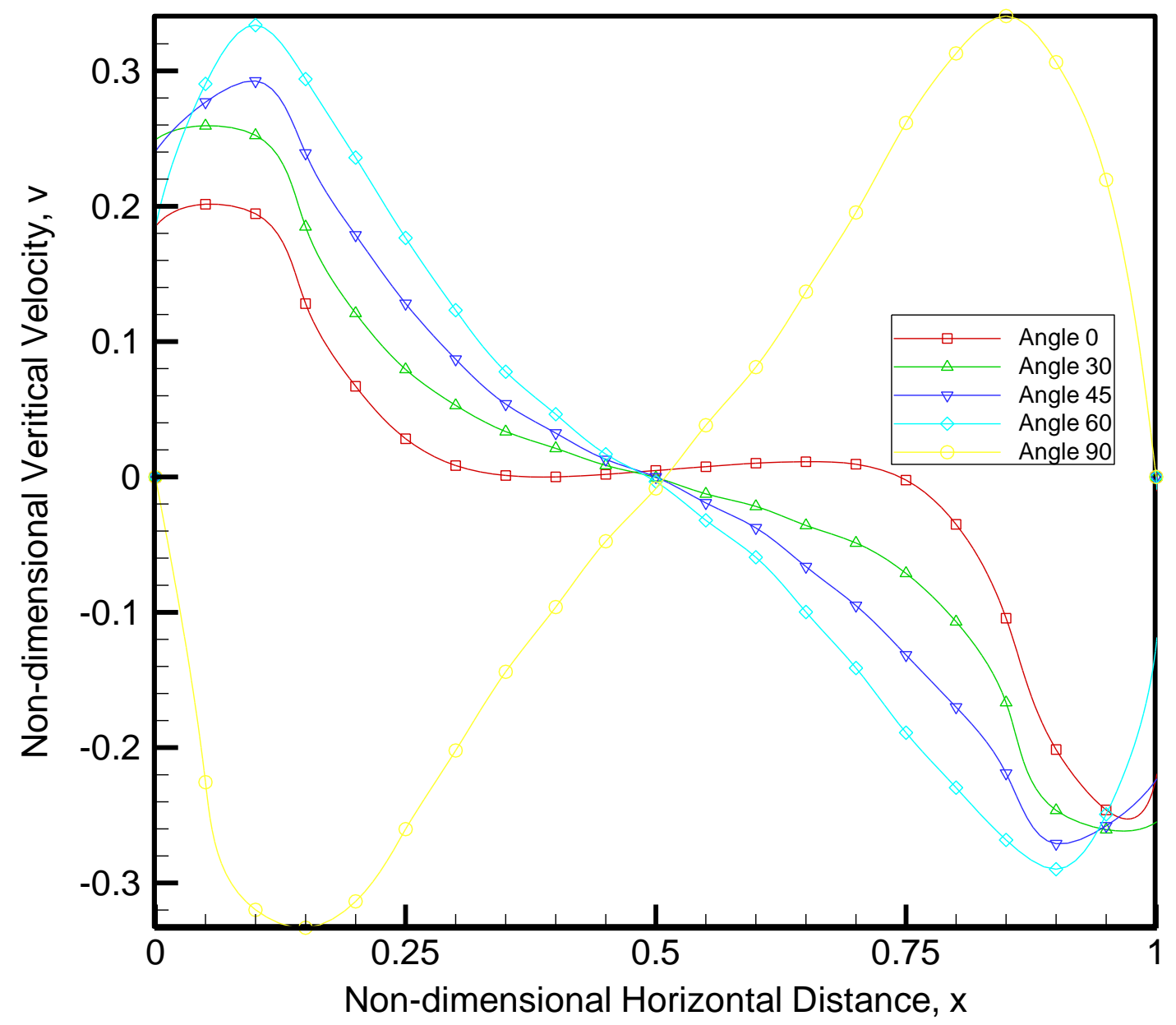

Figure 37- Steady State Non-dimensional Vertical Velocity Distributions along the Horizontal Centerline of the Inclined Enclosure for Constant Fluid Properties at $\mathrm{Ra}=10^{5}$ 


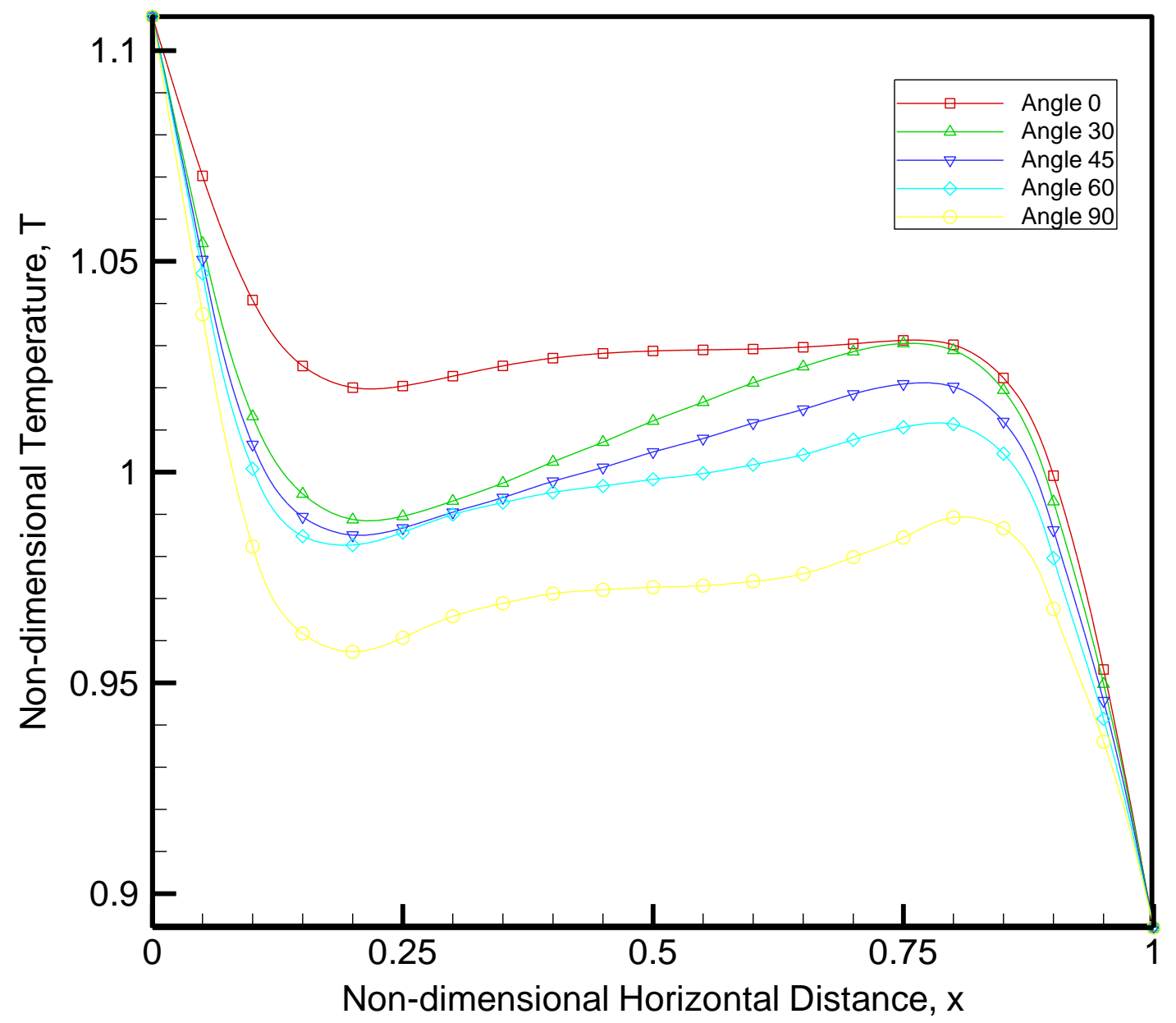

Figure 38- Steady State Non-dimensional Temperature Distributions along the Horizontal Centerline of the Inclined Enclosure for Constant Fluid Properties at $\mathrm{Ra}=10^{5}$ 


\section{Chapter 10}

\section{The Study of Natural Convection Using the Second Order Accurate in Time Model}

The study of natural convection phenomenon is also conducted using the second order accurate in time model. The results of the second order accurate in time model are presented in this chapter. Also, these results are compared to the first order accurate in time model to verify the accuracy of the second order accurate in time model for different Rayleigh numbers.

\subsection{Results of the Second Order Accurate in Time Model}

For, $\mathrm{Ra}=10^{5}$, the temperature between the vertical walls of the enclosure was taken to be 64.8 K. A uniform and orthogonal mesh of $21 \times 21$ was utilized. The predicted primitive variables along the horizontal centerline and vertical centerline of the enclosure are presented in Table 25 and 26 respectively at steady state. The qualitative results of general characteristics of computational mesh, vectors, streamlines, temperature contours are presented in Figure 39, 42, 43 and 44 . The flow inside square enclosure is not unicellular. Two secondary vortices formation is evident from Figure 43. The core flow is more stagnant relative to the boundary regions. The velocity ( $\mathrm{u}$ and $\mathrm{v}$ ) histograms at a point closer to the high temperature wall where $\bar{x}=0.05$ and $\bar{y}=0.5$ are presented in Figures 40 and 41 . The non-dimensional horizontal velocity distribution along the vertical centerline, vertical velocity distribution along the horizontal centerline and temperature distribution along the horizontal centerline are presented in Figure 45, 46 and 47 respectively. The maximum non-dimensional vertical velocity is observed as 0.25 at near the hot wall and the maximum non-dimensional horizontal velocity is observed as 0.11 at near the cold wall. The temperature gradients are higher near the walls and equal to zero at the center of the 
enclosure. This fact is easily illustrated by isotherms being almost horizontal in the center of the enclosure. The qualitative results of general characteristics of computational mesh, vectors, streamlines, temperature contours are also presented in Figure 48, 49, 50 and 51 for grid size of $81 \times 81$.

Table 25- Steady State Non-dimensional values of Primitive Variables along the Horizontal Centerline of the Enclosure for $\mathrm{Ra}=10^{5}$ in Second Order Time Accurate Approximation $(\Delta \bar{t}=1.0 \mathrm{E}-5$ and $21 \mathrm{X} 21)$

\begin{tabular}{|c|c|c|c|}
\hline $\begin{array}{c}\text { Non-dimensional } \\
\text { Horizontal } \\
\text { Distance, } \bar{x}\end{array}$ & $\begin{array}{c}\text { Non-dimensional } \\
\text { Vertical } \\
\text { Velocity, } \bar{v}\end{array}$ & $\begin{array}{c}\text { Non-dimensional } \\
\text { Pressure, } \bar{p}\end{array}$ & $\begin{array}{c}\text { Non-dimensional } \\
\text { Temperature, } \bar{T}\end{array}$ \\
\hline 1.00 & 0.0000000 & 1605.1374 & 0.8919274 \\
\hline 0.95 & -0.2440447 & 1605.1374 & 0.9541405 \\
\hline 0.90 & -0.2002889 & 1605.1374 & 0.9988405 \\
\hline 0.85 & -0.1043035 & 1605.1374 & 1.0214050 \\
\hline 0.80 & -0.0357540 & 1605.1374 & 1.0290520 \\
\hline 0.75 & -0.0031484 & 1605.1374 & 1.0300350 \\
\hline 0.70 & 0.0086785 & 1605.1374 & 1.0291910 \\
\hline 0.65 & 0.0106349 & 1605.1374 & 1.0283880 \\
\hline 0.60 & 0.0095869 & 1605.1374 & 1.0279430 \\
\hline 0.55 & 0.0070514 & 1605.1374 & 1.0277350 \\
\hline 0.50 & 0.0043028 & 1605.1374 & 1.0274820 \\
\hline 0.45 & 0.0015100 & 1605.1374 & 1.0269280 \\
\hline 0.40 & -0.0003056 & 1605.1374 & 1.0258250 \\
\hline 0.35 & 0.0007269 & 1605.1374 & 1.0240220 \\
\hline 0.30 & 0.0079743 & 1605.1374 & 1.0216240 \\
\hline 0.25 & 0.0276678 & 1605.1374 & 1.0193210 \\
\hline 0.20 & 0.0664488 & 1605.1374 & 1.0189950 \\
\hline 0.15 & 0.1278468 & 1605.1374 & 1.0242100 \\
\hline 0.10 & 0.1949693 & 1605.1374 & 1.0399920 \\
\hline 0.05 & 0.2027110 & 1605.1374 & 1.0697490 \\
\hline 0.00 & 0.0000000 & 1605.1374 & 1.1080730 \\
\hline & & & \\
\hline
\end{tabular}


Table 26- Steady State Non-dimensional values of Primitive Variables along the Vertical Centerline of the Enclosure for $\mathrm{Ra}=10^{5}$ in Second Order Time Accurate Approximation $(\Delta \bar{t}=1.0 \mathrm{E}-5$ and $21 \mathrm{X} 21)$

\begin{tabular}{|c|c|c|c|}
\hline $\begin{array}{c}\text { Non-dimensional } \\
\text { Vertical } \\
\text { Distance, } \bar{y}\end{array}$ & $\begin{array}{c}\text { Non-dimensional } \\
\text { Horizontal } \\
\text { Velocity, } \bar{u}\end{array}$ & $\begin{array}{l}\text { Non-dimensional } \\
\text { Pressure, } \bar{p}\end{array}$ & $\begin{array}{l}\text { Non-dimensional } \\
\text { Temperature, } \bar{T}\end{array}$ \\
\hline 1.00 & 0.0000000 & 1605.1353 & 1.0821941 \\
\hline 0.95 & 0.0595109 & 1605.1354 & 1.0821070 \\
\hline 0.90 & 0.0905230 & 1605.1357 & 1.0811453 \\
\hline 0.85 & 0.1101803 & 1605.1358 & 1.0782586 \\
\hline 0.80 & 0.1092251 & 1605.1361 & 1.0745235 \\
\hline 0.75 & 0.0986764 & 1605.1363 & 1.0685488 \\
\hline 0.70 & 0.0816850 & 1605.1365 & 1.0627430 \\
\hline 0.65 & 0.0644987 & 1605.1367 & 1.0548044 \\
\hline 0.60 & 0.0472117 & 1605.1370 & 1.0472641 \\
\hline 0.55 & 0.0340867 & 1605.1372 & 1.0370585 \\
\hline 0.50 & 0.0192216 & 1605.1374 & 1.0274822 \\
\hline 0.45 & 0.0071675 & 1605.1376 & 1.0151296 \\
\hline 0.40 & -0.0096449 & 1605.1379 & 1.0043528 \\
\hline 0.35 & -0.0278360 & 1605.1381 & 0.9916311 \\
\hline 0.30 & -0.0510775 & 1605.1383 & 0.9815297 \\
\hline 0.25 & -0.0815223 & 1605.1386 & 0.9703938 \\
\hline 0.20 & -0.1101736 & 1605.1388 & 0.9618196 \\
\hline 0.15 & -0.1394019 & 1605.1391 & 0.9521419 \\
\hline 0.10 & -0.1390995 & 1605.1393 & 0.9454112 \\
\hline 0.05 & -0.0867933 & 1605.1396 & 0.9394930 \\
\hline 0.00 & 0.0000000 & 1605.1398 & 0.9369507 \\
\hline
\end{tabular}




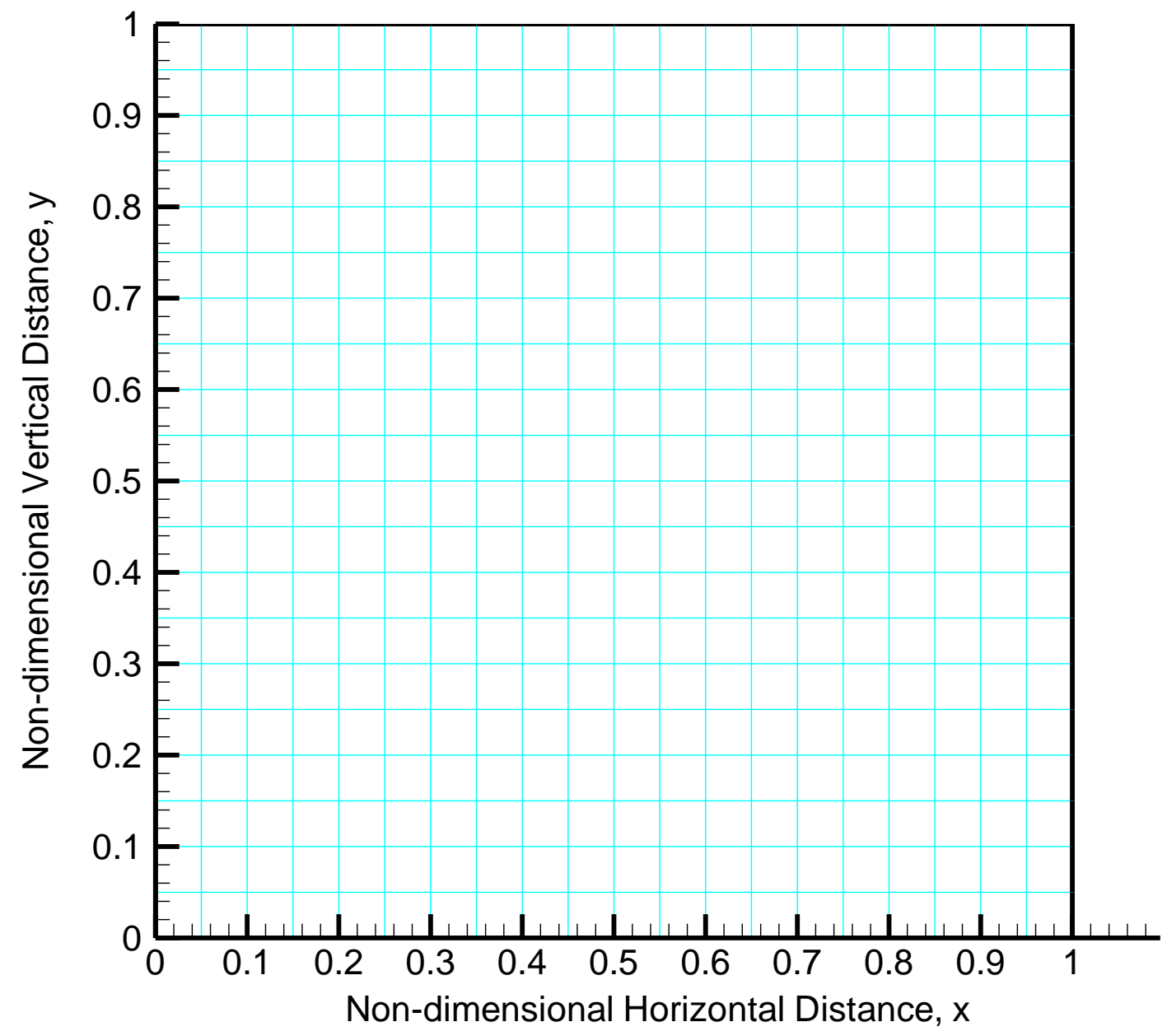

Figure 39- Computational Mesh of the Non-dimensional domain for the Natural Convection Case in Second Order Time Accurate Approximation $\left(21 \times 21, \mathrm{Ra}=10^{5}\right)$ 


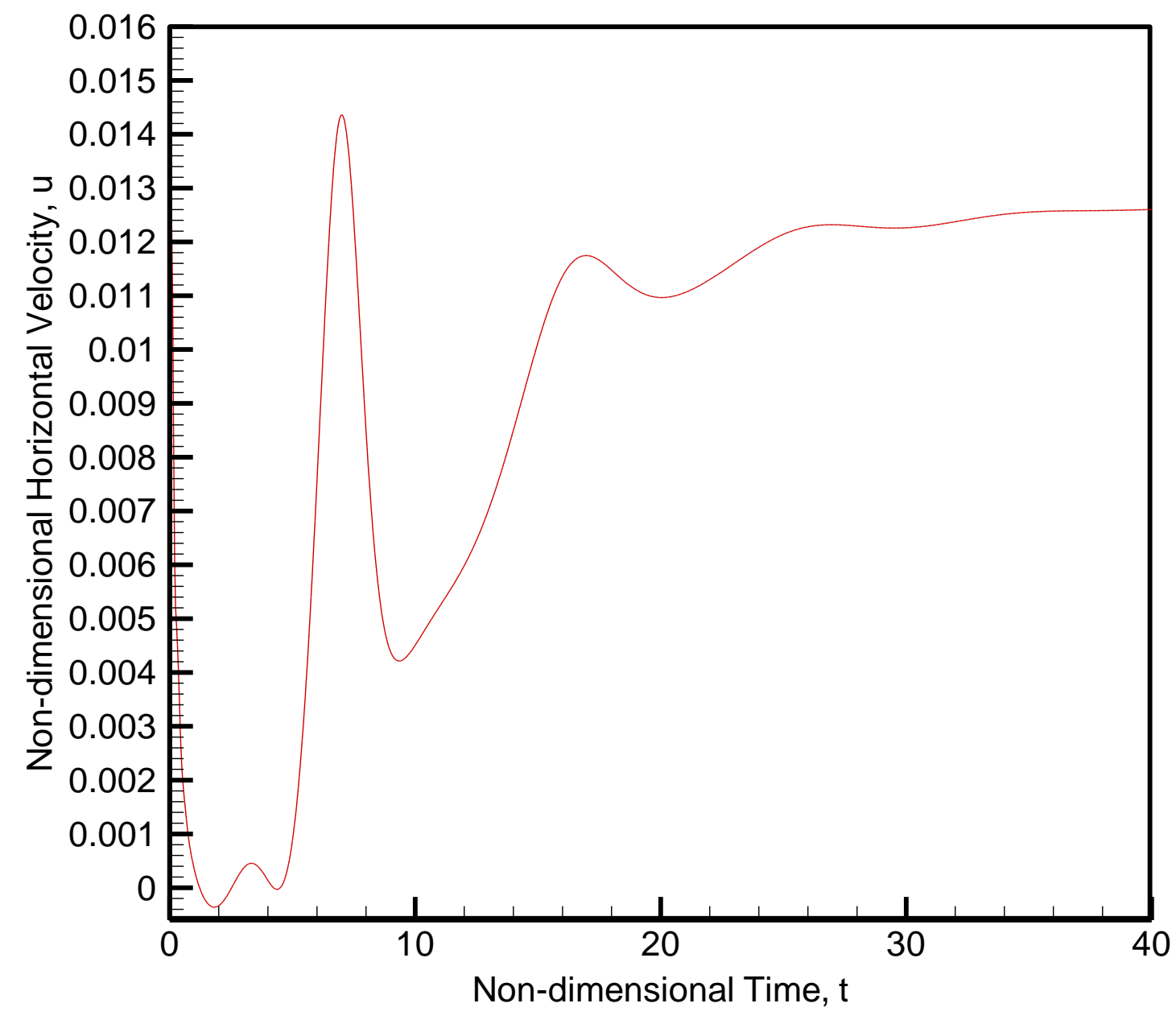

Figure 40- Non-dimensional Horizontal Velocity Histogram for $\operatorname{Ra}=10^{5}$ at $\bar{X}=0.2$ and $\bar{Y}=0.5$ (21 x 21, $\Delta \bar{t}=1.0 \mathrm{E}-5)$ in Second Order Time Accurate Approximation 


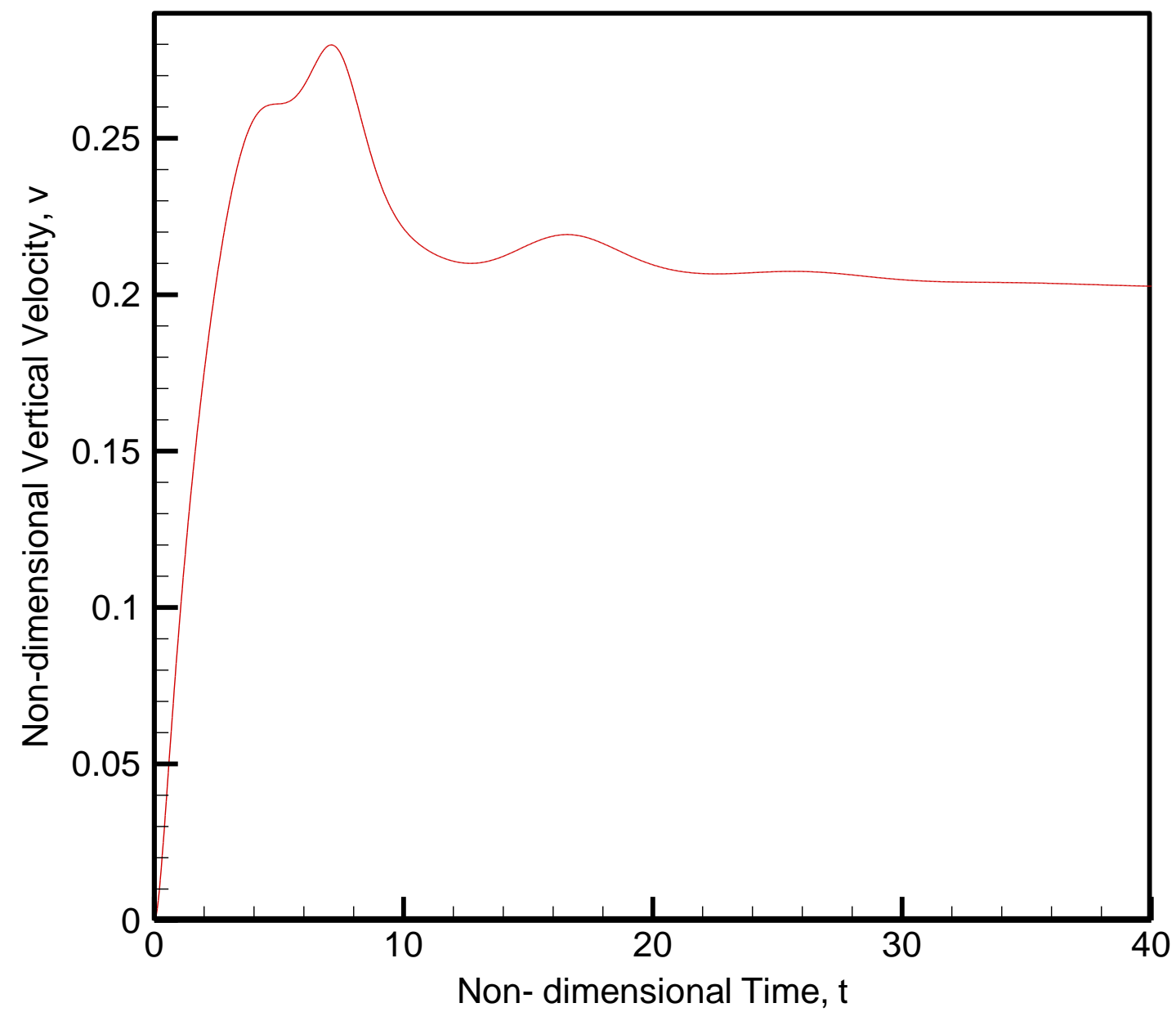

Figure 41- Non-dimensional Vertical Velocity Histogram for $\operatorname{Ra}=10^{5}$ at $\bar{X}=0.2$ and $\bar{Y}=0.5$ $(21 \times 21, \Delta \bar{t}=1.0 \mathrm{E}-5)$ in Second Order Time Accurate Approximation 


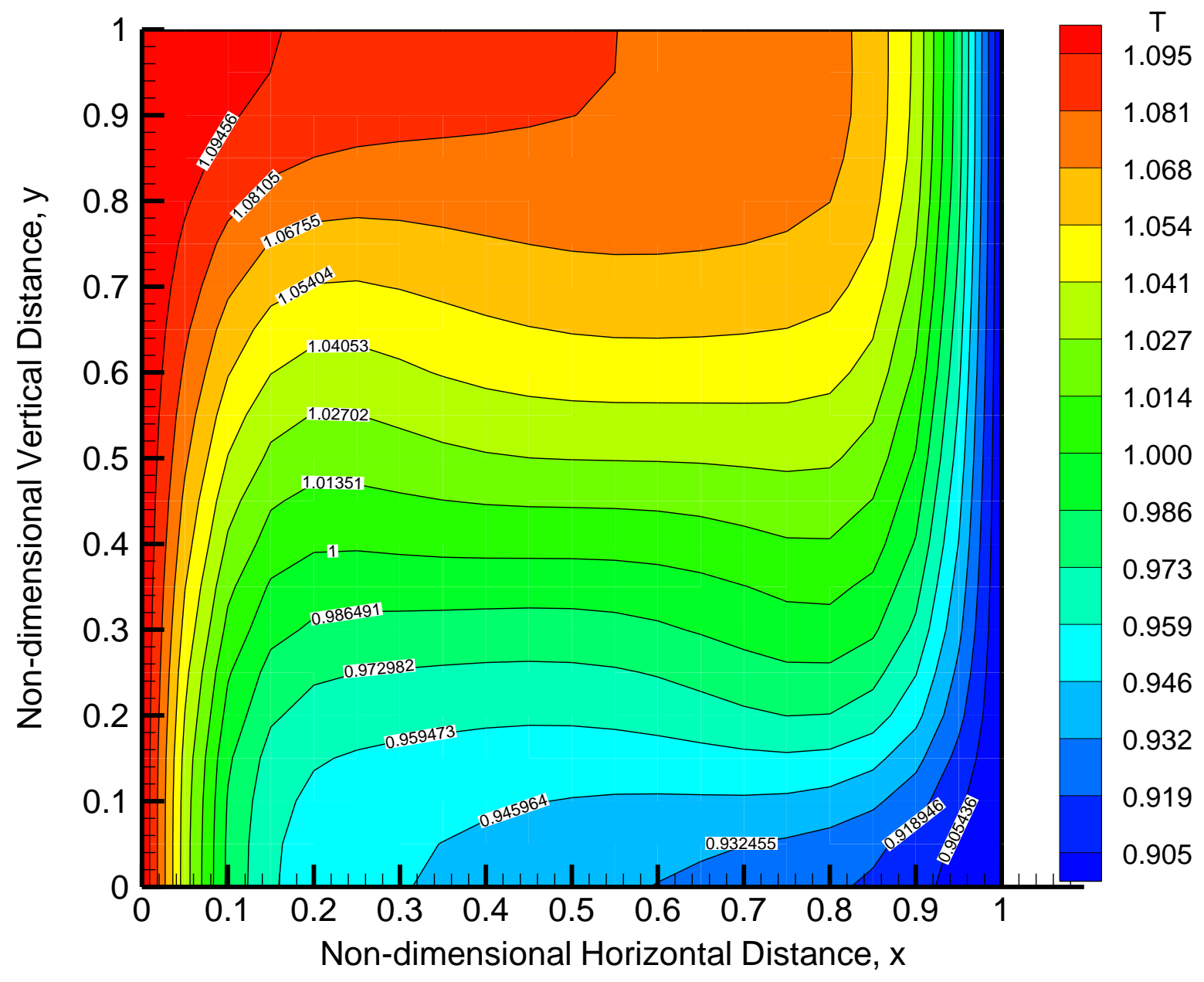

Figure 42- Steady State Non-dimensional Temperature Contours for $\mathrm{Ra}=10^{5}$ $(21 \times 21, \Delta \bar{t}=1.0 \mathrm{E}-5)$ in Second Order Time Accurate Approximation 


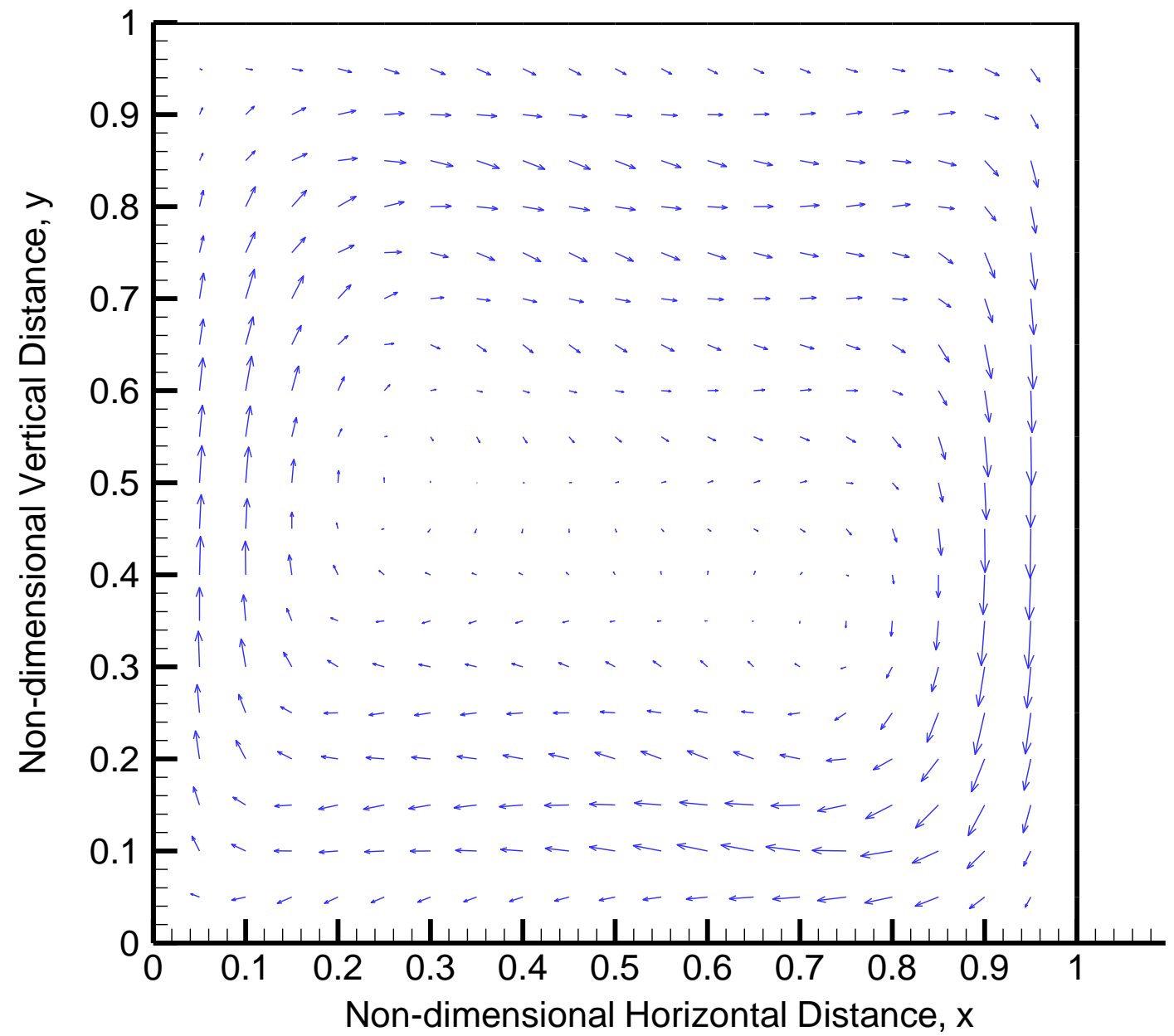

Figure 43- Steady State Non-dimensional Velocity Vectors for $\operatorname{Ra}=10^{5}(21 \times 21, \Delta \bar{t}=1.0 \mathrm{E}-5)$ in Second Order Time Accurate Approximation 


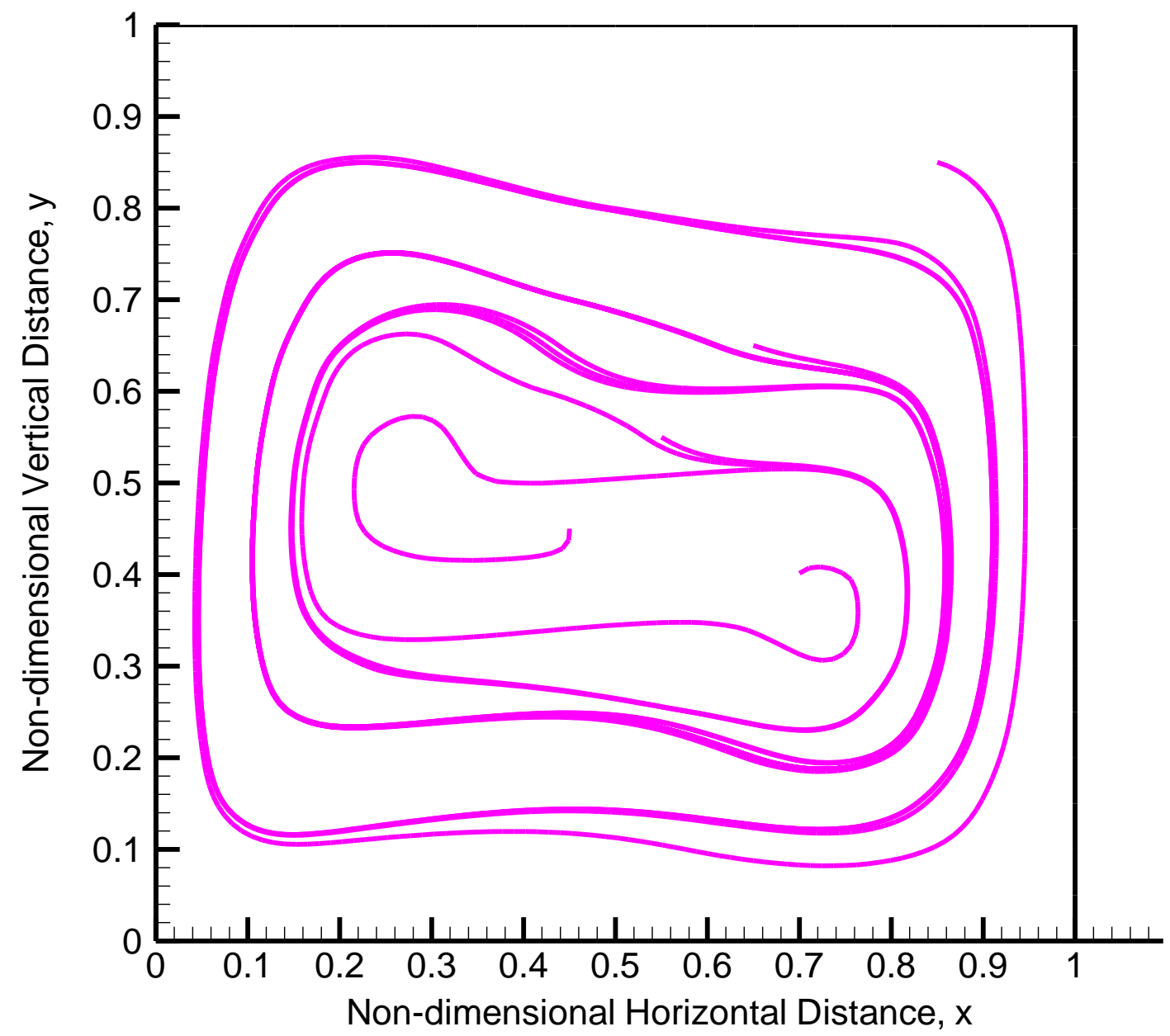

Figure 44- Steady State Non-dimensional Velocity Streamlines for $\mathrm{Ra}=10^{5}$ $(21 \times 21, \Delta \bar{t}=1.0 \mathrm{E}-5)$ in Second Order Time Accurate Approximation 


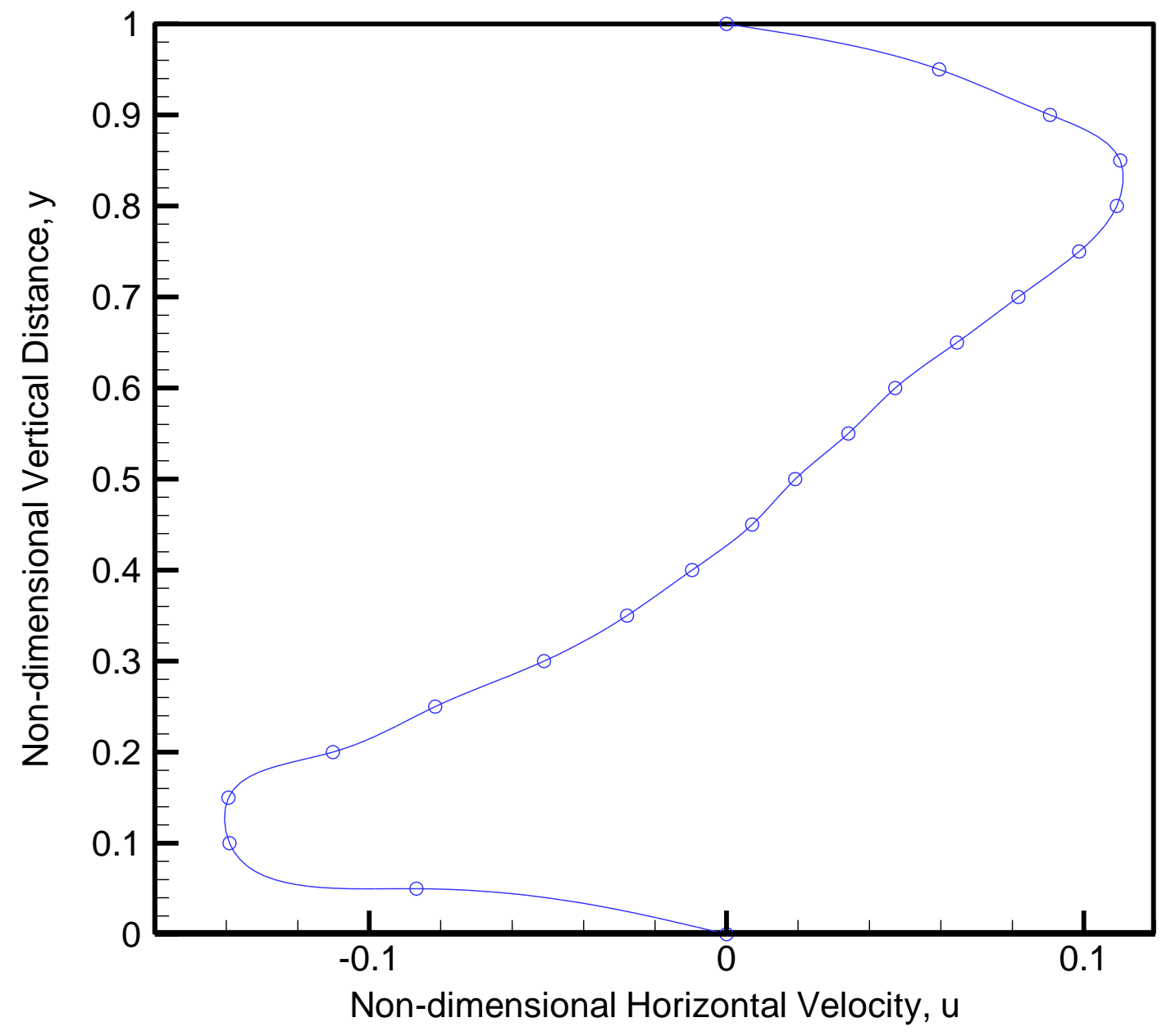

Figure 45- Steady State Non-dimensional Horizontal Velocity Distribution along the Vertical Centerline of the Enclosure for $\mathrm{Ra}=10^{5}(21 \times 21, \Delta \bar{t}=1.0 \mathrm{E}-5)$ in Second Order Time Accurate Approximation 


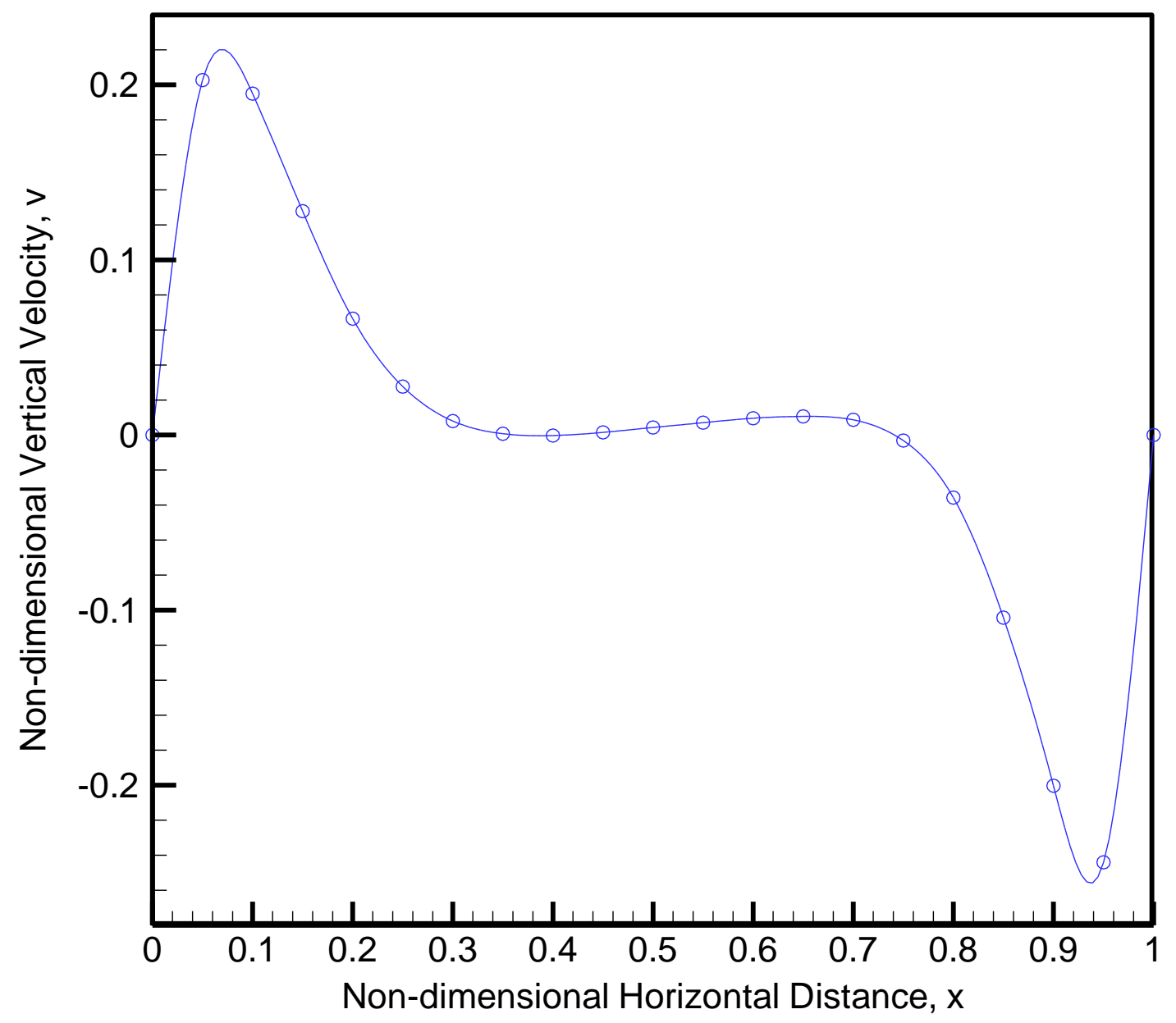

Figure 46- Steady State Non-dimensional Vertical Velocity Distribution along the Horizontal Centerline of the Enclosure for $\mathrm{Ra}=10^{5}(21 \times 21, \Delta \bar{t}=1.0 \mathrm{E}-5)$ in Second Order Time Accurate Approximation 


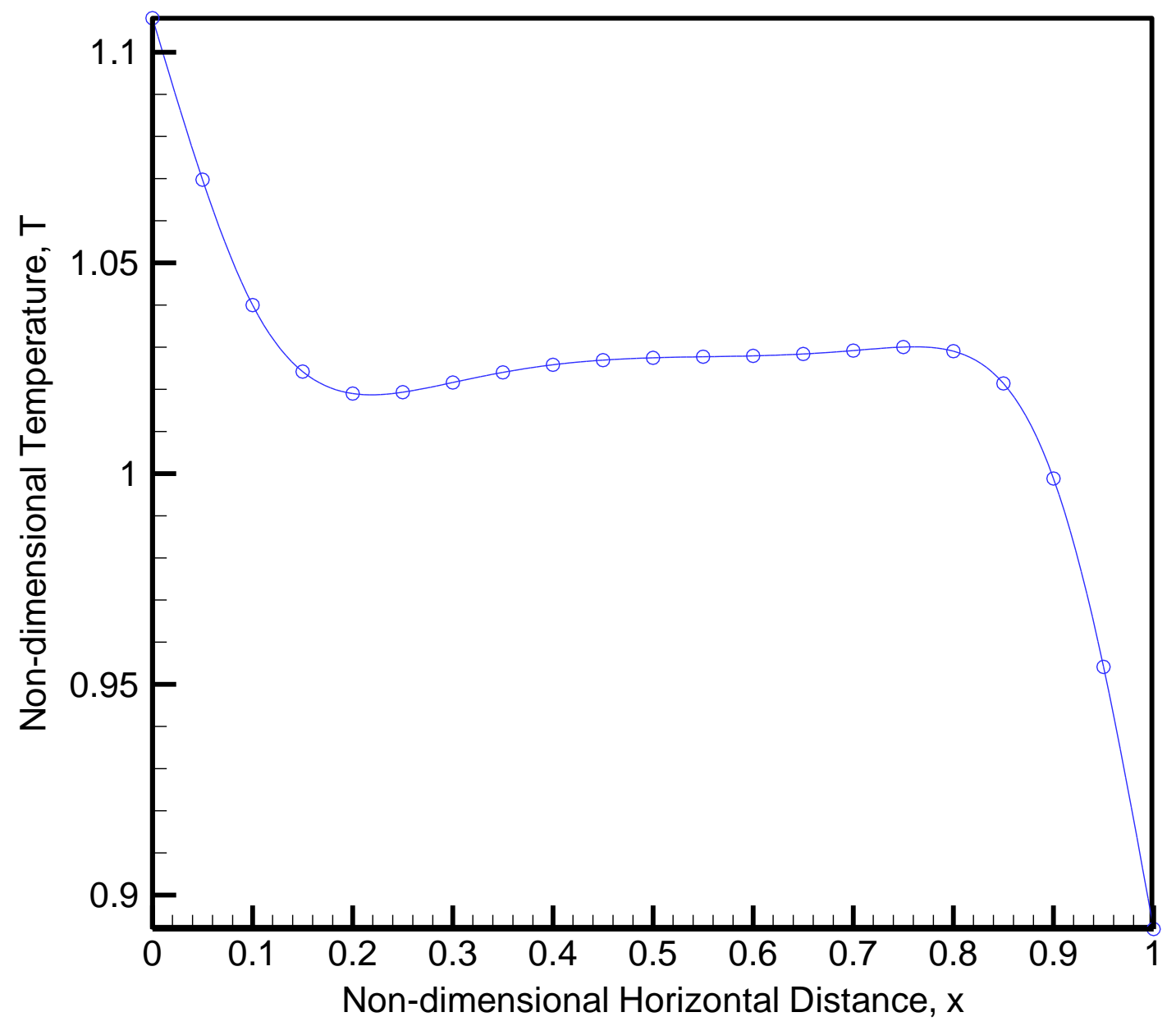

Figure 47- Steady State Non-dimensional Temperature Distribution along the Horizontal Centerline of the Enclosure for $\mathrm{Ra}=10^{5}(21 \times 21, \Delta \bar{t}=1.0 \mathrm{E}-5)$ in Second Order Time Accurate Approximation 


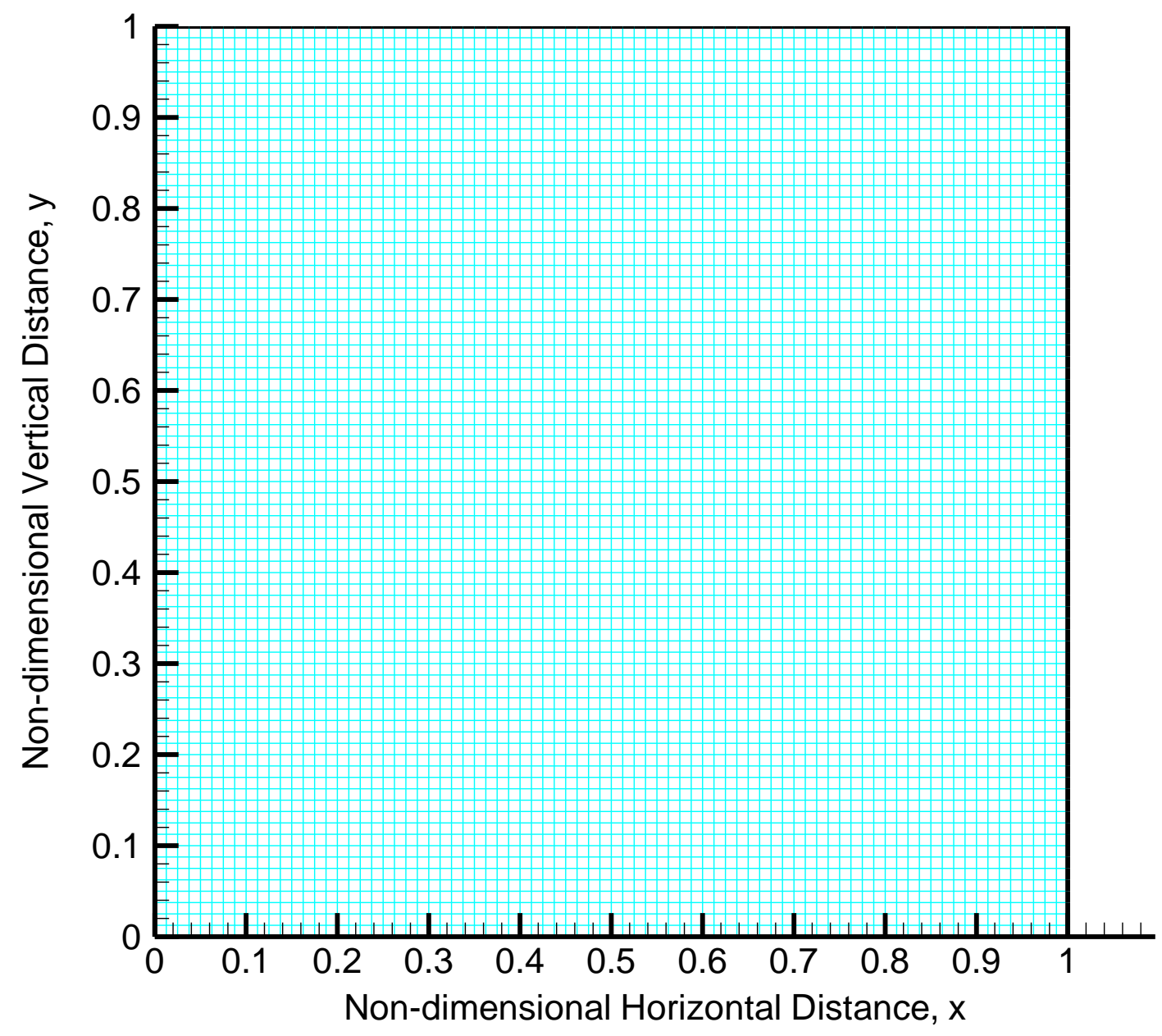

Figure 48- Computational Mesh of the Non-dimensional domain for the Natural Convection Case in Second Order Time Accurate Approximation $\left(81 \times 81, \mathrm{Ra}=10^{5}\right)$ 


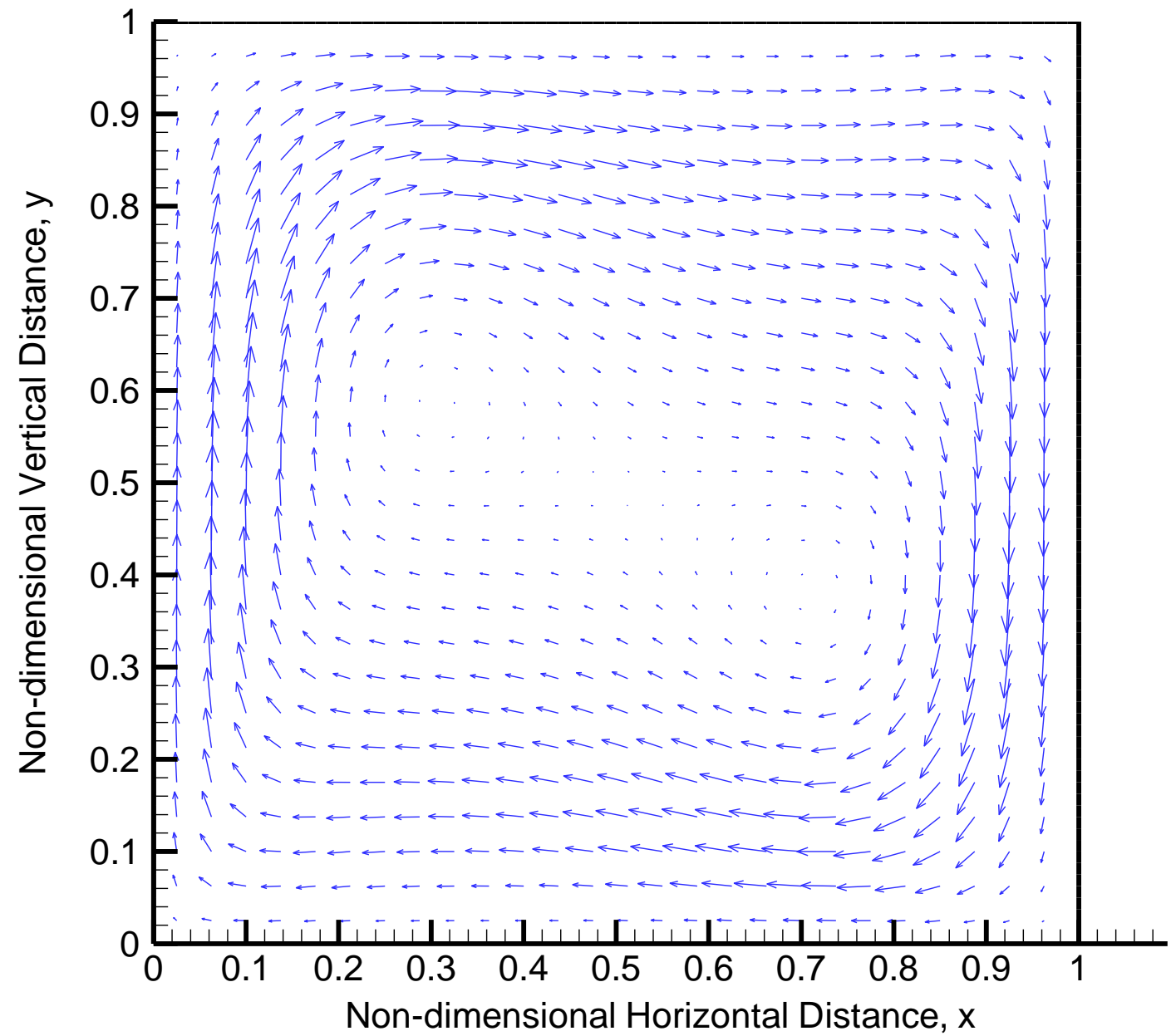

Figure 49- Steady State Non-dimensional Velocity Vectors for $\mathrm{Ra}=10^{5}(81 \times 81, \Delta \bar{t}=1.0 \mathrm{E}-6)$ in Second Order Time Accurate Approximation 


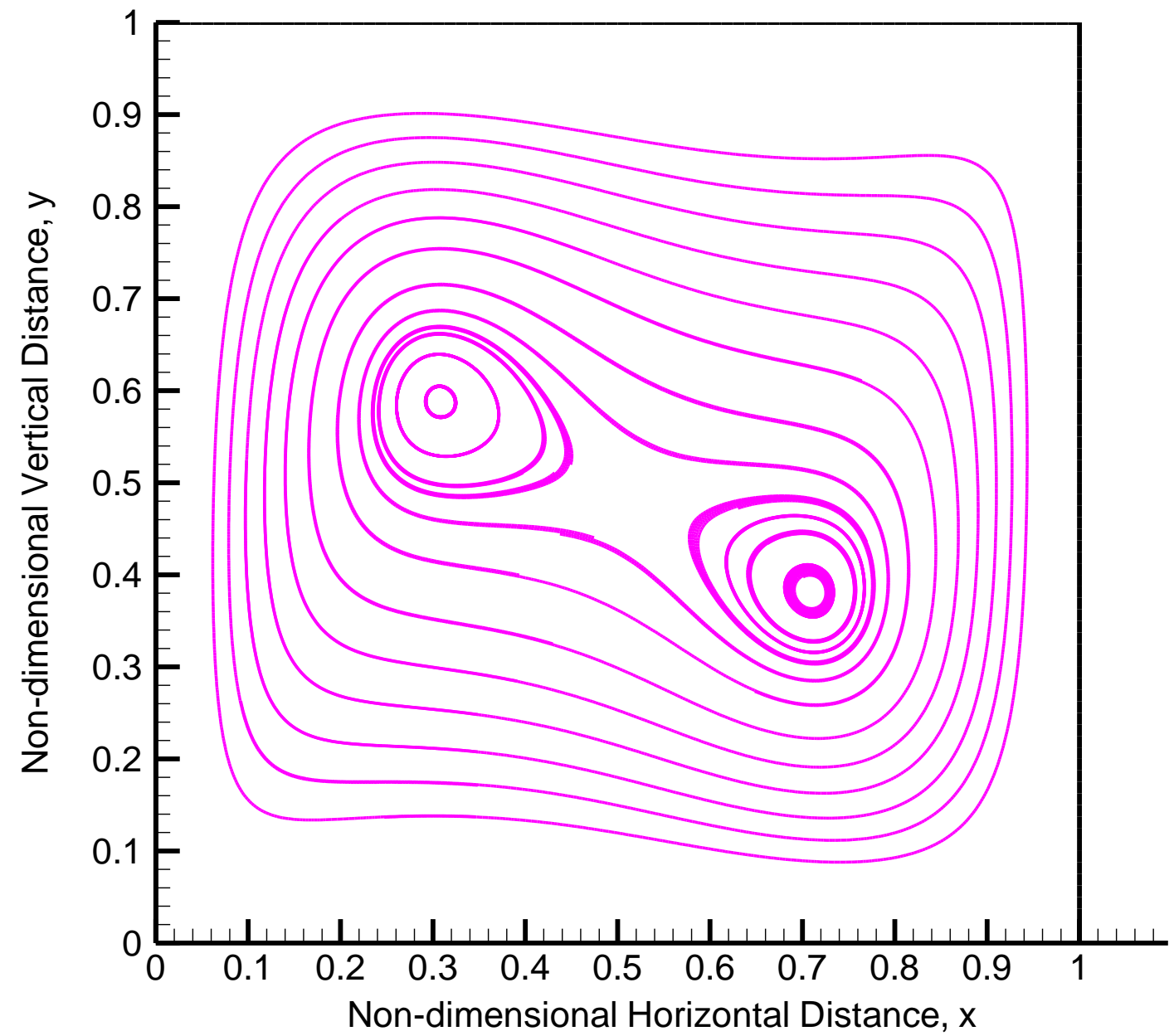

Figure 50- Steady State Non-dimensional Velocity Streamlines for Ra $=10^{5}$

( $81 \times 81, \Delta \bar{t}=1.0 \mathrm{E}-6)$ in Second Order Time Accurate Approximation 


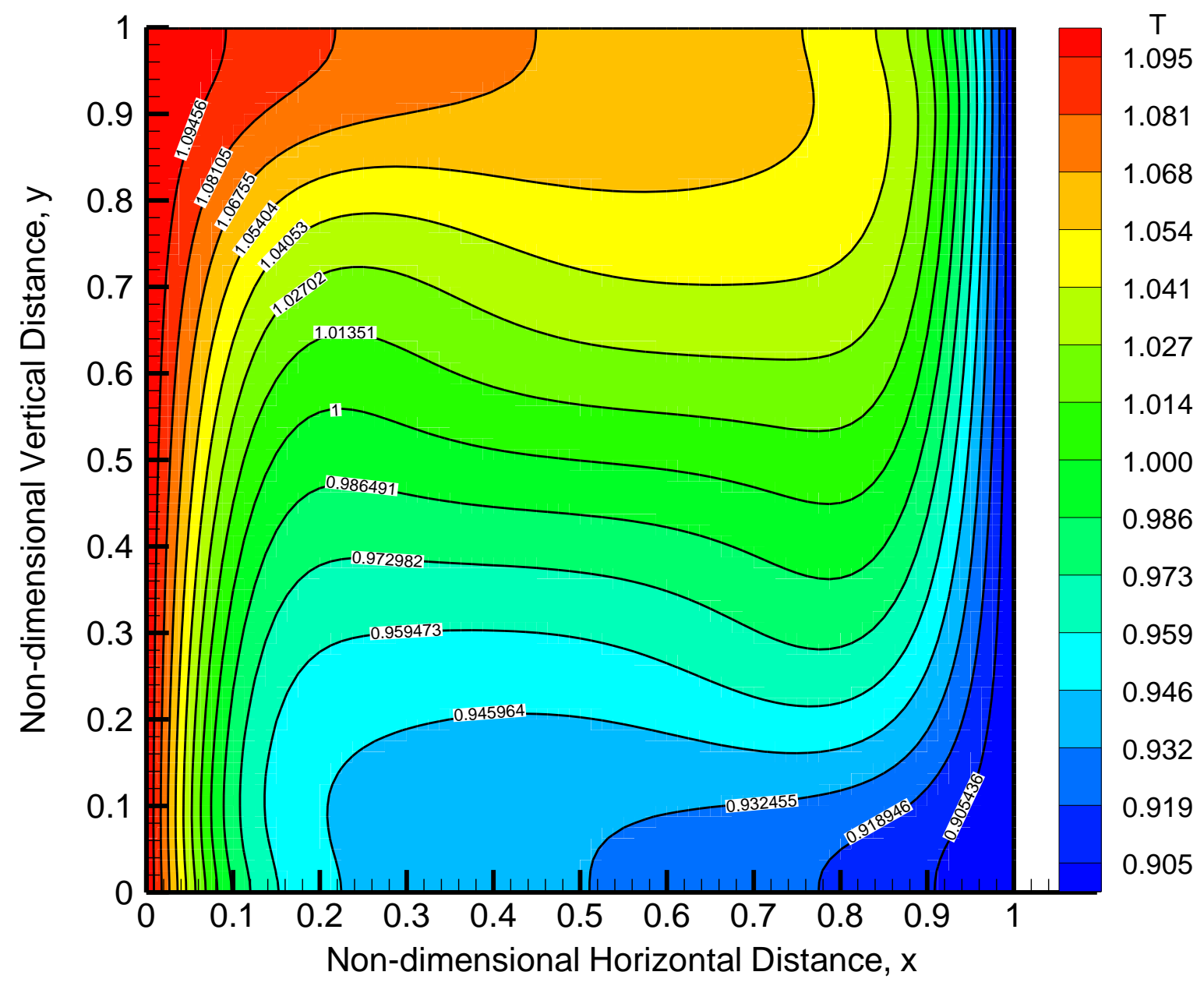

Figure 51- Steady State Non-dimensional Temperature Contours for $\mathrm{Ra}=10^{5}$ $(81 \times 81, \Delta \bar{t}=1.0 \mathrm{E}-6)$ in Second Order Time Accurate Approximation 


\subsection{The Comparison between First Order and Second Order Accurate in}

\section{Time Models}

The comparison of the present model with first order accurate in time CMSIP model shows negligible differences. A quantitative comparisons of the first order and second order accurate in time CMSIP models for Rayleigh number $10^{5}$ with $\Delta T=64.84 \mathrm{deg} \mathrm{K}$ are presented in Table 27 through 29. The qualitative comparison is presented in Figure 52 through 54. The results for Rayleigh number $10^{4}$ by changing the temperature difference between the vertical walls of the enclosure with the same size are presented quantitatively in Table 30 through 32 and qualitatively in Figures 55 through 57. These results indicate that the accuracy of second order accurate in time model can be verified successfully with first order accurate in time model.

The differences can be seen when one compares the velocity and temperature profiles in horizontal and vertical directions for different Rayleigh numbers. The comparisons of the above results at constant wall temperature difference for different Rayleigh numbers $10^{4}$ and $10^{5}$ are presented. The qualitative comparisons of these results (velocity and temperature) are presented in Figure 58 through 60. As shown in Figure 58, the magnitudes of the horizontal velocities are predicted higher for Ra number $10^{4}$ compared to Ra $10^{5}$. But the magnitudes of the vertical velocities and temperature are predicted higher for Ra $10^{5}$ as depicted in Figure 59 and 60, because of the increase in temperature difference between the walls of the enclosure. 
Table 27- Comparison of Non-dimensional values of Horizontal Velocity along the Vertical Centerline between First Order and Second Order Time Accurate Approximations $\left(\mathrm{Ra}=10^{5}, \Delta \bar{t}=1.0 \mathrm{E}-5\right.$ and $\left.21 \mathrm{X} 21\right)$

\begin{tabular}{|c|c|c|c|}
\hline $\begin{array}{c}\text { Non- } \\
\text { dimensional } \\
\text { Vertical } \\
\text { Distance, } \bar{y}\end{array}$ & $\begin{array}{c}\text { Non-dimensional } \\
\text { Horizontal } \\
\text { Velocity, } \bar{u} \\
\text { (1st Oder) }\end{array}$ & $\begin{array}{c}\text { Non-dimensional } \\
\text { Horizontal } \\
\text { Velocity, } \bar{u} \\
\text { (2nd Order) }\end{array}$ & $\begin{array}{c}\text { \% Deviation } \\
\text { in } \bar{u}\end{array}$ \\
\hline 1.00 & 0.0000000 & 0.0000000 & 0.0000000 \\
\hline 0.95 & 0.0592333 & 0.0595109 & 0.4665191 \\
\hline 0.90 & 0.0900378 & 0.0905231 & 0.5360290 \\
\hline 0.85 & 0.1097794 & 0.1101803 & 0.3638581 \\
\hline 0.80 & 0.1089421 & 0.1092251 & 0.2590979 \\
\hline 0.75 & 0.0986343 & 0.0986764 & 0.04262419 \\
\hline 0.70 & 0.0817787 & 0.0816850 & -0.1147088 \\
\hline 0.65 & 0.0647388 & 0.0644987 & -0.3723174 \\
\hline 0.60 & 0.0474760 & 0.0472117 & -0.5598186 \\
\hline 0.55 & 0.0344048 & 0.0340867 & -0.9334432 \\
\hline 0.50 & 0.0194978 & 0.0192216 & -1.4371830 \\
\hline 0.45 & 0.0074592 & 0.0071675 & -4.0704532 \\
\hline 0.40 & -0.0094205 & -0.0096449 & 2.3259011 \\
\hline 0.35 & -0.0276257 & -0.0278360 & 0.7554943 \\
\hline 0.30 & -0.0509145 & -0.0510775 & 0.3190640 \\
\hline 0.25 & -0.0814199 & -0.0815223 & 0.1257077 \\
\hline 0.20 & -0.1101176 & -0.1101736 & 0.0508288 \\
\hline 0.15 & -0.1395627 & -0.1394019 & -0.1153499 \\
\hline 0.10 & -0.1394197 & -0.1390995 & -0.2301949 \\
\hline 0.05 & -0.0870163 & -0.0867933 & -0.2568744 \\
\hline 0.00 & 0.0000000 & 0.0000000 & 0.0000000 \\
\hline
\end{tabular}


Table 28-Comparison of Non-dimensional values of Vertical Velocity along the Horizontal Centerline between First Order and Second Order Time Accurate Approximations $\left(\mathrm{Ra}=10^{5}, \Delta \bar{t}=1.0 \mathrm{E}-5\right.$ and $\left.21 \mathrm{X} 21\right)$

\begin{tabular}{|c|c|c|c|}
\hline $\begin{array}{c}\text { Non-dimensional } \\
\text { Horizontal } \\
\text { Distance, } \bar{x}\end{array}$ & $\begin{array}{c}\text { Non-dimensional } \\
\text { Vertical } \\
\text { Velocity, } \bar{v} \\
\text { (1st Order) }\end{array}$ & $\begin{array}{c}\text { Non-dimensional } \\
\text { Vertical } \\
\text { Velocity, } \bar{v} \\
\text { (2nd Order) }\end{array}$ & $\begin{array}{c}\% \text { Deviation } \\
\text { in } \bar{v}\end{array}$ \\
\hline 1.00 & 0.0000000 & 0.0000000 & 0.0000000 \\
\hline 0.95 & -0.2440669 & -0.2440447 & -0.0090966 \\
\hline 0.90 & -0.2001967 & -0.2002889 & 0.0460335 \\
\hline 0.85 & -0.1041439 & -0.1043035 & 0.1530149 \\
\hline 0.80 & -0.0356895 & -0.0357540 & 0.1803991 \\
\hline 0.75 & -0.0030238 & -0.0031484 & 3.9582403 \\
\hline 0.70 & 0.0087026 & 0.0086785 & -0.2781932 \\
\hline 0.65 & 0.0107321 & 0.0106349 & -0.9147241 \\
\hline 0.60 & 0.0096055 & 0.0095869 & -0.1936064 \\
\hline 0.55 & 0.0071374 & 0.0070514 & -1.2197429 \\
\hline 0.50 & 0.0043102 & 0.0043028 & -0.1719107 \\
\hline 0.45 & 0.0015751 & 0.0015100 & -4.3091294 \\
\hline 0.40 & -0.0003151 & -0.0003056 & -3.1057804 \\
\hline 0.35 & 0.0007948 & 0.0007269 & -9.3348089 \\
\hline 0.30 & 0.0079977 & 0.0079743 & -0.2939556 \\
\hline 0.25 & 0.0277972 & 0.0276678 & -0.4676911 \\
\hline 0.20 & 0.0664985 & 0.0664488 & -0.0748997 \\
\hline 0.15 & 0.1278577 & 0.1278468 & -0.0085258 \\
\hline 0.10 & 0.1946601 & 0.1949693 & 0.1585890 \\
\hline 0.05 & 0.2022876 & 0.2027110 & 0.2088687 \\
\hline 0.00 & 0.0000000 & 0.0000000 & 0.0000000 \\
\hline
\end{tabular}


Table 29- Comparison of Non-dimensional values of Temperature along the Horizontal Centerline between First Order and Second Order Time Accurate Approximations $\left(\mathrm{Ra}=10^{5}, \Delta \bar{t}=1.0 \mathrm{E}-5\right.$ and $\left.21 \mathrm{X} 21\right)$

\begin{tabular}{|c|c|c|c|}
\hline $\begin{array}{c}\text { Non-dimensional } \\
\text { Horizontal } \\
\text { Distance, } \bar{x}\end{array}$ & $\begin{array}{c}\text { Non-dimensional } \\
\text { Temperature, } \bar{T} \\
\text { (1st Order) }\end{array}$ & $\begin{array}{c}\text { Non-dimensional } \\
\text { Temperature, } \bar{T} \\
\text { (2nd Order) }\end{array}$ & $\begin{array}{c}\% \text { Deviation } \\
\text { in } \bar{T}\end{array}$ \\
\hline 1.00 & 0.8919274 & 0.8919274 & 0.0000000 \\
\hline 0.95 & 0.9541786 & 0.9541405 & -0.0039931 \\
\hline 0.90 & 0.9990383 & 0.9988405 & -0.0198029 \\
\hline 0.85 & 1.0216900 & 1.0214050 & -0.0279027 \\
\hline 0.80 & 1.0293790 & 1.0290520 & -0.0317768 \\
\hline 0.75 & 1.0303840 & 1.0300350 & -0.0338823 \\
\hline 0.70 & 1.0295550 & 1.0291910 & -0.0353675 \\
\hline 0.65 & 1.0287620 & 1.0283880 & -0.0363675 \\
\hline 0.60 & 1.0283270 & 1.0279430 & -0.0373561 \\
\hline 0.55 & 1.0281210 & 1.0277350 & -0.0375583 \\
\hline 0.50 & 1.0278720 & 1.0274820 & -0.0379568 \\
\hline 0.45 & 1.0273150 & 1.0269280 & -0.0376852 \\
\hline 0.40 & 1.0262080 & 1.0258250 & -0.0373358 \\
\hline 0.35 & 1.0243960 & 1.0240220 & -0.0365226 \\
\hline 0.30 & 1.0219900 & 1.0216240 & -0.0358253 \\
\hline 0.25 & 1.0196770 & 1.0193210 & -0.0349252 \\
\hline 0.20 & 1.0193410 & 1.0189950 & -0.0339550 \\
\hline 0.15 & 1.0245320 & 1.0242100 & -0.0314388 \\
\hline 0.10 & 1.0402610 & 1.0399920 & -0.0258655 \\
\hline 0.05 & 1.0699080 & 1.0697490 & -0.0148633 \\
\hline 0.00 & 1.1080730 & 1.1080730 & 0.0000000 \\
\hline & & & \\
\hline & & & \\
\hline & & & \\
\hline & & & \\
\hline 00 & & &
\end{tabular}




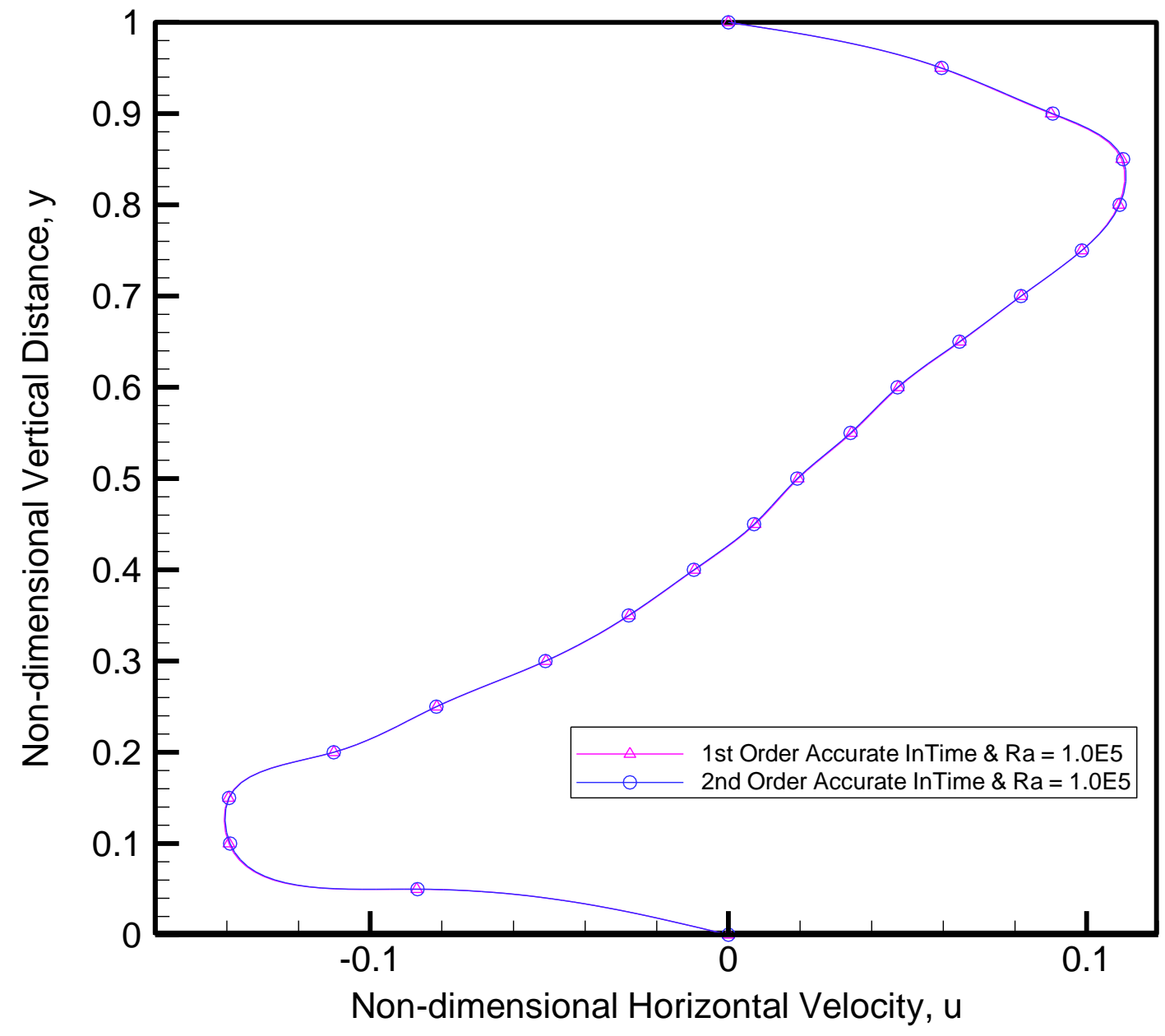

Figure 52- Comparison of Steady State Horizontal Velocity Distribution along the Vertical centerline of the Enclosure between First Order and Second Order Time Accurate Approximation for $\mathrm{Ra}=10^{5}$ 


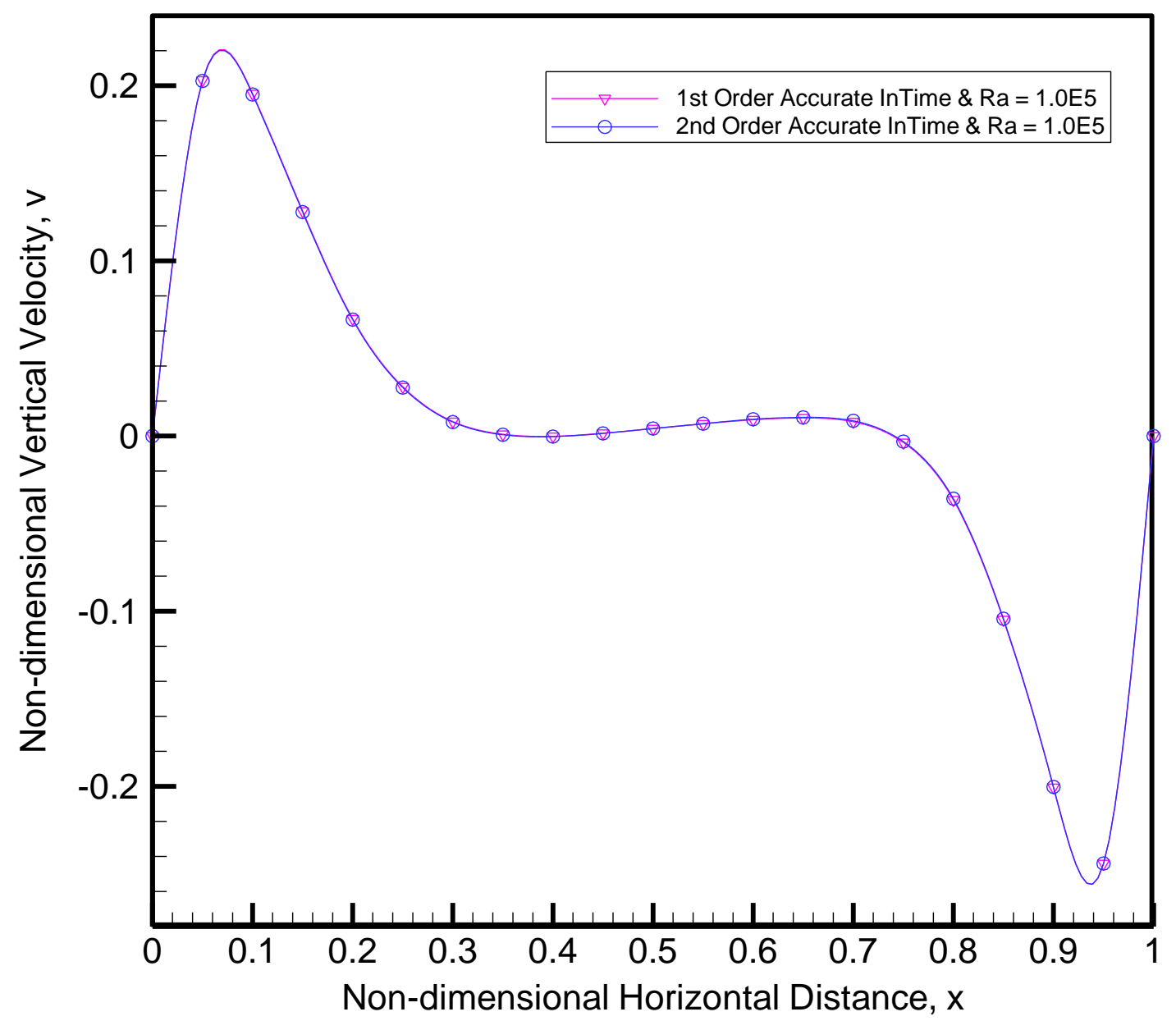

Figure 53- Comparison of Steady State Vertical Velocity Distribution along the Horizontal Centerline of the Enclosure between First Order and Second Order Time Accurate Approximation for $\mathrm{Ra}=10^{5}$ 


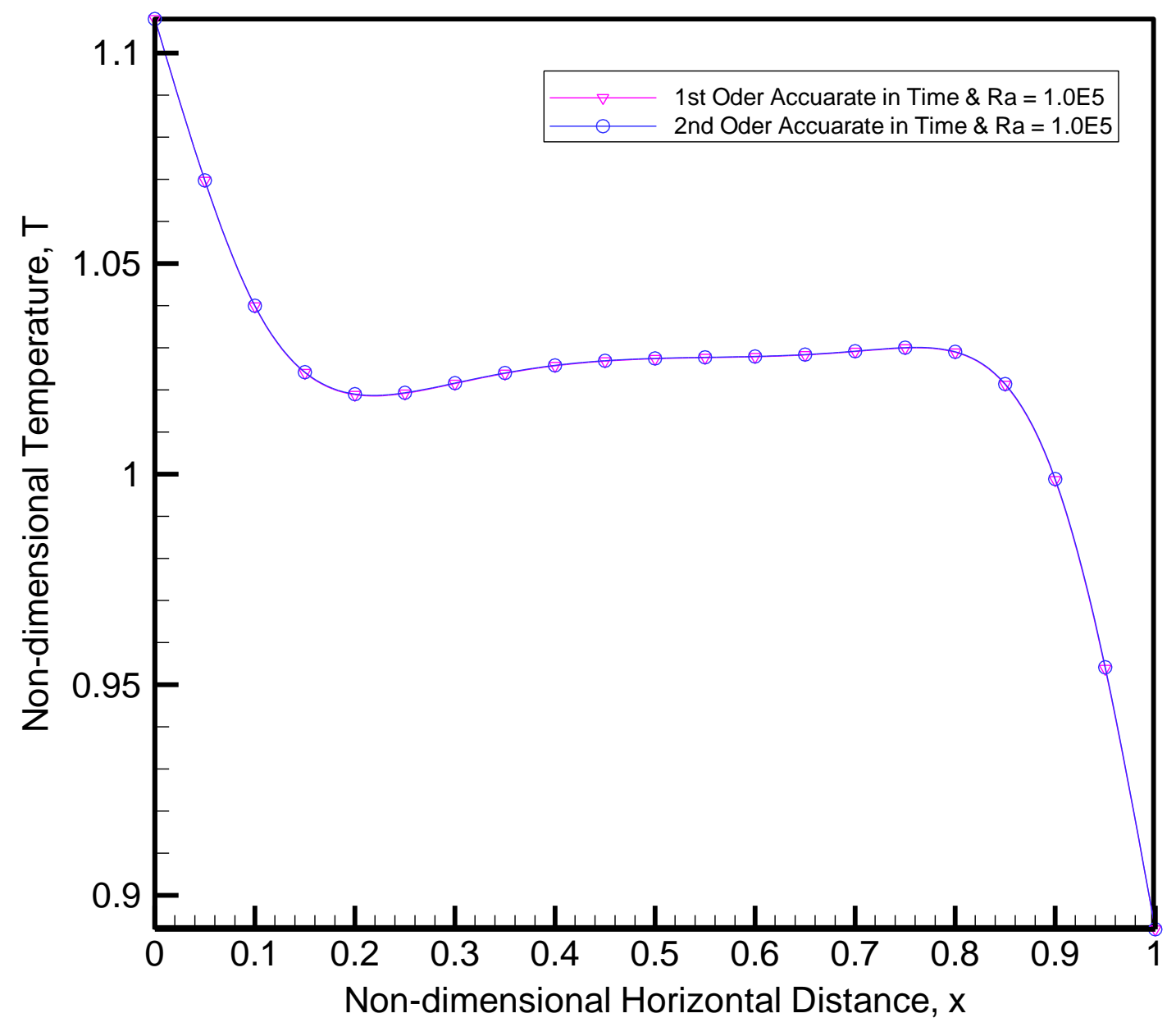

Figure 54- Comparison of Steady State Temperature Distribution along the Horizontal Centerline of the Enclosure between First Order and Second Order Time Accurate Approximation for $\mathrm{Ra}=10^{5}$ 
Table 30- Comparison of Non-dimensional values of Horizontal Velocity along the Vertical Centerline between First Order and Second Order Time Accurate Approximations $\left(\mathrm{Ra}=10^{4}, \Delta \bar{t}=1.0 \mathrm{E}-6\right.$ and $\left.21 \mathrm{X} 21\right)$

\begin{tabular}{|c|c|c|c|}
\hline $\begin{array}{c}\text { Non- } \\
\text { dimensional } \\
\text { Vertical } \\
\text { Distance, } \bar{y}\end{array}$ & $\begin{array}{c}\text { Non- } \\
\text { dimensional } \\
\text { Horizontal } \\
\text { Velocity, } \bar{u} \\
(1 \text { st Oder })\end{array}$ & $\begin{array}{c}\text { Non-dimensional } \\
\text { Horizontal } \\
\text { Velocity, } \bar{u} \\
\text { (2nd Order) }\end{array}$ & $\begin{array}{c}\text { \% Deviation } \\
\text { in } \bar{u}\end{array}$ \\
\hline 1.00 & 0.0000000 & 0.0000000 & 0.0000000 \\
\hline 0.95 & 0.0718289 & 0.0716946 & -0.1873362 \\
\hline 0.90 & 0.1109938 & 0.1108348 & -0.1434567 \\
\hline 0.85 & 0.1421789 & 0.1418300 & -0.2459987 \\
\hline 0.80 & 0.1526182 & 0.1521436 & -0.3119421 \\
\hline 0.75 & 0.1559837 & 0.1553692 & -0.3955095 \\
\hline 0.70 & 0.1456733 & 0.1449529 & -0.4969890 \\
\hline 0.65 & 0.1320233 & 0.1312004 & -0.6272084 \\
\hline 0.60 & 0.1075737 & 0.1067081 & -0.8111849 \\
\hline 0.55 & 0.0826481 & 0.0816952 & -1.1664944 \\
\hline 0.50 & 0.0481424 & 0.0472270 & -1.9384242 \\
\hline 0.45 & 0.0139338 & 0.0129922 & -7.2470014 \\
\hline 0.40 & -0.0285451 & -0.0292848 & 2.5260817 \\
\hline 0.35 & -0.0714584 & -0.0719673 & 0.7071402 \\
\hline 0.30 & -0.1186585 & -0.1186277 & -0.0259635 \\
\hline 0.25 & -0.1640687 & -0.1633397 & -0.4463091 \\
\hline 0.20 & -0.2022790 & -0.2006958 & -0.7888555 \\
\hline 0.15 & -0.2229911 & -0.2206229 & -1.0734153 \\
\hline 0.10 & -0.2130995 & -0.2103346 & -1.3145245 \\
\hline 0.05 & -0.1350920 & -0.1333185 & -1.3302729 \\
\hline 0.00 & 0.0000000 & 0.0000000 & 0.0000000 \\
\hline & & & \\
\hline & & & \\
\hline
\end{tabular}


Table 31- Comparison of Non-dimensional values of Vertical Velocity along the Horizontal Centerline between First Order and Second Order Time Accurate Approximations $\left(\mathrm{Ra}=10^{4}, \Delta \bar{t}=1.0 \mathrm{E}-6\right.$ and $\left.21 \mathrm{X} 21\right)$

\begin{tabular}{|c|c|c|c|}
\hline $\begin{array}{c}\text { Non-dimensional } \\
\text { Horizontal } \\
\text { Distance, } \bar{x}\end{array}$ & $\begin{array}{c}\text { Non-dimensional } \\
\text { Vertical } \\
\text { Velocity, } \bar{v} \\
\left(1^{\text {st }} \text { Order }\right)\end{array}$ & $\begin{array}{c}\text { Non-dimensional } \\
\text { Vertical } \\
\text { Velocity, } \bar{v} \\
\text { (2nd Order) }\end{array}$ & $\begin{array}{c}\% \text { Deviation } \\
\text { in } \bar{v}\end{array}$ \\
\hline 1.00 & 0.0000000 & 0.0000000 & 0.0000000 \\
\hline 0.95 & -0.1774396 & -0.1748586 & -1.4760497 \\
\hline 0.90 & -0.2428447 & -0.2397430 & -1.2937602 \\
\hline 0.85 & -0.2299650 & -0.2278353 & -0.9347541 \\
\hline 0.80 & -0.1823231 & -0.1809458 & -0.7611671 \\
\hline 0.75 & -0.1288377 & -0.1284063 & -0.3359648 \\
\hline 0.70 & -0.0824661 & -0.0822997 & -0.2021511 \\
\hline 0.65 & -0.0464804 & -0.0467008 & 0.4720043 \\
\hline 0.60 & -0.0195359 & -0.0196341 & 0.5004028 \\
\hline 0.55 & 0.0016007 & 0.0013556 & -18.078290 \\
\hline 0.50 & 0.0195719 & 0.0195468 & -0.1283070 \\
\hline 0.45 & 0.0374285 & 0.0372685 & -0.4293166 \\
\hline 0.40 & 0.0566598 & 0.0566889 & 0.0512798 \\
\hline 0.35 & 0.0796021 & 0.0793940 & -0.2621734 \\
\hline 0.30 & 0.1061552 & 0.1060370 & -0.1114705 \\
\hline 0.25 & 0.1366630 & 0.1361237 & -0.3961837 \\
\hline 0.20 & 0.1663514 & 0.1657783 & -0.3457026 \\
\hline 0.15 & 0.1886132 & 0.1874899 & -0.5991256 \\
\hline 0.10 & 0.1873610 & 0.1863276 & -0.5546145 \\
\hline 0.05 & 0.1414387 & 0.1402807 & -0.8254877 \\
\hline 0.00 & 0.0000000 & 0.0000000 & 0.0000000 \\
\hline
\end{tabular}


Table 32- Comparison of Non-dimensional values of Temperature along the Horizontal Centerline between First Order and Second Order Time Accurate Approximations $\left(\mathrm{Ra}=10^{4}, \Delta \bar{t}=1.0 \mathrm{E}-6\right.$ and $\left.21 \mathrm{X} 21\right)$

\begin{tabular}{|c|c|c|c|}
\hline $\begin{array}{c}\text { Non-dimensional } \\
\text { Horizontal } \\
\text { Distance, } \bar{x}\end{array}$ & $\begin{array}{l}\text { Non-dimensional } \\
\text { Temperature, } \bar{T} \\
\text { (1st Order) }\end{array}$ & $\begin{array}{l}\text { Non-dimensional } \\
\text { Temperature, } \bar{T} \\
\text { (2nd Order) }\end{array}$ & $\begin{array}{c}\% \text { Deviation } \\
\text { in } \bar{T}\end{array}$ \\
\hline 1.00 & 0.9891927 & 0.9891927 & 0.0000000 \\
\hline 0.95 & 0.9925951 & 0.9928062 & 0.0212629 \\
\hline 0.90 & 0.9959832 & 0.9961624 & 0.0179890 \\
\hline 0.85 & 0.9989185 & 0.9990303 & 0.0111908 \\
\hline 0.80 & 1.0011520 & 1.0012220 & 0.0069914 \\
\hline 0.75 & 1.0026770 & 1.0027260 & 0.0048866 \\
\hline 0.70 & 1.0036120 & 1.0036520 & 0.0039854 \\
\hline 0.65 & 1.0041200 & 1.0041590 & 0.0038838 \\
\hline 0.60 & 1.0043510 & 1.0043920 & 0.0040820 \\
\hline 0.55 & 1.0044200 & 1.0044650 & 0.0044799 \\
\hline 0.50 & 1.0044090 & 1.0044590 & 0.0049778 \\
\hline 0.45 & 1.0043770 & 1.0044310 & 0.0053761 \\
\hline 0.40 & 1.0043710 & 1.0044290 & 0.0057744 \\
\hline 0.35 & 1.0044400 & 1.0045010 & 0.0060726 \\
\hline 0.30 & 1.0046400 & 1.0047040 & 0.0063700 \\
\hline 0.25 & 1.0050360 & 1.0051000 & 0.0063675 \\
\hline 0.20 & 1.0056900 & 1.0057500 & 0.0059656 \\
\hline 0.15 & 1.0066410 & 1.0066930 & 0.0051654 \\
\hline 0.10 & 1.0078790 & 1.0079160 & 0.0036709 \\
\hline 0.05 & 1.0093140 & 1.0093330 & 0.0018824 \\
\hline 0.00 & 1.0108070 & 1.0108070 & 0.0000000 \\
\hline
\end{tabular}




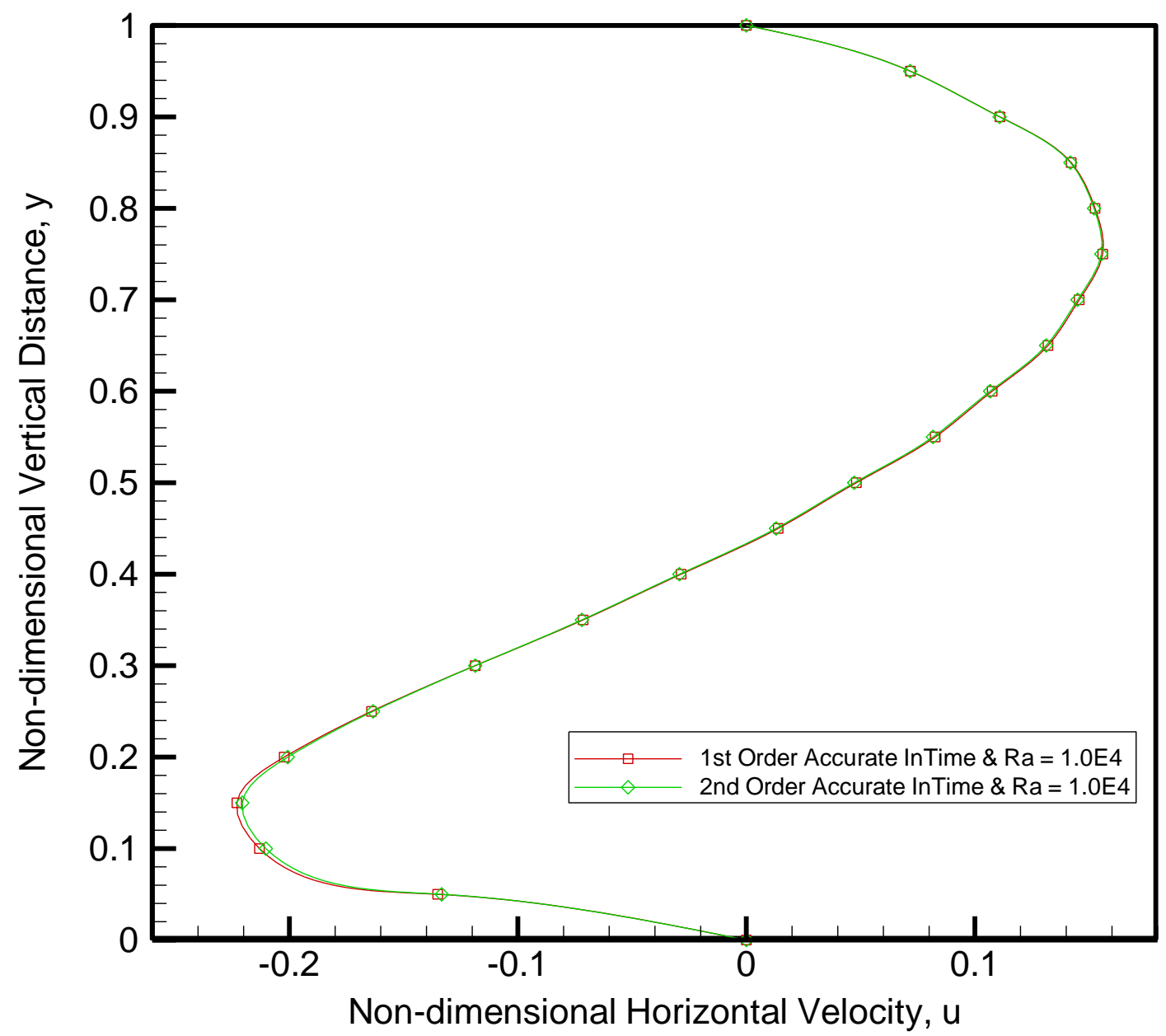

Figure 55- Comparison of Steady State Horizontal Velocity Distribution along the Vertical Centerline of the Enclosure between First Order and Second Order Time Accurate Approximation for $\mathrm{Ra}=10^{4}$ 


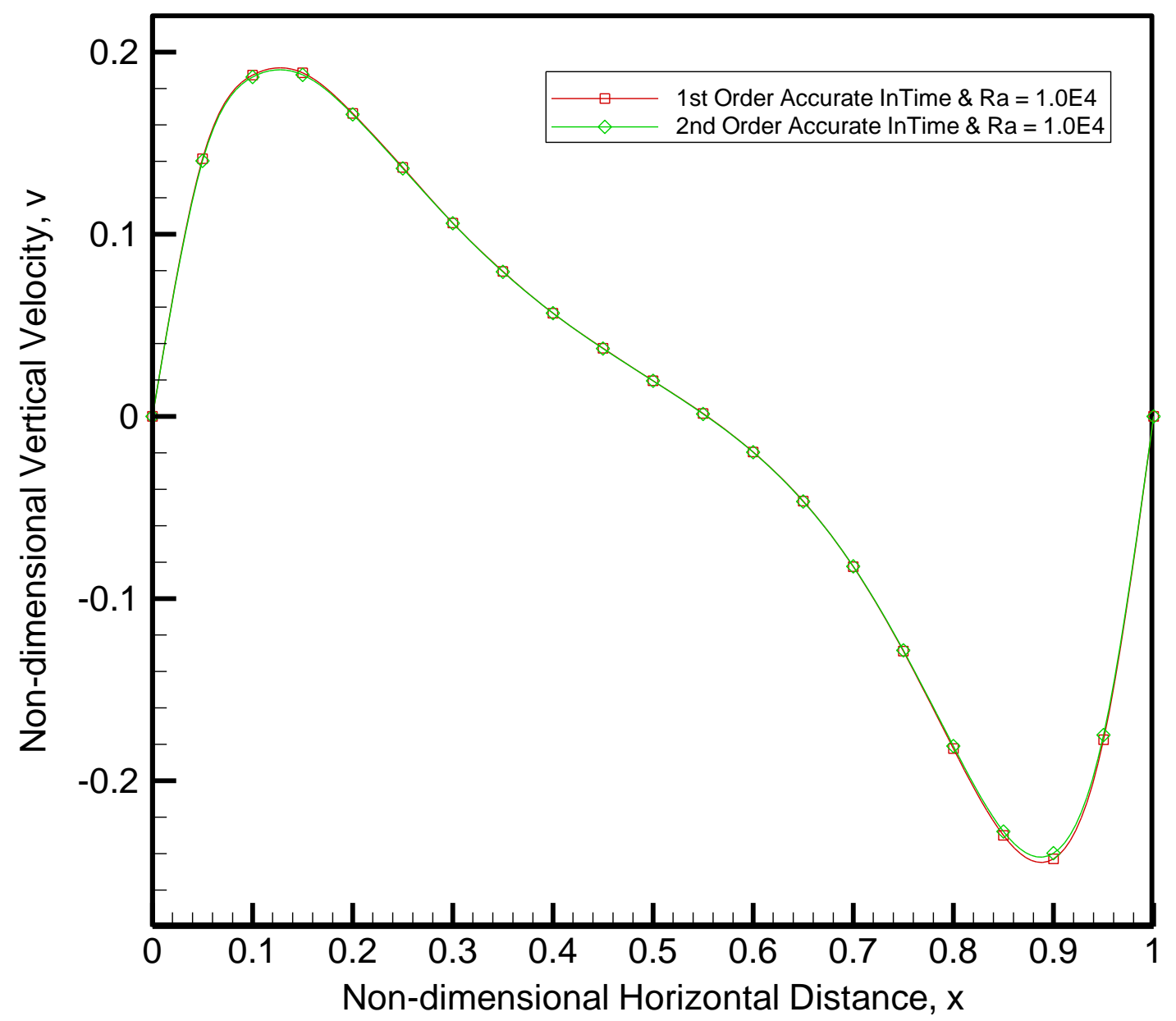

Figure 56- Comparison of Steady State Vertical Velocity Distribution along the Horizontal Centerline of the Enclosure between First Order and Second Order Time Accurate Approximation for $\mathrm{Ra}=10^{4}$ 


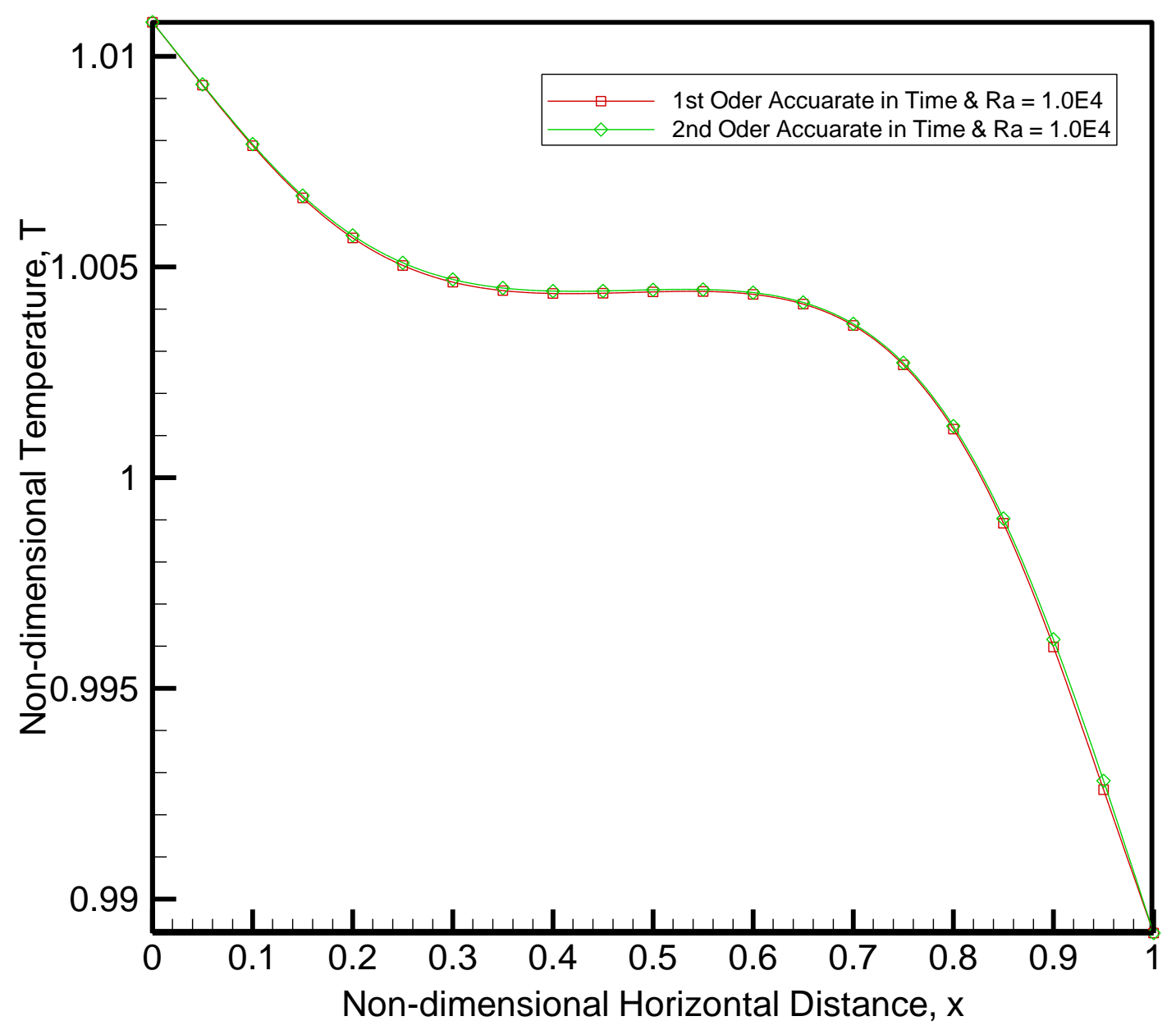

Figure 57- Comparison of Steady State Temperature Distribution along the Horizontal Centerline of the Enclosure between First Order and Second Order Time Accurate Approximation for $\mathrm{Ra}=10^{4}$ 


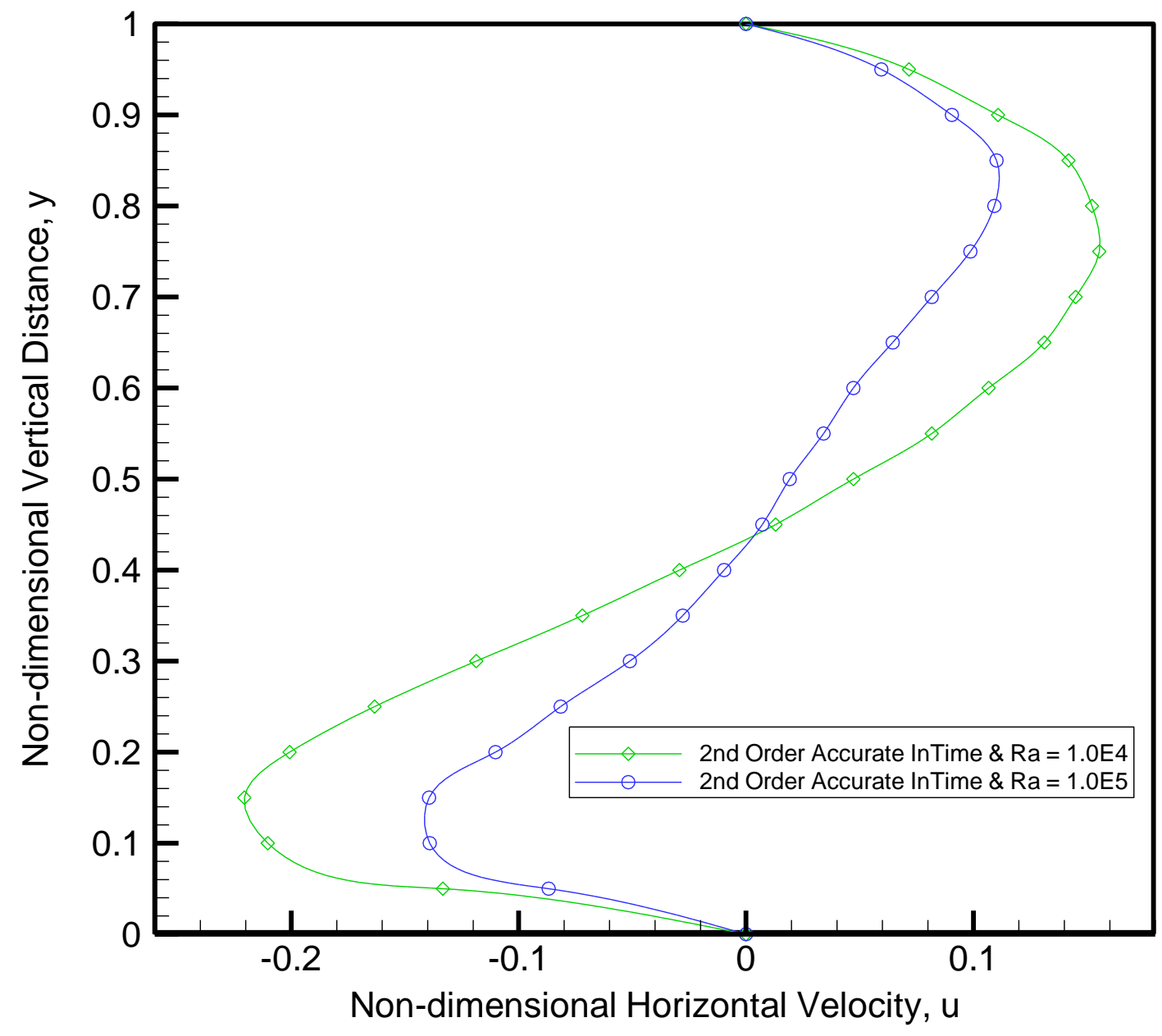

Figure 58- Comparison of Steady State Horizontal Velocity Distribution along the Vertical Centerline of the Enclosure between $\mathrm{Ra}=10^{4}$ and $\mathrm{Ra}=10^{5}$ in Second Order Time Accurate Approximation 


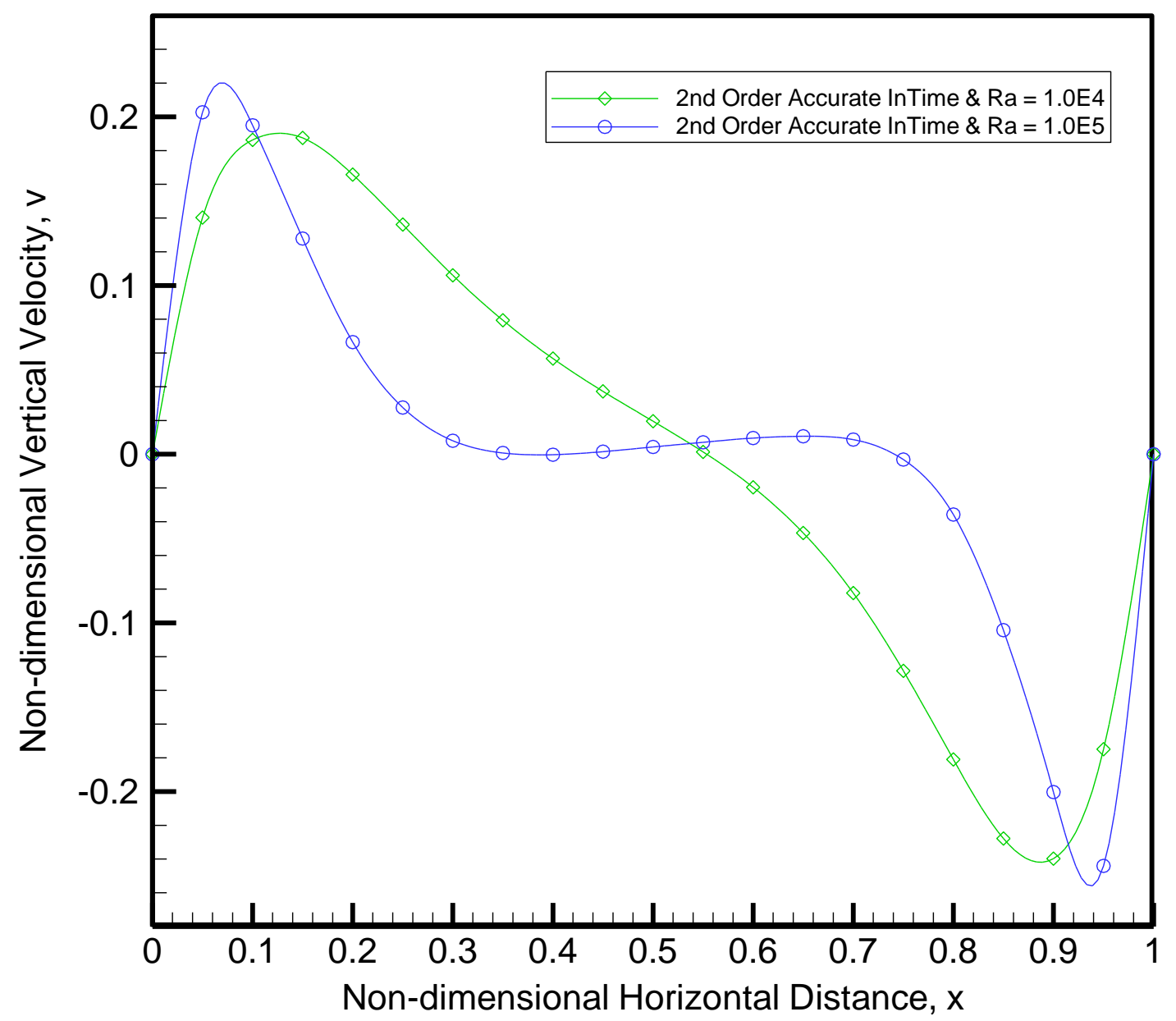

Figure 59- Comparison of Steady State Vertical Velocity Distribution along the Horizontal Centerline of the Enclosure between $\mathrm{Ra}=10^{4}$ and $\mathrm{Ra}=10^{5}$ in Second Order Time Accurate Approximation 


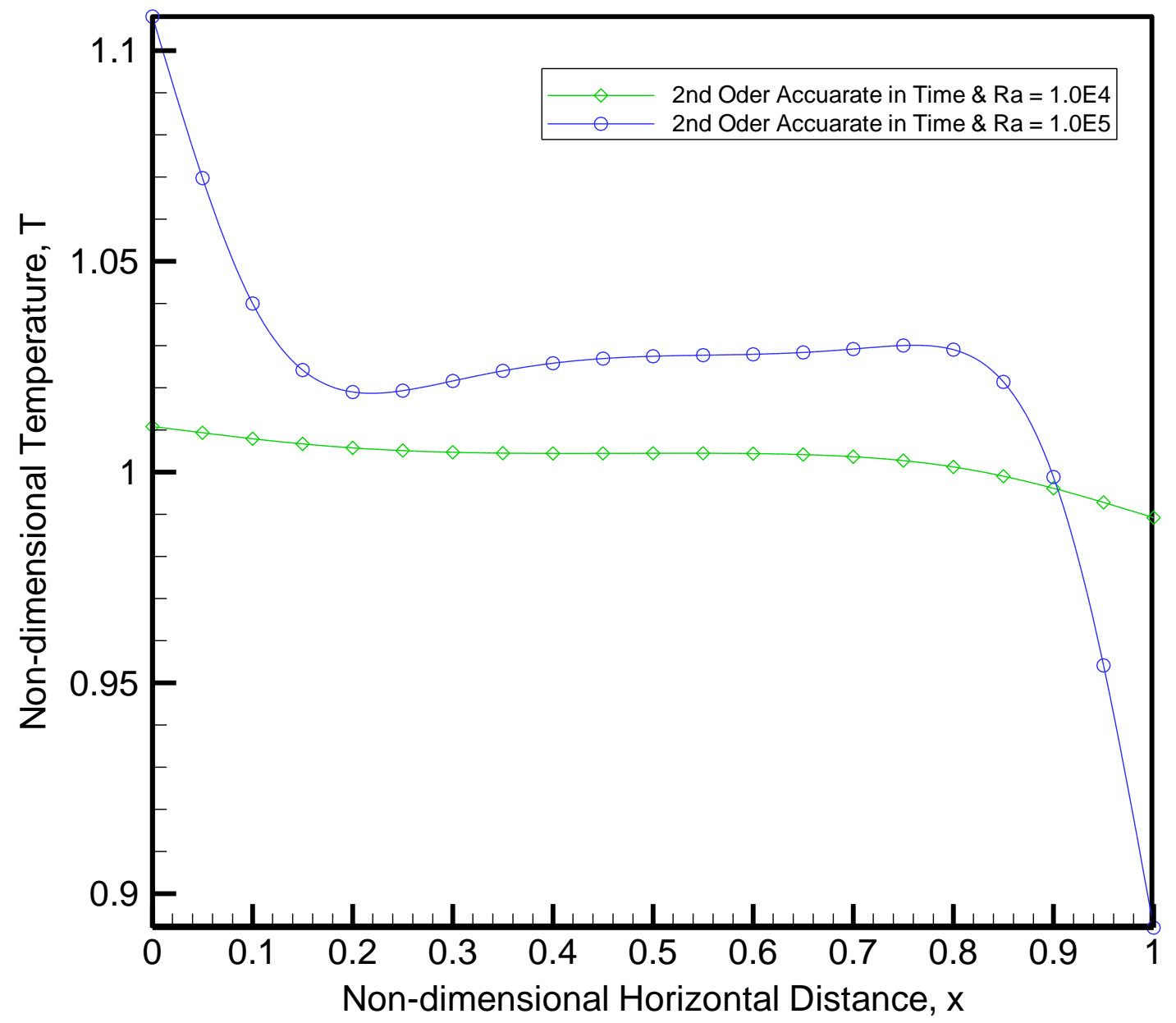

Figure 60- Comparison of Steady State Temperature Distribution along the Horizontal Centerline of the Enclosure between $\mathrm{Ra}=10^{4}$ and $\mathrm{Ra}=10^{5}$ in Second Order Time Accurate Approximation 


\section{Chapter 11 \\ The Study of Unsteady Natural Convection in Square Enclosure}

The unsteady thermal and hydrodynamic behavior of the working fluid was studied by imposing a sudden wall temperature change in a square enclosure. The unsteady development of the velocity vectors and temperatures for $\mathrm{Ra}=10^{5}$ and grid size of $41 \times 41$ for different nondimensional time levels $(1 \mathrm{~s}, 5 \mathrm{~s}, 10 \mathrm{~s}, 15 \mathrm{~s}, 20 \mathrm{~s}$, and $50 \mathrm{~s})$ using second order accurate in time model are presented in this chapter. The density of the air near the hot wall is lower than that of the cold wall. As a result, the hot air rises near the left hot wall and falls near the cold right wall ensuring in a clockwise circular motion. These results are presented in Figures 62 through 67 in terms of velocity vectors. The flow is not unicellular as evident that the formation of two secondary vertices. The temperature contours are presented in Figures 68 through 73 . These plots show the development of the expected temperature stratification at vertical centerline of the square enclosure. The isotherms are parallel to the side walls of the enclosure depicting that conduction is the major mode of heat transfer before imposing a sudden wall temperature change. They compare favorable to ones given by Kublbeck [36]. A histogram of nondimensional temperature at location $\bar{x}=0.05$ and $\bar{y}=0.5$ is given in Figure 61 . 


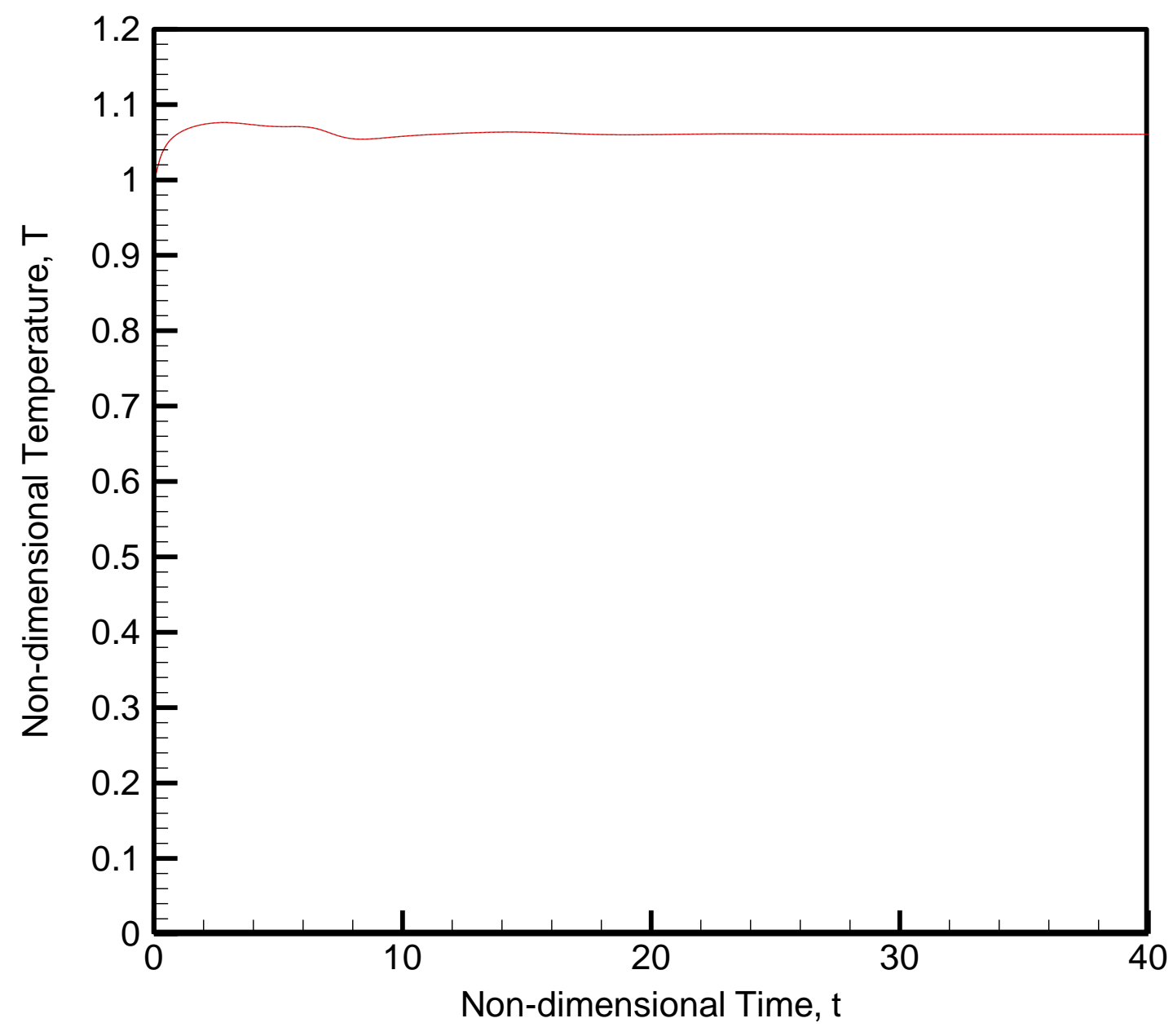

Figure 61- Non-dimensional Temperature Histogram for Ra $=10^{5}$ at $\bar{x}=0.05$ and $\bar{y}=0.5$ (41 x 41, $\Delta \bar{t}=5.0 \mathrm{E}-6)$ in Second Order Time Accurate Approximation 


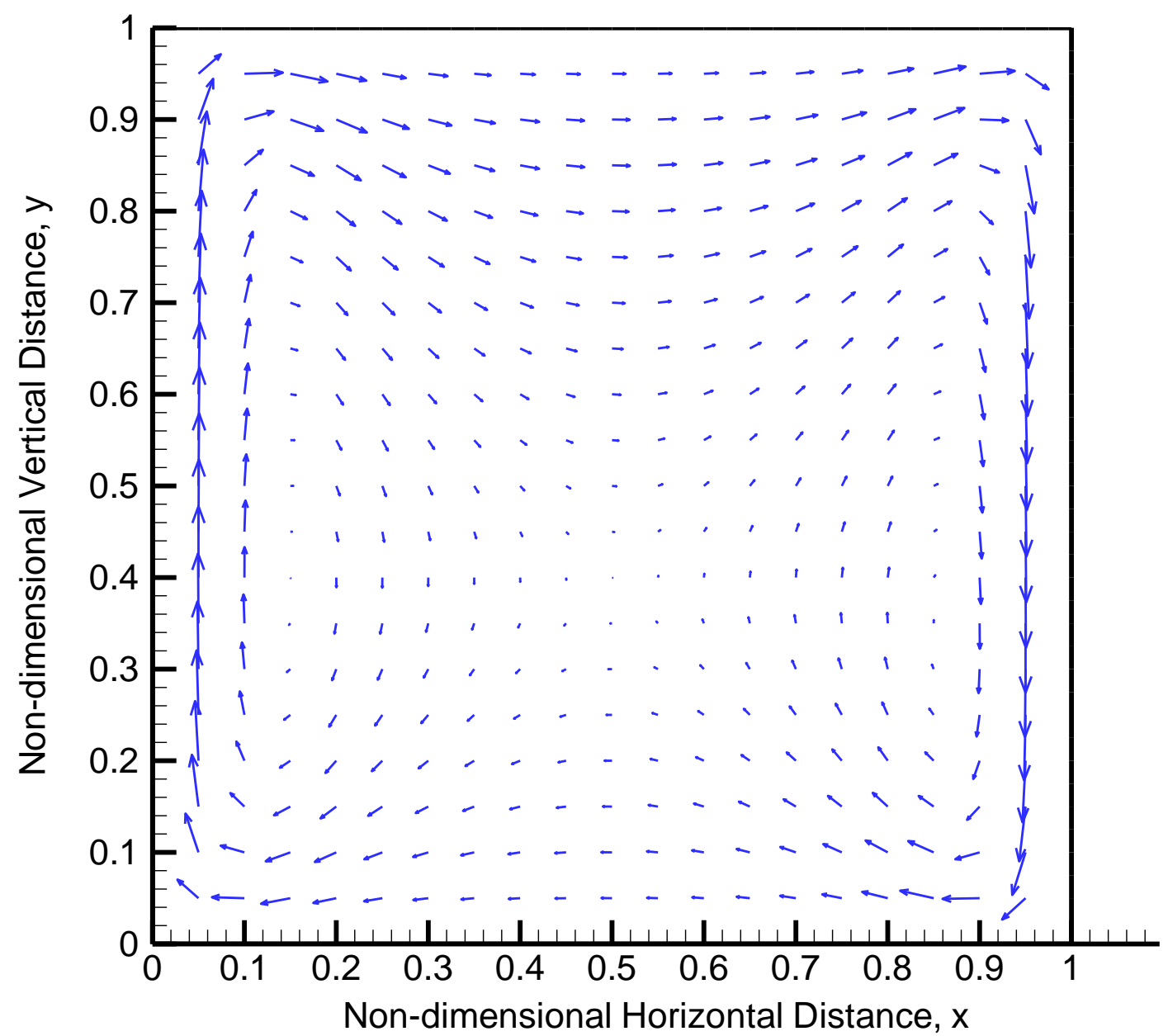

Figure 62- Unsteady State Non-dimensional Velocity Vectors for $\mathrm{Ra}=10^{5}$ at Non-dimensional Time, $\bar{t}=1(41 \times 41, \Delta \bar{t}=5.0 \mathrm{E}-6)$ in Second Order Time Accurate Approximation 


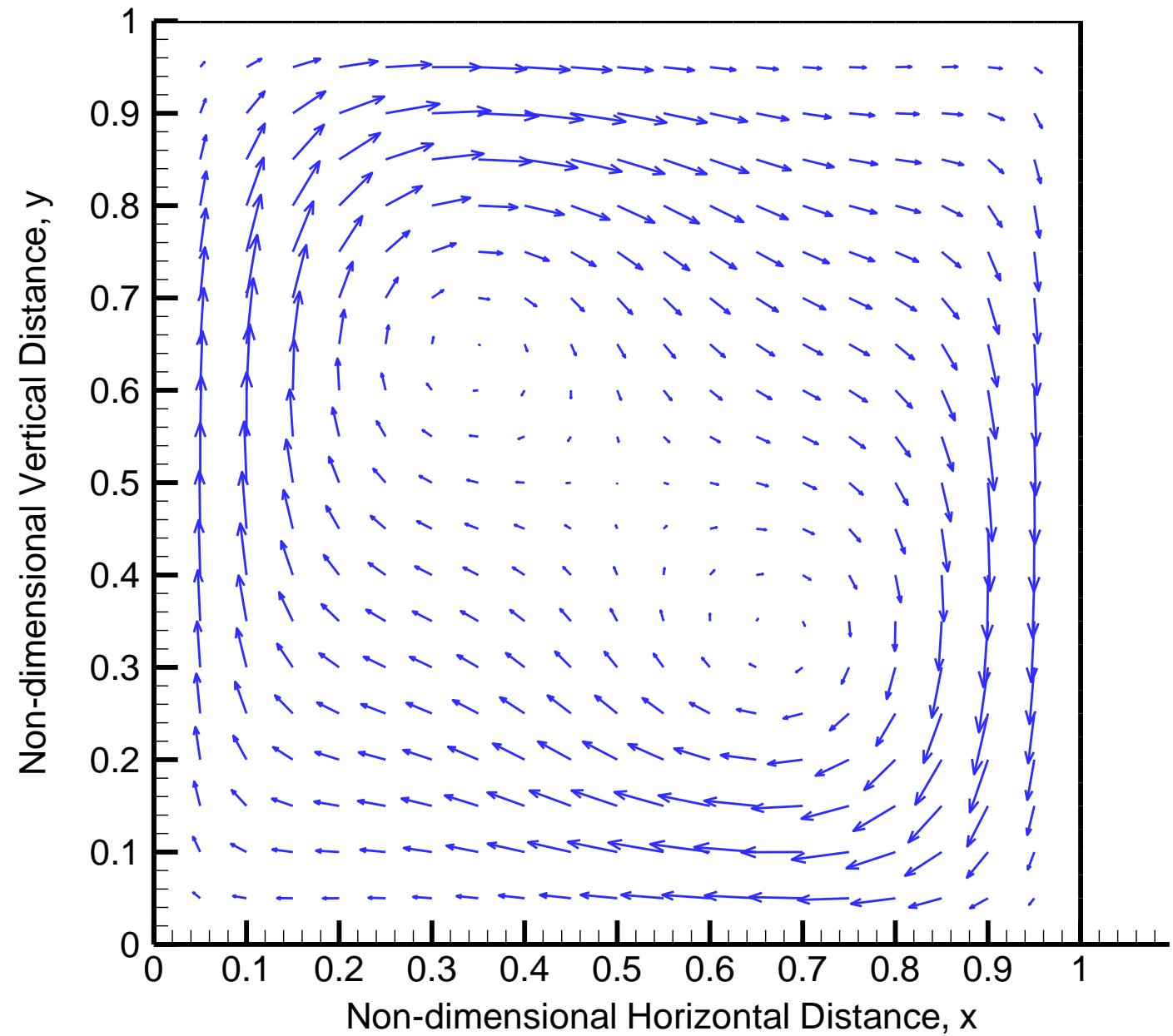

Figure 63- Unsteady State Non-dimensional Velocity Vectors for $\mathrm{Ra}=10^{5}$ at Non-dimensional Time, $\bar{t}=5(41 \times 41, \Delta \bar{t}=5.0 \mathrm{E}-6)$ in Second Order Time Accurate Approximation 


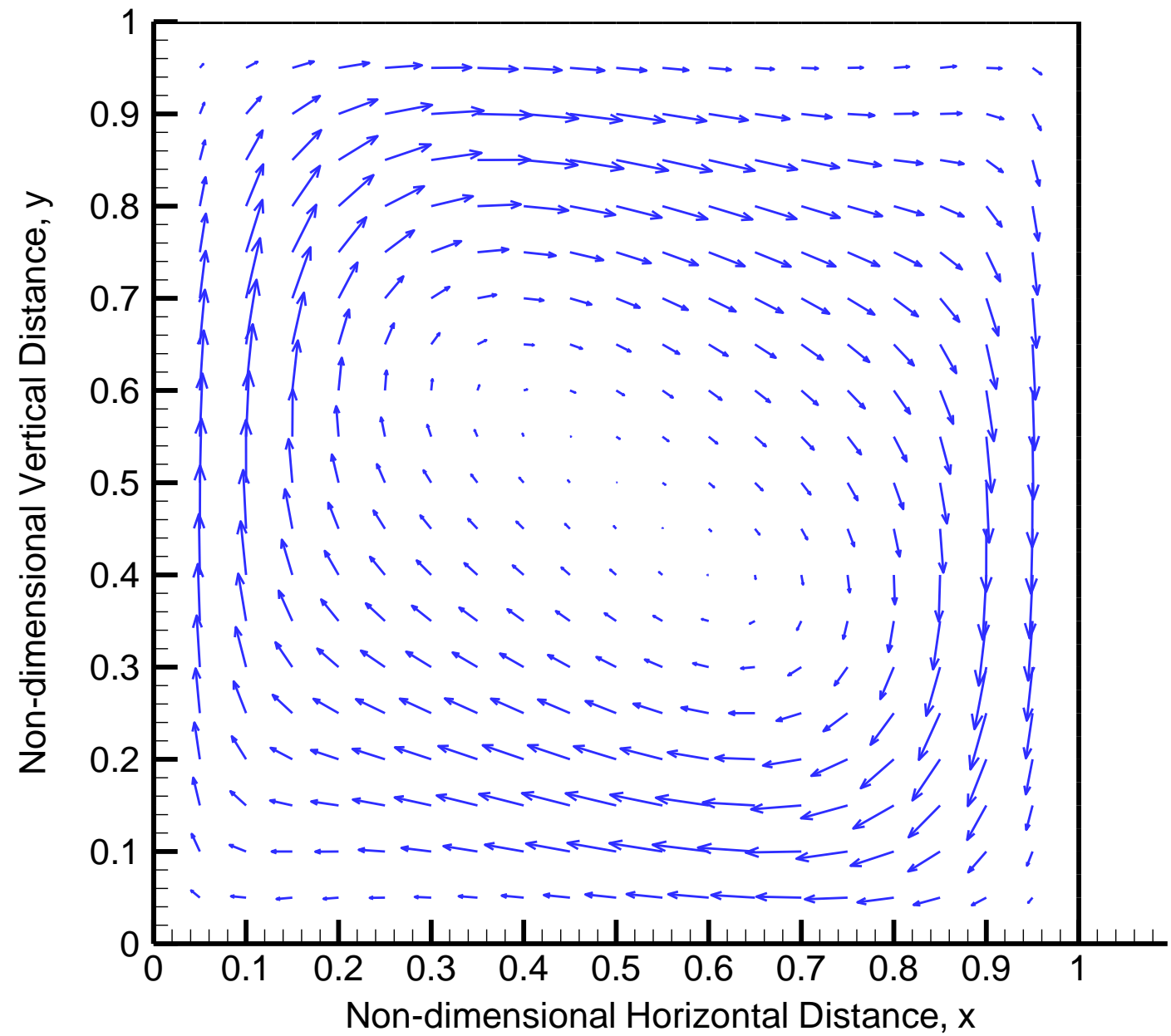

Figure 64- Unsteady State Non-dimensional Velocity Vectors for $\mathrm{Ra}=10^{5}$ at Non-dimensional Time, $\bar{t}=10(41 \times 41, \Delta \bar{t}=5.0 \mathrm{E}-6)$ in Second Order Time Accurate Approximation 


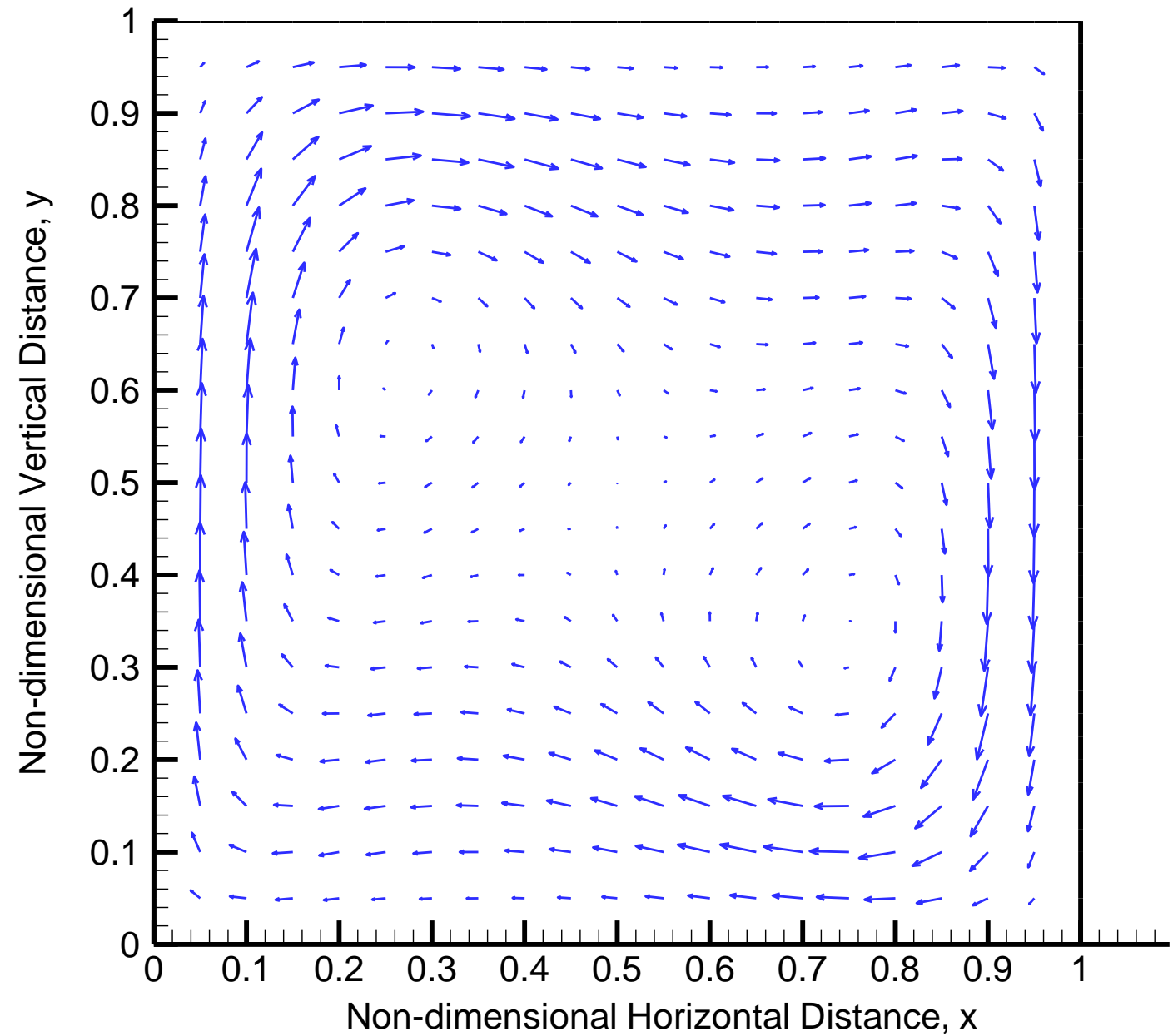

Figure 65- Unsteady State Non-dimensional Velocity Vectors for $\mathrm{Ra}=10^{5}$ at Non-dimensional Time, $\bar{t}=15$ (41 x 41, $\Delta \bar{t}=5.0 \mathrm{E}-6)$ in Second Order Time Accurate Approximation 


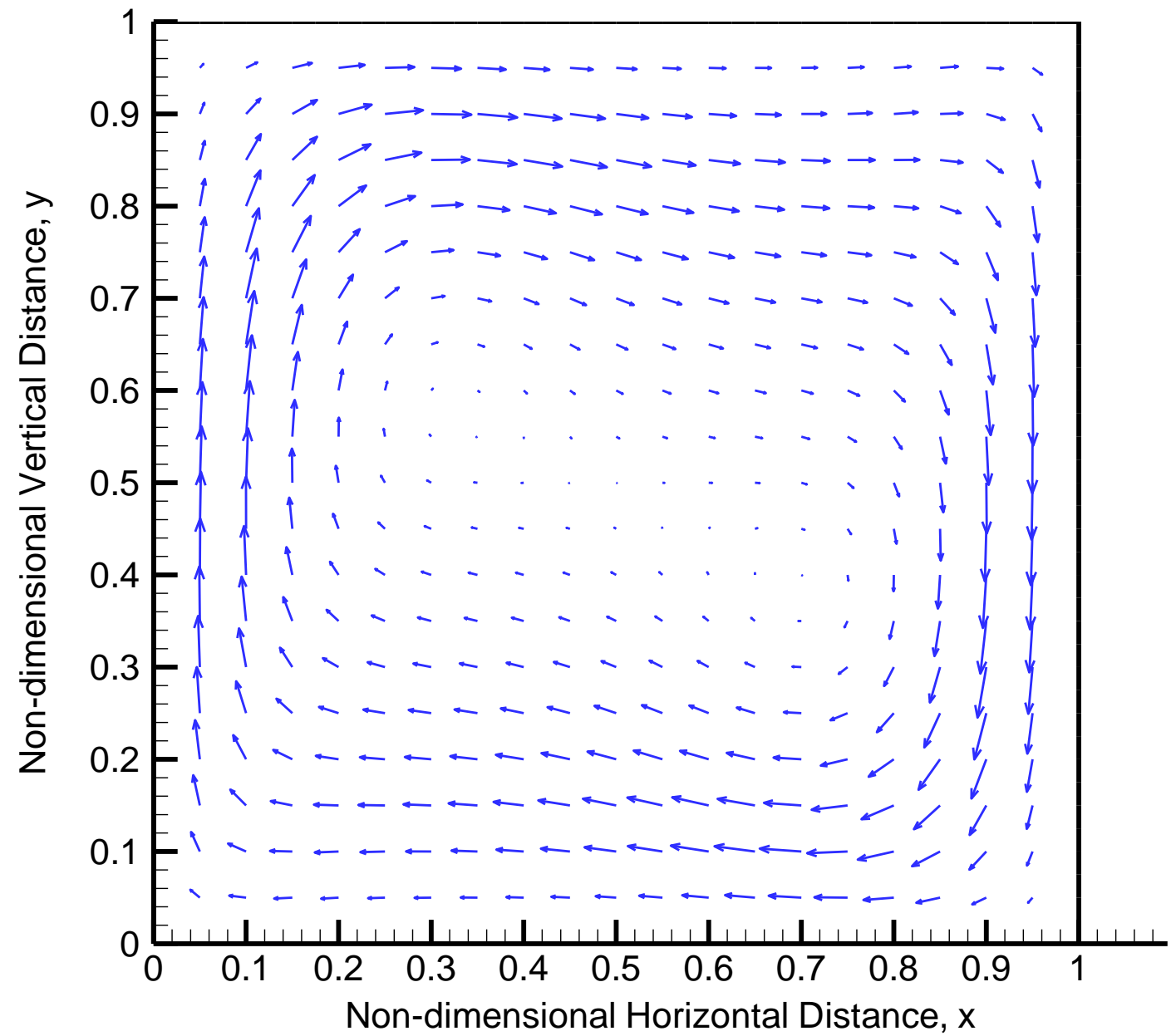

Figure 66- Unsteady State Non-dimensional Velocity Vectors for $\mathrm{Ra}=10^{5}$ at Non-dimensional Time, $\bar{t}=20$ (41 x 41, $\Delta \bar{t}=5.0 \mathrm{E}-6)$ in Second Order Time Accurate Approximation 


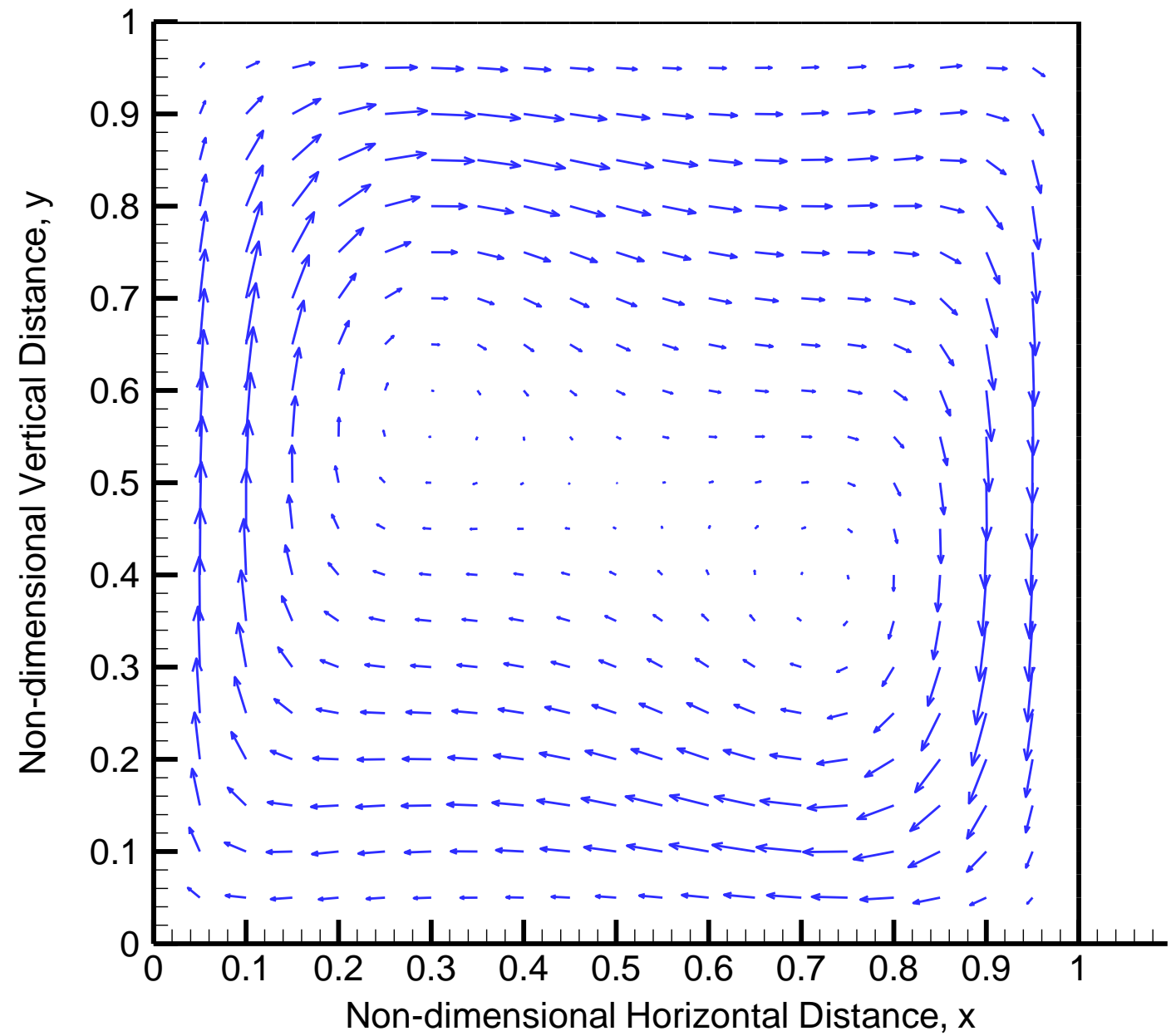

Figure 67- Unsteady State Non-dimensional Velocity Vectors for $\mathrm{Ra}=10^{5}$ at Non-dimensional Time, $\bar{t}=50(41 \times 41, \Delta \bar{t}=5.0 \mathrm{E}-6)$ in Second Order Time Accurate Approximation 


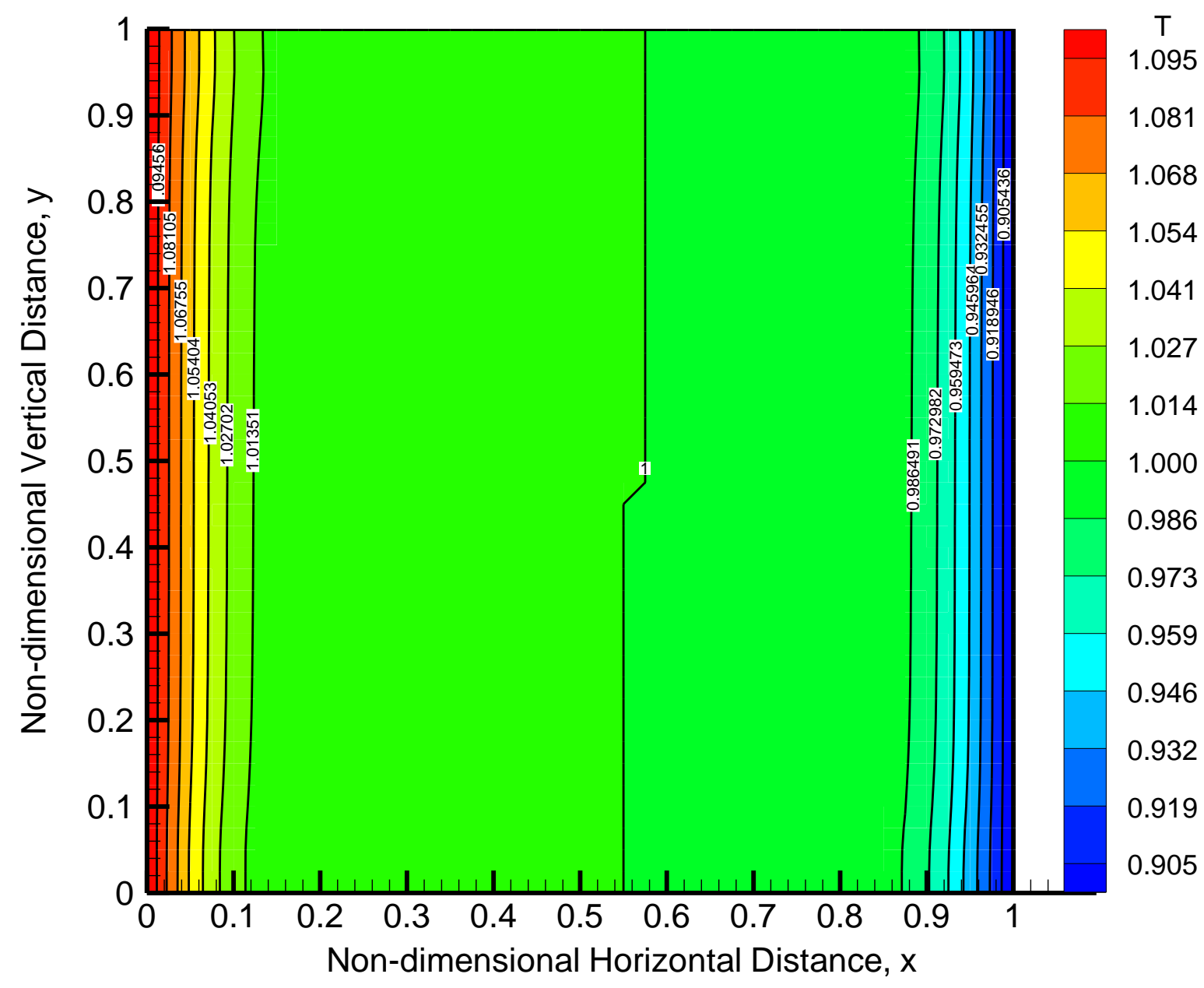

Figure 68- Unsteady State Non-dimensional Temperature Contours for $\mathrm{Ra}=10^{5}$ at Nondimensional Time, $\bar{t}=1$ (41 x 41, $\Delta \bar{t}=5.0 \mathrm{E}-6)$ in Second Order Time Accurate Approximation 


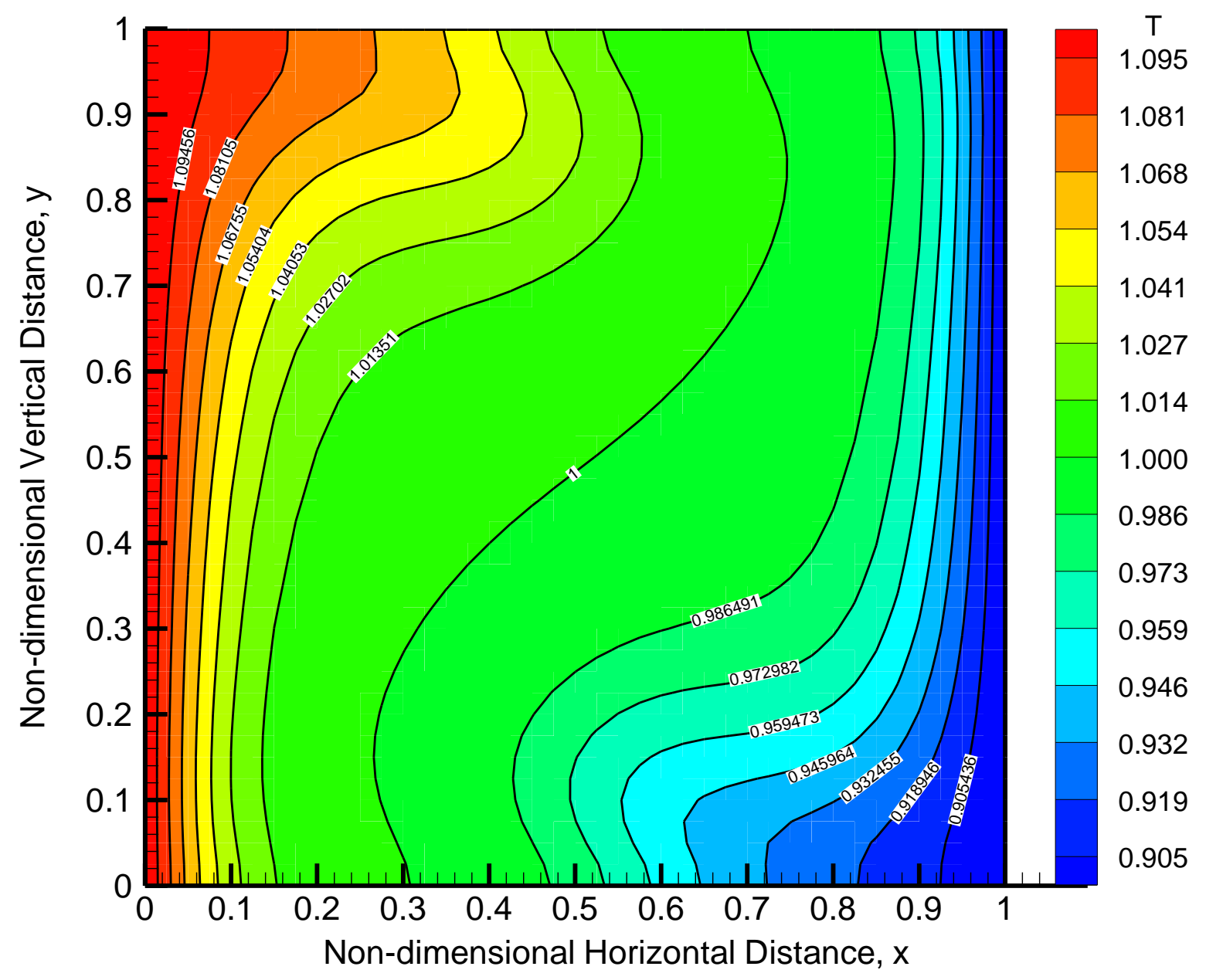

Figure 69- Unsteady State Non-dimensional Temperature Contours for $\mathrm{Ra}=10^{5}$ at Nondimensional Time, $\bar{t}=5$ (41 x 41, $\Delta \bar{t}=5.0 \mathrm{E}-6)$ in Second Order Time Accurate Approximation 


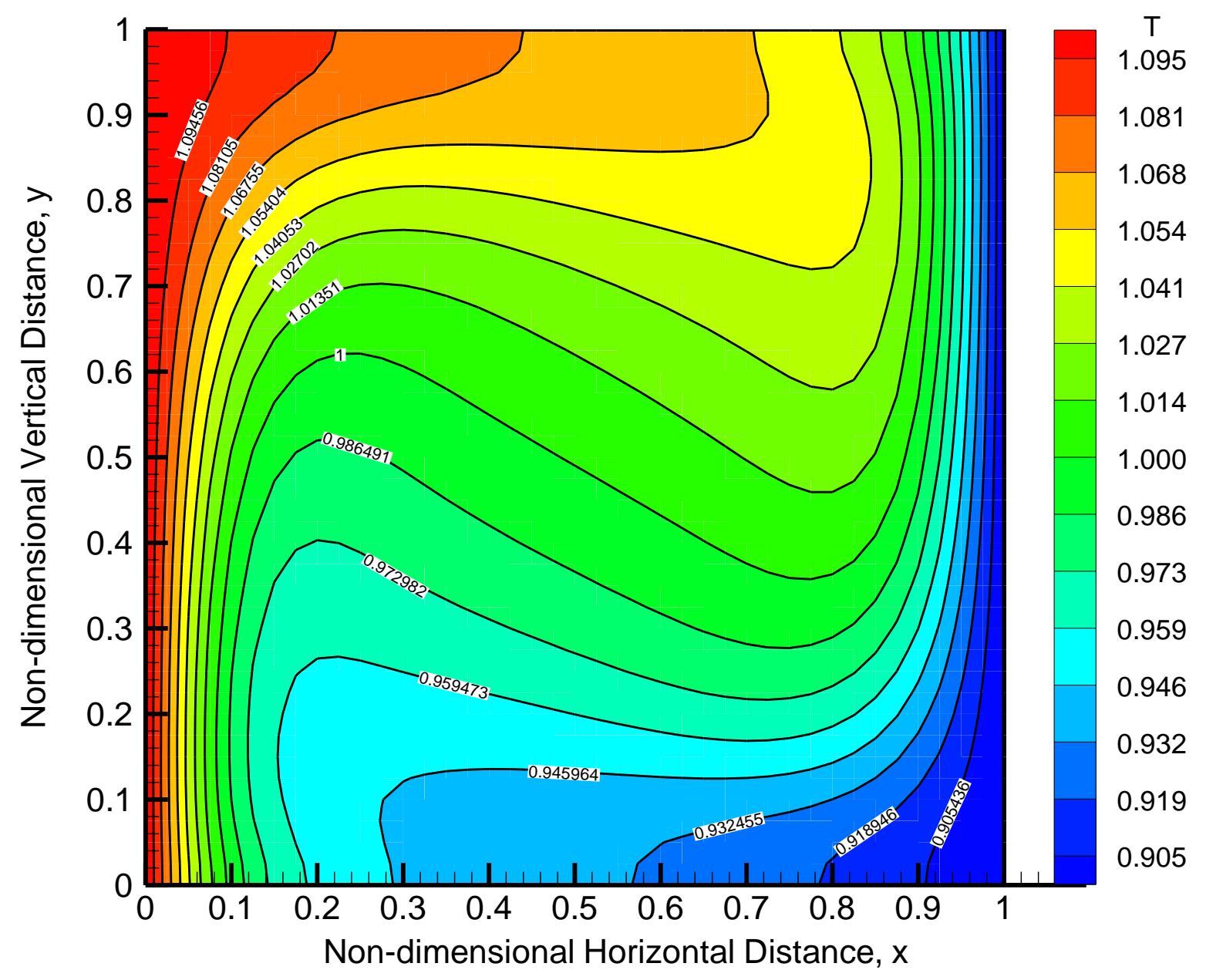

Figure 70- Unsteady State Non-dimensional Temperature Contours for $\mathrm{Ra}=10^{5}$ at Nondimensional Time, $\bar{t}=10$ (41 x 41, $\Delta \bar{t}=5.0 \mathrm{E}-6)$ in Second Order Time Accurate Approximation 


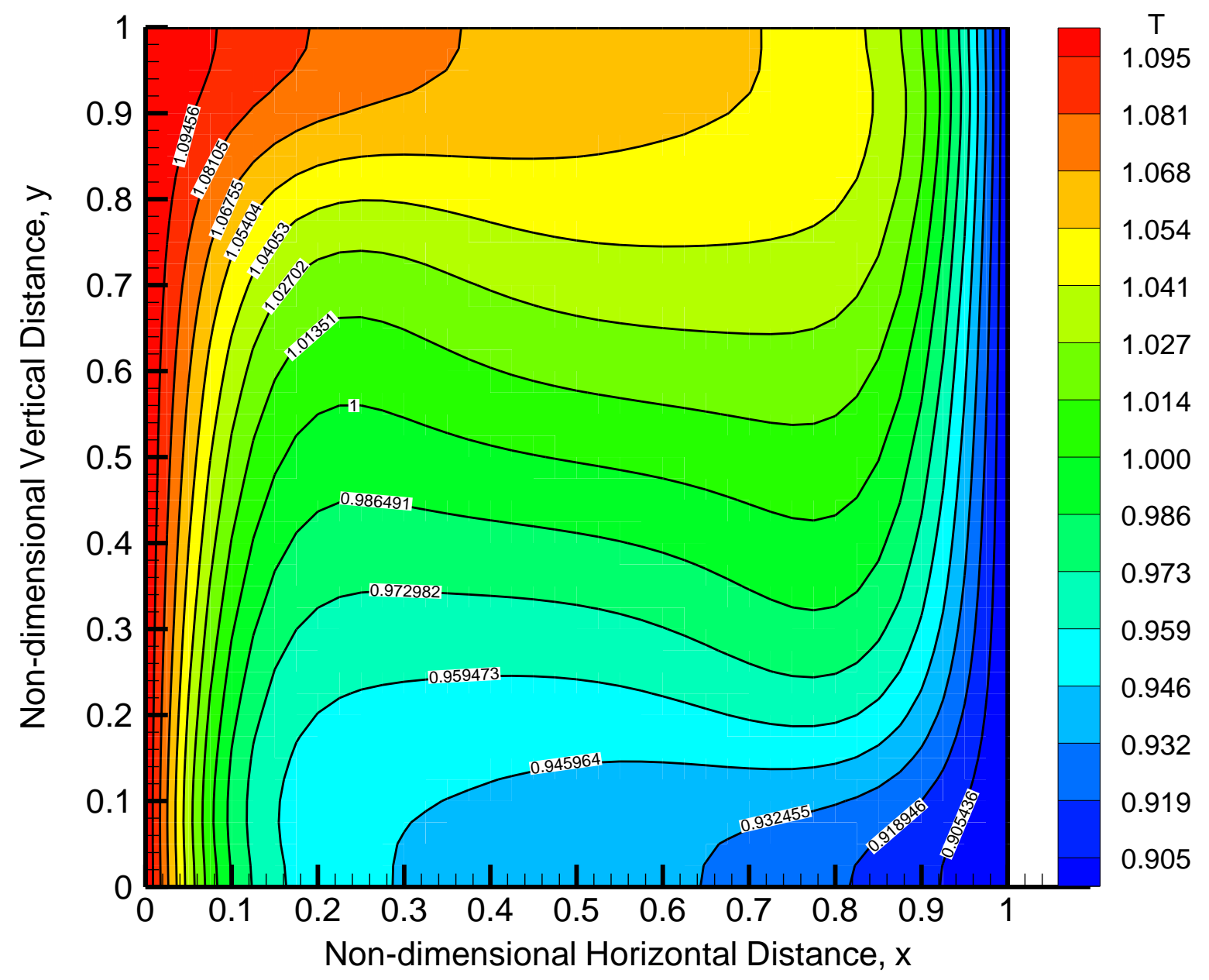

Figure 71- Unsteady State Non-dimensional Temperature Contours for $\mathrm{Ra}=10^{5}$ at Nondimensional Time, $\bar{t}=15$ (41 x 41, $\Delta \bar{t}=5.0 \mathrm{E}-6)$ in Second Order Time Accurate Approximation 


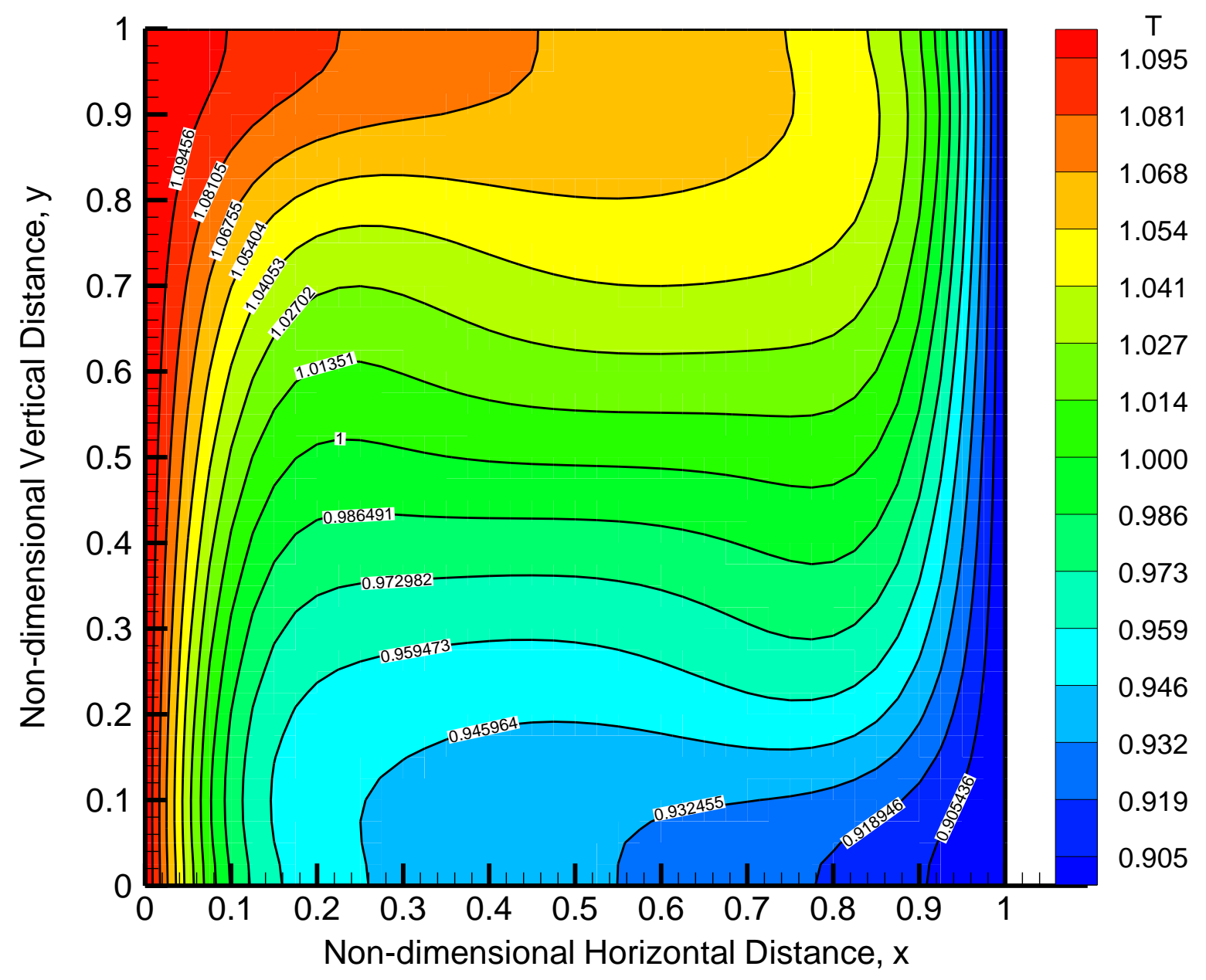

Figure 72- Unsteady State Non-dimensional Temperature Contours for $\mathrm{Ra}=10^{5}$ at Nondimensional Time, $\bar{t}=20$ (41 x 41, $\Delta \bar{t}=5.0 \mathrm{E}-6)$ in Second Order Time Accurate Approximation 


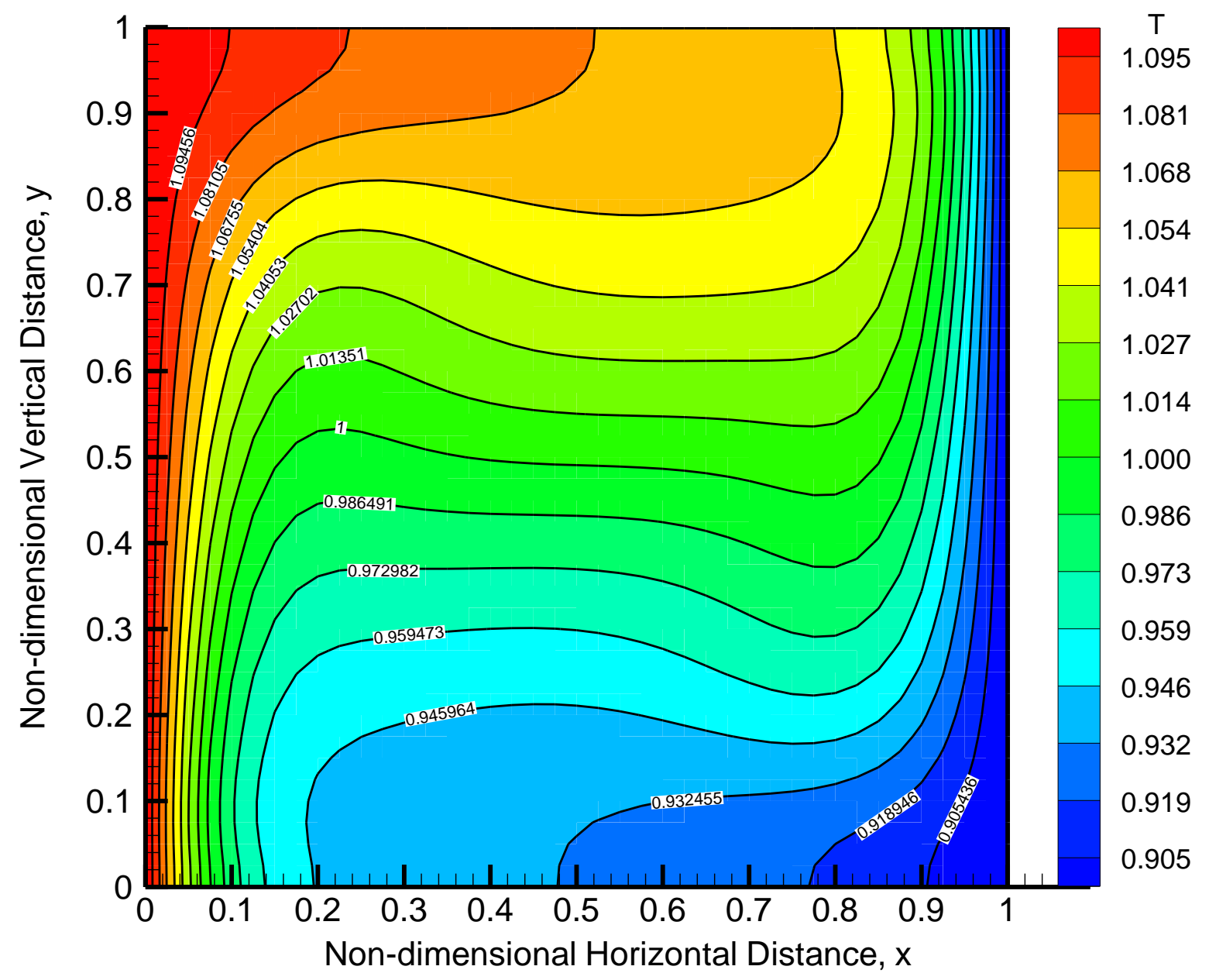

Figure 73- Unsteady State Non-dimensional Temperature Contours for $\mathrm{Ra}=10^{5}$ at Nondimensional Time, $\bar{t}=50$ (41 x 41, $\Delta \bar{t}=5.0 \mathrm{E}-6)$ in Second Order Time Accurate Approximation 


\section{Chapter 12}

\section{Calculations of Wall Heat Flux and Nusselt Number}

The calculations of heat flux at the walls of the enclosure (the high temperature wall in this case) and Nusselt number are presented in this chapter.

The rate of heat transfer is observed to be proportional to the temperature difference and is expressed by Newton's law of cooling as

$$
\dot{q}_{c o n v}=h\left(T_{w}-T_{\infty}\right)
$$

where $h$ is the heat transfer coefficient in $\mathrm{W} / \mathrm{m}^{2}-\mathrm{K}, T_{w}$ is temperature at hot wall side of the enclosure, and $T_{\infty}$ is the reference temperature.

The heat transfer from the solid surface to the fluid adjacent to the surface is by pure conduction can be expressed as

$$
\dot{q}_{\text {cond }}=-k\left(\frac{d T}{d x}\right)_{x=0}
$$

where $T$ is the temperature distribution in the fluid, $\left(\frac{d T}{d x}\right)_{x=0}$ is the temperature gradient at the surface of hot wall, and $k$ is thermal conductivity of the fluid in $\mathrm{W} / \mathrm{m}-\mathrm{K}$

Conduction heat flux from the solid surface to the fluid is equal to the convection heat flux to the fluid adjacent to surface, at $\mathrm{x}=0$. Therefore, equating equations 9.1 and 9.2 and solving for the heat transfer coefficient yields,

$$
h=\frac{-k\left(\frac{d T}{d x}\right)_{x=0}}{T_{w}-T_{\infty}}
$$


Non-dimensional heat transfer coefficient (or) Nusselt number is defined as,

$$
N u=\frac{h H}{k}
$$

The wall heat fluxes and Nu numbers for $\Delta T=64.8 \mathrm{deg} \mathrm{K}$ and $\Delta T=356.6 \mathrm{deg} \mathrm{K}$ at $\mathrm{Ra}=10^{5}$ were calculated from the temperature profiles (see Figures 74 through 77 ) near the high temperature wall as predicted by both models, the constant property and the variable property. The results of these calculations are presented in Table 33. 


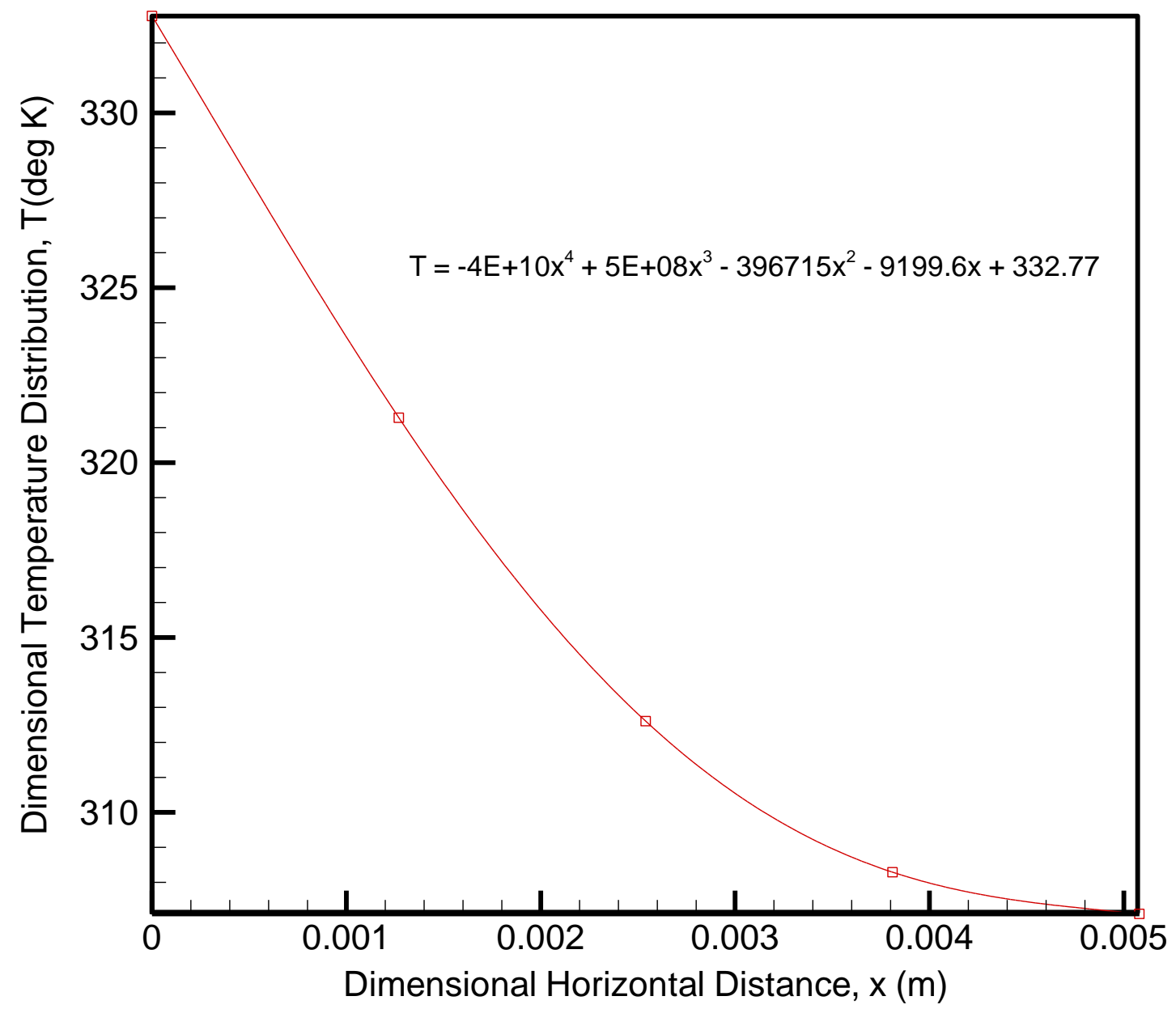

Figure 74- Dimensional Temperature Distribution along the Horizontal Distance for Constant Properties $(\Delta T=64.8 \mathrm{deg} \mathrm{K})$ 


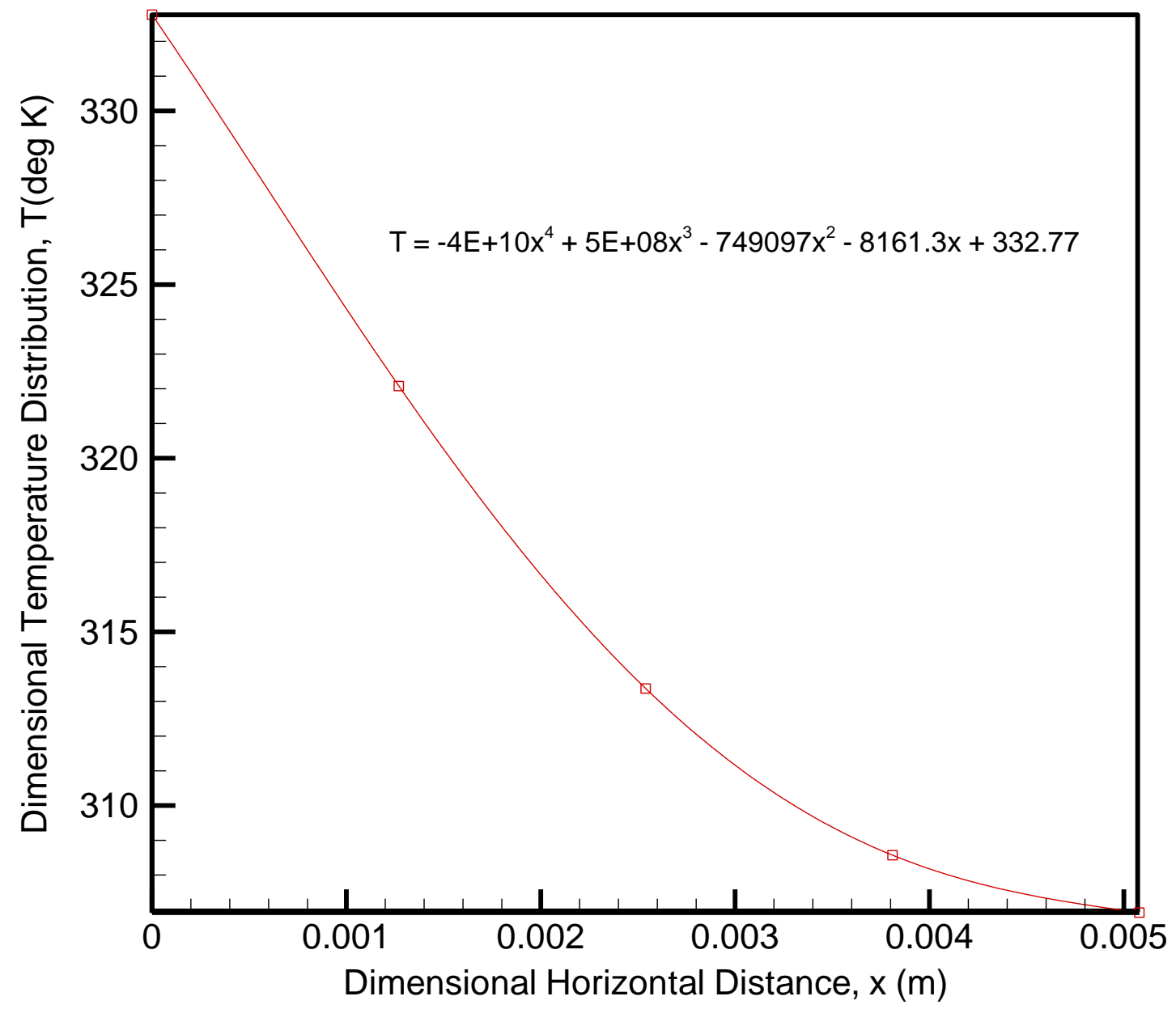

Figure 75- Dimensional Temperature Distribution along the Horizontal Distance for Variable Properties $(\Delta T=64.8 \mathrm{deg} \mathrm{K})$ 


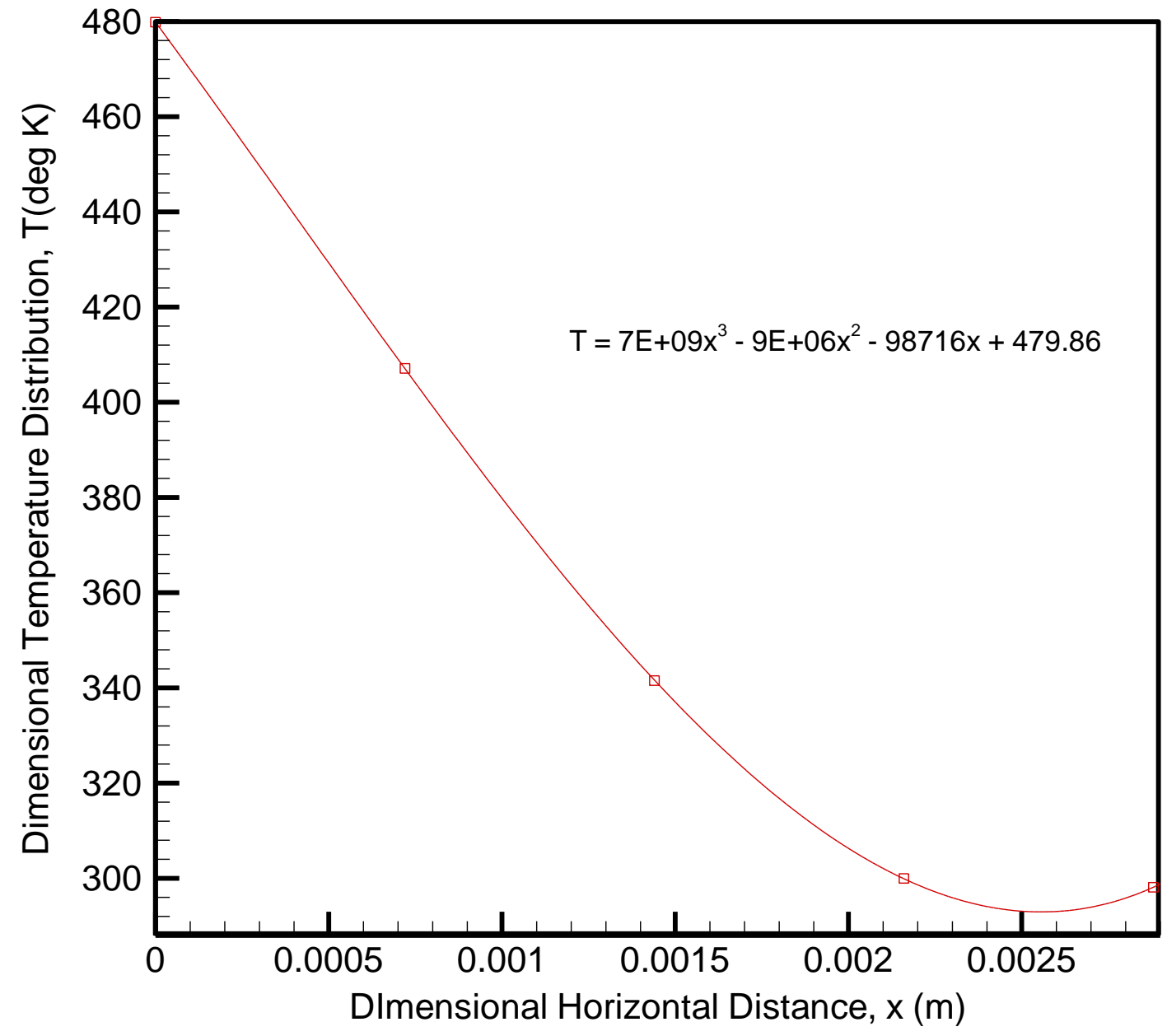

Figure 76- Dimensional Temperature Distribution along the Horizontal Distance for Constant Properties $(\Delta T=356.6 \mathrm{deg} \mathrm{K})$ 


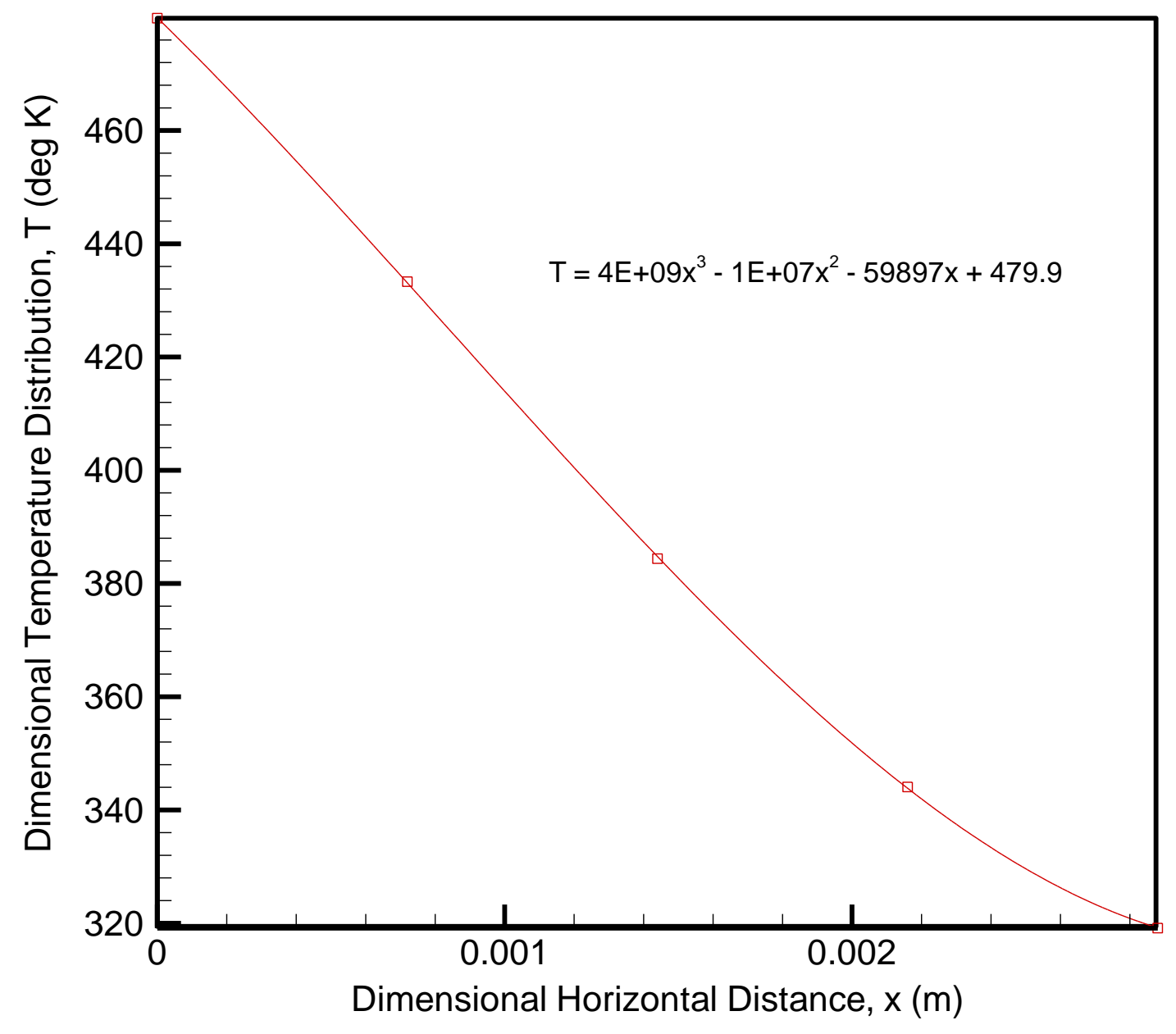

Figure 77- Dimensional Temperature Distribution along the Horizontal Distance for Variable Properties $(\triangle T=356.6 \mathrm{deg} \mathrm{K})$ 
Table 33 - Comparison of the Results of the Present Study (Variable properties) and Constant Properties for Different Wall Temperature differences at $\mathrm{Ra}=10^{5}$

\begin{tabular}{|c|c|c|c|}
\hline$\Delta T\left({ }^{0} K\right)$ & $\begin{array}{c}\text { Variable } \\
\text { Properties } \\
\dot{q}_{w}\left(\mathrm{~W} / \mathrm{m}^{2}\right)\end{array}$ & $\begin{array}{c}\text { Constant } \\
\text { Properties } \\
\dot{q}_{w}\left(\mathrm{~W} / \mathrm{m}^{2}\right)\end{array}$ & $\begin{array}{c}\% \\
\text { Deviation } \\
\text { in } \dot{q}_{w}\end{array}$ \\
\hline 64.8 & 234.23 & 264.03 & -12.80 \\
\hline 356.6 & 2180.00 & 3593.30 & -64.82 \\
\hline
\end{tabular}

\begin{tabular}{|c|c|c|c|}
\hline \multirow{2}{*}{$\Delta T\left({ }^{0} \mathrm{~K}\right)$} & $\begin{array}{c}\text { Variable } \\
\text { Properties } \\
\mathrm{Nu}\end{array}$ & $\begin{array}{c}\text { Constant } \\
\text { Properties } \\
\mathrm{Nu}\end{array}$ & $\begin{array}{c}\% \\
\text { Deviation } \\
\text { in } \mathrm{Nu}\end{array}$ \\
\hline 64.8 & 6.40 & 7.21 & -12.65 \\
\hline 356.6 & 4.83 & 7.97 & -65.02 \\
\hline
\end{tabular}

As shown in the above table, the variable property model predicts the wall heat flux and the $\mathrm{Nu}$ number values lower than the constant property model. The wall heat flux predicted by the variable property model deviates by $-12.8 \%$ from the values predicted by the variable property model for $\Delta T=64.8{ }^{0} \mathrm{~K}$. However, this difference is more for higher wall temperature differences. Similarly, the computed value of Nusselt number of the variable property model is $12.6 \%$ less than the corresponding value predicted by the constant property model, and this difference is high for higher wall temperature differences. 


\section{Chapter 13}

\section{Conclusions}

A numerical study of unsteady natural convection inside a square enclosure has been carried out to determine the effect of variable properties, i.e., thermodynamic and transport properties, on circulation patterns, velocity profiles in vertical and horizontal directions, and temperature characteristics for a fluid with Pr number 0.72 and a Ra number ranging from $10^{3}$ to $10^{6}$. The following conclusions are drawn from this study.

1. A newly updated Coupled Modified Strongly Implicit Procedure (CMSIP) was successfully employed to solve the governing equations of unsteady laminar natural convection inside an enclosure using a first order and a second order accurate in time finite difference approximations.

2. The results of the numerical study carried out using the mathematical model and solution procedure proposed in this thesis fair well when compared to the results of the benchmark case given in the literature.

3. There is a notable difference between the results of the variable property and the constant property models. The variable property model predicts the wall heat fluxes and the $\mathrm{Nu}$ number values lower than the constant property model.

4. The effect of variable properties on circulation patterns and velocity profiles is more pronounced for high Ra numbers when the temperature difference between the walls of the enclosure is high.

5. There is negligible difference between the results of the first order and second order accurate in time models. 
6. Transient development of circulation patterns and temperature isotherms were qualitatively comparable to those found in literature. 


\section{Chapter 14}

\section{Recommendations}

The following recommendations are made to improve the present model in simulating natural convection inside an enclosure with differentially heated side walls.

1. A finer mesh should be utilized to obtain more accurate results, especially at high Rayleigh numbers.

2. Due to the boundary layer nature of the flow for high Rayleigh numbers, a stretched grid should be incorporated near the walls of the enclosure to improve the accuracy of the predicted results.

3. Effects of different boundary conditions such as constant and variable heat flux should be considered.

4. A turbulence model k- $\varepsilon$ should be incorporated to study natural convection in the turbulent region, that is for $\mathrm{Ra}>10^{6}$.

5. Density should be considered as a primitive variable instead of pressure so that the model can be applied to any fluid (liquid or gas). 


\section{List of References}

1. S. Ostrach, 1988, "Natural Convection in Enclosures," ASME Journal of Heat Transfer, Vol.110, pp. 1175-1190.

2. G. de Vahl Davis., 1983, "Natural Convection of Air in a Square Cavity:

A Bench Mark Numerical Solution," International Journal for Numerical Methods in

Fluids, vol. 3, 249-264

3. G. de Vahl Davis and I.P. Jones, 1983, "Natural Convection in Square Cavity: a

Comparison Exercise," International Journal for Numerical Methods in Fluids, Vol.3, pp. 249-264.

4. S. Kimura and A. Bejan, 1984, "The Boundary Layer Natural Convection Regime in a Rectangular Cavity with Uniform Heat Flux from the Side," ASME Journal of Heat Transfer, Vol. 106, pp. 98-106.

5. T. H. Chen and L. Y. Chen, 2007, " Study of Buoyancy-Induced Flows Subjected to Partially Heated Sources on the Left and Bottom Walls in a Square Enclosure," International Journal of Thermal Sciences , Vol. 46, Issue 12, pp. 1219-1231

6. N. Nithyadevi, P. Kandaswamy and J. Lee, 2007, "Natural Convection in a Rectangular Cavity with Partially Active Side Walls," Int. Journal of Heat and Mass Transfer, Vol. 50, Issues 23-24, pp.4688-4697

7. D. E. Cormack, G. P. Stone, and L. G. Leal, 1975, "The Effect of Upper Surface Conditions in a Shallow Cavity with Differentially Heated End-Walls," Int. J. Heat and Mass Transfer, Vol. 18, pp.635-648

8. M. Sathiyamoorthy, T. Basak, S. Roy, and N. C. Mahanti, 2007, "Effect of the Temperature Difference Aspect Ratio on Natural Convection in a Square Cavity for Nonuniform Thermal Boundary Conditions," Journal of Heat Transfer, Vol.129, pp.17231728

9. B. Calcagni, F. Marsili, M. Paroncini, 2005, "Natural Convective Heat Transfer in Square Enclosures Heated from Below," Applied Thermal Engineering , Vol. 25, Issue 16, pp. 2522-2531

10. M. M. Ganzarolli and L. F. Milanez, 1995, "Natural Convection in Rectangular Enclosures Heated from Below and Symmetrically Cooled from the Sides," Int. J. of Heat and Mass Transfer, Vol. 38, Issue 6, pp. 1063-1073

11. Y. Le Peutrec and G. Lauriat, 1990, "Effects of the Heat Transfer at the Side Walls on Natural Convection in Cavities," Transactions of the ASME, Vol.112, pp. 370-378

12. V. C. Mariani, and A. da Silva, "Natural Convection: Analysis of Partially Open Enclosures with an Internal Heated Source," Numerical Heat Transfer, Part A: Applications, Vol. 52, Issue 7, pp.595-619

13. O. Aydin, A. Ünal, T. Ayhan, 1999, "Natural Convection in Rectangular Enclosures Heated from One Side and Cooled from the Ceiling," Int. J. of Heat and Mass Transfer, Vol. 42, Issue 13, pp. 2345-2355

14. T. Basak, S. Roy, and A. R. Balakrishnan, 2006, "Effects of Thermal Boundary Conditions on Natural Convection Flows within a Square Cavity," Int. J. of Heat and Mass Transfer, Vol. 49, pp. 4525-4535 
15. D. S. Lin and M. W. Nansteel, "Natural Convection Heat Transfer in a Square Enclosure Containing Water at its Density Maximum,” Int. J. Heat and Mass Transfer, Vol.30, No.11, pp. 2319-2328.

16. D. A. S. Rees and J. L. Lage, 1997, "The Effect of Thermal Stratification on Natural Convection in a Vertical Porous Insulation Layer, "Int. J. Heat and Mass Transfer, Vol.40, No.1, pp. 111-121.

17. R. Viskanta, D. M. Kim, and C. Gau, 1986, "Three dimensional Natural Convection Heat Transfer of a Liquid Metal in a Cavity," Int. Journal of Heat and Mass Transfer, Vol.29, No.3, pp.475-485.

18. W. J. Hiller, S. T. Koch, T. A. Kowalewski, G. de Vahl Davis, and M. Behnia, 1990, "Experimental and Numerical Investigation of Natural Convection in a Cube with TwoHeated Side Walls," Proceedings of IUTAM Symposium, Cambridge, England.

19. J. H. Moh, T. L. Bergman and D. C. Kuo, 1997, " Simulation of Two-Dimensional, Low- Prandtl Number Natural Convection in Harmonically Oscillated, Differentially Heated Enclosures," Numerical Heat Transfer, Part A: Applications, Vol. 31, Issue 1, pp. $1-19$

20. R. A. W. M. Henkes, F. F. Van Der Vlugt, and C. J. Hoogendoorn, 1991, "NaturalConvection Flow in a Square Cavity calculated with Low-Reynolds Number Turbulence Model," Int. J. of Heat and Mass transfer, Vol.34, no.2, pp. 377-388.

21. E. Evren-Selamet, V. S. Arpaci, and C. Borgnakke, 1992, "Simulation of Laminar Buoyancy-driven Flows in an Enclosure," Numerical Heat Transfer; Part A: Applications, Vol. 22, Issue 4, pp. 401-420

22. C. Xia and J. Y. Murthy, 2002, “Buoyancy-Driven Flow Transitions in Deep Cavities Heated from Below," Journal of Heat Transfer, Vol.124, Issue 4, pp. 650-659

23. Anil Kumar Sharma, K. Velusamy, and C. Balaji, 2007, "Turbulent Natural Convection in an Enclosure with Localized Heating from Below," International Journal of Thermal Sciences, Vol. 46, Issue 12 , pp.1232-1241

24. D. Elkaim, M. Reggio, and R. Camarero, 1992, "Simulating Two-dimensional Turbulent Flow by using the k- $\varepsilon$ Model and the Vorticity-Stream Function Formulation," International Journal for Numerical Methods in Fluids, Vol. 14, Issue 8, pp. 961-980

25. J. P. Coulter and S. I. Guceri, 1987, "Laminar and Turbulent Natural Convection within Irregularly Shaped Enclosures," Numerical Heat Transfer, Part A: Applications, Vol.12, Issue 2, pp. 211-227

26. C. J. Ho and F. J. Tu, 2001, “Visualization and Prediction of Natural Convection of Water Near its Density Maximum in a Tall Rectangular Enclosure at High Rayleigh Numbers," Journal of Heat Transfer, Vol.123 , Issue 1, pp. 84-95

27. K. M. Akyuzlu, Y. Pavri and A. Antoniou, 2004, “ A Numerical Study of Unsteady Natural Convection in Rectangular Enclosure - The Effect of Compressibility," Proceedings of IMECE'04, ASME International Mechanical Engineering Congress and Exposition

28. S. Mazumder, 2007, "On the Use of the Fully Compressible Navier-Stokes Equations for the Steady-State Solution of Natural Convection Problems in Closed Cavities," Journal of Heat Transfer, Vol.129, pp. 387-390

29. D. D. Gray and A. Giorgini, 1976, "The Validity of the Boussinesq Approximation for Liquids and Gases,” Int. J. of Heat and Mass Transfer, Vol.19, pp.545-551. 
30. M. V. Joshi, U. N. Gaitonde, and S. K. Mitra, 2006, "Analytical Study of Natural Convection in a Cavity With Volumetric Heat Generation," Transactions of the ASME, Vol.128, pp.176-182

31. R. Cai and N. Zhang, 2003, "Explicit Analytical Solutions of Incompressible Unsteady 2D Laminar Flow with Heat Transfer," Int. J. of Heat and Mass transfer, Vol. 46, pp. 931934

32. T. Fusegi, J. M. Hyun, and K. Kuwahara, 1992, "Numerical Study of Natural Convection in a Differentially Heated Cavity With Internal Heat Generation: Effects of the Aspect Ratio," Journal of Heat Transfer, Vol.114, pp.773-777

33. T. Fusegi, J. M. Hyun, K. Kuwahara, and B. Farouk, 1991, "A Numerical Study of Three-Dimensional Natural Convection in a Differentially Heated Cubical Enclosure," Int. J. of Heat and Mass Transfer, Vol.44, pp. 1543-1557.

34. S. Wakitani, 2001, "Numerical Study of Three-dimensional Oscillatory Natural Convection at Low Prandtl Number in Rectangular Enclosures," Journal of Heat Transfer, Vol.123, pp. 77- 83

35. G. de Vahl Davis, 1968, "Laminar Natural Convection in an Enclosed Rectangular Cavity," Int. J. Heat and Mass Transfer, Vol.11, pp. 1675-1693.

36. K. Kublbeck, G. P. Merker, and J. Straub, 1980, "Advanced Numerical Computation of Two-Dimensional Time-Dependent Free Convection in Cavities," Int. J. of Heat and Mass Transfer, Vol.23, pp. 203-217.

37. P. H. Oosthuizen and J. T. Paul, 2004, "Effect of Wall Thermal Boundary Conditions on the Development of Three-dimensional, Unsteady Natural Convective Flow in a Horizontal Enclosure with a Heated Strip on the Lower Surface," ASME, Heat Transfer Division, Vol. 375, Issue 3, Article No. IMECE2004-61381, pp. 173-180

38. S. Wakitani., 1997, "Development of Multicellular Solutions in Natural Convection in an Air-filled Vertical Cavity," Journal of Heat Transfer, Vol. 119. Pp. 97-

39. K. M. Akyuzlu, A. Antoniou, L. Manalo, and K. Nguyen., 2001, "A Numerical Study of the effect of Subcooling on Natural Convection in a Densified Cryogenic Propellant," Proceedings of the IMECE2001, Paper No. HT-2859, New York, New York.

40. V. F. Nicolette, K. T. Yang, and J. R. Lloyd, 1985, "Transient Cooling by Natural Convection in a Two-Dimensional Square Enclosure," Int. J. Heat and Mass Transfer, Vol. 28, No.9, pp. 1721-1731.

41. A. T. Kirkpatrick and M. Bohn, 1986, "An Experimental Investigation of Mixed Cavity Natural Convection in the high Rayleigh Number Regime," Int. Journal of Heat and Mass Transfer, Vol.29, No.1, pp. 69-82.

42. S. J. M. Linthorst, W. M. M. Schinkel, and C. J. Hoogendoorn, 1981, "Flow Structure with Natural Convection in Inclined Air-Filled Enclosures," ASME Journal of Heat Transfer, Vol.103, pp. 535-539.

43. F. Corvaro and M. Paroncini, 2009, "An Experimental Study of Natural Convection in a Differentially Heated Cavity Through a 2D-PIV System," Int. J. of Heat and Mass transfer, Vol. 52, pp. 355-365

44. F. Corvaro and M.Paroncini, 2007, "Experimental Aanalysis of Natural Convection in Square Cavities Heated from Below with 2D-PIV and Holographic Interferometry,"

45. J. L. Wright, H. Jin, K.G.T. Hollands, and D. Naylor, 2006, "Flow Visualization of Natural Convection in a Tall, Air-filled Vertical Cavity," Int. J. of Heat and Mass Transfer, Vol. 49, pp. 889-904 
46. P. W. Giel, and F. W. Schmidt, 1986, "Experimental Study of High Rayleigh Number Natural Convection in an Enclosure," Heat Transfer, Proceedings of the International Heat Transfer Conference, Vol. 4, pp. 1459-1464

47. F. Ampofo and T. G. Karayiannis, 2003, "Experimental Benchmark Data for Turbulent Natural Convection in an Air Filled Square Cavity,” Int. J. of Heat and Mass transfer, Vol. 46, pp. 3551-3572

48. K. M. Akyuzlu, S. Nemani, and K. Chakravarthy, 2003, "An Experimental Study of Circulation Patterns in Natural Convection Using PIV," Proceedings of IMECE2003, Washington, D.C.

49. E. Báez and A. Nicolás, 2006, " 2D Natural Convection Flows in Tilted Cavities: Porous Media and Homogeneous Fluids," Int. J. of Heat and Mass Transfer, Vol. 49, pp. 47734785

50. A. Dalal, M. K. Das, 2005, "Laminar Natural Convection in an Inclined Complicated Cavity with Spatially Variable Wall Temperature," Int. J. of Heat and Mass Transfer, Vol. 48, pp. 3833-3854

51. L. Adjlout, O. Imine, A. Azzi, and M. Belkadi, 2002, "Laminar Natural Convection in an Inclined Cavity with a Wavy Wall,” Int. J. of Heat and Mass Transfer, Vol. 45, pp. 2141-2152

52. M. De Souza, R. F. De Miranda, H. A. Machado, 2003, "Natural Convection in Enclosures with Variable Fluid Properties," International Journal of Numerical Methods for Heat and Fluid Flow, Vol. 13, Issue 8, pp. 1079-1096

53. M. A. Leal, H. A. Machado, R. M. Cotta, 2000, "Integral Transform Solutions of Transient Natural Convection in Enclosures with Variable Fluid Properties," Int. J. of Heat and Mass Transfer, Vol.43, pp. 3977-3990

54. Z. Y. Zhong, K. T. Yang, and J. R. Lloyd, 1985,"Variable Property Effects in Laminar Natural Convection in a Square Enclosure", Journal of Heat Transfer, Vol. 107, Issue 1, pp. $133-138$

55. A.F. Emery and J. W. Lee., 1999, "The Effects of Property Variations on Natural Convection in a Square Enclosure," Transactions of the ASME, Vol.121. pp.57-62

56. M. A. Waheed, 2006, " Temperature Dependent Fluid Properties Effects on the Heat Function Formulation of Natural Convective Flow and Heat Transfer," International Journal of Numerical Methods for Heat and Fluid Flow, Vol. 16, Issue 2, pp. 240-260

57. N. C. Markatos and K. A. Pericleous, 1984, "Laminar and Turbulent Natural Convection in an Enclosed Cavity,” Int. Journal of Heat and Mass Transfer, Vol. 27, pp. 755-772.

58. K. M. Akyuzlu, A. Antoniou, L. Manalo, and K. Nguyen., 2001, "A Numerical Study of the effect of Subcooling on Natural Convection in a Densified Cryogenic Propellant," Proceedings of the IMECE2001, Paper No. HT-2859, New York, New York.

59. L. Manalo, and K. M. Akyuzlu, 2003, "A Study of Unsteady Natural Convection in Cryogenic Storage Tanks for Densified Propellants," Proceedings of the ASME IMECE2003, Paper No.41810, Washington, D.C.

60. M. Zedan and G. E. Schneider, 1985, "A Coupled Strongly Implicit Procedure for Velocity and Pressure Computation in Fluid Flow Problems," Numerical Heat transfer, Vol.8, pp. $537-557$

61. K. H. Chen, 1990, “A Primitive Variable, Strongly Implicit Calculation Procedure for Two and Three-Dimensional Unsteady Viscous Flows Applications to Compressible and 
Incompressible Flows Including Flows with Free Surfaces," Ph.D. Dissertation, Iowa State University, Ames, IA.

62. K.M. Akyuzlu and A. Antoniou., 2004, "A physics based Comprehensive Mathematical Model to Predict Motor Performance in Hybrid Rocket Propulsion Systems,"

Proceedings of AIAA 2004 Joint Propulsion Conference.

63. A. Antoniou, 2004, "A Physics Based Comprehensive Mathematical Model to Predict Motor Performance in Hybrid Rocket Propulsion Systems," Ph.D. Dissertation, Department of Mechanical engineering, University of New Orleans.

64. Y. Pavri, 2004, "A Numerical Study of Unsteady Natural Convection of a Compressible Fluid Inside an Enclosed Cavity Using the Coupled Modified Strongly Implicit Method." M.S. Thesis, Department of Mechanical Engineering, University of New Orleans, New Orleans, Louisiana.

65. L. Manalo, A Numerical Study of Thermal Stratification Due to Transient Natural Convection in Densified Liquid Propellent Tanks, Ph. D. Dissertation, University of New Orleans, New Orleans, LA, 2003

66. U. Ghia, K. N. Ghia, and C. T. Shin, 1982, "High-Re Solutions for Incompressible Flow Using the Navier-Stokes Equations and a Multigrid Method," Journal of Computational Physics, Vol. 48, pp. 387-411

67. K. H. Chen, and R. H. Pletcher, 1991, "Primitive Variable, Strongly Implicit Calculation Procedure for Viscous Flows at All Speeds," AIAA Journal, Vol. 29, No. 8, pp. 1241-1249

68. G. H. Golub and C. F. Van Loan. 1983. Matrix Computations. Johns Hopkins University Press, Baltimore, Maryland.

69. Tannehill, J. C., Anderson, D. A., and Pletcher, R. H., 1984, Computational Fluid Mechanics and Heat Transfer, Second Edition, Hemisphere, New York.

70. Arpaci, V. S., and Laren, P. S., 1984, Convective Heat Transfer, Prentice-Hall, New Jersey.

71. Anderson, J. D. Jr., 1995, Computational Fluid Dynamics: The Basics with Applications, McGraw Hill, Inc., New York.

72. F, M. White., 1991, Viscous Fluid Flow, Second Edition, McGraw Hill, Inc., New York, pp. 27-30, Chap. 1.

73. Sonntag, R. E., Borgnakke, C., Van Wylen G. J., 1998, Fundamentals of Thermodynamics, Fifth Edition, John Wiley \& Sons, Inc., New York, pp. 113-117, Chap. 5.

74. Akyuzlu, K. M., 2009, "A Second Order Accurate in Time SIM Algorithm for Solution of Unsteady Compressible Navier-Stokes equations," submitted to SIAM Journal of Numerical Analysis.

75. Akyuzlu, K. M., Albayrak, K., and Karaeren, C., 2009, "A Numerical Study of Thermoacoustic Oscillations in a Rectangular Channel using CMSIP Method," Proceedings of IMECE2009, paper no 13109, Lake Buena Vista, Florida.

76. Akyuzlu, K. M., 2009, "Unsteady Driven Cavity Flow with Moving Boundaries using a Second Order Accurate in Time CMSIP Algorithm," submitted to International Journal for Numerical Methods in Fluids.

77. Akyuzlu, K. M., and Chidurala, M., 2009, “A Numerical Study of Unsteady Natural Convection in a Rectangular Enclosure - The Effect of Variable Thermodynamic and Transport Properties," Proceedings of IMECE 2009, paper no. 13005, Lake Buena Vista, Florida 
Appendices 


\section{Appendix I}

\section{Vector Form of Governing Differential Equations}

The continuity equation is given by:

$$
\frac{D \rho}{D t}+\rho(\vec{\nabla} \cdot \vec{V})=0
$$

The momentum equations are given by:

$$
\rho \frac{D \vec{V}}{D t}=\rho \vec{g}-\vec{\nabla} p+\frac{\partial}{\partial x_{j}}\left[\mu\left(\frac{\partial u_{i}}{\partial x_{j}}+\frac{\partial u_{j}}{\partial x_{i}}\right)-\frac{2}{3} \delta_{i, j} \frac{\partial u_{k}}{\partial x_{k}}\right]
$$

where

$$
\delta_{i, j}=\left\{\begin{array}{lll}
1 & \text { if } & i=j \\
0 & \text { if } & i \neq j
\end{array}\right\}
$$

The energy equation is given by:

$$
\rho \frac{\partial E_{t}}{\partial t}+\vec{\nabla} \cdot E_{t} \vec{V}=\frac{\partial Q}{\partial t}-\vec{\nabla} \cdot \vec{q}+\rho \vec{f} \cdot \vec{V}+\vec{\nabla} \cdot\left(\vec{\Pi}_{i, j} \cdot \vec{V}\right)
$$

where total energy, $E_{t}$,

$$
E_{t}=\rho\left(e+\frac{V^{2}}{2}+P E+\ldots\right)
$$

and the stress tensor,

$$
\vec{\Pi}_{i, j}=-p \delta_{i, j}+\mu\left[\left(\frac{\partial u_{i}}{\partial x_{j}}+\frac{\partial u_{j}}{\partial x_{i}}\right)-\frac{2}{3} \delta_{i, j} \frac{\partial u_{k}}{\partial x_{k}}\right] \quad \text { where i, j, k =1, 2, 3 }
$$

The heat transfer by conduction in Eq. I.3 is

$$
\vec{q}=k \vec{\nabla} T
$$


Equation of state for ideal gas is given by:

$$
p=\rho R T
$$




\section{Appendix II}

\section{Dimensional Form of Governing Differential Equations}

\section{(A. Conservative Form)}

The continuity equation is given by:

$$
\frac{\partial \rho}{\partial t}+\frac{\partial}{\partial x}(\rho u)+\frac{\partial}{\partial y}(\rho v)=0
$$

The momentum equation in the $\mathrm{x}$-direction is given by:

$$
\begin{aligned}
& \frac{\partial}{\partial t}(\rho u)+\frac{\partial}{\partial x}\left(\rho u^{2}\right)+\frac{\partial}{\partial y}(\rho u v)+\frac{\partial p}{\partial x}-\frac{\partial}{\partial x}[\left.\frac{2}{3} \mu\left(2 \frac{\partial u}{\partial x}-\frac{\partial v}{\partial y}\right)\right] \\
&-\frac{\partial}{\partial y}\left[\mu\left(\frac{\partial u}{\partial y}+\frac{\partial v}{\partial x}\right)\right]+\rho g \sin \theta=0
\end{aligned}
$$

The momentum equation in the y-direction is given by:

$$
\begin{aligned}
\frac{\partial}{\partial t}(\rho v)+\frac{\partial}{\partial x}(\rho u v) & +\frac{\partial}{\partial y}\left(\rho v^{2}\right)+\frac{\partial p}{\partial y} \\
& -\frac{\partial}{\partial x}\left[\mu\left(\frac{\partial u}{\partial y}+\frac{\partial v}{\partial x}\right)\right]-\frac{\partial}{\partial y}\left[\frac{2}{3} \mu\left(2 \frac{\partial v}{\partial y}-\frac{\partial u}{\partial x}\right)\right]+\rho g \cos \theta=0
\end{aligned}
$$

The energy equation is given by:

$$
\begin{aligned}
\frac{\partial}{\partial t}\left(\rho c_{p} T\right)+\frac{\partial}{\partial x}\left(\rho c_{p} T u\right) & +\frac{\partial}{\partial y}\left(\rho c_{p} T v\right) \\
& -\frac{\partial}{\partial x}\left(k \frac{\partial T}{\partial x}\right)-\frac{\partial}{\partial y}\left(k \frac{\partial T}{\partial y}\right)=0
\end{aligned}
$$




\title{
Appendix II
}

\section{Dimensional Form of Governing Differential Equations}

\author{
(B. Using in terms of Primitive Variables $u, v, p, T$ )
}

The continuity equation is given by:

$$
\frac{\partial}{\partial t}\left(\frac{p}{T}\right)+\frac{\partial}{\partial x}\left(\frac{p u}{T}\right)+\frac{\partial}{\partial y}\left(\frac{p v}{T}\right)=0
$$

The momentum equation in the $\mathrm{x}$-direction is given by:

$$
\begin{aligned}
& \frac{\partial}{\partial t}\left(\frac{p u}{T}\right)+\frac{\partial}{\partial x}\left(\frac{p u u}{T}\right)+\frac{\partial}{\partial y}\left(\frac{p u v}{T}\right)+\frac{\partial(R p)}{\partial x}-\frac{\partial}{\partial x}\left[\frac{2}{3} R \mu\left(2 \frac{\partial u}{\partial x}-\frac{\partial v}{\partial y}\right)\right] \\
&-\frac{\partial}{\partial y}\left[R \mu\left(\frac{\partial u}{\partial y}+\frac{\partial v}{\partial x}\right)\right]+\left(\frac{p}{T}\right) g \sin \theta=0
\end{aligned}
$$

The momentum equation in the y-direction is given by:

$$
\begin{aligned}
\frac{\partial}{\partial t}\left(\frac{p v}{T}\right)+\frac{\partial}{\partial x}\left(\frac{p u v}{T}\right) & +\frac{\partial}{\partial y}\left(\frac{p v v}{T}\right)+\frac{\partial(R p)}{\partial y} \\
& -\frac{\partial}{\partial x}\left[R \mu\left(\frac{\partial u}{\partial y}+\frac{\partial v}{\partial x}\right)\right]-\frac{\partial}{\partial y}\left[\frac{2}{3} R \mu\left(2 \frac{\partial v}{\partial y}-\frac{\partial u}{\partial x}\right)\right]+\left(\frac{p}{T}\right) g \cos \theta=0
\end{aligned}
$$

The energy equation is given by:

$$
\frac{\partial}{\partial t}\left(c_{p} p\right)+\frac{\partial}{\partial x}\left(c_{p} p u\right)+\frac{\partial}{\partial y}\left(c_{p} p v\right)-\frac{\partial}{\partial x}\left(R k \frac{\partial T}{\partial x}\right)-\frac{\partial}{\partial y}\left(R k \frac{\partial T}{\partial y}\right)=0
$$




\section{Appendix III}

\section{Sub Models of Thermodynamic and Transport Properties}

\section{Variable Specific Heat at Constant Pressure $\left(C_{p}(T)\right)$}

Constant-volume and constant-pressure specifics heats are assumed to be functions of temperature. That is,

$$
\mathrm{C}_{\mathrm{v}}=\mathrm{f}(\mathrm{T}) \text { and } \mathrm{C}_{\mathrm{p}}=\mathrm{f}(\mathrm{T})
$$

because all gases approach ideal-gas behavior as the pressure approaches zero.

The specific heat at constant pressure function of temperature for an ideal gas, $C_{p 0}$ can be given as (refer to Sonntag, Engineering Thermodynamics)

$$
C_{p 0}=C_{0}+C_{1} \phi+C_{2} \phi^{2}+C_{3} \phi^{3} \quad \mathrm{KJ} / \mathrm{Kg} \mathrm{K}
$$

where

$$
\phi=\frac{T}{1000}
$$

For Air, values of constants in the above equation are as follows

$$
C_{0}=1.05, C_{1}=-0.365, C_{2}=0.85, C_{3}=-0.39
$$

This approximate form can be valid from $250 \mathrm{~K}$ to $1200 \mathrm{~K}$

\section{Variable Viscosity $(\mu(T))$}

A widely used approximation resulted from a kinetic theory by Sutherland (1893) using an idealized intermolecular-force potential. The formula is (refer to Frank M. White, Viscous Flow)

$$
\frac{\mu}{\mu_{0}}=\left(\frac{T}{T_{0}}\right)^{3 / 2} \frac{T_{0}+S}{T+S}
$$


where
$\mu$ is the Viscosity, N.s/m $\mathrm{m}^{2}$
$\mu_{0}$ is the Reference value, N.s $/ \mathrm{m}^{2}$
$T$ is the Absolute Temperature, $\mathrm{K}$
$T_{0}$ is the Reference Value, $\mathrm{K}$ and
$S$ is the Sutherland Constant, which is characteristic of the gas, K

For Air, Values of constants in the above equation are as follows

$$
\begin{aligned}
& \mu_{0}=1.716 \times 10^{-5} \mathrm{~N} \cdot \mathrm{s} / \mathrm{m}^{2} \\
& T_{0}=273 \mathrm{~K} \\
& S=111 \mathrm{~K}
\end{aligned}
$$




\section{Appendix IV}

\section{Non-Dimensional Form of Governing Differential Equations}

Continuity Equation

$$
\frac{\partial}{\partial \bar{t}}\left(\frac{\bar{p}}{\bar{T}}\right)+\frac{\partial}{\partial \bar{x}}\left(\frac{\bar{p} \bar{u}}{\bar{T}}\right)+\frac{\partial}{\partial \bar{y}}\left(\frac{\bar{p} \bar{v}}{\bar{T}}\right)=0
$$

Momentum equation in $\mathrm{x}$-direction

$$
\begin{aligned}
\frac{\partial}{\partial \bar{t}}\left(\frac{\bar{p} \bar{u}}{\bar{T}}\right)+\frac{\partial}{\partial \bar{x}}\left(\frac{\bar{p} \bar{u} \bar{u}}{\bar{T}}\right) & +\frac{\partial}{\partial \bar{y}}\left(\frac{\bar{p} \bar{u} \bar{v}}{\bar{T}}\right)+\frac{\partial}{\partial \bar{x}}(\bar{R} \bar{p}) \\
& +\frac{1}{G r^{1 / 2}} \frac{\partial}{\partial \bar{x}}\left[\frac{2}{3} \bar{R} \bar{\mu}\left(2 \frac{\partial \bar{u}}{\partial \bar{x}}-\frac{\partial \bar{v}}{\partial \bar{y}}\right)\right]-\frac{1}{G r^{1 / 2}} \frac{\partial}{\partial y}\left[\bar{R} \bar{\mu}\left(\frac{\partial \bar{u}}{\partial \bar{y}}+\frac{\partial \bar{v}}{\partial \bar{x}}\right)\right]+\frac{1}{F r}\left(\frac{\bar{p}}{\bar{T}}\right) \sin \theta=0
\end{aligned}
$$

Momentum equation in $\mathrm{y}$-direction

$$
\begin{aligned}
\frac{\partial}{\partial \bar{t}}\left(\frac{\bar{p} \bar{v}}{\bar{T}}\right)+\frac{\partial}{\partial \bar{x}}\left(\frac{\bar{p} \bar{u} \bar{v}}{\bar{T}}\right)+\frac{\partial}{\partial \bar{y}}\left(\frac{\bar{p} \bar{v} \bar{v}}{\bar{T}}\right)+\frac{\partial}{\partial \bar{y}}(\bar{R} \bar{p}) \\
\quad-\frac{1}{G r^{1 / 2}} \frac{\partial}{\partial \bar{x}}\left[\bar{R} \bar{\mu}\left(\frac{\partial \bar{v}}{\partial \bar{x}}+\frac{\partial \bar{u}}{\partial \bar{y}}\right)\right]-\frac{1}{G r^{1 / 2}} \frac{\partial}{\partial \bar{y}}\left[\frac{2}{3} \bar{R} \bar{\mu}\left(2 \frac{\partial \bar{v}}{\partial \bar{y}}-\frac{\partial \bar{u}}{\partial \bar{x}}\right)\right]+\frac{1}{F r}\left(\frac{\bar{p}}{\bar{T}}\right) \cos \theta \quad=0
\end{aligned}
$$


Energy equation

$$
\begin{aligned}
\frac{\partial}{\partial \bar{t}}\left(\bar{c}_{p} \bar{p}\right)+\frac{\partial}{\partial \bar{x}}\left(\bar{c}_{p} \bar{p} \bar{u}\right)+\frac{\partial}{\partial \bar{y}}\left(\bar{c}_{p} \bar{p} \bar{v}\right) & -\frac{1}{\operatorname{Pr} G r^{1 / 2}} \frac{\partial}{\partial \bar{x}}\left(\bar{R} \bar{c}_{p} \bar{\mu} \frac{\partial \bar{T}}{\partial \bar{x}}\right) \\
& -\frac{1}{\operatorname{Pr} G r^{1 / 2}} \frac{\partial}{\partial \bar{y}}\left(\bar{R} \bar{c}_{p} \bar{\mu} \frac{\partial \bar{T}}{\partial \bar{y}}\right)=0
\end{aligned}
$$




\section{Appendix V}

\section{Formula to Calculate the Lower [L] and Upper [U] Matrices for CMSIP Method}

The lower and upper diagonal matrices [L], and [U] have the following form

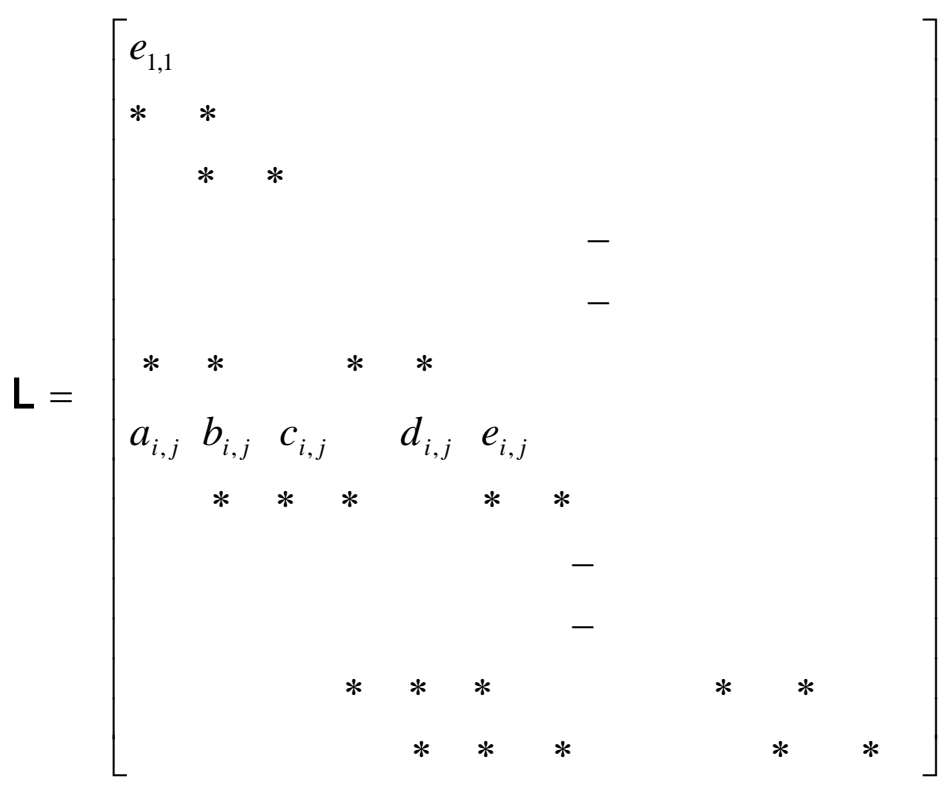




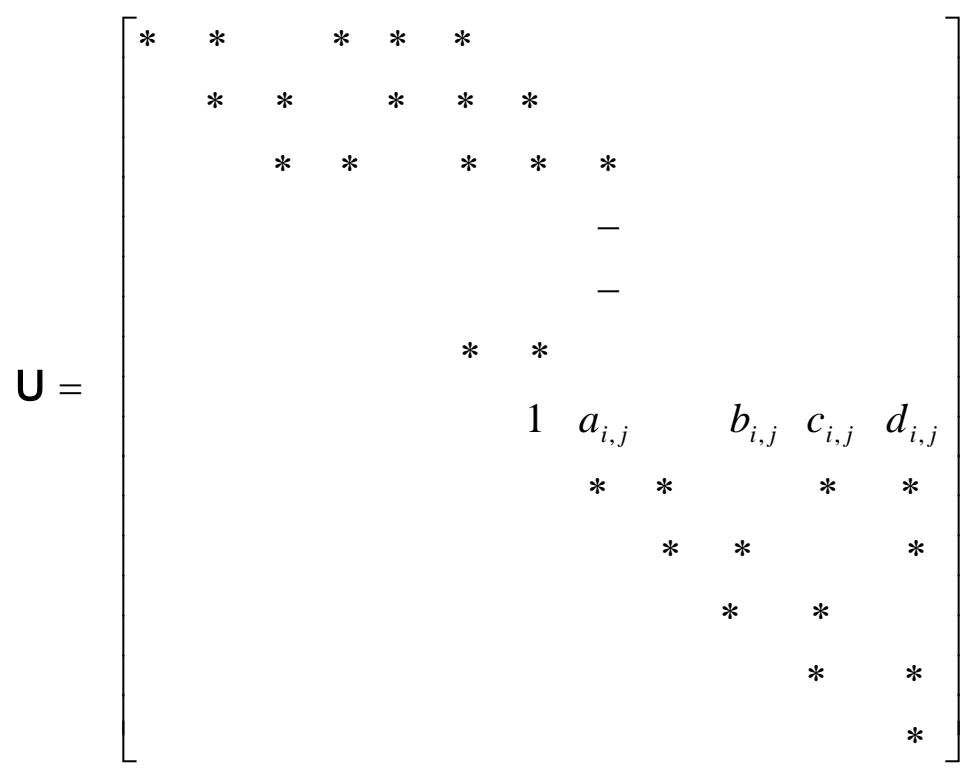

The elements of these matrices are calculated using the following formulas:

$$
\begin{gathered}
a_{i, j}=A_{i, j}^{6} \\
b_{i, j}=\left(A_{i, j}^{5}-a_{i, j} f_{i-1, j-1}-\alpha A_{i, j}^{4} f_{i+1, j-1}\right)\left(1-\alpha f_{i, j-1} f_{i+1, j-1}\right)^{-1} \\
c_{i, j}=A_{i, j}^{4}-b_{i, j} f_{i, j-1} \\
d_{i, j}=\left(A_{i, j}^{7}-a_{i, j} h_{i-1, j-1}-b_{i, j} g_{i, j-1}-2 \alpha a_{i, j} g_{i-1, j}\right) \quad\left(1+\alpha g_{i-1, j}\right)^{-1} \\
e_{i, j}=\left(A_{i, j}^{9}-a_{i, j} h_{i-1, j-1}-b_{i, j} g_{i, j-1}-2 \alpha a_{i, j} g_{i-1, j}-d_{i, j} f_{i-1, j}\right) \\
+\alpha\left(2 \varphi_{i, j}^{1}+\varphi_{i, j}^{2}+\varphi_{i, j}^{3}+2 \varphi_{i, j}^{4}\right) \\
f_{i, j}=\left(e_{i, j}\right)^{-1}\left(A_{i, j}^{3}-b_{i, j} s_{i, j-1}-c_{i, j} h_{i+1, j-1}-2 \alpha\left(\varphi_{i, j}^{1}+\varphi_{i, j}^{3}\right)\right) \\
g_{i, j}=\left(e_{i, j}\right)^{-1}\left(A_{i, j}^{3}-b_{i, j} s_{i, j-1}-c_{i, j} h_{i+1, j-1}-2 \alpha\left(\varphi_{i, j}^{1}+\varphi_{i, j}^{3}\right)\right) \\
\left.g_{i, j}\right)^{-1}\left(A_{i, j}^{8}-d_{i, j} h_{i-1, j}\right)
\end{gathered}
$$




$$
\begin{gathered}
h_{i, j}=\left(e_{i, j}\right)^{-1}\left(A_{i, j}^{1}-d_{i, j} s_{i-1, j}-\alpha \varphi_{i, j}^{4}\right) \\
s_{i, j}=\left(e_{i, j}\right)^{-1}\left(A_{i, j}^{2}\right)
\end{gathered}
$$

where

$$
\begin{gathered}
\varphi_{i, j}^{1}=c_{i, j} f_{i+1, j-1} \\
\varphi_{i, j}^{2}=a_{i, j} g_{i-1, j-1} \\
\varphi_{i, j}^{3}=c_{i, j} s_{i+1, j-1} \\
\varphi_{i, j}^{4}=d_{i, j} g_{i-1, j}
\end{gathered}
$$




\section{Appendix VI}

\section{Flow Chart for the Computer Program}

\section{(A. First Order Accurate in Time Model)}

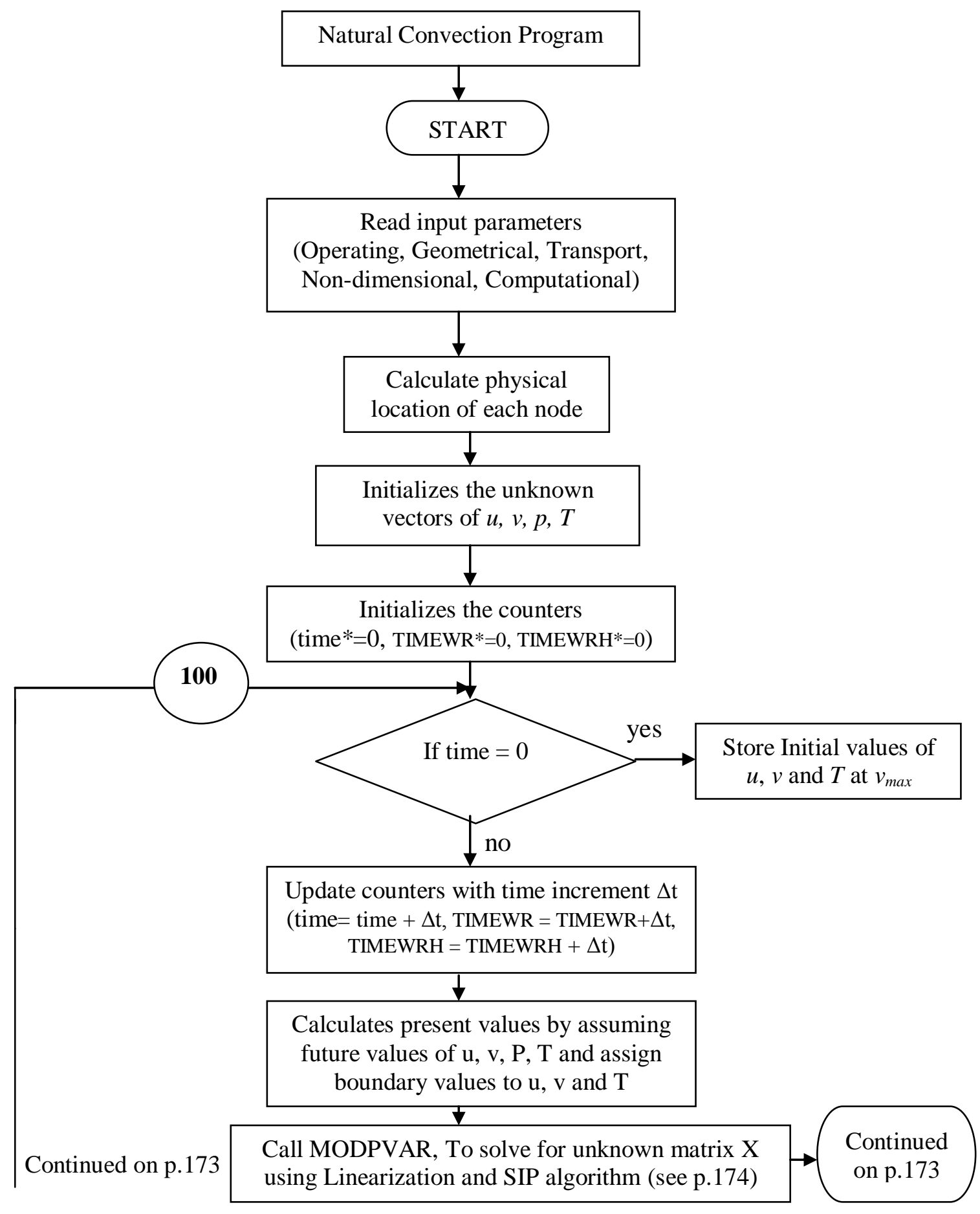




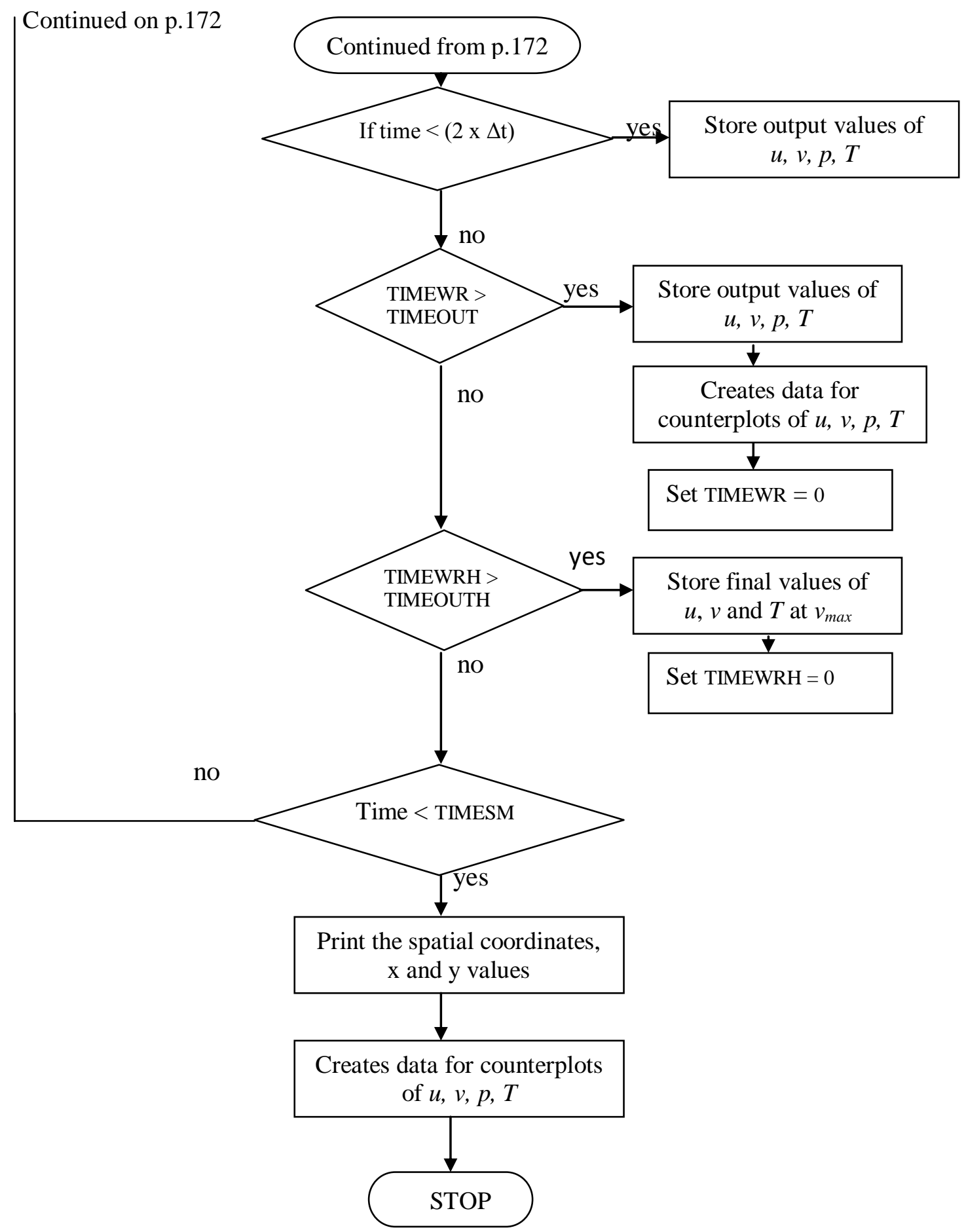




\section{MODPVAR}

(Subroutine for Modification of Primitive Variables using Linearization Iteration)

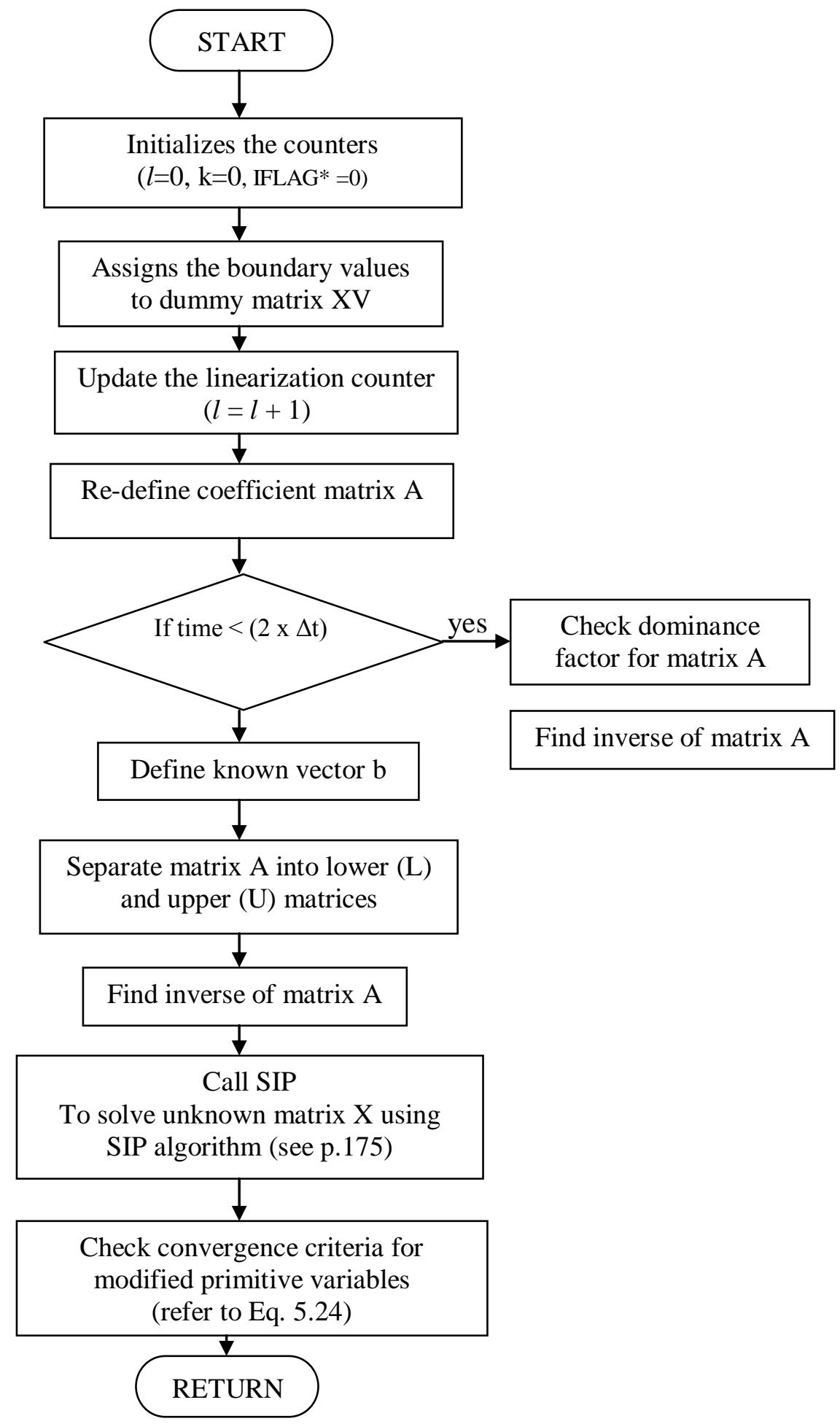




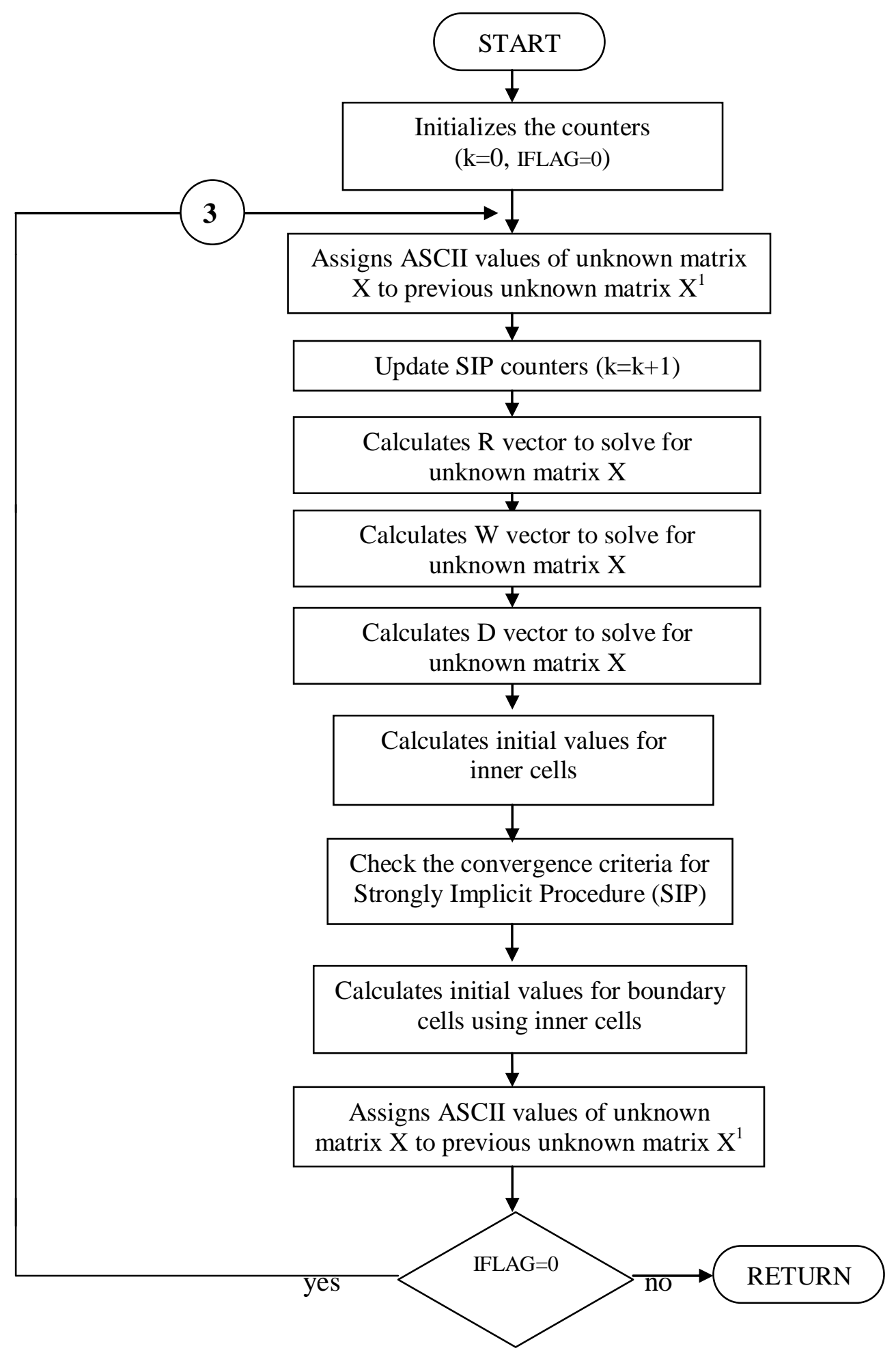


* List of Program Variables used in the Flow Chart

Time - Non-dimensional time

TIMESH - Total time of simulation

TIMEOUT - Time interval for prints

TIMEOUTH - Time interval for histograms

IFLAG - Conditional counter

TIMEWR - Time to write ASCII values of output primitive variables

TIMEWRH - Time to write ASCII values of output primitive variables as histogram data 


\section{Appendix VI}

\section{Flow Chart for the Computer Program}

\section{(B. Second Order Accurate in Time Model)}

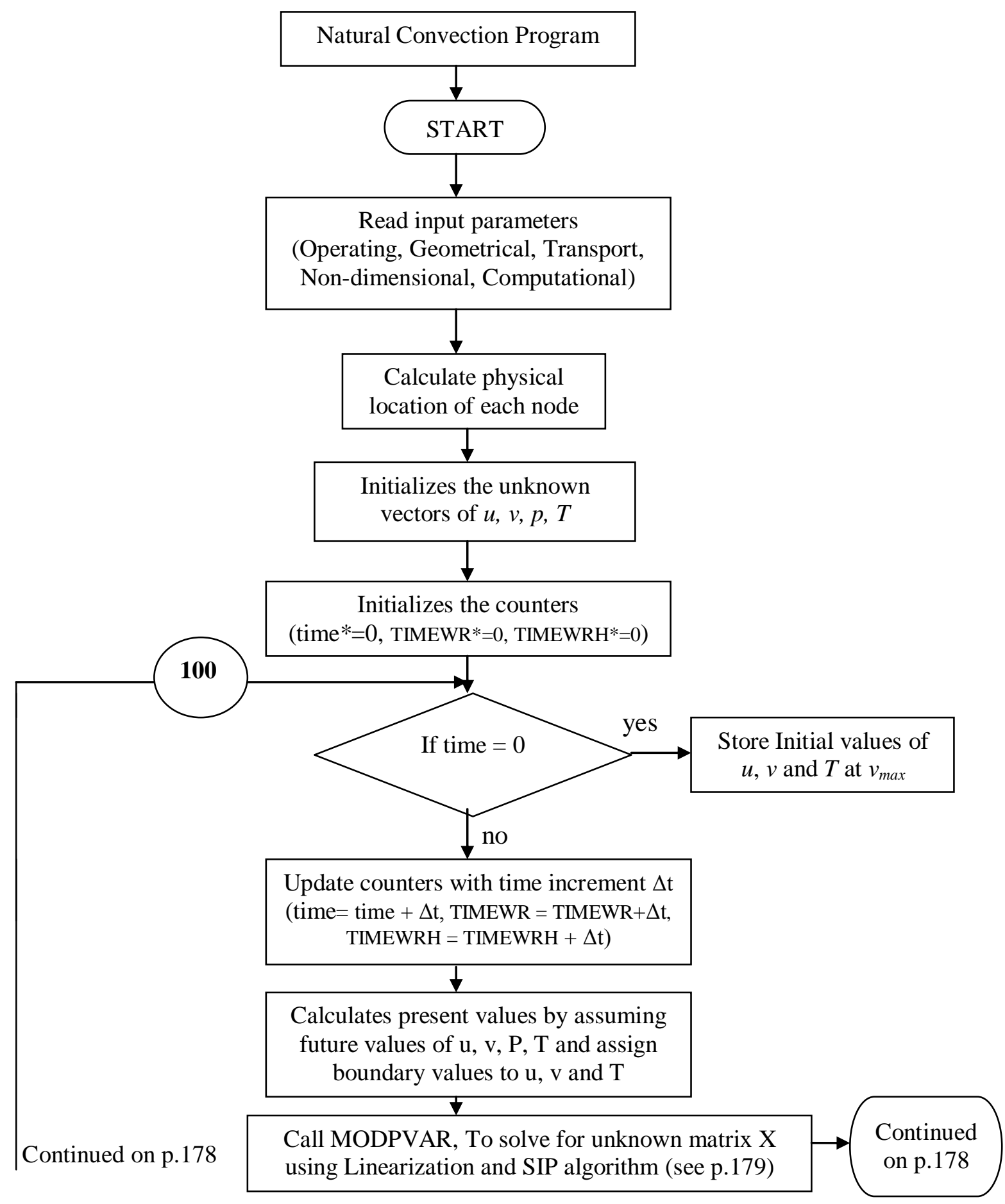




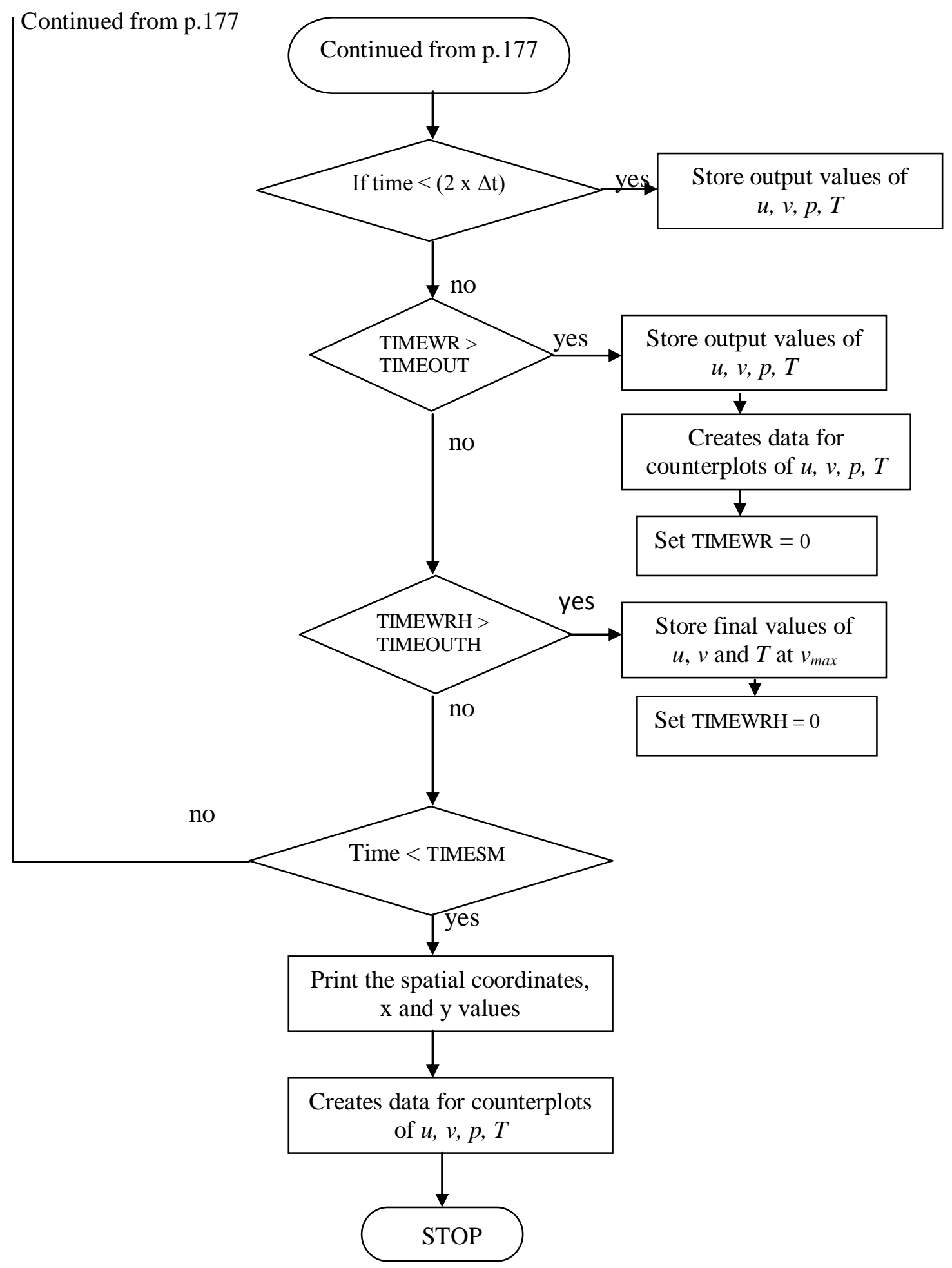




\section{MODPVAR}

(Subroutine for Modification of Primitive Variables using Linearization Iteration)

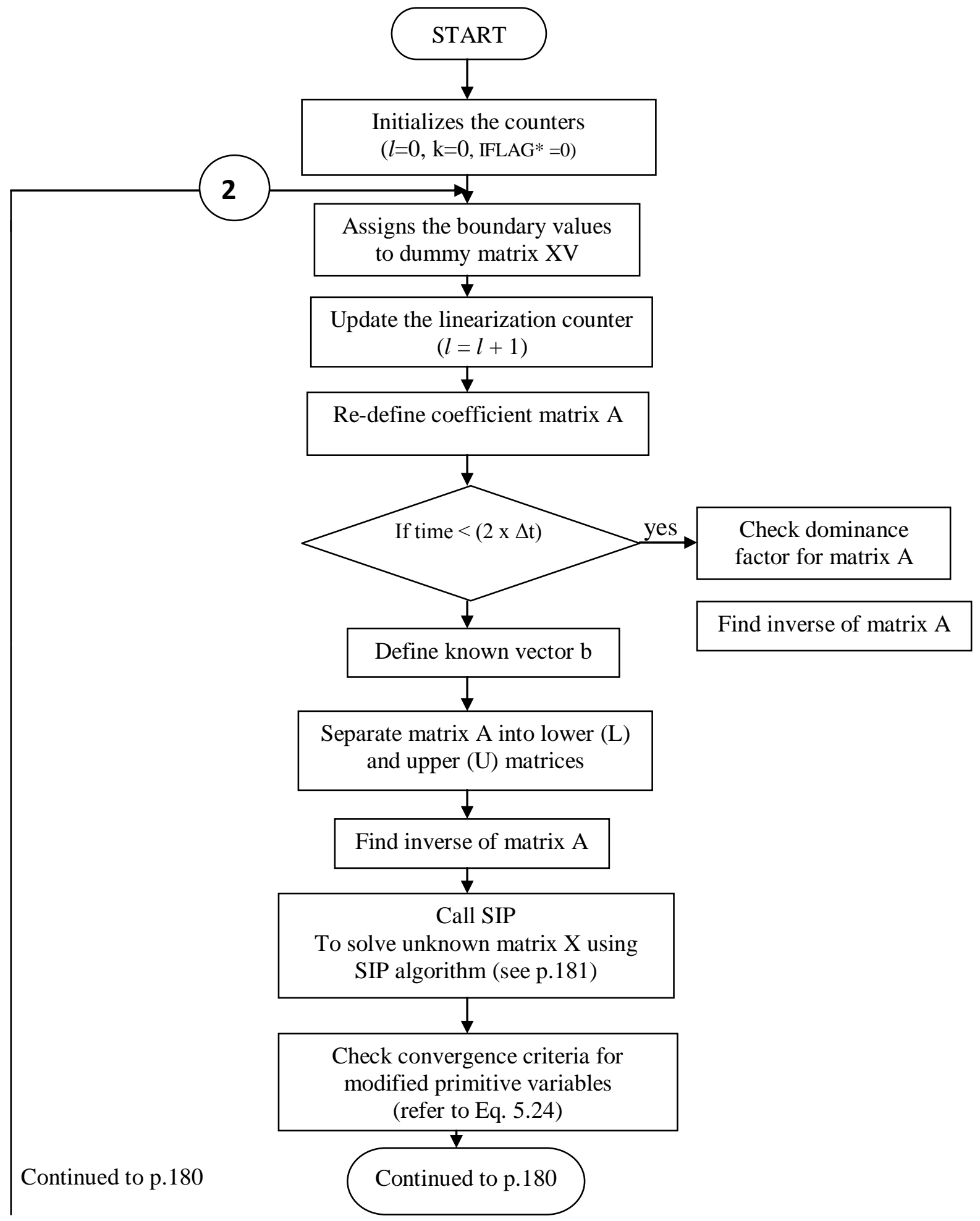




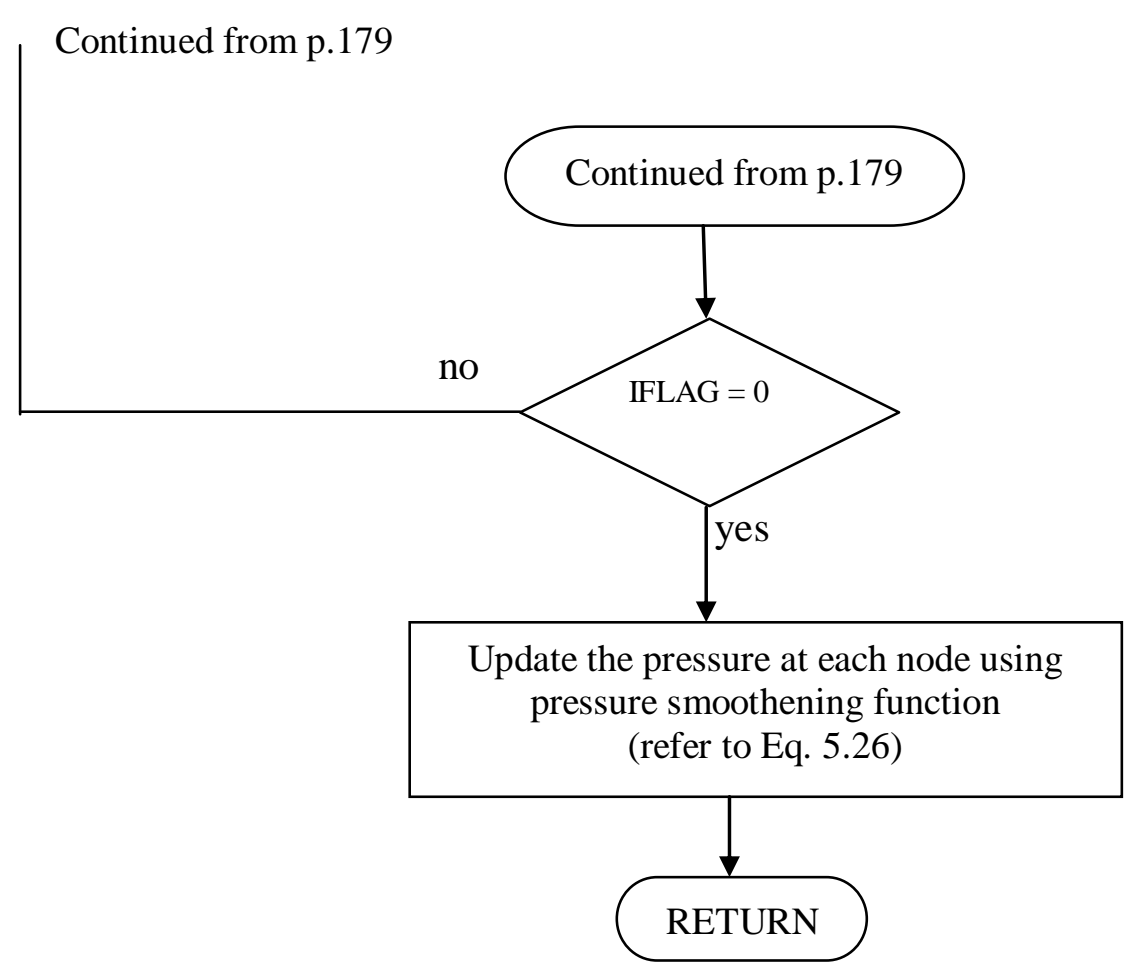




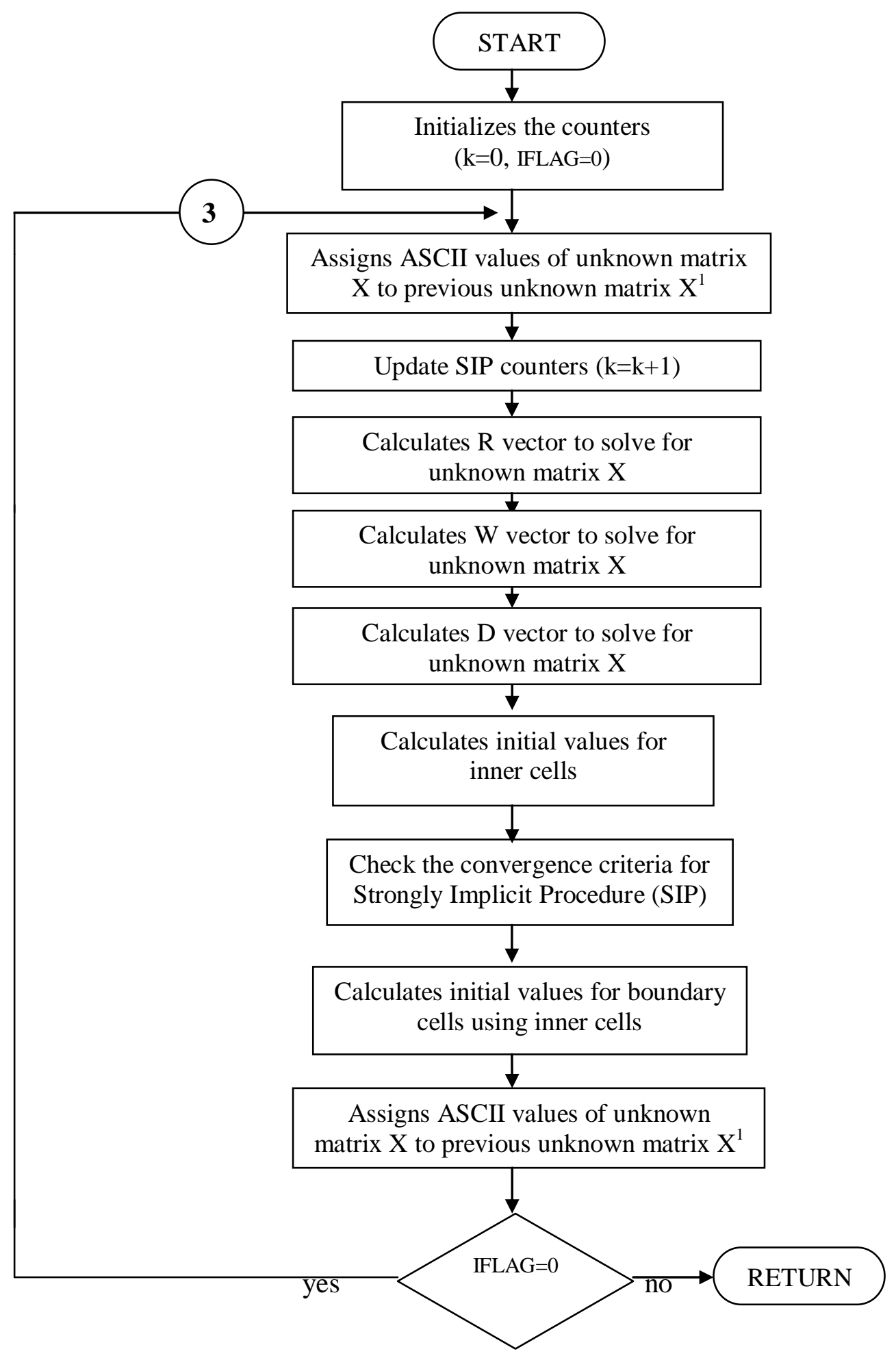


* List of Program Variables used in the Flow Chart

Time - Non-dimensional time

TIMESH - Total time of simulation

TIMEOUT - Time interval for prints

TIMEOUTH - Time interval for histograms

IFLAG - Conditional counter

TIMEWR - Time to write ASCII values of output primitive variables

TIMEWRH - Time to write ASCII values of output primitive variables as histogram data 


\section{Appendix VII}

\section{Program Parameters - Common to all Runs}

List of program Parameters used in the Computer Program that are common to all runs:

$$
\begin{aligned}
& A R=1 \\
& g=9.81 \mathrm{~m} / \mathrm{s}^{2} \\
& \alpha=2.21 \times 10^{5} \mathrm{~m} / \mathrm{s}^{2} \\
& R=287.0 \mathrm{~J} / \mathrm{Kg}-\mathrm{K} \\
& c_{p 0}=1006.5 \mathrm{~J} / \mathrm{Kg}-\mathrm{K} \\
& \mu_{0}=1.716 \times 10^{-5} \mathrm{~J} / \mathrm{Kg}-\mathrm{K} \\
& P r=0.72 \\
& \gamma=1.4 \\
& \alpha=0.2 \\
& \varepsilon=1.0 \times 10^{-7} \\
& \varepsilon_{p}=1.0 \times 10^{-7}
\end{aligned}
$$




\section{Appendix VIII}

\section{Program Parameters - Specific to Each Run}

List of parameters that are specific to the Base Run:

$$
\begin{aligned}
& \text { Mesh size: } 21 \times 21 \\
& \Delta \bar{t}=1 \times 10^{-5} \\
& R a=1 \times 10^{5} \\
& G r=1.413265 \times 10^{5} \\
& p_{r e f}=1 \times 10^{5} \mathrm{~N} / \mathrm{m}^{2} \\
& T_{r e f}=300 \mathrm{~K} \\
& u_{r e f}=0.232073 \mathrm{~m} / \mathrm{s} \text { (calculated) } \\
& L_{r e f}=0.0254 \mathrm{~m} \\
& \Delta T=64.84 \mathrm{~K} \\
& T_{h}=332.42 \mathrm{~K} \text { (calculated) } \\
& T_{c}=267.58 \mathrm{~K} \text { (calculated) } \\
& F r=0.464914
\end{aligned}
$$




\section{Vita}

Manohar Chidurala was born on August 31, 1984 in Mutharam, Andhra Pradesh, India. He received his bachelor's degree in mechanical engineering from the Jawaharlal Nehru Technological University, Hyderabad, India in June, 2006. He was admitted to the University of New Orleans as a graduate student in mechanical engineering. During the course of his study, he worked as a graduate teaching assistant and had a chance to assistant in fluid mechanics and thermal sciences Laboratories. His research interests include fluid mechanics, heat transfer and computational fluid dynamics. In August 2009, he was granted a Master of Science degree in mechanical engineering from the University of New Orleans. 